\title{
The London School of Economics and Political Science
}

Implementing Regulatory Reforms in Multi-Level Governance Systems: The Case of the Reform of the Water Sector in Italy (1994-2006)

Alberto Asquer

A thesis submitted to the Department of Management of the London School of Economics for the degree of Doctor of Philosophy, London, December 2012 



\section{Declaration}

I certify that the thesis I have presented for examination for the MPhil/PhD degree of the London School of Economics and Political Science is solely my own work other than where I have clearly indicated that it is the work of others (in which case the extent of any work carried out jointly by me and any other person is clearly identified in it).

The copyright of this thesis rests with the author. Quotation from it is permitted, provided that full acknowledgement is made. This thesis may not be reproduced without the prior written consent of the author.

I warrant that this authorization does not, to the best of my belief, infringe the rights of any third party.

$10^{\text {th }}$ December 2012

Alinso soquer 



\begin{abstract}
Within the field of regulation policy and politics, various scholarly works have examined policy reforms intended to change the regulation of large-scale infrastructure-based public service industries. Relatively little attention has been placed, however, on the jagged and ineffectual implementation of regulatory reforms that especially takes place when the implementation context includes features of a multi-level governance system. For reasons especially related to the technical, economic, and territorial characteristics of infrastructure and sub-national governments' political responsibilities towards local communities, within this type of scenario the implementation of regulatory reforms tends to exhibit high levels of political confrontation between actors of the reformed infrastructure industry, with respect to what is ordinarily experienced when a regulatory reform is implemented by public agencies or any body of the executive at the central level.

This thesis aims to contribute furthering our understanding of the political economy of implementing regulatory reforms by conducting an exploratory case study whose episode is the implementation stage of the 12 year long (1994-2006) policy cycle to liberalise, re-regulate, and privatise Italy's (drinking water and waste) water sector. The main explanatory issues at stake relate to why the implementation trajectory changed over time (i.e., a period of obstructed implementation was followed by one of accelerated execution of the policy reform content) and across space (i.e., implementation progressed faster in Alto Valdarno in Tuscany than elsewhere in the country). The analysis of the case is conducted by
\end{abstract}


following two alternative theoretical approaches in turn, namely institutional rational choice and institutional processualism. Answers to these questions provide some evidence for qualifying existing generalised arguments about the policy process of implementing regulatory reforms and for assessing the relative strengths and weaknesses of alternative theoretical perspectives. 


\section{Contents}

Acknowledgements

Introduction

\section{Part I}

Chapter 1 Literature Review 25

1. Definitions 26

2. Regulatory reforms of infrastructure: a review of the literature 30

3. Limitations of existing research on infrastructure regulatory reforms 39

4. A processual approach to the study of policy reform implementation 46

5. Chapter summary

Chapter 2 The Research Design

1. The research question 60

2. The selection of the case 62

3. Overview of the case 64

4. The boundaries of the case 68

5. Data collection 72

6. Narrative writing and analysis 75

7. Chapter summary 80 


\section{Part II}

Chapter 3 Historical Background: Water policy in Italy (1865-1994) 85

1. The evolution of water policy in Italy (1865-1994) 86

2. The 1976 water reform $\quad 89$

3. The 1989 water reform 93

4. The making of the 1994 water reform 98

5. The design of the 1994 water reform 104

$\begin{array}{ll}\text { 6. Chapter summary } & 114\end{array}$

Chapter 4 The Implementation of the Water Reform in Italy (1994- 117 2001)

1. The implementation of the water reform in Italy (1994-2001): an 118 overview

2. Aligning regional legislation to the national water reform (1994-1997) 120

3. Implementing the water reform in Alto Valdarno (1994-1999) 128

4. Aligning regional legislation to the national water reform (1997-1999) 132

5. Establishing the OTA authorities (1997-2001) 135

6. Awarding water franchises (1999-2001) 138

7. An assessment of the partial water reform implementation outcome 145 (2001)

8. Chapter summary 148

Chapter 5 The Implementation of the Water Reform in Italy (2001- 151 2006)

1. The implementation of the water reform in Italy (2001-2006): an overview 
2. Awarding water franchises (2001-2003)

3. Awarding the water franchises (2003-2006)

4. An assessment of the water reform implementation outcome (2006)

5. Chapter summary

\section{Part III}

Chapter 6 Analysing the implementation of the water reform in Italy 185 (1994-2006): institutional rational choice approach

1. Explaining the implementation of the liberalisation and re-regulation 186 part of the water reform

1.1. Explaining the faltering implementation process in the first period (1994-1997)

1.2. Explaining variation from the overall pattern in Alto Valdarno area

1.3. Explaining the acceleration of the implementation process after the 196 turning point (1997-2006)

2. Explaining the implementation of the privatisation part of the water reform

2.1. Explaining the obstructed implementation in the first period (19942001)

2.2. Explaining the acceleration of the implementation process after the turning point (2001-2006)

3. Chapter summary

Chapter 7 Analysing the implementation of the water reform in Italy (1994-2006): institutional processualism approach

1. Explaining the implementation of the liberalisation and re-regulation part of the water reform

1.1. Explaining the faltering implementation process in the first period (1994-1997)

1.2. Explaining variation from the overall pattern in Alto Valdarno area

1.3. Explaining the acceleration of the implementation process after the turning point (1997-2006)

1.4. Synthesis

2. Explaining the implementation of the privatisation part of the water reform 
2.1. Explaining the obstructed implementation process in the first period 234 (1994-2001)

2.2. Explaining the acceleration of the implementation process after the turning point (2001-2006)

2.3. Synthesis

3. Chapter summary

1. Explaining the implementation of the liberalisation and re-regulation part of the reform

1.1. Accounting for the inertia to implement the water reform

1.2. Accounting for within-case variation

1.3. Accounting for the acceleration part of the implementation process

2. Explaining the implementation of the privatisation part of the reform 


\section{Acknowledgements}

I would like to express, first, my deep and sincere gratitude to my supervisor Prof. Michael Barzelay for his advice, guide, help, criticisms, and assistance during the several years spent on this study.

I would like to thank the many people who made this thesis possible by sharing with me their knowledge and expertise in the field of water regulation and management, in particular at the Ministry of Public Works and the Ministry of the Environment of Italy, the Senato, the Camera dei Deputati, the Comitato di Vigilanza per l'Uso delle Risorse Idriche, Federutility, ACEA, AMGA, ESAF, Istituto per la Ricerca Sociale, and several Autorità d'Ambito. I also wish to thank the LSE and CARR for the financial support received while working on this thesis.

I am extremely grateful to Prof. Roger Levy for his advice, support, and constant encouragement.

My sincere appreciation goes to my parents for their support.

I am especially and extremely grateful to my wife Inna, for her patience, understanding, and stimulation to carry out and bring this study to the end. 
To Sophie 


\section{Introduction}

Within the field of regulation policy and politics, scholarly interest in regulatory reforms aimed to restructuring entire sectors of the economy has increased substantially in the last decades. Topics such as the design and the making of regulatory systems, the administration of the day-to-day working of regulatory regimes, and the assessment of the performance of regulatory reforms figure high in the research agendas of economists and political scientists alike. Within this body of literature, quite an amount of attention has been placed, in particular, on regulatory reforms of infrastructure. On the basis of a wealth of evidence on episodes of infrastructure regulatory reforms carried out in sectors such as electricity, gas, telecommunications, highways, railways, and water, several studies especially tackled issues related to what kind of regulation better suits the technological, economic, and social features of infrastructure industries, whether the government should play an invasive role or whether the private sector should be largely involved in the provision of infrastructure-related services, and whether and how regulation ultimately affects the performance of regulated infrastructure industries.

Generally, most of the scholarly literature on regulatory reforms of infrastructure focused on either the design of regulatory systems or the performance effects of infrastructure regulation. Relatively less efforts have been exerted, instead, to address issues related to the process of putting a new regulatory system into place. Yet, the central issue of how regulatory reforms are implemented - or, how the process of installing a new regulatory system unfolds - deserves careful 
consideration. Rather than the mere administrative execution of a policy mandate, the implementation of regulatory reforms is a highly political process that bears important implications for the very establishment of a new regulatory regime. While putting the regulatory reform mandate into effect, implementers and target groups make decisions that may well reshape the original regulatory policy design, with the effect that, first, the resulting regulatory regime may well differ from what policy-makers intended to establish and, second, performance of the infrastructure industry cannot be plainly related to features of the regulatory system that were contained in the regulatory reform mandate. Accordingly, if attention is not placed on how regulatory reforms are implemented, we miss fully understanding whether and why the making of regulatory reforms results in any change of regulatory regimes and of the performance of infrastructure industries.

Broadly stated, this thesis aims to contribute furthering our understanding of the political economy of implementing regulatory reforms. More precisely, this study aims to explain the trajectory (i.e., path and outcome) of the process of implementing regulatory reforms in infrastructure industries under special conditions that arise when the implementation context includes features of a multi-level governance system. In such context, sub-national governments often play the function of direct providers of public services at the local level and typically enjoy prerogatives like the exercise of veto powers provided by the constitution and/or relevant legislation, the right to appeal to supra-national, constitutional, and administrative courts, and exclusive competences on the regulation of local public services. For reasons especially related to the technical, 
economic, and territorial characteristics of infrastructure and sub-national governments' political responsibilities towards local communities, within this type of scenario the implementation of regulatory reforms tends to exhibit high levels of political confrontation between actors of the reformed infrastructure industry, with respect to what is ordinarily experienced when a regulatory reform is implemented by public agencies or any body of the executive at the central level. The study of regulatory reform implementation in multi-level governance systems, therefore, allows to enrich our analysis of the emergence of new regulatory regimes by looking at how new regulatory systems are put into place when political confrontation is a salient feature of the interaction between policy-makers, implementers, and target groups.

The aim of this thesis is attained through the case study of the episode of the implementation stage of the policy cycle to reform Italy's (drinking and waste) water sector regulation in the period 1994-2006. The episode originated from the enactment of a piece of legislation (Act 36/1994) that the central government advanced with the aim to improve the dismal state of water infrastructure and dissatisfying performance of the water industry. This policy objective would be attained through the combined effect of the execution of three features of the reform policy content, namely to liberalise access to the water industry that had been traditionally dominated by public sector organisations, to re-regulate the provision of water services through combined mechanisms of franchise allocation and discretionary regulation, and to privatise water services by opening up ownership of water firms to private operators and investors. The policy reform would be 
especially executed by sub-national governments, which bore responsibilities and enjoyed prerogatives sanctioned by the constitution and general public service legislation on the organisation and delivery of local water services within their respective jurisdictions.

The implementation of the water reform included two events that related to the liberalisation and re-regulation part of the reform, namely aligning subnational legislation with the national reform statute and establishing new regulatory authorities, and an event that related to the privatization part, namely awarding water franchises. Both the liberalization and re-regulation part and the privatization part of the episode were characterised by a first period of slow motion followed by one of acceleration in the execution of the implementation tasks after "turning points": the liberalisation and re-regulation of water services proceeded relatively slowly first, and then accelerated from 1997 onwards, and the privatisation of water service provision progressed relatively slowly first, and then accelerated after 2001. Additionally, the implementation of the water reform exhibits some variation across the country: both the liberalization and re-regulation part and the privatization part of the policy reform were executed remarkably faster in a particular area of Tuscany named Alto Valdarno, where the new regulatory regime was established already in 1999, than elsewhere in the country. The episode, therefore, exhibits some intriguing features - precisely, variation over time (when comparing the trajectory of the implementation episode before and after the "turning points" in 1997 and 2001) and across space (when comparing the trajectory of the implementation of the water reform in Alto Valdarno with respect to the rest of the country). 
The analysis of the case will aim to explain what accounts for the observed variety of the path and outcome of water reform implementation over time and across space. Such variety of water reform implementation trajectories may not surprise anyone familiar with the general scholarly literature on public policy implementation. After all, the episode of the water reform implementation in Italy is illustrative of the well-known obstacles, detours, and mixed results that are often encountered when implementing a regulatory reform - if not any public policy (Mazmanian and Sabatier, 1981, 1983, 1989; Pressman and Wildavsky, 1973). The episode of the water reform implementation in Italy, however, contains more than meets the eye. As we shall see, the difficulties encountered to implement the water reform cannot be fully explained by ordinary administrative factors or by the resistance of sub-national governments against the mandate to give up full ownership of incumbent water firms and to open up water services to competition. The episode includes variation of implementation trajectories over time and across space that calls for an explanation for why reluctant implementers became favourably inclined towards executing the implementation tasks and for why the water reform implementation proceeded faster in some areas than in the rest of the country (and, as we shall see, why this mattered for the implementation of the water reform in the rest of the country).

The analysis of the case will be conducted by following two alternative theoretical frameworks in turn, namely an analytic narrative based on institutional rational choice and an institutional processualist perspective. The recourse to different theoretical frameworks is a strategy that is often followed when, given the 
complexity of the phenomenon under consideration, alternative theoretical perspectives are expected to provide complementary insights and to overcome the limitations of the assumptions inherent in any specific approach. Explaining the variation of the trajectory of water reform implementation over time and across space requires such kind of combined analytic effort. The first approach institutional rational choice - will provide an explanatory argument that builds on the assumptions and the logic generally related to game theoretic modelling. The second approach - institutional processualism - will offer an explanatory argument that places greater attention to the way in which the context is brought to bear into actors' decisions and behaviour than institutional rational choice analysis does. When taken together, the two explanations will result in a comprehensive and balanced account of how the implementation of the water reform unfolded. When contrasted and compared, the two explanations will also form the basis for some discussion about the relative strengths and limitations of the two alternative theoretical approaches.

This thesis is organised into three parts. Part I (Chapters 1-2) will set up the stage for conducting the case study of the implementation of the regulatory reform of the water sector in Italy in the period 1994-2006. Building on a review of the literature on regulatory reform, Chapter 1 will present an argument for the lack of satisfactory theoretical arguments about how regulatory reforms are put into effect and for the adoption of a processual perspective for researching regulatory reform implementation. Chapter 2, then, will outline the research design of the thesis, especially including formulation and justification of the research question, criteria 
for case selection, methods of data collection and analysis, and principles followed for the application of the two theoretical frameworks.

Part II (Chapters 3-5) will provide the narrative history of the episode of implementing the regulatory reform of the water industry in Italy in the period 1994-2006. As a prelude, Chapter 3 will outline the historical background of the water reform, by illustrating the evolution of water policies in the country since 1865 until the making of the 1994 water reform. Chapter 4 will narrate the part of the episode comprised between 1994, when the water reform statute was enacted, and 2001, when all parts of the water reform policy content - liberalising, reregulating, and privatising water service provision - started to be executed full steam. Chapter 5 will continue the narration of the episode in the period between 2001 and the 2006, when the water reform legislation was eventually abrogated.

Finally, part III of the thesis (Chapters 6-8) will analyse and discuss the case study. Chapter 6 will present the analysis of the case conducted by following the institutional rational choice approach, while Chapter 7 will present the analysis of the case conducted along the lines of the institutional processualist approach. Lastly, Chapter 8 will contrast and compare the explanatory arguments provided by the two theoretical perspectives and will discuss the findings of the case study with respect to existing studies on the political economy of policy reforms in the implementation stage. Finally, the Conclusions will especially discuss how this case study contributes to our understanding of the regulatory reform policy process and of the relative strength and weaknesses of the two analytical perspectives. 


\section{PART I}




\section{Chapter 1}

\section{Literature Review}

Within the field of study of regulation and regulatory reforms, relatively little attention has been placed on the issue of how regulatory reforms are implemented. A review of the scholarly literature shows that works on regulation and regulatory reforms primarily focused on issues related to the design and performance effects of regulatory systems. The issue of how a new regulatory system is put into place, instead, has been relatively neglected so far. Yet, this issue is important because the process through which a regulatory reform is put into place includes efforts of implementers and target group that are intended to reshape the regulatory reform mandate, in a way that bears important consequences for the emergence of the new regulatory regime and for the delivery of infrastructurerelated services. This gap in the literature, therefore, should be filled if we wish to attain a better understanding of the features of regulatory regimes and of the extent to which design choices made in the making of regulatory reforms result in any change of the performance of regulated sectors of the economy.

The chapter begins with a section on definitions, that is intended to clarify the meaning of key terms are used in the thesis. Section two will discuss the scholarly literature on regulation and regulatory reforms of infrastructure. Section three will discuss limitations of current research on regulation and regulatory reforms. Section four will outline a way forward for overcoming the limitations of 
existing studies by following a processual approach to researching regulatory reform implementation.

\section{Definitions.}

This section aims to clarify the meaning of key terms - especially regulation, regulatory system, regulatory regime, and regulatory reform - that will be repeatedly used throughout this thesis. The first of such terms is "regulation", that is often subjected to various interpretations depending on both different theoretical and historical perspectives. Baldwin, Scott, and Hood (1998) distinguished between a relatively narrow sense of the term (intended as "the promulgation of an authoritative set of rules, accompanied by some mechanism, typically a public agency, for monitoring and promoting compliance with these rules"; Baldwin et al., 1998: 3), a middle-range sense ("all efforts of state agencies to steer the economy"; Baldwin et al., 1998: 3), and a relatively broad sense (any kind of mechanism of social control). Jordana and Levi-Faur (2004), instead, outlined the variety of meanings attached to the term "regulation" in relation to different historical and institutional settings, where indeed the term has been associated to indicate partially divergent phenomena (Cook et al, 2004; Jayasiriya, 2001; Jordana and Levi-Faur, 2003; Majone, 1994, 1997; Müller, 2002; Selznick, 1985). In this thesis, the terms "regulation" will be used in its middle-range scope, in the sense of referring to diverse kinds of regulatory activities as those carried out by independent regulatory agencies as well as those performed through direct governmental interventions. 
The term "regulatory system" will be used here to refer to the set of institutions and processes that are installed by the government for subjecting an industry to economic regulation. This meaning of the term "regulatory system" broadly correspond to the one generally employed in the scholarly literature as well as in professional publications. For example, OECD works typically refer to regulatory systems as "the processes and institutions through which regulations are developed, implemented, enforced, adjudicated, and revised" (OECD, 1994, 1997). World Bank publications ordinarily consider "regulatory systems" as "the combination of institutions, laws, and processes that give a government control over the operating and investment decisions of enterprises" of the regulated sector of the economy (World Bank, 2006). While any "regulatory system" consists of various institutions and processes put together, it is occasionally convenient to broadly characterise any regulatory systems in terms of a given set of regulatory tools, as it is the case for regulatory systems such as "public ownership", "franchise allocation", or "discretionary regulation" (Gómez Ibáňez, 2003).

The term "regulatory regime" will be employed here to refer to the specific way in which a sector is regulated. In the scholarly literature, however, the term is variously defined. Eisner (2000:1) explained it as "a historically specific configuration of policies and institutions which structures the relationship between social interests, the state, and economic actors in multiple sectors of the economy". Francis (1993: 43) considered it as a "reasonably enduring purposive arrangement [...], embracing both formal and informal organizations, incorporating the relationship between private interests and public bodies that make governing 
decisions". Vogel (1998: 20) referred to it more generally as a "specific constellation of ideas and institutions". More accurately, Harris and Milkis (1996: 25) conceived it as a constellation of ideas justifying governmental control over business activity, institutions that structure regulatory politics, and a set of policies impinging on business. With respect to a "regulatory system", then, a "regulatory regime" is understood as the particular way in which a regulatory system - as a set of institutions and processes - is run in particular historical and local circumstances.

"Regulatory reform" is a term that has been used to indicate a policy cycle where policy-makers intend to replace an existing regulatory regime with a new one, typically with the general aim to improve regulatory quality (OECD, 1997). Regulatory quality, in turn, is defined as "a regulatory framework in which regulations and regulatory regimes are efficient in terms of cost, effective in terms of having a clear regulatory and policy purpose, transparent and accountable" (Jordana and Levi-Faur, 2004; OECD, 2002, 2004). Regulatory reforms have also been related to policy cycles where regulatory regimes are changed for the sake of attaining policy objectives generally related to improvement of performance of the regulated sector of the economy. Regulatory reforms, in this sense, may include policy content features that relate the liberalisation, re-regulation, and privatisation of industries where policy-makers' concerns are openly directed towards fixing perceived or constructed problems with existing regulatory regimes. (Bel and Fageda, 2007, 2009; Doern and Wilks, 1996; Donahue, 1989; Levi-Faur, 2005; Simmons and Elkins, 2004; Vickers and Yarrow, 1988).

Finally, multi-level governance is a term that is used in this thesis to refer to 
a form of governance where policy and administrative decisions result from continuous negotiation between governments at different territorial levels rather than in any particular single jurisdiction. This definition broadly draws from the one of Marks (1993), who defined multi-level governance, in a more articulated way, as "a system of continuous negotiation among nested governments at several territorial tiers" (Marks, 1993: 392), "characterised by co-decision-making across several nested tiers of government, ill-defined and shifting spheres of competence (creating a consequential potential for conflicts about competences), and an ongoing search for principles of decisional distribution that might be applied to this emerging polity" (Marks, 1993:407) ${ }^{1}$. In multi-level governance systems, the constitution of non-unitary states attributes exclusive powers to sub-national governments with respect to the central government. Unitary states, in contrast, are understood here as those where the central government is attributed supreme sovereignty and any subnational government only exercise the powers that are delegated by the central government (Cole and John, 2001; Elazar, 2005). Federal governments are typically regarded as the clearest form of non-unitary state, although also other forms of non-

1 Within the political science literature, the term multi-level governance has been related to various meanings, such as "a change in the meaning of government, referring to a new process of governing; or a changed condition or ordered rule; or the new method by which society is governed" (Rhodes, 1997: 35; Rhodes, 1996). The same term "governance", however, might deserve some further clarification. The EU White Paper on European Governance (2001: 8), for example, defines it as "rules, processes and behaviour that affect the way in which powers are exercised at European level, particularly as regards openness, participation, accountability, effectiveness and coherence". The OECD report Thematic Evaluation of the EC support to good governance (2006: 11) defines governance as "the structure, functioning and performance of public authorities/institutions at all levels. Governance is about the way public functions are carried out (including public service delivery), public resources (human, natural, economic and financial) are managed and public regulatory powers are exercised (including enforcement) in the management of a country's affairs". Following Peters and Pierre (2004: 78), governance is here understood as "the process through which collective interests are defined and pursued". The authors conceived governance as a process through which public and private actions and resources are coordinated and given a common direction and meaning. As such, it is important to highlight that the governance context is conceived as a process, rather than a structure. 
unitary states exist based on various forms of "regionalism" that is constitutionally sanctioned.

The role played by a system of multi-level governance on the policy cycle has been highlighted by several studies especially concerned with the policy process in the EU and in non-unitary countries such as Germany and Spain (e.g., Eberlein, 2000; Gallego and Subirats, 2012; Jeffrey, 1996; Lodge and Wegrich, 2005). Works done in this area include, for instance, those on the making and implementation of EU policies in general (Börzel, 1998a, 2000, 2001; Levy, 2000; La Spina and Sciortino, 1993), EU cohesion policy (Blom-Hansen, 2005; Hooghe, 1996), EU environmental policy (Börzel, 1998b; Knill and Lenschow, 2000), and EU agri-environmental policy (Jones and Clark, 2000). Some works, among others, have also particularly addressed issues related to regulatory reforms within multilevel governance systems (Doern, 2003; Doern and Johnson, 2006; Levi-Faur, 2006), including those of infrastructure industries (Coen and Thatcher, 2008; Eberlein and Grande, 2000). While these studies did not precisely focus on the process dynamics of putting infrastructure regulatory reforms into place, nevertheless they showed how special conditions related to features of the multilevel governance systems affect the policy process in ways that are not ordinarily contemplated when policy cycles unfold within unitary systems of government.

\section{Regulatory reforms of infrastructure: a review of the literature.}

Regulation and regulatory reforms is a field of study that has attracted considerable amount of scholarly attention in the last decades. From the side of 
economists, research efforts have been especially directed towards the design and performance effects of regulatory systems that are intended to offset the negative effects of natural monopoly, asymmetric information, moral hazard, and regulatory capture that generally plague the working of imperfect markets (Armstrong et al., 1999; Bishop et al., 1995; Joskow, 1996, 1997; Newbery, 2000; Stigler, 1971). From the side of political scientists, scholarly works have been primarily made on the rationales for which regulatory reforms are made, on the features of the "regulatory state", and on the variety of modes of governance of regulatory regimes (Baldwin and Cave, 1999; Dunleavy, 1985; Gilardi, 2003; Hood et al., 2001; James, 2003; Jordana and Levi-Faur, 2004; Kirkpatrick and Parker, 2005; Lodge, 2002, 2003, 2008; Lodge and Stirton, 2006; Majone, 1994; Majone, 1994, 1996, 1997; Thatcher, 2002a, 2002b). In addition, regulation and regulatory reforms have been the subject of countless works done within professional circles, especially within the OECD and the World Bank.

Within this body of literature, lot of attention has been placed, in particular, on regulatory reforms of infrastructure - that is, systems for widespread and continuous public service provision that extend over a territory and that crucially depend on sunk investments in relatively large and networked physical assets that exhibit common good features ${ }^{2}$. Research in this area has largely focused on two main issues, namely how infrastructure should be regulated and what are the performance effects of infrastructure regulation. On the basis of a wealth of

2 As highlighted by Tenbücken (2006), the term "infrastructure" partially overlaps with the one of "public utilities". The latter, however, is generally understood to refer to sectors which are managed in the public interest, such as electricity, gas, postal services, telecommunications, waste disposal, water supply and sanitation services, but the term public utilities typically does not include the transportation sector, which falls into the category of infrastructure. 
evidence collected from episodes of infrastructure regulatory reforms carried out in various sectors (especially electricity, telecommunications, gas, highways, railways, and water) and countries, scholarly works highlighted what kind of regulation better suits the technological, economic, and social features of infrastructure industries, especially including specific concern towards whether the government should play an invasive role in the regulation of infrastructure or let the private sector be largely involved in infrastructure development and the provision of infrastructure-related services (Eberlein, 2000; Eberlein and Grande, 2000; Estache, 2001; Finger et al., 2005, 2010; Finger and Künneke, 2006, 2009; Gómez Ibáňez, 2003; Kessides, 2004; Kirkpatrick and Parker, 2005; Newbery, 2000).

A brief review of the literature on infrastructure regulatory reform is illustrative of the kind of studies that have been done so far in this area. Several works have been primarily focused on developing theoretical arguments for the need to regulate infrastructure on both social and economic basis ${ }^{3}$. The general argument builds on the premise that infrastructure industries are typically conducive to market failure for reasons related to the natural monopoly features of infrastructure (Joskow, 2005), such as presence of expensive and specialised assets, provision of services for which few substitutes exist, cost structures which tend to

3 Social regulation is concerned with the protection of the public interest, in such terms as environmental preservation, safety, consumer protection, and achievement of social objectives (Groom et al., 2006). Economic regulation, instead, is concerned with providing a substitution for competition in relation to natural monopolies (Ogus, 1994; Joskow and Rose, 1989; Joskow, 2005). Economic regulation aims to fix market failure by means of rules and organisations that set, enforce, and change the allowed tariffs and service standards for the operators of regulated industries. A few authors (Liou, 2001, 2007; Hopkins, 2005) also distinguish economic and social regulation from another third class, named administrative regulation, that refers to paperwork and administrative formalities (so-called 'red tape') through which governments collect information and intervene in individual decisions. In this thesis, however, we only refer to the more common distinction between economic and social regulation. 
favour the presence of one operator only, and network externalities. Firms that operate in infrastructure industries tend to adopt anti-competitive practices, for example by exploiting the high switching costs and lock-in effects of consumers in order to increase their market power (Farrell and Shapiro, 1988; 1989), restricting network interconnection and access to new entrants or minor competitors (Economides and White, 1994), and charging consumers above marginal cost or cream-skimming the most lucrative segments of the demand (Gómez Ibáňez, 2003). The governments, therefore, should design regulatory systems in order to prevent firms' opportunistic behaviour and stimulate investments, cost efficiency, and service improvement.

Several works have been also done on alternative options for designing regulatory systems. Gómez Ibáňez (2003), for example, widely discusses four main regulatory "models", namely public ownership, franchise allocation, discretionary regulation, and private ownership in conjunction with liberalisation and regulation of access, prices, and quality. Why public authorities adopt any particular regulatory model and what are the relative strengths and weaknesses of alternative regulatory systems have been largely examined by several works (Amato and Conti, 2005; Baumol, 1982; Beecher, 2001; Bishop and Walker, 1999; Christoffersen and Paldam, 2003; Demsetz, 1968; Ferris, 1986; Ferris and Graddy, 1988; Finger and Allouche, 2003; Groom et al., 2006; Hefetz and Warner, 2004, 2007; Hirsch, 1995; Kay and Thompson, 1986; Littlechild, 1986; Lobina and Hall, 2003; Massarutto, 2007; McGuire et al., 1987; Megginson and Netter, 2002; Merrett, 1997; Miranda, 1994; Ogus, 1994; Rees, 1998; Schmalensee, 1979; Tenbüken, 2006; Vickers and 
Yarrow, 1998; Warner and Hebdon, 2001; Williamson, 1976). Some authors hold that there may be no single "best way" to regulate infrastructure (Glachant, 2002; Goldberg, 1976), while others argue that the design of regulatory systems should follow "standard prescriptions" (Joskow, 1996, 1997) that suggest that the potentially competitive activities in infrastructure industries should be disentangled (unbundled) from those characterised by natural monopoly conditions and that regulations should be tailored in order to facilitate competition in the former activities to restrain rent-seeking behaviour in the latter ones.

Various other works have addressed issues related to the performance effects of infrastructure regulatory systems. Some of these studies focused on the criteria and methods for appraising the performance of infrastructure regulatory systems (Brown et al., 2006; Stern and Holder, 1999). Others were concerned with the assessment of performance of new regulatory systems (Gönenç et al., 2000; Kessides, 2004). Others were especially focused on the performance effects of changes of regulatory systems that included some amount of privatisation of infrastructure-related services (Estache, 2003; Kirkpatrick et al., 2006; Saal and Parker, 2001). These works shed considerable light onto the issues as to whether and to what extent regulation bears any impact on the functioning of infrastructure. As we shall discuss below, however, this copious amount of studies have some limitations, that especially relate to a lack of attention towards the process through which a new regulatory system is put into place.

Among the various infrastructure industries, water ${ }^{4}$ has attracted

4 We understand the water industry here as the economic and social system concerned with the production and delivery of water supply and sanitation services, i.e., the supply of drinkable water to urban and rural users and the management of sewage and wastewater treatment 
considerable interests because of its peculiar features and daunting challenges. The supply of safe drinking water and the proper functioning of sanitation services are essential requisites for the conduct of effective economic activities and decent human existence. The performance of water supply and sanitation services, however, is far from satisfying in many countries. Many water infrastructure systems do not provide access to basic water services (e.g., according to UNICEF, 2007, in the world about 884 million people do not use improved drinking water sources and about 2.5 billion people do not use improved sanitation services yet), or do not guarantee safe and reliable water services even in developed countries. Additionally, the water industry presents, more clearly than any other infrastructure, conditions which make the industry a natural monopoly ${ }^{5}$ such as high capital intensity and economies of scale in each segment of the industry ${ }^{6}$ (Noll et al., 2000; Spulber and Sabbaghi, 1994), high sunk $\operatorname{costs}^{7}$ and excess capacity (Ballance and

activities. As such, the water industry does not include other economic and social systems concerned with the management of water resources for other purposes, e.g., irrigation, industrial uses, and recreational uses of water.

5 Natural monopoly can be variously defined. A natural monopoly occurs when the industry is characterised by continuing economies of scale in production (Gómez Ibáňez, 2003). In a more articulate definition, Newbery (2000) considered the natural monopoly as being characterised by economies of scale, high capital intensity, non-storability and fluctuating demand, locational specificity, essentiality of its goods or services for a community, and direct connection to the customers. In a broader review of the concept, Joskow (2005) provided several definitions of natural monopoly, based on technological features (e.g., the monopolistic firm enjoys increasing returns of scale), behavioural and market equilibrium considerations (e.g., the monopolistic firm supplies essential, non-storable goods from a favourable production location), and sunk costs.

6 The water industry includes several segments or activities, including water collection in the form of abstraction from underground and surface sources (such as aquifers and rivers), storage (natural or artificial), treatment (needed to remove natural and other pollutants), bulk transport (before and or after treatment), local storage (which covers diurnal variation in demand), distribution to consumers via a network of mains, customer interface or retailing (connections, billing, payment), collection in sewers, pumping to sewage treatment works (where solids and liquids are separated), removal and incineration of solids or sludge, or dumping at sea or converting into fertilisers on agricultural land, and treatment of liquids (or effluent), usually through oxygenation before discharge to the estuarine environment (in rare cases liquids go into water treatment and supply to customers). In a simplified way, the water industry is often decomposed into the segments of water collection, storage, transport, distribution, sewage, and wastewater treatment.

7 Sunk costs in the water industry especially relate to infrastructure assets, that may account up to 
Taylor, 2005), high cost of water transport, negative environmental impact, and information asymmetries (Massarutto, 2007).

Because of these features, the need for regulation of the water industry is widely acknowledged. Less consensus exists, instead, on how exactly the water industry is to be regulated (Ballance and Taylor, 2005). Various countries in the EU and elsewhere have pursued quite different models of regulation of their water industries. Several regulatory systems in the world primarily attribute full ownership and control of water firms to governmental authorities, especially at the sub-national level. Since the 1980 's, however, various regulatory reforms that aimed to improve water industry performance contained provisions to liberalise, reregulate, and privatise the water industry that resulted in the adoption of new regulatory systems especially centred on mechanisms of franchise allocation and discretionary regulation, both within the $\mathrm{EU}^{8}$ and elsewhere in the world (Rivera, 1996; Shirley, 2002; Winpenny, 2003). Efforts to reform water regulation, however, generally fell short of fixing the performance gap of the water industry so far (Rees et al., 2008).

Regulating the water industry is particularly challenging because of various intertwined issues that relate to providing reliable, affordable, and environmentally sustainable services. One of such issues relates to how the territorial areas where water policies are made and water services are delivered should be defined available options including the "municipal model" (i.e., the level of local about $80-90 \%$ of total costs.

8 It should be noted that, in the EU, the European Commission never issued any directive on the economic regulation of water services yet. Anyway, it did issue directives on related areas, such as water quality and water resource management, that bear some effects on the regulation of the water industry anyway, in such terms as quality standard setting and control and as the definition of watershed areas. 
governments) and the "river basin management model" (i.e., the level of the

watershed river basin $\left.{ }^{9}\right)^{10}$. Another issue relates to whether and how segments of the

water industry should be opened to competitive pressures - alternative options

ranging from full opening up of the water industry to private operators and

investors, to selective unbundling of segments of the water industry that could be

tendered out to private operators, and to full public ownership and control of all

water activities ${ }^{11}$. Another more issue relates to how water tariffs should be set,

9 The watershed river basin is the whole geographical area drained by a river and its tributaries.

10 In the municipal model, water policies are mostly made and implemented at the level of local governments (e.g., on development of the local water network, on the water tariffs, and on the issue of permissions for water intakes and discharges), and water services are usually managed by firms operating in the territorial jurisdictions of local governments only (Rouse, 2007). In the municipal model, the provision of local water services may be contracted out to business companies, as it often happens in France. Quite often, local governments directly manage the water services, either through local government departments or firms owned by the municipality, as it typically happens in Germany. When the municipal model is coupled with local government ownership, several problems typically arise. Water tariff setting generally lacks transparency, because the water service costs are usually confounded with those of the other activities performed by the local government and no explicit link is made between water service cost and water tariff. Water tariffs, moreover, are often set lower than the water service full cost, because water service tariff increase usually is very unpopular and local governments prefer to subsidise the water services from taxation. By setting relatively low water tariffs, furthermore, local governments often lack the financial resources for the infrastructure development needed to meet rising quality standards and to replace ageing assets. In the river basin management model, instead, water policies are made and implemented at the level of the river basin, and water services are usually managed by firms operating in the territory of the river basin catchment area. In the river basin management model, all kinds of water-related policies made at the national and sub-national level (e.g., policies regarding water supply and sanitation, environmental preservation, public health, flooding and other hazardous events, and coordination between conflicting uses of water resources) are keyed to the scale of the river basin. The overall principle for managing water resources in the river basin is the so-called 'Integrated Water Resources Management', that is, "a process that promotes the coordinated development and management of water, land and related resources in order to maximize the resultant economic and social welfare in an equitable manner without compromising the sustainability of vital ecosystems" (Global Water Partnership, 2000). Accordingly, in the river basin management model water services are typically managed by vertically integrating all the segments of the water industry within the river basin area in one water firm only.

11 In general, in infrastructure industries it may be possible to distinguish activities which are open to competition, for which the regulatory system should set rules concerning market entry and requisites of the operators (so-called regulation for competition or ex ante regulation), and activities which could be open to competition if appropriate regulations are provided, for which the regulatory system should set rules regarding pricing, service quality, and consumers' access (so-called regulation of competition or ex post regulation) (Jordana and Levi-Faur, 2004). The very features of the water infrastructure and of water services, however, make unbundling the activities of the water production and management system relatively impractical for at least three reasons. First, the water industry is characterised by higher operating leverage than other 
especially when water infrastructure and services are managed by private firms -

alternative options typically including price-cap or rate-of-return mechanisms ${ }^{12}$.

The design of water regulatory systems in the world does vary considerably.

Within the EU, for example, the water industry is largely retained under public ownership and control in Germany; it hosts various forms of public-private partnerships in France (especially in the form of water franchises that municipalities award to water business companies); and it has been largely privatised in England and Wales (Ballance and Taylor, 2005; Ménard and Saussier, 2000; Parker, 1990; Reimer, 1999; Rouse, 2007; Stoker, 1997; Wackerbauer, 2007). In England and

infrastructure, such as gas and electricity (i.e., there is higher incidence of fixed costs than variable costs with respect to the other infrastructure industries), and therefore water firms tend to benefit from large scale by vertically integrating their activities more than in the other infrastructure industries (Finger and Allouche, 2003). Second, the water industry is also characterised by relatively high transportation costs, in comparison to gas and electricity, and therefore operators in the water industry tend to supply water services within very fragmented regional water grids (Ballance and Taylor, 2005) rather than large markets. Third, the water industry is characterised by a technology which does not allow a clear-cut separation between upstream production and distribution, as is the case of gas and electricity (Kay, 1996). On the whole, then, there seems to be little scope for unbundling activities and benefit from competition in the water industry (Rees, 1998; Massarutto, 2007), apart from some outsourcing of a few service activities (Kraemer, 1998).

12 As a system of tariff regulation, rate-of-return consists of the regulator setting the maximum rate of return on capital that the regulated water firms are allowed to earn. Once the dominant tariff regulation mechanisms in the U.S. for many years, later rate-of-return regulation was subjected to intense criticism because it provided an incentive to inefficiently expand the capital base (Averch and Johnson, 1962) and because its application required a demanding amount of detailed and continuous information about the asset base and costs of the regulated companies. Price-cap regulation consists, instead, of the regulator setting a cap on water tariff increase for a specified period, subjected to periodical review. In between the tariff reviews, water firms have an incentive to minimise their costs (Beesley and Littlechild, 1989), therefore they are expected to invest in cost-saving technologies. Price-cap regulation, however, is exposed to potential pitfalls. If the regulator believes that water firms earn excessive profits, then the regulator may anticipate the review of the tariff. Such violation of the implicit regulatory practice weakens the incentives to minimise the water firms' costs and, by introducing some regulatory risk, increases the company's cost of capital (Alexander and Irwin, 1996). Moreover, the regulator may be inclined to closely monitor water firms' costs in order to reap the efficiency gains and pass them on to the customers as soon as possible. Because of this, the administration of the price-cap regulation may be as much intrusive as the rate-of-return regulation and quite demanding in terms of information from as many water firms as possible in order to better estimate the cost function of the regulated water firms and benchmark their performance (Ballance and Taylor, 2005). Furthermore, water firms may exploit the discretion in setting the detailed tariff basket in order to cross-subsidise selected services. This behaviour is likely to lead to allocative inefficiency and to be used anticompetitively (Vickers and Yarrow, 1988; Armstrong et al., 1999). 
Wales, the territorial organization of water services is based on ten relatively large jurisdictions of Water Authorities, while in France and Germany water services are generally provided by firms operating at the municipal level, in either individual or associated form. Rate-or-return tariff rules have been generally applied in the regulation of water utilities in the U.S., while price-cap mechanism has been adopted for tariff setting by the Water Authorities in England and Wales. Other countries often present quite unique regulatory systems formed through the combination of selected features of different regulatory models (Gómez Ibáňez, 2003; Groom et al., 2006).

\section{Limitations of existing research on infrastructure regulatory reforms.}

The literature review suggests that most of the scholarly literature on regulation and regulatory reforms of infrastructure focused on either the design of regulatory systems or the performance effects of infrastructure regulatory reforms. Relatively less works have been made, instead, to address issues related to the process through which new regulatory systems are put into place and eventually result in a new regulatory regime that supplants another one that had been originally present. Yet, issues related to this how regulatory reforms are implemented deserve careful consideration. As already suggested by a few studies (Dinar, 2000; Durant, 1984; Gönenç et al., 2001; Hanf, 1982; Vogel, 1998), the implementation of regulatory reforms is important in order to account for the emergence of particular features of any new regulatory regime. Decisions and actions made during the implementation stage of regulatory reform policy cycles may divert - and possibly 
significantly reshape - the design of the regulatory system originally provided by policy-makers. Accordingly, attention to regulatory reform implementation is needed in order to fully understand whether and how the making of regulatory reforms results in any change of regulatory regimes and how to assess the performance of regulatory systems of infrastructure industries.

That the implementation stage of regulatory reform policy cycles is important should not obviously surprise any social science scholar. Indeed, the general scholarly literature on public policy implementation - conceived as a kind of process that includes the implementation of regulatory reforms as a particular type - has long highlighted the political nature of the policy process in the implementation stage of the policy cycle (Bardach, 1977; Bunker, 1972; Dror, 1968; Wildavsky and Majone, 1978). It is generally accepted that the political confrontation between implementers and target group entails that the policy reform content is often recast in such a way as to modify, to a greater or lesser extent, the substance of the original formulation of the policy reform mandate. Accordingly, it would count as a reasonable expectation that the implementation of regulatory reforms implies some amount of "re-policymaking" of the original reform intent. This view of public policy implementation - one that places particular emphasis on the political confrontation that takes place between implementers and target groups resulting in some amount of deviation from the original policy mandate - is the one that is followed in this thesis.

Within the scholarly literature on public policy implementation, several works adopted theoretical frameworks that explicitly take into account the role of 
the political confrontation between implementers and target groups. These studies generally hold the view that the implementation stage of the policy cycle should be seen as a "continuation of politics by other means" (Wildavsky and Majone, 1979) - that is to say, that the public policy implementation process should be conceived as no less exposed to political controversies than the policy-making stage, rather than as a bunch of mundane administrative activities that are executed in order to put a policy mandate into effects. An attention to the political nature of the public policy implementation process permeated, for example, the works of Mazmanian and Sabatier (1981, 1983, 1989), Sabatier (1986), Berman (1978), and Lipsky (1978). Among more recent works, those of Patashnik's $(2003,2008)$ are exemplar of the way in which the political confrontation between implementers and target groups affects the "sustainability" of policy reforms in the implementation (or "post-enactment") stage, that is, "the capacity of any public policy to maintain its stability, coherence, and integrity as time passes, achieving its basic promised goals amid the inevitable vicissitudes of politics" (Patashnik, 2003: 207).

One limitation of existing theories of public policy implementation, however, is their lack of attention to the jagged and ineffectual type of implementation process that especially takes place when the execution of the policy reform mandate entails the political confrontation between government authorities situated at different levels of a governmental system. The scenario of multi-level governance bears particular traits that make the unfolding of the public policy implementation process fundamentally different from what is generally observed in the context of unitary countries. As a distinctive trait of multi-level governance 
systems, sub-national governments play an influential role that relates to their functions of direct providers of public services within their respective territorial jurisdiction, to their political responsibility towards local communities, and to their prerogatives such as the exercise of veto powers provided by the constitution and/or relevant legislation, the right to appeal to supra-national, constitutional, and administrative courts, and exclusive competences on the regulation of local public services. Such role played by sub-national governments is unmatched by the one generally attached to actors - like governmental agencies or branches of the executive - that are typically involved in implementing a policy reform in unitary countries. Theories of public policy implementation do not look well equipped to account for the political economy of implementing regulatory reforms of infrastructure in multi-level governance systems, for reasons that may be related to both distinguishing traits of the type of policy reform implementation under consideration and features of current public policy implementation research agenda.

Existing theories of public policy implementation do not seem to be especially attentive to the technical, economic, and territorial characteristics of the target domain of the policy reform as factors that contribute explaining the path and outcome of the implementation process. Yet, infrastructure possess quite peculiar traits that typically give rise to conflicting interests between the consumers of infrastructure-related services, on the one hand, and the providers of infrastructure, on the other one. The former are exposed to the possibility that the layout of the infrastructure network is not compatible with the delivery of infrastructure-related services at the place, time, and conditions of convenience. The latter confronts the 
risk that investment in the construction and maintenance of infrastructure networks clashes with consumers' (or, in their behalf, taxpayers') willingness to pay for infrastructure-related services at the place, time, and conditions of supply. Additionally, the territorial configuration of the infrastructure network may extend across the territorial organisation of sub-national governments' jurisdictions, with the effect that the political interests represented at the sub-national government level may collide with those of the providers of infrastructure or of the consumers based in other sub-national governments' jurisdictions. Because of these conditions, the implementation of regulatory reforms of infrastructure in multi-level governance systems entails a complex pattern of political confrontations whose effects on the path and outcome of the implementation process are difficult to discern through the "lenses" of existing general theories of public policy implementation.

It should be highlighted that, in the scholarly literature, there is no paucity of interest towards regulation and regulatory reforms that take place in countries characterised by a multi-layered system of governance. Instances of such works especially include Eberlein (2000) and Eberlein and Grande (2000) on regulatory reforms of infrastructure industries in Germany. These studies, however, respectively focused on political and regulatory management structures after the reform had been put into place, and on the persistence of domestic regulatory regimes in the context of the emerging EU regulatory framework. In contrast, the present case study is concerned with the process through which new regulatory systems are installed, including how they are affected by the political confrontation 
between actors at different levels of the multi-layered governance systems, rather than with regulatory institutions and behaviour in relatively stable regulatory and ownership regimes.

Existing theories of public policy implementation also tend to follow a research agenda that seems relatively apathetic towards issues related to the political economy of implementing regulatory reforms in multi-level governance systems. Early works on public policy implementation primarily explored the causes of public policy implementation problems or failures and suggested ways for increasing the likelihood of obtaining compliance with the policy mandate (Barrett, 2004; Mazmanian and Sabatier, 1981, 1989; van Meter and van Horn, 1979; Sabatier, 1986) or exposed the micro-level interactions that lead to the execution of a policy mandate within and between organisations (Berman, 1978; Hjern et al., 1978; Hjern and Porter, 1980; Hjern, 1982; Hjern and Hull, 1982; Hull and Hjern, 1987; Lipsky, 1978). Current studies ${ }^{13}$, instead, have decisively moved on from efforts to synthesise top-down and bottom-up perspectives (Elmore, 1979; Goggin

13 As an area of study, public policy implementation is fairly large and burgeoning, especially in about the last decade (Saetren, 2005; O'Toole, 2000; DeLeon, 1999; DeLeon and DeLeon, 2002; Lester and Goggin, 1998; Barrett, 2004; Schofield, 2001; Hill and Hupe, 2002; Lennon and Corbett, 2003). A complete review of the scholarly literature on public policy implementation lays beyond the scope of this thesis, however some general traits can be tentatively recalled here. Following the seminal work of Pressman and Wildavsky (1973), several studies were done with the aim of identifying barriers and obstacles that hampered the execution of policy mandates in either single organisation (Montjoy and O'Toole, 1979; Hjern and Porter, 1980; Milward, 1982) or inter-organisational settings (Bardach, 1977; O'Toole, 1993; 1997a; 1997b; 1997c; Hall and O'Toole, 2000; 2004; Meier and O'Toole, 2005). Then, over time public policy implementation studies gradually shifted their concerns towards also explaining possible sources of success in implementing public policies and programmes, especially in relation to collaborative efforts exerted within networks of implementers and target groups (Agranoff and McGuire, 1999, 2001; Bogason and Toonen, 1998; Borgatti and Foster, 2003; Börzel, 1998; van Bueren et al., 2003;Daugbjerg, 1998; Grantham, 2001; Hanf and O'Toole, 1992; Hanf and Scharpf, 1978; Jordan and Schubert, 1992; Kenis and Schneider, 1991; Klijn, 1996; Klijn and Koppenjan, 2000; Klijn et al., 1995; McGuire, 2002; Mayntz, 1993; Merier and O'Toole, 2003, 2005; Milward and Provan, 2000; O'Toole, 1997a, 1997b; O'Toole and Montjoy, 1984; Provan and Milward, 1995; Scharpf, 1990; 1991; 1993; 1994; 1997; Richardson and Jordan, 1979; Rhodes and Marsh, 1992; Toke and Marsh, 2003; van Waarden, 1992). 
et al., 1990; Hupe, 1990; Matland, 1995; Ryan, 1995) and embraced a research agenda keyed on developing "covering law" explanations for the performance of the public policy implementation process (Goggin, 1986; Goggin et al., 1990; O'Toole, 2000). Known as “third generation"of public policy implementation studies (Lester et al., 1987), this stream of works largely focused on hypothesis testing through relatively large-n surveys of experiences of implementing public programmes (e.g., Meier and O'Toole, 2003, 2005; O'Toole and Meier, 2004). As such, studies that follow the "third generation" approach to public policy implementation research generally neglect paying attention to the detailed interaction related to the political confrontation between implementers and target groups that takes place during the process of putting a policy mandate into effect ${ }^{14}$.

While the research programme framed as "third generation" studies marked a move forward in theory development, it seems that it also diverted attention away from the issue of better understanding the process dynamics of public policy implementation. The call for undertaking large-n, variable-oriented empirical studies - while, at the same time, picturing case studies as a typical "first generation" methodology that had been employed in the infancy stage of scholarly inquiry into public policy implementation for merely descriptive and exploratory purposes - possibly discouraged researchers from maintaining an interest towards disentangling the complexity of the political economy of implementing public

14 Lester et al. (1987) identified three stages or "generations" of public policy implementation studies, each characterised by different theoretical issues and methodological approaches. First generation studies consisted, "for the most part, [of] detailed accounts of how a single authoritative decision was carried out, i.e., a single case study. This body of research was primarily directed toward describing the numerous barriers to effective [public] policy implementation" (Lester et al., 1987: 201). Second generation studies "were concerned with explaining [public policy] implementation success or failure" (Lester et al., 1987: 201). Third generation studies, finally, were directed toward 'theory development' (Lester et al., 1987: 201). 
policies. Yet, theoretical approaches informed by the "third generation" research programme tend to paper over the issues that relate to apprehending the causal structure of the emergent properties of the public policy implementation process (Barrett, 2004; Schofield, 2001) - such as, for example, accounting for variation of the pace and direction of the trajectory of implementing a policy reform over time and across space. An alternative line of inquiry, that precisely takes into account the political confrontation between implementers and target groups and its impact upon the path and outcome of the policy reform implementation process, seems needed in order to provide a better account of the process dynamics of public policy implementation.

\section{A processual approach to the study of policy reform implementation.}

The kind of research issue addressed in this study entails to adopt a processual approach to researching regulatory reform implementation. A processual approach to the study of social phenomena has been largely followed in several fields of inquiry, especially sociology and organisational sociology (Pettigrew, 1997). To some extent, a processual view has also characterised the very original research on public policy implementation, in the sense that the same work of Pressman and Wildavsky (1973) showed a theoretical framework that was particularly attentive to the processual nature of the unfolding of policy in the implementation stage - in such traits as, for example, the importance placed on the dynamics of negotiation, on the sequenced order of decision points, and on the influence of context factors on situated interactions ${ }^{15}$. A processual approach to the 15 The insertion of Majone and Wildavsky's (1979) piece on Implementation as Evolution and of 
study of public policy implementation, however, has been relatively ignored in following decades, for reasons that appear related to the emergence of the research agenda of the so-called "third generation" of public policy implementation studies.

A processual approach to the study of the implementation of regulatory reforms in multi-level governance system can build on theoretical approaches that have been followed, within the political science discipline, in other areas of study. A processual approach to the study of international relations, for example, has been adopted by Alexander L. George in the terms that he labelled "process tracing" method (George, 1979; Bennett and George, 1997). Process tracing aims at identifying the intervening causal process (i.e., "causal chains") between an independent variable (or variables) and the process outcome (George and Bennett, 2005). The method focuses the attention on "the stimuli the actors attend to; the decision process that makes use of these stimuli to arrive at decisions; the actual behaviour that then occurs; the effect of various institutional arrangements on attention, processing, and behaviour; and the effect of other variables of interest on attention, processing, and behaviour" (George and McKeown, 1985). In the "process induction" variant of this approach (Bennett and George, 1997), process tracing also includes "the inductive observation of apparent causal mechanisms and the heuristic rendering of these mechanisms as potential hypothesis for future testing".

subsequent chapters on public policy implementation as mutual adaptation and exploration by Browne and Wildavsky (1983) in later editions even strengthened the processual traits of their research. Contemporary studies on public policy implementation, instead, often exhibit a "structural-configurational" approach to researching public policy implementation, such as in the stream of works centred on the concept of policy network done in the so-called "Dutch school" (Schofield and Sausman, 2004; Klijn et al., 1995; Klijn, 1996; Klijn and Koppenjan, 2000; van Bueren et al., 2003) and in those based on actor-centred institutionalism undertaken in the socalled "Max Plank School” (Börzel, 1998; Mayntz and Scharpf, 1995; Scharpf, 1997). 
Still in the field of political science, John Kingdon's book Agendas, Alternatives, and Public Policies (1984) exemplified the quest for a process understanding of the public policy cycle (especially the policy-making stage) conducted through the interrelation of processual and institutional theories of policy-making (Barzelay and Gallego, 2006). Kingdon's (1984) work showed how trajectory and outcomes of the policy-making process can be explained through a distinctive analysis of component sub-processes and the systemic understanding of influences across sub-processes and between the context and the situation. The theoretical framework included in his study, moreover, was social interactionist in character, as it placed attention to ideation as an interactive social process that takes place within a certain temporal-relational context (Emirbayer and Mische, 1998). His study illustrated how a process understanding of public policy-making could offer analytical generalisations about explaining politically visible authoritative decisions made by legislators or political officials.

By focusing on the effect of particular conditions that arise from the context of multi-level governance systems and by following a processual approach, research into the implementation of regulatory reforms of infrastructure can advance our understanding of how regulatory regimes emerge. Features related to multi-level governance systems make the political confrontation between implementers and target groups particularly intense and evident, especially when as it is typically the case when regulatory reforms relate to infrastructure - the territorial scope of the regulated activities does not necessarily correspond to the territorial jurisdictions of sub-national governments who possess the functions, 
responsibilities, and prerogatives to have a voice over the execution of the policy reform mandate. A processual approach, that is especially suited to highlight the social interactionist features of the political confrontation between implementers and target groups, provides theoretical "lenses" that are especially suited to identify intervening causal processes that account for the path and outcome of the regulatory reform implementation process - particularly, variation in the implementation trajectory over time and across space.

The analysis of the case will be conducted by following two theoretical approaches in turn. First, the path and outcome of the implementation episode of the water reform will be explained by following an institutional rational choice approach, in the form of the "analytic narrative" as illustrated in Bates et al. (1998, 2000) and Levi (2002). Then, the same features of the trajectory of the episode of the water reform implementation will be explained by following the institutional processualist approach, as developed in Barzelay (2003) and Barzelay and Gallego (2006). The use of two alternative theoretical perspectives for explaining features of the same case evidence is primarily intended to strengthen the explanatory argument by making it less dependent on any particular conceptual and theoretical "lenses" only. The two alternative theoretical perspectives, in particular, enable us to enlarge the repertoire of conceptual and analytical tools that can be used to better understand the nature of the interactions between implementers and target groups and their effects. Moreover, this feature of the research design also allows to contrast and compare the alternative explanations for the sake of assessing the relative strengths and weaknesses of the two theoretical approaches. In this sense, 
this case study also aims to contribute to existing scholarly discussion about the relationships between alternative theoretical perspectives in social science disciplines (Barzelay and Gallego, 2006; Hall and Taylor, 1996; Katznelson and Weingast, 2005; Lichbach, 2003; Thelen, 1999).

The analytic narrative based on institutional rational choice approach is taken here as exemplar of a "structural-configurational" theoretical perspective to explaining policy reform implementation. As highlighted by Bates et al. (2000) and Levi (2002), the institutional rational choice approach aims to show how social outcomes consist of self-enforcing equilibria that result from the strategic interaction between actors. This approach is typically applied by extracting key players, their goals, and the features of the environment that influence actors' behaviour (especially the rules of interaction, the constraints, and the incentives) from narratives of social episodes, in order to define game theoretic models tailored to the specific situations (Levi, 2002: 112). Game theoretic models result in subgame perfect equilibria that are compared to the observed behaviour. In case of mismatch between the model equilibria and the observed behaviour, the researcher can revise the model in order to single out the features that better account for the observed pattern of choice. Following this method, the researcher proceeds "back and forth between the model and the data, testing our ideas against reality" (Bates et al., 2000: 700). The institutional rational choice approach, therefore, informs the explanation of trajectories of policy reform implementation episodes in terms of "shift from an institutional equilibrium at one point in time to a different institutional equilibrium at a different point in time" (Levi, 2002: 111). 
The institutional rational choice approach accounts for the observed behaviour of the players in a way that attributes an important causal role to features of the choice settings. As highlighted by Levi (2002: 111), features of the choice setting, such as the distribution of bargaining power and resources among the players, contribute explaining what originates "the shift from an institutional equilibrium at one point in time to a different institutional equilibrium at a different point in time". The researcher attains such explanations by engaging in an exercise of "comparative statics" (Levi, 2002: 112), that consists of building models that fit different portions of data in time, and contrasting and comparing what accounts for the respective sub-game perfect equilibria. The result of the analysis is an explanatory argument that places particular emphasis on the role of institutions understood as self-enforcing equilibria that coordinate behaviour (Levi, 2002).

The institutional processualist approach is considered here as an alternative theoretical perspective to explaining policy reform implementation with explicit processual traits. As highlighted by Barzelay (2003) and Barzelay and Gallego (2006), the institutional processualist approach aims to obtaining historicallygrounded analytic generalisations of the policy process on the basis of explanations where causation arises from combinations of conditions and events (under the principle of "multiple conjunctural causation" as formulated in Ragin, 1989). This approach, as it has been employed in various works so far (Barzelay, 2003; Barzelay and Fuechtner, 2003; Barzelay and Gallego, 2010a, 2010b; Barzelay and Jacobsen, 2009; Cejudo, 2003; Corbett, 2010; Gaetani, 2003; Gallego, 2003; Gallego and Barzelay, 2006, 2010; Malee, 2003; Mele, 2010; Moynihan, 2003), is 
especially attentive to how process design features and process context conditions account (together with other theoretical resources, such as the use of social mechanisms) for the observed trajectory of selected parts of the policy cycle. The institutional processualist approach, therefore, results in explanation of trajectories of policy reform implementation episodes where reform content features, policy process features, and characteristics of the context account for flows of efforts and their variations over time.

The institutional processualist approach entails the formulation of causal reconstruction of implementation episodes with the employment of social mechanisms, especially "agency mechanisms"16 (Barzelay and Gallego, 2006; Emirbayer and Mische, 1998). Within processual theoretical approaches, social mechanisms play the important role of filling the knowledge gap on how social processes work in detail by acting in a similar way to "intervening variables" (George and Bennett, 2005; Bennett and George, 1997) between causal factors and outcomes (Sayer, 1992; Stinchcombe, 1991). Following this approach, the analysis entails the identification of social mechanisms that help providing interpretations (Shelling, 1998) or hypothetical causal models (Gambetta, 1998; Hedström and Swedberg, 1998) for explaining particular features of social phenomena. Social

16 Social mechanisms can be variously classified. Coleman (1986), for example, distinguished between macro-to-micro mechanisms (in which a situation affects individuals), micro-to-micro mechanisms (in which a specific combination of individual desires, beliefs, and action opportunities generate a specific action), and micro-to-macro mechanisms (in which individual actions are transformed into some collective outcome). In a similar vein, McAdam et al. (2001) differentiated between environmental mechanisms (in which externally generated influences affect social life), cognitive mechanisms (in which individual and collective perceptions are modified), and relational mechanisms (in which connections between individuals and groups are changed). Hedström (2005), instead, classified mechanisms as belief-mediated (those which change one actor's beliefs), desire-mediated (those affecting an actor's desires), and opportunitymediated (those which influence the opportunities available for actors). 
mechanisms that will be employed for explaining the path and outcome of the implementation of the water reform in Italy include, in particular, logic of appropriateness (March, 1994; March and Olsen, 1989), committed interpretation (Weick, 2001), network diffusion (Hedström and Swedberg, 1998), and attribution of opportunities and threats (McAdam et al., 2001).

The institutional processualist approach accounts for the observed events' trajectories in a way that places particular importance to the joint combination of initial conditions, policy design and policy process features, and characteristics (including changed features) of the temporal context. As highlighted by Barzelay and Gallego (2006: 53), these component parts of explanatory arguments are especially relevant for explaining "how situated interaction (and, in this way, human agency) can feed back upon context". The researcher attains such explanations by drawing on different analytic models in a rather eclectic fashion for example, the public management policymaking research programme (Barzelay and Gallego, 2006) variously draws on the models of Kingdon's (1994), Baumgartner and Jones' (1993), and Levitt and March's (1988) depending on the empirical patterns of the cases of public management policy change in the research programme and the chosen explanandum. The result of the analysis is typically characterised, within the literature related to this theoretical approach, as a pool of "historically grounded analytic generalizations" (Barzelay and Gallego, 2006: 538; Abbott, 2001; McAdam at al., 2001; Ragin, 1989, 1994; Yin, 1994).

An explicit comparison between institutional rational choice and institutional processualism has not been subjected to wide scholarly attention so far. 
In one piece of work where such comparison is made, Barzelay and Gallego (2006: 548) argue that "A major theoretical difference is that the institutional processual approach seeks to explain the context in which the various actors made their choices and interacted", and that "This difference suggests a more general advantage of the institutional processualist approach over the rational choice institutionalist one, when it comes to understanding public management reform". It seems, however, that the advantage of the institutional processualist approach over the institutional rational choice one should not be literally understood as related to the breadth of what is included in the explanandum, i.e., whether the explanatory argument should also account for features of the context that affect the trajectory of the policy process under consideration or whether it should take them as exogenous conditions. Various case studies conducted by following the institutional processualist approach rather suggest that the difference may be rather re-phrased in the sense that the institutional processualist approach provides an account of how features of the temporal context are brought to bear into the ways actors within the policy process under consideration make decisions and interact with each other. In this sense, institutional processualism suggests an understanding the process through which given context conditions may affect the trajectory of the policy process in a different way but the one provided by institutional rational choice perspective.

The relationship between institutional rational choice and institutional processualism can also be placed within a more general scholarly discussion about the characteristics of alternative varieties of new institutionalism in social science 
(Hall and Taylor, 1996). In assessing the relative strengths and weaknesses of institutional rational choice with respect to historical and sociological varieties of new institutionalism, for example, some authors highlight that, albeit by making use of a relatively simplified view of human nature, the institutional rational choice perspective has the merit of providing parsimonious explanations through propositions that are refutable (Bates et al., 2000; Levi, 2002). In contrast, others point out that explanatory arguments that are informed by the institutional rational choice perspective build on presuppositions about preferences (and possibly also about payoff) that are not observable and about hidden or unknown utility calculations (Boland, 1981; Winter, 1964). Katznelson and Weingast (2005) highlighted that institutional rational choice has a good deal in common with other institutionalist perspectives, especially with respect to the general argument that actors make "choices about feasible alternative [that] are structured by determinate situations regarding who the actors are and which choices are in fact on offer" (Katznelson and Weingast, 2005: 5). Thelen (1999; Thelen and Steinmo, 1992), on the other hand, remarked the presence of sharp differences between institutional rational choice and other forms of institutionalism, especially related to the point that preferences are treated as exogenous in the former while interests and objectives are created in institutional contexts in ways that make them inseparable from them in the latter (Zysman, 1994). Bates et al. (2000), finally, offered a complementary view of institutional rational choice and other theoretical perspectives, by suggesting that "an initial firm grip on rational choice models secures a solid analysis, which can be challenged or expanded by other theoretical 
approaches" (Bates et al., 2000: 699).

\section{Chapter summary.}

By reviewing the scholarly literature on regulation and regulatory reforms, this chapter argued that relatively little attention has been placed, so far, on the issue of how regulatory reforms are implemented. This gap in the literature is related, in part, to the substantive concern that is placed on issues related to the design of regulatory systems and on the assessment of performance effects of regulatory regimes, rather than on understanding how a policy reform mandate is put into place. Yet, the implementation of regulatory reforms bears important consequences on the way in which a regulatory system in installed and, consequently, on its performance effects. Within the implementation stage of regulatory reform policy cycles, the political confrontation between implementers and target groups may significantly reshape the design of the regulatory system originally provided by policy-makers. This political confrontation may be especially relevant in the implementation of regulatory reforms of infrastructure in particular, because of the technical, economic, and territorial characteristics of such type of target domain. Therefore, if attention is not placed on what happens during regulatory reform implementation, we miss a full understanding of whether and how the making of regulatory reforms results in any change of regulatory regimes and how to assess the performance of regulatory systems of infrastructure industries.

In part, the lack of attention on regulatory reform implementation within scholarly works may also be related to the way in which research on the 
implementation of public policies in general is currently conducted. Since the call for the so-called "third generation" of public policy implementation studies, research in this area focused on hypothesis testing through relatively large-n surveys of experiences of implementing public programmes. This research agenda diverted attention away from the issue of better understanding the process dynamics of public policy implementation. An alternative line of inquiry seems needed in order to provide a better account of the process dynamics of public policy implementation.

As a way forward to try and fill this literature gap, this thesis addresses the issue of how infrastructure regulatory reforms are implemented within the context of a multi-level governance system. In this type of scenario, conditions related to the functions, responsibilities, and prerogatives of sub-national governments play the role of sources of causal factors that affect the path and outcome of the reform implementation process, as we shall see. The issue of how infrastructure regulatory reforms are implemented is researched in this thesis by following a processual approach, that places particular attention on such process features as the dynamics of negotiation, the sequenced order of decision points, and the influence of context factors on situated interactions. This thesis will contrast and compare the use of two alternative theoretical perspectives for analysing the same empirical evidence in turn, namely institutional rational choice and institutional processualism. 


\section{Chapter 2}

\section{The Research Design}

This chapter illustrates the research design of this thesis. At the core of the research design lays the research question, namely how should generalised arguments about the implementation of regulatory reforms of infrastructure be qualified (or otherwise adapted) in order to reflect evidence of diverse causal tendencies within a multi-level governance context scenario? This research question is tackled through the analysis of a case of infrastructure regulatory reform in multilevel governance system, that builds on the evidence provided by the episode of implementation of a regulatory reform of the water infrastructure that took place in Italy in the period 1994-2006. The trajectory of the case episode presents some particularly interesting features, especially variation in the path and outcome of policy reform efforts over time (i.e., a period of relatively slow implementation was followed by one of more rapid execution of the policy reform mandate) and across space (i.e., policy reform efforts were more intense and faster in some areas of the country than others). The explanation of the case, that will be provided by following two alternative theoretical frameworks in turn, will be precisely concerned with accounting for these features of the episode of regulatory reform implementation.

The chapter begins with a section that provides the rationale for the research question, and then another that justifies the case selection. Section three will introduce the case episode of the implementation of the water reform in Italy in the 
period 1994-2006, including an overview of the event structure and a brief description of the trajectory of the water reform implementation episode. Section four will discuss the boundaries of the case with respect to other stages of the policy cycle, the implementation outcome, and the context. Section five will describe the methods employed for data collection. Finally, section six will illustrate how narrative writing and analysis have been conducted.

\section{The research question.}

As highlighted in the literature review chapter, scholarly works done on the implementation stage of regulatory reforms in infrastructure industries do not place lot of attention on the process dynamics through which policy reforms are put into place. This lack of attention seems surprising, provided that the implementation stage of such regulatory reforms may be jagged and ineffectual, especially when the implementation process requires political confrontation between governmental authorities situated at different levels of the multi-layered governmental system. The presence of this "blind spot", however, may be understood if taking into account that systematic empirical research on regulatory reforms of infrastructure has traditionally focused on either the design of regulatory systems or the performance effects of infrastructure regulation. The implementation of a regulatory reform mandate, instead, has been often regarded as a mere administrative and technical matter, as it may be the case especially when the execution of the reform policy mandate takes place within unitary countries.

This thesis aims to contribute filling this gap by focusing on the process of 
implementing regulatory reforms of infrastructure which takes place within context conditions that include multi-level governance features. As we shall see, this type of implementation process of regulatory reforms of infrastructure brings to the fore the role of high-intensity political confrontation between governmental authorities in a way that has profound consequences for the path and outcome of the reform implementation process, as we shall see. Within multi-level governance systems, regulatory reform of infrastructure typically calls into play sub-national governments that voice their concerns over the impact of the regulatory reform on the communities hosted within their respective territorial jurisdictions. Taking into account the functions, responsibilities, and prerogatives of sub-national governments that are typically provided by the constitution or relevant legislation in multi-level governance systems, the implementation of regulatory reforms of infrastructure in multi-layered systems of governance is a type of scenario where the regulatory reform mandate is deeply exposed to the possibility of being significantly reshaped during the implementation stage.

The research question posed in this study is how should existing generalised arguments about the implementation of regulatory reforms of infrastructure be qualified (or otherwise adapted) in order to reflect evidence of diverse causal tendencies within a multi-level governance context scenario?

This research question directs the inquiry towards the process dynamics of how a regulatory reform policy mandate is executed. This kind of inquiry is pursued through a case study because this method is particularly suited to researching complex social phenomena that need to be understood as wholes, rather than 
dissected into sets of isolated cause-effect relationships (Ragin and Becker, 1992; Stake, 1994, 1995; Yin, 1994). As highlighted by Yin (1994), case studies allow the researcher to gain a deep historical understanding of the experience studied and to identify, track, and assess the role played by the concurrence of various factors in specific historical circumstances. These characteristics of the case study make this method fit to tackle the kind of knowledge gap that is addressed by the research question of this thesis, i.e., understanding "how" the process of implementing a regulatory reform of infrastructure industries unfolds ${ }^{17}$.

\section{The selection of the case.}

The case selected for addressing the research question tackled in this thesis relates to the episode of the implementation stage of a policy cycle to reform the regulation of the water industry that took place in Italy in the period 1994-2006. The case is selected because of distinguishing features that make it suitable to research how regulatory reform implementation of infrastructure unfolds within multi-level governance systems, provided that the episode of the water reform implementation in Italy took place within a context that includes a multi-layered structure of governance as provided by the constitution and relevant legislation of the country. Additionally, as we shall see, the episode includes a significant role

17 The case study method is also regarded as appropriate for researching the working of regulatory regimes of infrastructure industries, in particular. In commenting on the use of casuistic method in his book Infrastructure Regulation, for example, Gómez Ibáňez (2003: 13-14) argued, "Cases are also valuable because they allow one to examine how the interplay of economics, politics and institutions affect regulatory commitment and performance. Some researchers have tried to examine this interplay using large data sets, and their results are reported here. Few such data sets exist, however, and they capture only a portion of the many variables that might be involved. To appreciate how regulation works in practice, there is simply no substitute for examining the evolution of a specific concession contract or the history of a particular regulatory agency". 
played by sub-national governments in the execution of the water reform mandate, in such a way that the political confrontation between sub-national governments, regional governments, and the central government played an important role on the trajectory of the water reform implementation - especially, in the form of variation both over time (i.e., a first period of slow motion was followed by one of acceleration in the execution of the implementation tasks) and across space (i.e., the execution of the implementation tasks was conducted more rapidly in some areas of the country than others and resulted in the emergence of heterogeneous forms of regulation across the country). The present case study, therefore, allows to extend the empirical range of studies on regulatory reform implementation in ways that have not been generally pursued in the existing scholarly literature so far.

The selection of the case reflects, in other words, a variation-centred strategy for researching the implementation of regulatory reforms of infrastructure. Existing studies on this area did not pay enough attention to the political economy of the implementation stage of the regulatory reform policy cycle. Instead, how a regulatory reform mandate is executed bears important consequences for the establishment of a new regulatory regime and for the performance effects of regulatory systems. Existing studies, moreover, did not especially focus on the role played by context conditions related to multi-level governance systems on the path and outcome of the regulatory reform implementation process. Instead, features attached to a multi-layered system of governance - such as the functions, responsibilities, and prerogatives of sub-national governments - play an important causal role in the process dynamics of regulatory reform implementation, especially 
when the territorial configuration of the regulated infrastructure network extends across the territorial organisation of sub-national governments' jurisdictions. Because of the characteristics of the selected case episode, the execution of this research design in the form of the present case study yields some explanatory arguments that have no clear counterpart in the existing literature on reforming the regulatory systems of infrastructure industries.

\section{Overview of the case.}

The case selected for this study is the episode of the implementation of the regulatory reform of the water industry in Italy conducted in the period between 1994 and 2006. The episode begun in January 1994, when a piece of legislation, that had been made with the aim to improving the dismal state of water infrastructure and dissatisfying performance of the water industry (Act 36/1994), came into force. Until that time, the water industry in Italy had been mostly regulated through public ownership and control of water firms, while a minimal part of water services were provided by business companies. The water reform, instead, provided that the water industry would be regulated through a new system which combined selected features of franchise allocation and discretionary regulation models. The reform content provided the liberalisation (i.e., water services would be assigned through competitive tenders for franchises rather than be retained under public ownership and control) and the re-regulation of the water industry (i.e., water firms would be subjected to tariff and quality regulation by a system that combined both local regulatory authorities - called Autorità d'Ambito - 
and a central regulatory authority - called Comitato di Vigilanza per l'Uso delle Risorse Idriche). Additionally, the reform entailed the privatisation of the water industry, provided that franchise allocation would open up the possibility for private operators and investors to enter the water business.

The temporal structure of the episode of the implementation of the water reform can be conceived to include two events that relate to the liberalisation and re-regulation part of the implementation part of the policy cycle, namely aligning sub-national legislation with the national reform statute and establishing new regulatory authorities, and an event that relates to the privatisation part, namely awarding water franchise contracts. The liberalisation and re-regulation part of the process is characterised by a first period of slow motion (1994-1997) followed by one of acceleration to establish the new regulatory system (1997-2006), and the privatisation part is characterised as well by a first period of slow motion (19942001) followed by one where water franchises were awarded at increasing speed across the country (2001-2006). Additionally, the implementation of the water reform did not proceed at equal pace all over the country. In some areas of Tuscany called Alto Valdarno, local governments executed the implementation tasks required to liberalise, re-regulate, and privatise water services relatively faster than in other areas of Italy, as the local water regulatory authority was established in 1997 and the water franchise was awarded in 1999. As we shall see, this variation over time and across space relates to a complex process dynamics of water reform implementation where an important role was played by the multi-layered structure of the country's governance. 
The outcome of the implementation of the water reform in Italy was the set up of a new water regulatory regime in most of the country. By the end of the episode in 2006, the execution of the water reform mandate resulted in the establishment of 91 local regulatory authorities (Autorità d'Ambito) in the country and the award of water franchises by 47 local regulatory authorities. According to a 2009 survey, water franchises were eventually awarded in 67 watershed areas to 102 firms in total. Most of these firms (58) were fully owned by local governments (so-called "in house" firms), 27 were mixed public-private ownership firms, 11 were public sector firms that enjoyed some special "incumbent's right" that made them exempt from tender offer competitions, and 6 were business companies selected through tender offer competitions. The implementation of the 1994 water reform in Italy, therefore, resulted in quite heterogeneous forms of water service management at the local level. As we shall see, the same process dynamics of implementing the regulatory reform of the water industry plays an important role in order to account for such heterogeneity of the implementation outcome.

The episode of the implementation of the water reform in Italy presents quite specific features, with respect to both the country and sector context. Taking into account these specific features is important, in order to clarify whether the particular context conditions place limitations to the generalisability of the research findings of the case study. At least two cautionary notes should be addressed. First, the episode happened in Italy, a country that traditionally experienced difficulties in implementing public policies in general, especially those which originate from EU directives (La Spina and Sciortino, 1993). As pointed out by Börzel (2001:819), for 
example, the group of countries which consistently infringed the transposition of EU legislation is "led by Italy, whose non-compliance record almost makes it a class of its own!" (exclamation mark in the original). Such a negative record of performance in implementing EU policies might suggest that Italy as a country presents some "limit conditions" that relate to a country environment that is not particularly supportive of public policy implementation, at least. Rather than a limitation, however, this particular feature of Italy constitutes an opportunity, as it allows to research the implementation of regulatory reform in a context that is expected to pose difficulties to substitute a regime of public ownership of service provision with one based on franchise allocation and discretionary regulation. In other words, if the case episode were selected in a case country context that plainly supports the implementation of public policies, then we would miss gathering evidence of how the process dynamics of the implementation stage matters in the execution of a regulatory reform mandate.

A second cautionary note is that the episode took place in the water industry, a sector which presents unique economic and social features with respect to other infrastructure (Rees, 1998). The water industry presents stronger traits of natural monopoly than other infrastructure industries. Moreover, the water industry provides services which are considered an essential requisite for human health and well-being, and whose delivery is often claimed to rest in the direct responsibility of the government. Because of this, the substitution of public ownership with some competition-based mechanism for regulating the water industry is often strongly opposed in many countries, where the public generally favours public ownership of 
water firms rather than exposing water services to the private interests of business companies, in particular multi-national ones (Finger and Allouche, 2003). This particular feature of the water industry might suggest that implementing water regulatory reforms presents quite specific challenges which are not faced in the implementation of regulatory reforms in other infrastructure industries. Researching the implementation of the water reform in Italy, however, is particularly interesting exactly because of such difficulties. Indeed, the implementation of the water reform in Italy is exemplar of how regulatory reforms can take place also in an industry like water, which has been subject to liberalisation, re-regulation, and privatisation reforms more rarely than other infrastructure (Ballance and Taylor, 2005; Massarutto, 2007).

\section{The boundaries of the case.}

Some care should be placed on the definition of the boundaries of the case episode. At least three issues, here, should be addressed. The first issue is how the case episode can be analytically distinguishable from the rest of the policy cycle related to the regulatory reform of the water industry, in particular from the policymaking stage of the 1994 water reform. It is well known that the distinction between policy-making, implementation, and evaluation is a convenient, albeit simplistic, "textbook" approach to disentangle the complexity of the policy cycle into stages (Barrett and Fudge, 1981). Such distinction papers over the fundamental continuity between policy making, implementation and evaluation, and the difficulties which arise, both conceptually and empirically, to define where policy 
ends and implementation begins (Dunsire, 1978). Policy implementation, indeed, can be hardly separated from the rest of the policy cycle, in particular if we take into account that implementers may still engage in making public policy and in evaluating it, and that policy-makers may intervene during the implementation stage with supplementary policy actions (Hambleton, 1983; Hupe, 1990; Schofield, 2004).

The view that the implementation of public policies goes hand in hand with its making and evaluation has been endorsed, among others, by Wildavsky and Majone (1978: 408), who argued that "implementation will inevitably reformulate as well as carry out policy". A similar point was made by Dror (1968: 191), who argued that "re-policymaking is needed during the execution of the policy", and by Bunker (1972:72), who pointed out that in implementation "the [policy] content is re-assessed, interpreted, and recast sometimes with care to preserve the core of the original intent, sometimes, with thoughtful revision of the original assumptions and objectives, and sometimes as an unreflective response in terms of bureaucratic conventions or situational constraints which tend to counter the framers' intent". More recently, also Hill (1997: 375) highlighted that "there has been a dangerous tendency to separate implementation issues from policy-making issues, when what is important is to understand their inter-relationships". These views suggest that research on the implementation stage of policy cycles should be particularly attentive to anything going on in the temporal context where the public policy implementation process is embedded.

Research on the implementation stage of a policy cycle, however, is also 
conventionally characterised by precise temporal boundaries. The enactment of a policy reform, in particular, is an important "reference point" in time, because it is related to the introduction of new formal institutions into the regulated policy domain. The implementation stage of a policy cycle is typically understood as a process that begins after a reform is enacted in a piece of legislation and then comes into force. Accordingly, the case episode of the implementation of the water reform in Italy includes the events that took place after the coming into force of Act no. 36/1994 in January 1994. The events related to the drafting and approval of Act no. 36/1994 by the Parliament of Italy until its coming into force in January 1994, therefore, constitute part of the "background history" with respect to the episode of water reform implementation (background history to the 1994 water reform will be briefly narrated in Chapter 3).

The second issue to discuss is what is the outcome of the case of the implementation of the water reform in Italy, conceived as an instance of the process of implementing an infrastructure regulatory reform. As Pettigrew (1997:344) argued, processual research should specify an outcome to explain, which is used "to create variability in the research design and provide an anchor in the study - a constant simple repetitive question which keeps the researcher on track through the interactive cycles of deduction and induction". The outcome of a regulatory reform implementation process is a multi-faceted construct. Within the present case study, it can be conceptualised along at least three dimensions. First, we can consider the extent to which the new regulatory system is put into place, i.e., how much of the country's water infrastructure resulted subjected to the new regulatory system by the 
end of the case episode. Second, we can take into account the period of time needed to set up the new regulatory system, i.e., how long it took to execute the mandate contained in Act 36/1994. Third, we can also look at the extent to which the new regulatory regime differs from the original one, i.e., how much of the water industry resulted opened up to the participation of private operators and investors.

The outcome of the implementation of the water reform in Italy is defined along each of these three dimensions. With respect to the extent to which the new regulatory system is put into place, and with reference to 2009 data, the implementation of the water reform resulted in the award of water concessions by 67 local regulatory agencies, out of 92 which had been established in the country. With respect to the period of time needed to set up the new regulatory system, the implementation of the water reform took a a period of about 12 years (1994-2006) until water services were subjected to the new regulatory system almost all over the country's territory (setting aside just 4 watershed areas). With respect to the extent to which the new regulatory regime differs from the original one, the implementation of the water reform resulted in the entry of private operators and investors in part of the water industry only, in the form of water franchises assigned to mixed public-private ownership firms (27) and to business companies (6), while originally close to all water services were provided by firms owned and controlled by public authorities.

The third issue to discuss is how the case of the implementation of the water reform in Italy can be distinguished from the context. As Yin (1994) highlighted, the context is typically deeply intertwined with the case under investigation, yet 
clear boundaries should be drawn between the two. As we shall see, the context of the implementation of the water reform in Italy includes previous events, such as the making of the 1994 water reform and the implementation of EU water-related directives (e.g., those on drinkable water and nitrate pollution ${ }^{18}$, on urban waste water treatment ${ }^{19}$, and on water management ${ }^{20}$ ), and contemporaneous events, such as the implementation of the 1994-2000 and 2000-2006 Community Support Framework (CSF) programmes (EU-funded programmes for infrastructure development), the passing of legislation for funding sewage and wastewater treatment infrastructure in 1997, a decision of the European Court of Justice in 1999, the making of a constitutional reform which came to force in 2001 , and the making of two reforms of local public services that were enacted in 2001 and 2003. As part of the context, all these events related to the process dynamics of the water reform implementation episode. It is not an explanatory task that is undertaken here, however, to account for the process dynamics of these previous and contemporaneous events, that are rather brought to bear into the analysis insofar as they exerted any influence on the path and outcome of the water reform implementation episode only.

\section{Data collection.}

Data on the implementation of the water reform in Italy were collected from primary, secondary, and tertiary sources. Primary sources included parliamentary minutes, official reports and other documents issued by the national water

18 Directive $91 / 676 /$ EC.

19 Directive $21 / 271 /$ EC.

20 Directive 2000/60/EC. 
regulatory agency (Comitato di Vigilanza per l'Uso delle Risorse Idriche or Supervising Committee on the Use of Water Resources), and interviews ${ }^{21}$. Secondary sources included reports issued by the water research centres Proaqua, Astrid, and Utilitatis, proceedings of the conferences "H2Obiettivo 2000" organised by the water firms' association Federgasacqua (renamed Federutility from 2005), and articles from the press Il Sole 24 Ore and La Repubblica. Tertiary sources included various scholarly works done on the water reform in Italy, such as Massarutto (1993, 2005), Barraqué (1995), Bigatti et al., (1997), Guffanti and Merelli (1997), Riccaboni and Grossi (2000), Muraro (2003), Gilardoni and Marangoni (2004), Fraquelli and Moiso (2004), Anwandter and Rubino (2006a, 2006b), Citroni and Lippi (2006), Citroni et al. (2007), Lippi et al. (2008), Carrozza (2008), and Danesi et al. (2008).

The collection of data from primary sources mostly relied on written documents, in particular those issued by the Supervising Committee on the Use of Water Resources. These included 13 yearly reports to Parliament issued between 1996 and 2009, and 22 documents concerning the state of the water industry and the implementation of the water reform issued between 2000 and 2005. Other primary sources included the parliamentary minutes regarding the making of the water reform between 1992 and 1994, and 20 interviews with informants based in the Supervising Committee on the Use of Water Resources (4), in the local regulatory authorities (11), in the water firms (3), in the association of water firms Federgasacqua (1), and in the research centre Istituto Ricerche Sociali (1). Interviews were conducted in person (9), on the phone (2), and by email (9). 21 All sources in Italian that are quotes in this thesis were translated into English by the Author. 
Secondary sources included 23 reports of the water research centre Proaqua issued between 1995 and 2001, 546 articles from the press Il Sole 24 Ore and 60 from La Repubblica published between 1990 and 2006. The full list of data sources is in the Appendix of the thesis.

The collection of data from interviews deserves some additional qualifications. Access to interviewees, which were selected on the basis of their positions in the main organisations of the water policy community in Italy, proved difficult because of unavailability, dispersion of the potential interviewees over several locations, and confidentiality of information that, at the time when the fieldwork was conducted, related to water franchises that were under administrative trials or investigation. Several cases of water franchise award, in fact, were appealed to courts by applicants that had lost the tender offer competitions including the very first instance of award of water franchise in the country, in Alto Valdarno. Some cases of water franchise award, instead, were subjected to inspection by Anti-mafia Investigation Department of the Ministry of Home Affairs because of suspicion of influence of crime organisations on water public contracts. Because of these reasons, part of the water reform implementation episode at the local level has not been investigated so deeply as it would be otherwise possible once investigations and trials are concluded.

Apparently, difficulty to access interviewees did not seriously compromise data collection, however. Interview data were mainly used to complete and triangulate data which were collected from other primary and secondary sources. The interviews provided confirmation of the information already possessed from 
documentary sources and strengthened the overall understanding of the water reform implementation episode, while they offered relatively little additional insights than was inferred from written sources. On a few occasions only did some interviewees privately disclose some information concerning, in particular, the coordination between local governments, local government-owned water firms, and the local regulatory agencies regarding the award of water concessions. These bits of information were provided off-records, therefore they have not been explicitly used in the analysis of the case (although they contributed to clarifying the understanding of details of the water reform implementation episode).

\section{Narrative writing and analysis.}

The collected data were stored and coded through the Nvivo software package. Originally, the coding frame was based on theoretically-derived concepts and constructs that originated from the literature review on regulation and regulatory reforms. During the process of examining the empirical evidence, the coding frame was progressively amended and enriched in order to reflect the variety of the public discourse carried out in the water policy community in Italy in the period between 1994 and 2006. In anthropological terms, the evolution of the coding frame reflected the learning of the emic knowledge of the water policy community, while at the outset the coding frame was only based on the etic knowledge of the researcher ${ }^{22}$. In methodological terms, this evolution of the coding

22 The distinction between emic and etic knowledge arose in the field of linguistics (Pike, 1954) and was later employed in anthropology (Harris, 1964). Emic knowledge refers to "accounts, descriptions, and analyses expressed in terms of the conceptual schemes and categories regarded as meaningful and appropriate by the native members of the culture whose beliefs and behaviours are being studied. An emic construct is thus correctly termed emic if and only if it is in accord with the epistemological principles deemed appropriate by the insider's culture. Thus 
frame broadly follows the "grounded theory" approach (Glaser and Strauss, 1967; Strauss and Corbin, 1994) to data collection, which highlights the importance of progressively understanding the cognitive structures of the empirical social domain under study. The resulting coding frame is shown in the Appendix of the thesis.

Coded data provided input sources for writing the narrative history of the episode of the water reform implementation. Writing the narrative history required to construct accounts of events on the basis of the information collected about who performed what actions, when, under which circumstances, and in relation to what rationales or intended aims. The coding process provided the ordering of data according to code categories (i.e., nodes, in Nvivo framework). Writing the narrative, however, entailed the arrangement and use of data about the episode of the water reform implementation in relation to a structure of events, that are understood as abstract entities that are intellectually constructed for making sense of history. In operational terms, the process of writing the narrative history required to formulate accounts of events in linear narrative form, while bits of information on the same events were possessed in the form of a hierarchical tree structure of nodes. The result of the writing effort, therefore, presents itself in a form of a narrative history that bears little resemblance of the coded data structure based on

the validation of emic knowledge becomes a matter of consensus - namely, the consensus of the native informants, who must agree that the construct matches the shared perceptions characteristics of their culture" (Lett, 1990: 130). Etic knowledge, instead, refers to "accounts, descriptions, and analyses expressed in terms of the conceptual schemes and categories as meaningful and appropriate by the community of scientific observers. An etic construction is thus correctly termed etic if and only if it is in accord with the epistemological principles deemed appropriate by science; in other words, any and all etic constructs must be precise, accurate, logical, comprehensive, replicable, falsifiable, and observer-independent. Thus the validation of etic knowledge becomes a matter of logical and empirical analysis - in particular, the logical analysis of whether or not the construct has been falsified and whether or not the conclusion has been replicated" (Lett, 1990: 131). The distinction between the two perspectives is also presented in Stake (1995). 
the Nvivo tree structure of nodes.

The process of writing the narrative history of the water reform implementation was consonant with accounts of narrative writing in social science research. Connelly and Clandinin (1990), for example, described the process as relatively unstructured and fragmented - one where "material written throughout the course of the inquiry often appears as major pieces of the final document", and where "materials written for different purposes such as conference presentations may become part of the final document" (Connelly and Clandinin, 1990: 7). Writing the narrative history proceeded through successive stages of reformulation and refinement of the text, that was provisionally incorporated in conference papers and working papers before reaching the final outlook contained in the present thesis.

The analysis of the empirical evidence, as anticipated in the previous chapter, was conducted through the application of two theoretical frameworks in turn - namely, institutional rational choice approach in the form of the analytic narrative (Bates et al., 1998, 2000; Levi, 2002) and institutional processualism (Barzelay, 2003; Barzelay and Gallego, 2006). The first theoretical framework has been applied by modelling the interaction between local governments, regional governments, and the central government as a series of games. Modelling the interaction between actors as a series of games is a relatively common research approach adopted in current public policy implementation studies (Hill and Hupe, 2002; Klijn, 1996; Klijn and Koppenjan, 2000; Klijn et al., 1995; Meier and O'Toole, 2003; O'Toole, 1997a, 1997b; Scharpf, 1990, 1991, 1994, 1997). Among these works, for example, O'Toole (1997a) encouraged to make use of a game 
theoretic approach for researching policy making and implementation even in a non-technical sense, i.e., through an explanatory framework which uses the assumptions, the logic, and the language of game theory as heuristics, even without any formal (mathematical) modelling. In a similar vein, Bates et al. $(1998,2000)$ and Levi (2002) suggest to conduct the analysis by identifying, first, the key players (e.g., central government, regional governments, local governments), their goals (e.g., local governments' maximising expected utility from ownership and control of water firms), and features of the environment that influence actors' behaviour (e.g., local governments' choice options available in the execution of the water reform mandate) from the narrative history of the case. They advise, then, that the analysis should entail the definition of game theoretic models tailored to specific situations (Levi, 2002: 112), where "situations" are understood as choice settings where players take into account other players' choice options and payoff for determining their own strategies (e.g., settings where local governments choose whether to cooperate with each other to define new water district jurisdictions or not). Game theoretic models are fashioned in such a way that sub-game perfect equilibria parallel the observed behaviour of the players.

The institutional processualist approach has been applied by formulating the causal reconstruction of the trajectory of water reform implementation through explanatory arguments that place particular attention to how initial conditions, policy design features, and changing context conditions affect the flow of efforts of local governments, regional governments, and central government. In the formulation of these explanatory arguments, hypothesised social mechanisms 
perform the important function of providing rationales for any particular feature of the water reform implementation trajectory that is explained. Because of such important role, the identification of social mechanisms deserves some clarification. Within the social science literature, several social mechanisms have been defined ${ }^{23}$. An issue arises, then, concerning how to select - out of the "repertoire" of social mechanisms generally discussed in social science disciplines - those that can help detailing how the social process under consideration works and why. A general guideline for the identification of relevant social mechanisms that is followed in this study builds on the requirement that the selected mechanism should contribute to the explanatory argument by relating particular features of the explanandum under consideration (e.g., inaction, continuity, or change with respect to actors' past behaviour) to causal factors that are included within the present case process conditions. For instance, as we shall see, the mechanism of network diffusion (Hedström and Swedberg 1998, Coleman et al., 1957) is selected to help explaining the observed spreading of liberalisation, re-regulation, and privatisation of water services across the country, provided that process conditions include the presence of a policy community of water experts who provided connections between local governments and water firms through which ideas on the implementation of the water reform were conveyed from one site to another. In addition, guidelines for the

23 A tentative, albeit incomplete, list of social mechanisms would include, for example, instrumental rationality (Gambetta, 1998), logic of appropriateness (March and Olsen, 1989; March, 1994); incentives (Cowen, 1998), belief formation (Hedström and Swedberg, 1998), selffulfilling prophecies (Merton, 1968), network diffusion (Hedström and Swedberg 1998, Coleman et al., 1957), threshold-based behaviour (Granovetter, 1978), contagion (Schelling, 1978, 1998), rational imitation (Hedström and Swedberg, 1998), wishful thinking and spillover (Elster, 1998), committed interpretation (Salancik and Pfeffer, 1978; Weick, 2001), attribution of opportunities and threats, organisational and social appropriation, actor certification, brokerage, category formation, identity shift, opportunity spirals, framing of the dispute, attribution of similarity, and emulation (McAdam et al., 2001). 
selection of social mechanisms include the requirement that empirical evidence should not contradict the hypothesised causal relationship between process conditions and the explanandum under consideration. For example, empirical accounts of the spreading of liberalisation, re-regulation, and privatisation of water services across the country include an active role played by the policy community of water experts, who contributed to the diffusion of ideas concerning the viability and effects of implementing the water reform (especially building on the experience in Alto Valdarno) among local governments and water firms.

\section{Chapter summary.}

This chapter presented the research question posed in this thesis, namely how should generalised arguments about the implementation of regulatory reforms of infrastructure be qualified (or otherwise adapted) in order to reflect evidence of diverse causal tendencies within a multi-level governance context scenario? This question is tackled through a case study of the episode of the implementation stage of a policy cycle intended to reform the regulatory system of the water industry in Italy in the period 1994-2006. This episode is selected because of its features, especially a context that includes a system of multi-level governance. In addition, the episode presents variation both over time (i.e., a period of relatively slow implementation was followed by one of more rapid execution of the policy reform mandate) and across space (i.e., policy reform efforts were more intense and faster in some areas of the country than others). The explanation of the case will be precisely concerned with accounting for these features of the episode of regulatory 
reform implementation.

The rest of the chapter illustrated the sources of data collection, criteria for data coding and principles of narrative writing, and features of the analytic frameworks. Data were collected from primary, secondary, and tertiary sources. Data coding followed a "grounded theory" approach insofar as the coding frame was progressively enriched to mirror the variety of data content from informants and other data sources. The process of narrative writing, however, followed the principle of adhering to the structure of events, with the effect that the resulting historical narrative bears little resemblance of the coded data structure based on the Nvivo hierarchical tree structure of nodes. Finally, the chapter illustrated how the two analytic frameworks - institutional rational choice and institutional processualism - have been applied for explaining the path and outcome of the episode of the water reform implementation in Italy. 
PART II 


\section{Chapter 3}

\section{Historical Background: Water Policy in Italy (1865-1994)}

This chapter provides the historical background of the implementation of the water reform in Italy in the period between 1994 and 2006. The chapter will begin by narrating the evolution of water policy in Italy during the period between 1865 and 1994 and it will focus, in particular, on three water reforms made in 1976, 1989, and 1994. Then, it will describe the design of the 1994 water reform, with particular attention paid to illustrate the type of new regulatory tools for the water industry in the country. The content of this chapter, therefore, does not strictly belong to the empirical focus of this thesis, by chronological criteria. How water policy in Italy evolved over time, however, is important in order to gain an historical understanding of the context where the 1994 water reform was made. Moreover, the reasons for the making of the 1994 water reform - especially, those that account for the particular content of the policy design choices made by policymakers - are critical for comprehending the causal role played by features of the water reform design on the path and outcome of the water reform implementation process.

This chapter is organised into five sections. The first one will narrate the evolution of water policy in Italy since the very origins of the country, in 1865, until the 1970s. Section two will illustrate the water reform that was passed in 1976, and section three will focus on the water reform passed in 1989. Section four will 
provide an account of the making of the 1994 water reform, including the rationales that led policy-makers to propose, consider, and eventually pass the reform bill. Finally, section five will describe the design of the 1994 water reform.

\section{The evolution of water policy in Italy (1865-1994).}

During the period from 1865 and 1994, the regulatory regime of the water industry in Italy - that is, the "specific constellations of ideas and institutions" (Vogel, 1998: 20) regarding the structure, behaviour and performance of the water industry - went through a remarkable evolution (Goria and Lugaresi, 2002). At the beginning of this period, in 1965 the recently formed Kingdom of Italy mainly focused on carrying out public works for protecting land and population from water-related dangers (e.g., flooding) and constructing aqueducts for both civil and agricultural uses. By the end of this period, in 1994 the regulatory regime of the water industry was remarkably different. It included several regulations on various water-related areas, e.g., from infrastructure development to civil and soil protection, from environment sustainability and preservation to pollution, from health and sanitation to recreational uses of water. In that very year, moreover, a reform had been just enacted and would radically redesign the economic regulation of water services in the country.

During the early decades after its constitution, the Kingdom of Italy promoted the development of infrastructure for extending the provision of water supply and sewage services over the whole national territory, for protecting urban areas from flooding and other water-related dangers, and for exploiting water for 
hydro-electric power generation (Bigatti et al., 1997; Gilardoni, 1936; Lugaresi, 1995). Water regulation centred on Royal Decree 2248/1865, which drew a legal distinction between public and private water and provided that the latter (which originated from springs, rivers, and lakes) could be freely disposed by either the State or private citizens, only subjected to limitations to prevent conflicting uses (e.g., allowing free flow of water channels). The use of water was mainly regulated through a system of concessions, which were generally awarded by the Ministry of Public Works (Castelli Avolio, 1936; Vacchelli, 1940; Vitale, 1921; Vitta, 1930).

Local water services were often provided by privately-owned firms, especially in the major cities where resident populations were steadily growing over time $^{24}$. This feature of the water sector changed after the enactment of a reform of local governments (Act 103/1903, also known as "Legge Giolitti”), which allowed municipalities to own local public service firms. After Legge Giolitti, several privately-owned water firms were acquired by local governments, especially in the northern and the central regions of the country. This so-called "municipalisation process" of water services resulted in the diffusion of full local governmentownership, that became the most common form of regulation of water services in the country.

After the turn of the century, the growth of population in urban areas and the development of heavy and motor industry led to a sharp increase of demand for hydroelectric power generation. In face of greater pressure for the use of water resources, in 1933 the king enacted Royal Decree 1775 (also known as "Unified

24 As a rough indicator of the growth rate of major Italian cities, during the period between 1891 and 1901 the population of Rome grew by $54 \%$, the one of Milan $43 \%$, the one of Turin $32 \%$, the one of Palermo 27\% and the one of Naples 14\% (Spadoni, 2005). 
Code on Public Waters"), which provided that any water which was relevant for serving the "general public interest" was granted "public utility" legal status. The conferment of "public utility" status, which was sanctioned by royal decree (after 1946, by decree of the President of the Republic), marked a limitation of private claims on water on the one hand, and expanded the competences of the State on the regulation of water for the "public interest" on the other one (Caravita, 1990).

After the constitution of the Republic of Italy in 1946, water policies were especially keyed to developing the infrastructure needed to support post-war reconstruction and to promote the industrialisation of the whole country. In 1950, the central government launched a large public infrastructure development programme targeted to the infrastructure-poor southern regions of the country, which was carried out by the special-purpose central government-owned agency "Cassa per opere straordinarie di pubblico interesse nel Mezzogiorno d'Italia" ("Fund for special public works in the South of Italy", also known as "Cassa per il Mezzogiorno"). For several decades, the agency played an important role in carrying out planning and construction of large water public works (especially, dams and long-range aqueducts). Until its termination in 1992, Cassa per il Mezzogiorno played a fundamental role in filling most of infrastructure deficit of southern regions, and contributed forming a class of engineers and managers with significant technical expertise and hydro-geographical knowledge (Gualini, 2004).

Since the 1970s, Italy's water policies started to address issues related to environmental preservation and sustainability, pollution, health and sanitation. Most of these policies originated from the transposition of environmental directives 
issued by the European Community, especially in the area of quality standards for drinking and bathing waters and the discharge of particularly dangerous or polluting substances, into the national legislation. At that time, the European Community lacked explicit competences to regulate environmental matters ${ }^{25}$, but the directives were justified on the basis that harmonised environmental standards across EC Member States served the goal of levelling competition in the common market ${ }^{26}$ and generally were received favourably by the public within EC member states. The rise of environmental concerns in the public domain encouraged the making of further standard-setting directives at the EC level (Knill and Liefferink, 2007) and triggered pressure for compliance in the Member States - albeit not so much in Italy, where the transposition of EC directives often lagged behind the set deadlines (Börzel, 2000, 2001; La Spina and Sciortino, 1993).

\section{The 1976 water reform.}

Since late 1960s, the public opinion in Italy became increasingly disturbed by the mounting evidence that people and the environment were not effectively protected from water-related dangers. In 1951, the flooding of river Polesine caused

273 deads and the evacuation of more than 100,000 people from their houses ${ }^{27}$. In

25 Originally, environmental, water, and health and sanitation policies had not been included in the domains of the European Community provided in the founding Treaty of Rome in 1957.

26 The issue of environmental directives was justified on the basis of articles 100 ("the Council "shall, acting unanimously on a proposal from the Commission and after consulting the European Parliament and the Economic and Social Committee, issue directives for the approximation of such laws, regulations or administrative provisions of the Member States as directly affect the establishment or functioning of the common market") and 235 ("if action by the Community should prove necessary to attain, in the course of the operation of the common market, one of the objectives of the Community and this Treaty has not provided the necessary powers, the Council shall, acting unanimously on a proposal from the Commission and after consulting the European Parliament, take the appropriate measures") of the Treaty.

27 Source, Sistema Informativo sulle Catastrofi Idrogeologiche, National Research Centre. 
1966, the flooding of the river Arno resulted 34 deads and over 5,000 people becoming homeless (Lees, 2006), and put the historical and cultural heritage of Florence at high risk. These events dramatically showed that the country lacked adequate defence from water-related hazards, in particular in highly populated urban areas. Following the river Arno flooding, in 1966 the Minister of Public Works and the Minister of Agriculture and Forestry established an inter-ministerial committee, chaired by MP Professor Giulio De Marchi, which was charged with reviewing the state of the water sector in the country and proposing new policy measures for better protecting people, private property, and national heritage.

The De Marchi committee, which concluded its works in 1970 (the committee proceedings were published in 1974), advised that the problems of the national water system (in particular, the risks of droughts and flooding) should be tackled through a comprehensive approach to water resource planning at the level of the watershed river basin (Passino, 2005). The idea of managing water resources at the watershed river basin level had gained attention within international academic and professional water community circles after it had been adopted by various countries, in particular France, where six river basin agencies had been established in 1964. In 1974, the idea that watershed river basin management could be the solution to the problems of the water system in Italy was widely discussed at the 4th Conference of FNAMGAV, the main national association of local governmentowned water and gas firms. During the conference, speakers from the academic and practitioners' ranks praised the watershed river basin management approach, especially in the relatively decentralised "British variant" (i.e., referred to the 
experience of England and Wales, where ten independent authorities had been established in 1973) rather than in the the more centralised French one.

After about six years of parliamentary works, in 1976 the government enacted a water reform (Act 319, titled "Norms on the protection of water from pollution"), which contained a new regulation for water resource and service management. The water reform partially decentralised the competences on regulating water resources and service management to the regions, the provinces, and local governments. The central government (precisely, a committee formed by the Minister of Public Works, the Minister of Health, and the Minister of Maritime Trade) would provide the criteria for surveying water resources, set and update the standards for wastewater discharges, and issue the general water restoration plan, which included all water infrastructure works needed in the sewage and wastewater treatment systems in order to contain pollution. The regional governments were required to map water resources, to organise the monitoring system of wastewater discharges, and to issue, within three years (in agreement with local governments), regional water restoration plans, which provided the reorganisation of water technical and administrative offices, detailed the quantitative and qualitative standards for wastewater discharges, and programmed water infrastructure works ${ }^{28}$. The provinces were required to maintain a registry of wastewater discharges and to monitor discharges quality. Local government were assigned the task to manage (either individually or jointly into consortia) local water service delivery - supply, sewage and wastewater treatment services. Users of water services would be

28 The information provided by the mapping of water resources and the regional water restoration plans would be later used by the national government for drafting the general (country-wide) water restoration plan. 
charged two distinct tariff fees ${ }^{29}$, one for water supply and the other for sewage and wastewater treatment services.

The making of the 1976 water reform took place at a time when the EC Commission had just started to focus on environmental policy issues. In 1975, the EC Commission issued the so-called "first wave" of environmental directives (Kallis and Nijkamp, 1999), which mainly intended to harmonise national environmental laws in order to remove trade barriers and prevent distortion of competition in the Common Market, protect public health, protect and preserve the environment, and promote measures for dealing with regional and cross-national environmental problems. The "first wave" included, in particular, directives COM 75/440 and COM 76/464, which provided an overall regulatory framework for drinkable water and wastewater discharge. COM 75/440 required member States to monitor surface waters and undertake the actions needed to comply with drinkable water quality standards. COM 76/464 required member States to undertake the necessary actions to eliminate pollution of water from selected dangerous substances, and set up a regime of wastewater discharge permits. The provisions contained in these directives partially contradicted the regulation contained in the 1976 water reform. For example, COM 76/464 provided that wastewater discharge permits would expire after a given deadline, while Act 319/1976 did not set any expiry date nor any review of the water discharge permits. Since the very origin of EC water policy, therefore, a certain degree of "mismatch" was created between the

29 A committee formed by the Minister of Public Works, the Minister of Health, the Minister of Maritime Trade, and the Minister of Finance issued the formula for calculating the sewage and wastewater treatment tariff fees in the Decree of the President of the Republic on $24^{\text {th }}$ May 1977. The actual tariff, articulated through users categories, would be set, within 180 days, by the regions. 
EC normative system and the national legislation.

The implementation of the 1976 water reform delivered modest results, on the whole. Deadlines which had been set for complying with quality standards were repeatedly postponed by the central government. Delays occurred in drafting the regional water restoration plans, because of both the emergence of both timeconsuming technical matters and political issues related to the regulation of competing uses of water resources. Control and sanction systems were not effectively enforced, with the effect that water quality standards were often violated by both local governments and private users alike. No evidence was collected, moreover, about whether the water reform resulted in any improvement of water resource protection and preservation, environmental pollution, and safety for people, property, and national heritage.

\section{The 1989 water reform.}

During the 1970-80s, the EC Commission issued a growing number of environmental directives. Part of these directives regulated water quality standards, like COM 80/778 (which set standards for water in the distribution network), COM 76/160 (on water standards for bathing), and COM 78/659 and COM 79/923 (on water standards for supporting fish and shellfish life). Part of them, instead, were focused on regulating pollution control and wastewater discharges, like various “daughter" directives which followed COM 76/464 (including a list of dangerous and polluting substances subjected to discharge standards) and COM 80/68 (on discharges to groundwater). 
In Italy, most of these directives were transposed into the national legislation with considerable delays. Between 1976 and 1989, only 4 directives were transposed (COM 75/440, 79/869, 80/778 and 86/290) out of 17 which had been issued (Lanz and Scheuer, 2001). The transposition of many directives (e.g., those on water standards for supporting fish and shellfish life) was deferred by appealing to presumed vagueness of the text. The pollution control and wastewater discharges directives were transposed only partially because the European Council did not come to an agreement about the detailed list of substances subjected to regulation for several years (still two decades after the COM 76/464, standards had been agreed on only 18 of about 130 substances originally listed). Despite the modest record of transpositions into the national legislation, however, these directives did affect the domestic policy debate on water and the environment. Politicians and the media started to devote more and more attention to issues like the control of water pollution and of wastewater discharges, which had been largely neglected in the past. Public opinion came to gradually develop a concern with water and environmental problems and to favour the making of new public policies in this field, especially when, in 1988, a massive eutrophication process affected the northern Adriatic sea and experts imputed the phenomenon to the poor wastewater treatment systems of the Po Valley.

Within this historical context, in 1989 the government came to enact a water reform (Act 183, titled "Norms on the organisational and functional reconfiguration of the protection of the soil") that aimed to provide a comprehensive regulatory framework for pollution control and preservation of water resources. Act 183/1989 
centred on the concept that the watershed river basin was the most appropriate territorial unit for planning and managing water resources. The design of the water reform identified 11 watershed river basins of national relevance ${ }^{30}, 18$ watershed river basins of interregional relevance ${ }^{31}$, and provided that the regions would establish local watershed river basins for minor streams. It also provided that newly established River Basin Authorities (Autorità di Bacino) would formulate watershed river basin plans which contained the survey of water resources, the identification of water problems to tackle, and a plan of interventions on water infrastructure and of water resource management.

The 1989 water reform provided that, at the national level, the Chairman of the Council of Ministers would issue the plans of the watershed river basins of national relevance (proposed by the Minister of Public Works and approved by the Council of Ministers ${ }^{32}$ ) and the national programme of interventions ${ }^{33}$. The Minister of Public Works would supervise the design and construction of water infrastructure works under the State competence. The Minister of the Environment, which had been recently instituted by Act 349/1986, would exercise powers on pollution

30 The 11 watershed river basins of national relevance were those of the rivers Isonzo, Tagliamento, Livenza, Piave, Brenta-Bacchiglione, Adige, Po, Arno, Tevere, Liri-Gaigliano, and Volturno.

31 The 18 watershed river basins of interregional relevance were those of the rivers Lemene, FissaoTartaro-Canal Bianco, Reno, Marecchia, Conca, Tronto, Sangro, Trigno, Saccione, Fortore, Ofanto, Bradano, Sinni, Magra, Fiora, Sele, Noce, and Lao.

32 The Chairman of the Council of Ministers would issue the plans of the watershed river basins of national relevance after also hearing the so-called National Committee for the Protection of the Soil, which included representatives from various ministries, public agencies, regions, and local governments. The National Committee for the Protection of the Soil, however, was later abolished by Act 281/1997, and its functions were assigned to the Standing Committee for the Relationships between the State and the Regions.

33 The national programme of interventions was proposed by a committee formed by the Minister of Public Works, the Minister of the Environment, the Minister of Agriculture and Forestry, the Minister for Coordination of Civil Protection, the Minister for the Extraordinary Intervention in the Mezzogiorno, the Minister for Regional Affairs, and the Minister for Cultural and Environmental Heritage. 
prevention and waste disposal. At the sub-national level, the 1989 water reform provided that the regions defined the watershed river basins of regional relevance, establish the regional watershed river basin committees, coordinate the surveying of water resources and the planning of water resource preservation and use, draft and issue the regional watershed river basin plans, and plan and carry out water infrastructure works and maintenance programmes in the regional and inter-regional basins. Local governments were assigned a relatively minor role, as the regions defined how they could take part in planning water resource preservation and use. Concerning the management of water services, Act 183/1989 also provided the possibility that the watershed river basins plans could define so-called "optimal territorial areas" where local governments would form compulsory consortia for the joint management of water supply, sewage, and wastewater treatment services.

The idea that local governments should form compulsory consortia for managing the water services had been debated for some time in water policy circles. Since the national meeting held in Trieste in 1977, the association of water and gas local government-owned firms (which was named FNAMGAV at that time and was later renamed Federgasacqua) argued that water firms could not improve operational efficiency and cost-effectiveness because of the relatively small territories of the local governments, and because the legislation prohibited local government-owned firms to operate outside the municipal territory of the owner. The formation of consortia of local governments, in conjunction with some relaxation of legislative constraints, could help bypassing these limitations to business growth. The idea of forming compulsory consortia, however, was opposed 
by the association of local government-owned firms operating solid waste disposal and wastewater treatment, which were concerned with the loss of control over local public services if they were pooled together with other municipalities.

The 1989 water reform was enacted at about the time in which the European Union came to consolidate its "image" to the public opinion as a "benevolent protector" of public health and the environment (Knill and Liefferink, 2007). After a meeting of the Ministers of the Environment of EU member States held in Frankfurt in 1988, the EC Commission launched the IV Framework Programme for the Environment, which centred around the "prevention at source" principle (which led to COM 91/271 directive on urban and industrial wastewater treatment). A few years later, the inclusion of environmental policy and sustainable development within the action domain of the European Union was definitively sanctioned by the Maastricht Treaty in 1992. By that time, EU Member States and sub-national governments had come to experience the role played by EU directives on the national and local water domains, and had started, on the basis of the"'subsidiarity" principle, to call for a more decentralised approach to the implementation of the EU directives $^{34}$.

34 On the reaction of sub-national governments to the implementation of EU environmental directives, Kallis and Nijkamp (1999) commented: "Deregulation has been used together with subsidiarity as a response to the increasing costs of the water directives to generate a call for "repatriation" and "relaxation" of water standards. ... Subsidiarity was "designed" as a term in order to reconcile the debate between "federalists" and "anti-federalists" over the future of the Union, and was formally expressed in Article $3 \mathrm{~b}$ of the Maastricht Treaty. The central idea in the concept of subsidiarity is that action should be taken at an EU level when policy objectives can be best achieved at this level. In essence, this definition leaves its practical interpretation open to political agreement and definition on a case by case basis and therefore the way it will be perceived and implemented in the future, depends much on the wider dynamics of the European unification processes". 


\section{The making of the 1994 water reform.}

During the 1980s, water firms came under mounting financial pressure because of faltering revenues, growing demand for infrastructure development, and lack of financing sources ${ }^{35}$. During the 1970, changes of tariff regulation provided that water tariffs would be set locally by provincial prices committees (Comitati Provinciali Prezzi, CPP) on the basis of the actual costs, in order for the water firms to achieve financial self-sufficiency. Water tariffs, however, were set relatively cheap because of central government's policies that aimed to contain inflation. Water firms, therefore, were not able to increase their revenues and kept asking the central government to subsidise their net cash outflow ${ }^{36}$. Water firms also needed to carry out investments in water infrastructure in order to comply with rising environmental and quality standards set by EC directives. Access to financing sources, however, was hampered by the heavily leveraged financial structure of water firms, that had formed especially after a change of legislation in the late 1950s that had allowed them to finance their net cash outflows through loans.

Among water firms, those owned by local governments as semi-independent organisations (i.e., so-called "municipalizzate" ${ }^{37}$ ) became particularly active in advocating the need for a reform of the economic regulation of the water sector. At the 1989 national conference of Federgasacqua that took place in Bologna on $20^{\text {th }}$ -

35 The overall deficit of local government-owned water firms, in particular, raised from Lire 3.5 billion in 1960 (about $2011 € 43$ million) to Lire 800 billion in 1975 (about $2011 € 3.9$ billion), to Lire 1,800 billion in 1980 (about $2011 € 4.1$ billion) (Spadoni, 2005).

36 In the 1970s, public sector water firms followed cash accounting (rather than accrual or modified accrual accounting) rules. Therefore, subsidies were based on net cash outflows rather than losses.

37 The term "municipalizzate" generally referred to organisations owned and controlled by municipalities and operating local public services, including local water supply, sewage, and wastewater treatment, as well as gas supply, local public transports, waste disposal, local schools, pharmacies, and other kinds of services. 
$22^{\text {nd }}$ November, water policy professionals and delegates of the water firms widely discussed the economic problems of the water sector and the possible solutions. The conference participants came to agree that the water industry's performance was negatively affected by high fragmentation of the sector, lack of unitary management of water services, and inadequacy of the water tariff to cover full costs and return to investments. They claimed the need for a drastic reform of the whole water industry based on the principles of integrated watershed management, involvement of private operators and investors in the water industry, cost-effectiveness, and adequate water tariffs, if water firms were to improve their performance ${ }^{38}$.

Evidence of relatively poor performance of the water industry had been recently provided by the national statistics office (Istituto Nazionale di Statistica, ISTAT). Through a survey conducted in 1987, ISTAT showed that most of the country's population suffered from relatively poor water services, supply shortages, leakage, unreliable service, and pollution (ISTAT, 1991). For example, the survey showed that more than $45 \%$ of the population experienced interruptions in water supply and was not served by sewage networks and treatment of water discharges. The share of population affected by poor water services was particularly high in the southern regions of the country, where unreliable service and lack of proper sanitation affected more than $70 \%$ of the residents. The northern and central regions were mainly affected by inadequate wastewater treatment of water used for industrial and civil purposes. Investments in water infrastructure, in contrast, were

38 It may be highlighted that, at that time, gas firms of Federgasacqua were reputed to achieve better performance than water ones in terms of financial self-sufficiency and customer service. In the 1989 Federgasacqua conference, this performance gap was occasionally raised as a point to argue that water firms should aspire to the same level of performance that gas firms had been able to achieve. 
steadily declining during the 1980's and early 1990's (Figure 3.1; Ermano, 2012).

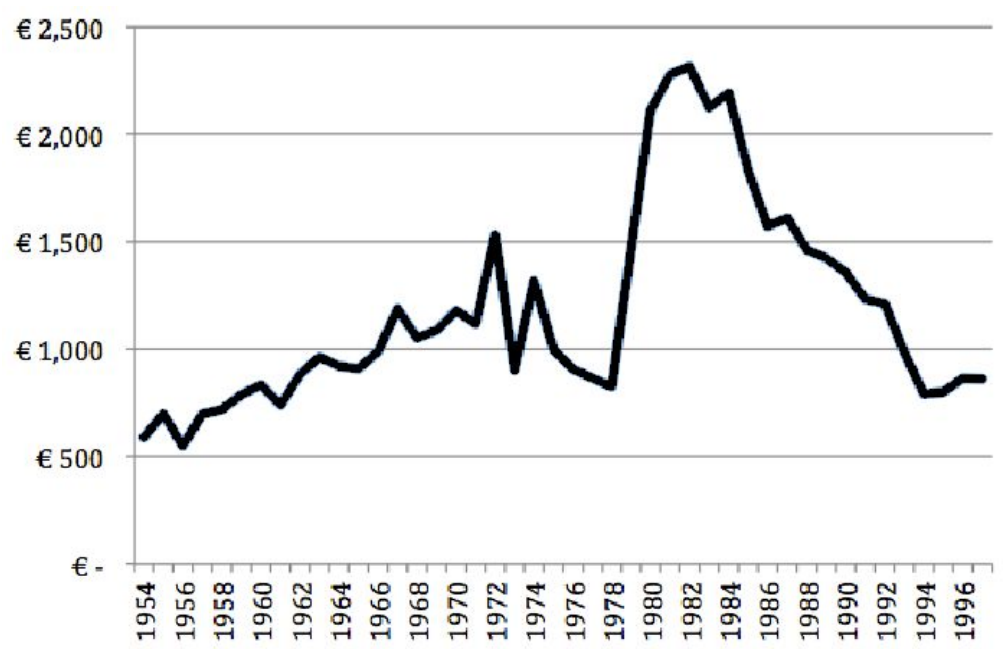

Figure 3.1. Total investments in water infrastructure, 1954-1997, constant prices $2010 €$ million (source: ISTAT data elaborated in Ermano, 2012).

The ISTAT report also showed that the structure of the water industry was highly fragmented and differentiated across the country. The reported counted 5,500 firms ${ }^{39}$ which managed the drinkable water supply, 7,000 which managed sewage services, and 11,000 which provided water treatment. In the segment of water supply, water was directly provided by local governments (that delivered about $34.5 \%$ of water to households and businesses), local government-owned water firms (24\%), consortia of local governments $(18.5 \%)$ and other public bodies $(17.7 \%)$ owned by either the regional or the central governments. Privately owned business companies played a relatively marginal role (about 4.5\%) (Table 3.1). Based in the

39 Firms included departments of the local governments (directly managing water services), consortia of local governments, local government-owned water firms, regional governmentowned water firms, central government-owned water firms, and privately owned business companies. 
southern regions of the country, the regional and central government-owned water firms were among the biggest players: the Ente Autonomo Acquedotto Pugliese, for example, served a user basin of about 4.6 million people through a network almost $20,000 \mathrm{~km}$ long (the biggest aqueduct network in Europe). Some local governmentowned water firms based in the largest cities, such as Rome, Milan, Turin, and Genoa were also relatively large players.

\begin{tabular}{lccc}
\hline \multicolumn{1}{c}{ Operators } & $\begin{array}{c}\text { \% number } \\
\text { of operators }\end{array}$ & $\begin{array}{c}\text { \% water } \\
\text { volume supply }\end{array}$ & \% turnover \\
\hline Local government branches & $81.90 \%$ & $34.50 \%$ & $43.90 \%$ \\
Municipal companies & $1.40 \%$ & $24.00 \%$ & $25.30 \%$ \\
Local government consortia & $12.40 \%$ & $18.50 \%$ & $18.10 \%$ \\
Other public bodies & $2.20 \%$ & $17.70 \%$ & $7.70 \%$ \\
Private business companies & $2.10 \%$ & $4.50 \%$ & $4.90 \%$
\end{tabular}

Table 3.1. Percentage of operators and percentage of water volume served, per type of water firm (Sources: ISTAT, 1991; Supervising Committee on the Use of Water Resources $(1997,1998)$. Report to Parliament on the state of water services. Istituto Poligrafico e Zecca dello Stato, Rome).

The call for reforming the water industry took the form of a proper proposal to the Parliament. In 1992, the Christian Democrat MP Giancarlo Galli filed a reform bill which aimed at changing the economic regulation of the water industry $^{40}$. The task to draft the bill was assigned to the VIII Standing Committee (Environment, Territory, and Public Works) of the House ${ }^{41}$, which (during the XI

40 Galli submitted reform bill no. 512 together with the MPs Cerrutti, Botta, Filippini, Sartoris, Manfredi, Faraguti, Matarrese, uonsignore, Morgando, Mazzucconi, Azzolini, and Gualco.

41 The process of making laws in the Republic of Italy begins with proposals of bills to either the House or the Senate. Bills can be proposed by either voting citizens (at least 50,000), or the government, or members of the parliament, or the National Committee of Economics and Labour (Consiglio Nazionale dell'Economia e del Lavoro), or the regional councils. The bill is then assigned to one of the standing committees of the House or the Senate, according to the subject. The committee discusses and drafts the bill, which is later discussed and eventually approved by the House or the Senate (depending on which branch of the parliament the bill was originally proposed to). After the approval, the bill is transmitted to the other branch of the parliament for approval or further discussion. If any amendment is made by this other branch of the parliament, 
legislature of the Republic of Italy in the period 23.04.1992-14.04.1994) included MPs from the parties Movimento Sociale Italiano(MSI)-Destra Nazionale, Lega Nord, Partito Repubblicano, Democrazia Cristiana, Partito Socialista Italiano, Partito Democratico della Sinistra, Verdi, and Rifondazione Comunista. Also subsecretaries of Public Works, Agriculture and Forestry, and Finance occasionally participated to the drafting process. Reviews of the bill were also conducted by the I (Constitutional affairs), II (Justice), V (Balance), VI (Finance), VII (Culture), X (Productive Activities), XI (Work), XII (Social Affairs), and XIII (Agriculture) Parliament Committees.

Because of the variegated composition of the VIII Standing Committee, the drafting of the bill was affected by quite diverse positions on water policy held by the MPs and the sub-secretaries. Nevertheless, the members of the VIII Standing Committee broadly shared a consensual view on the principles that the water reform should follow. Since the very first "drawing up" meeting of the committee, on $30^{\text {th }}$ July 1993, Giancarlo Galli highlighted some of them:

This [bill] is an attempt to dramatically overcome the fragmentation of current management systems in order to reorganise the water service at a scale adequate to the current needs, in the optimal areas, also trying to disentangle the management system from competences based on the administrative jurisdictions. [...] Another important point concerns the

then the bill is transmitted back to the first branch of the parliament for further approval or discussion. The process terminates when both branches of the parliament approve the same text. Then, the bill is signed by the President of the Republic and issued in the Official Bulletin of the Republic of Italy (Gazzetta Ufficiale). 
public status of water. This is an essential element of the bill which allows the State to plan the whole resource cycle, although water is available for any use of the private business. [...] With this text we also aimed to provide an overall restructuring of tariffs $[\ldots]^{42}$.

During the course of the discussion, the MP Rosa Filippini (Socialist Party) remarked that "apart from the general principles highlighted [by Galli], there is also the one of the financial self-sufficiency of the water management cycle, which needs to be based on the water tariffs, which should not be used to cover public finance deficit. The overall objective, in fact, is the one to provide a direct link between the level of the tariff and the quality of the service, in such a way as to overcome an outdated idea of intermediation of the State in collecting and redistributing financial resources"43. The MP Valerio Calzolaio (Left Democrats Party) agreed that:

[The bill] incorporates the fundamental principles of the reform: conceiving water as a good to protect; adopting an efficient policy of scarce resource management; linking the level of the tariff and the cost of service management; charging higher tariffs for non-essential uses; protecting water resources and granting priority to drinking uses; planning of optimal territorial areas and setting tariffs in relation to the actual quality of the service provided ${ }^{44}$.

42 House of Parliament - VIII Standing Committee minutes, 1993: 235.

43 House of Parliament - VIII Standing Committee minutes, 1993: 236.

44 House of Parliament - VIII Standing Committee minutes, 1993: 237. 
Also the MP Edo Ronchi (The Greens) pointed out that "The bill under discussion is to be improved and completed, but the basic underlying concepts and institutions should not be changed"45. After some months of works, the water reform was eventually approved ${ }^{46}$ by the House on $6^{\text {th }}$ December 1993 and, with minor amendments, by the Senate on $16^{\text {th }}$ December $1993^{47}$. After the President of the Republic Oscar Luigi Scalfaro signed the bill on $5^{\text {th }}$ January 1994, Act 36/1994 ("Norms on the subject of water resources") was enacted on $19^{\text {th }}$ January 1994.

\section{The design of the 1994 water reform.}

The design of the water reform built on four key principles. First, water services should be comprehensively organised and managed in relatively large territories (so-called Ambiti Territoriali Ottimali, that is, Optimal Territorial Areas or OTA) in order to reduce the fragmentation of the industry and allow water firms to achieve economies of scale. Second, all the segments of water services should be

45 House of Parliament - VIII Standing Committee minutes, 1993: 237.

46 The VIII Standing Committee was assigned the role of both drafting the water reform bill and discussing, with detailed attention on each article, the text which was later proposed to the parliament for approval. This procedure (so-called 'commissione in sede redigente', that is, "drawing up committee") was provided by article 72 of the Constitution of Italy. This provision allowed the standing committee to deal with "technicalities" (e.g., combining the texts of two or more similar bills which have been proposed on the same subject) while the parliament only voted on the whole text, therefore streamlining the law-making process. The VIII Standing Committee, therefore, could work to combine the bill presented by Giancarlo Galli (No. 512) with another one that had been presented on the same subject, shortly afterwards, by the MP Ferrarini (No. 1397).

47 Following the amendments done by the Senate, the definitive version of the reform bill was eventually approved by the VIII Standing Committee on $21^{\text {st }}$ December 1993. Also this procedure (so-called "commissione in sede legislativa", that is, "law-making committee") was provided by article 72 of the Constitution of Italy. This provision allowed, in special circumstances, for the standing committee to vote on the approval of a law in place of the parliament. In the final vote of the Committee, 23 voted in favour of the bill, 1 voted against it (the MP of Rifondazione Comunista) and 3 abstained (the MPs of Partito Repubblicano and the one of MSI-Destra Nazionale). 
managed "under one roof", i.e., by a solitary water firm that could better coordinate the stages of the water management cycle than multiple ones. Third, planning and control functions should be separated from those of operational management and service delivery (the former being assigned to local regulatory agencies, named Autorità di Ambito, or OTA authorities, and the latter to the water firms) in order to improve the entrepreneurial management of water firms. Finally, water tariffs should cover the full cost of water services (i.e., including investment depreciation and return on capital invested) in order to allow water firms to achieve financial self-sufficiency (Massarutto and Fontana, 1994; Fazioli and Massarutto, 1998; Malaman and Cima, 1998).

These principles were broadly reflected in the detailed institutional arrangement contained in Act 36/1994. The regions were required to define the OTAs (either within their own territories or across regional borders), where water services would be comprehensively managed. Local governments located in each OTA would establish local regulatory agencies (OTA authorities). The OTA authorities would plan local water infrastructure development and set the tariff that water firms should charge. The OTA authorities would also award water franchises to water firms. As a general rule, one water firm only would manage water services in each OTA, although Act 36/1994 also contained some exemptions for safeguarding the position of incumbent water firms which satisfied criteria of efficiency, cost-effectiveness, and economy ${ }^{48}$. After the award of the water

48 In the early nineties, ideas about public management reform broadly inspired by the "New Public Management" doctrine had started to affect public management policy-making as well as other public sector reforms in Italy. These ideas contained, in particular, the normative argument that public services should be managed in accordance with the principles of efficiency, effectiveness, and economy (i.e., financial self-sufficiency) - also commonly known as the "three Es" in the national public management policy discourse (Borgonovi, 1996). 
franchises, the OTA authorities would regulate the water firms by enforcing the tariff regulation and monitoring the implementation of water infrastructure development plans.

The details of this regulatory design also partially reflected political compromises and institutional constraints that had affected the making of the 1994 water reform. During the drafting of the bill at the VIII Standing Committee of the House, four main issues attracted MPs' attention. The first issue was how the OTAs should be designed. In principle, the VIII Standing Committee agreed that the OTAs should include relatively large territories of about 500,000 water users ${ }^{49}$, which was believed by water policy experts to be the minimum size for achieving economies of scale. The VIII Standing Committee also agreed that the OTAs should be designed according to the hydro-geographical features of watershed river basins, rather than on administrative jurisdictions ${ }^{50}$. However, the VIII Standing Committee could not single-handedly define the boundaries of the OTA territories on the basis of these principles, because it would violate local governments' autonomy (sanctioned by the Constitution) on the organisation of local public services. The VIII Standing Committee, then, agreed to require local governments to define the OTA authorities through a consultative process.

The second issue was how local governments should establish the OTA authorities. Members of the VIII Standing Committee generally shared the view that local governments should cooperate in order to centralise their water planning

49 Therefore, about one hundred OTAs would be established in the country, which at that time counted about 56.7 million inhabitants (ISTAT population survey, 1991).

50 This principle, which was commonly accepted in water policy circles, had been already followed in the design of Act 183/1989, which had provided the territorial boundaries of 11 national basins and 18 inter-regional basins. 
and regulatory functions into the OTA authorities. Early drafts of the reform bill provided that local governments were mandated to establish compulsory consortia for pooling their water planning and regulatory functions together. During the review of the reform bill, however, the I (Constitutional Affairs) Standing Committee pointed out that requiring local governments to establish mandatory consortia for jointly regulating water services was not constitutionally legitimate. The VIII Standing Committee, therefore, agreed that the regions would select a local government in each OTA charged with the task of leading the negotiations for centralising the water planning and regulatory functions ${ }^{51}$.

The third issue concerned the choice of the criteria for the selection of the water firms that would be awarded the water franchises. In principle, the members of the VIII Standing Committee broadly agreed that water services should be managed with an "entrepreneurial spirit". Anecdotal evidence, instead, suggested them that public officers in local governments often administered water firms with the aim of gaining the electoral support of a local "clientele" made of job-seekers and small-medium construction firms rather than pursuing good service performance. Local governments, however, could not be authoritatively excluded from managing local water services. As pointed out by the I (Constitutional Affairs)

51 The final decision of the Committee resulted from the anticipation that the local governments would oppose any reform which would threaten their autonomy. Some years later, the Chairman of the Supervising Committee on the Use of Water Resources, Gilberto Muraro, commented on the design choice made by the VIII Standing Committee in these terms: "At the roots of the reform there is clearly a political compromise, that can be described in this way: the national legislator considered that, without any amendment to the Constitution, it would be necessary to respect the municipal authority on this field [of local water management], and that, in any case, the reform could not be carried out without the [collaboration of the] municipalities. [...] In order for the reform to be approved [by the Parliament], therefore, local governments were accepted as main players in the new organisation [of the water regulatory system], by requiring them to cooperate and establish together the OTA authorities to which water service planning would be assigned, choose the firms which would manage the water services, and monitor the conduct [of the water firms]" (Muraro, 2003). 
Standing Committee during the reviews of the reform bill, local water services had to be managed according to any of the forms provided, at that time, by Act $142 / 1990$, that offered local governments the options to provide local public services (including water) by either tendering out the franchise to business companies, or by awarding it to mixed public-private ownership firms ${ }^{52}$ or to local government-owned special statute organisations or (in special cases) to local government departments. The VII Standing Committee agreed that local governments could not be compelled to withdraw from directly managing water service provision, but they limited the range of option choices for awarding the water franchises to two only: either to business companies selected through tender offer competition, or to mixed public-private ownership firms ${ }^{53}$. Pressed by local governments' lobby, the VIII Standing Committee agreed to exempt from privatising water service provision those incumbent water firms which matched criteria of effectiveness, financial self-sufficiency, and economy ${ }^{54}$.

52 Originally, Act 142/1990 provided that local governments should retain majority ownership of the firms. In 1992, Act 498 removed this constraint, hence local government could also give up the majority of firms' shares.

53 In other words, the VIII Standing Committee blocked the option to award the water franchises to local government-owned special statute organisation and local government departments, which were considered inadequate to manage relatively large-scale water firms. The options were blocked by framing the attribution of water service provision as a franchise contract, hence local governments could not directly manage water service provision through special-statute organisations or own departments.

54 The design of Act 36/1994, therefore, allowed local governments to choose whether to retain ownership and direct management of local water services or to centralise the planning and regulatory functions in the OTA authorities while decentralising the operational management to business companies. This design partially contradicted public management policies which had been generally followed in the early nineties. Some years later, the Chairman of the Supervising Committee on the Use of Water Resources, Gilberto Muraro, commented on the design choice made by the VIII Standing Committee in these terms: "A new political culture had emerged since 1992, when, under financial pressures, the government led by Giuliano Amato aimed to establish a clear-cut separation between the regulatory and monitoring activities [on the one hand] and the management activities [on the other one] [...] [In the making of Act 36/1994,] in order to reduce the opposition [to the reform], and even to gain the broadest support from the political, technical and administrative ranks of public sector companies, which are particularly diffused especially in the centre and north of the country, the legislator accepted the compromise of an "optional 
The last issue was how water tariff should be set. Most of the members of the VIII Standing Committee shared the view that users should be fairly charged for the water services in order to cover full costs, including asset depreciation and fair return to investment ${ }^{55}$. Water tariff setting was designed as a "two stage" system, according to which (a) at the central level the Minister of Public Works would issue (according to a proposal of the Supervising Committee on the Use of Water Resources) the criteria for setting water tariffs (the so-called metodo normalizzato or "normalised method", which was based on an econometric model which estimated the water industry average production costs), and (b) at the local level the OTA authorities would set the water tariff according to a calculation based on the normalised method, on the tariff charged in the past (the so-called tariffa di riferimento or "reference tariff"), and on the tariff proposed by the water firm (the so-called tariffa di progetto or "project tariff”). In order to provide incentives to improve performance over time, the VIII Standing Committee also decided that yearly water tariff increase would be subjected to a cap based on econometric estimates of average efficiency improvements in the industry. The price-cap

privatisation", thus [it] granted to the public sector the opportunity of retaining involvement in the [direct] management [of water services]". This design of Act 36/1994 was criticised, at the time, by the national association of business companies (Confindustria), which complained about the possibility granted to the local governments to prevent business companies from entering the water industry. In an interview to the business press Il Sole 24 Ore on $10^{\text {th }}$ October 1993 , the Chairman of Confindustria Giancarlo Piombino said: "We need some clarity about whether water services are open to the market or not. At the moment, we cannot see any clear attitude in this direction. Rather, the House introduced some provisions which allow the local governments, the provinces, and their consortia to directly award the concession to manage the water services to their own water firms without any tender offer competition. The tender offer competition, instead, is required in the case of awarding the concession to any third party business company. There is an unfair impartiality here, which lacks any legal or economic ground. There is no equality, and we cannot accept that anyone gains a position of privilege".

55 Within the VIII Standing Committee, only the Communist Party generally criticised the "commercialisation" of water, according to which - its members claimed - water firms could profit from the supply of such a basic resource for human life. 
mechanisms would also take into account a fair return on capital invested, in order to elicit water firms to invest in infrastructure development projects.

In terms of allocation of tasks, responsibilities, and powers, the 1994 water reform involved entities placed at all levels of the multi-layered governance system of Italy (Table 3.2 summarises the implementation and regulatory activities provided by Act 36/1994). The central government was required to establish a semiindependent authority called the Supervising Committee on the Use of Water Resources and to issue regulations concerning, in particular, water tariff setting (the normalised method) and eligibility for the award of the water service franchises through tender offer competitions. The regions were required to define the boundaries of the OTAs, the legal terms of collaboration between local governments, the procedure for awarding water franchises, and the template franchise contract between the OTA authorities and the water firms. Local governments were required to collaborate to define the OTA boundaries and to establish the OTA authorities. Finally, the OTA authorities were required to plan water infrastructure development and service management improvement, award the water franchises, and monitor the compliance of water firms with the infrastructure development and tariff plan. 


\begin{tabular}{|c|c|c|c|}
\hline References & Provisions & Public authorities involved & Deadlines \\
\hline Art. 2, par. 2 & $\begin{array}{l}\text { The Minister of Environment issues a decree which regulates human } \\
\text { interventions on the natural water cycle. }\end{array}$ & $\begin{array}{l}\text { The Minister of Environment, in concert } \\
\text { with the Minister of Public Works. }\end{array}$ & $\begin{array}{l}\text { Within six months after } \\
\text { the law coming into } \\
\text { force. }\end{array}$ \\
\hline Art. 4, par. 1 & $\begin{array}{l}\text { The Chairman of the Council of Ministers issues decrees which regulate: } \\
\text { a) general guidelines about the census of water resources, water economy, and } \\
\text { protection of water from pollution; } \\
\text { b) general methodology about planning the rational use of water resources and } \\
\text { guidelines for multiple competing uses of water resources; } \\
\text { c) criteria and guidelines about planning the transfer of water for human } \\
\text { resources between regions (ruled in article 17); } \\
\text { d) methodology and criteria for the revision and update of the general aqueduct } \\
\text { regulatory plan (regulated by the law 129/1963); } \\
\text { e) guidelines and technical standards for mapping the territories subject to risk } \\
\text { of drought with the aim of preventing water emergencies; } \\
\text { f) criteria for the management of the integrated water service, made up of the } \\
\text { public services of water catchment, distribution, sewage, and treatment; } \\
\text { g) minimum service standards which are to be guaranteed in each optimal } \\
\text { territorial area, and criteria and guidelines for water transfer, catchment and } \\
\text { storage but for human consumption; } \\
\text { h) financial mechanisms and rules for settlement of water transfers between } \\
\text { basins; } \\
\text { i) existing systems which allow achieving the objectives of water transfer } \\
\text { between regions (ruled in article 17). }\end{array}$ & $\begin{array}{l}\text { The Chairman of the Council of } \\
\text { Ministers, following the initiative of the } \\
\text { Committee of the ministers for the } \\
\text { national technical services and } \\
\text { interventions in the protection of the } \\
\text { soil, having heard the Standing } \\
\text { Committee for the Relationships } \\
\text { between the State, the Regions, and the } \\
\text { Autonomous Provinces of Trento and } \\
\text { Bolzano. }\end{array}$ & None. \\
\hline Art. 5, par. 2 & $\begin{array}{l}\text { The Minister of Public Works issues a decree which regulates the definition of } \\
\text { the criteria and methods for measuring the leakage from aqueducts and sewage } \\
\text { networks. }\end{array}$ & The Minister of Public Works. & . \\
\hline Art. 6 , par. 1 & $\begin{array}{l}\text { The Minister of Environment issues a technical guideline which regulates: } \\
\text { a) the type of wastewater which can be recycled; the type of wastewater which } \\
\text { can be reused; quality and consumption standards; technological requisites of } \\
\text { the treatment process; } \\
\text { b) the ways of using treated water, taking into account hygiene and health; } \\
\text { c) the ways of building, managing and upgrading treatment plants and } \\
\text { wastewater distribution networks. }\end{array}$ & $\begin{array}{l}\text { The Minister of Environment, having } \\
\text { heard the Ministers of Health, Public } \\
\text { Works, and Industry, Commerce and } \\
\text { Handicraft. }\end{array}$ & $\begin{array}{l}\text { Within one year after } \\
\text { the law coming into } \\
\text { force. }\end{array}$ \\
\hline Art. 7, par. 1 & $\begin{array}{l}\text { The Minister of Environment issues a decree which lays out a national plan } \\
\text { containing the guidelines and requirements for the implementation of the } \\
\text { 91/271/CEE directive. }\end{array}$ & $\begin{array}{l}\text { The Minister of Environment, in concert } \\
\text { with the Ministers of Health, Public } \\
\text { Works, and Industry, Commerce and } \\
\text { Handicraft, after having received the }\end{array}$ & $\begin{array}{l}\text { Within one year after } \\
\text { the law coming into } \\
\text { force }\end{array}$ \\
\hline
\end{tabular}




\begin{tabular}{|c|c|c|c|}
\hline & & $\begin{array}{l}\text { binding opinion of the Standing } \\
\text { Committee for the Relationships } \\
\text { between the State, the Regions, and the } \\
\text { Autonomous Provinces of Trento and } \\
\text { Bolzano. }\end{array}$ & \\
\hline Art. 7, par. 2 & $\begin{array}{l}\text { The Minister of Environment issues a decree which regulates the } \\
\text { implementation of the } 91 / 271 / \mathrm{CEE} \text { directive. }\end{array}$ & $\begin{array}{l}\text { The Minister of Environment, in concert } \\
\text { with the Ministers of Health, Public } \\
\text { Works, and Industry, Commerce and } \\
\text { Handicraft. }\end{array}$ & $\begin{array}{l}\text { Within eighteen months } \\
\text { after the coming into } \\
\text { force of the law. }\end{array}$ \\
\hline Art. 8, par. 2 & The Regions formally establish the optimal territorial areas. & $\begin{array}{l}\text { The Regions, having heard the } \\
\text { provinces affected, and the competent } \\
\text { River Basin Authority. }\end{array}$ & $\begin{array}{l}\text { Within six months after } \\
\text { the coming into force } \\
\text { of the law. }\end{array}$ \\
\hline Art. 8, par. 5 & $\begin{array}{l}\text { The Regions approve rules about the control of sewage drainage, pre-treatment } \\
\text { equipment, and the detection of compliance with the licensed drainage and } \\
\text { equipment. }\end{array}$ & The Regions. & None. \\
\hline Art. 9, par. 3 & $\begin{array}{l}\text { The Regions regulate the forms and ways of cooperation between the local } \\
\text { governments among those provided in law } 142 / 1990 \text { and included in the same } \\
\text { optimal territorial area. }\end{array}$ & The Regions. & $\begin{array}{l}\text { Within six months after } \\
\text { the coming into force } \\
\text { of the law. }\end{array}$ \\
\hline $\begin{array}{l}\text { Art. } 10, \text { par. } \\
5\end{array}$ & $\begin{array}{l}\text { The Minister of Public Works regulates the reorganisation of the water firms } \\
\text { under State control. }\end{array}$ & $\begin{array}{l}\text { The Minister of Public Works, in } \\
\text { concert with the Minister of Treasury, } \\
\text { having heard the Minister of } \\
\text { Environment and the Regions affected, } \\
\text { and the competent Parliamentary } \\
\text { Committees. }\end{array}$ & $\begin{array}{l}\text { Within twelve months } \\
\text { after the coming into } \\
\text { force of the law. }\end{array}$ \\
\hline $\begin{array}{l}\text { Art. } 10, \text { par. } \\
6\end{array}$ & $\begin{array}{l}\text { The Chairman of the Council of Ministers issues a decree which lays out a plan } \\
\text { about the transfer of the aqueducts, sewage and water treatment plants managed } \\
\text { by the consortia of the areas of industrial development to the firm managing the } \\
\text { integrated water service. }\end{array}$ & $\begin{array}{l}\text { The Chairman of the Council of } \\
\text { Ministers, following the initiative of the } \\
\text { Minister of Public Works, in concert } \\
\text { with the Minister of Environment, } \\
\text { having heard the Regions, the provinces, } \\
\text { and the agencies affected. }\end{array}$ & None. \\
\hline $\begin{array}{l}\text { Art. 11, par. } \\
1\end{array}$ & $\begin{array}{l}\text { The Regions approve a template contract for regulating the relationships } \\
\text { between the local governments setting up the integrated water services. (The } \\
\text { same contract also included the conditions for the activation of substitutive } \\
\text { powers against the local governments and the provinces, if they did not set up } \\
\text { the integrated water service within the set deadline, art. 19, par. 3) }\end{array}$ & The Regions. & None. \\
\hline Art. 12, par. & $\begin{array}{l}\text { The Regions regulate the forms and ways for transferring the personnel which } \\
\text { worked in the incumbent water firms owned and controlled by the local }\end{array}$ & The Regions. & None. \\
\hline
\end{tabular}


governments to the firms managing the integrated water service.

\begin{tabular}{|c|c|c|c|}
\hline $\begin{array}{l}\text { Art. 13, par. } \\
3\end{array}$ & $\begin{array}{l}\text { The Minister of Public Works defines the normalised method which determines } \\
\text { the cost components to be taken into account and the formulation of the } \\
\text { reference tariff. }\end{array}$ & $\begin{array}{l}\text { The Minister of Public Works, in } \\
\text { concert with the Minister of } \\
\text { Environment, following the initiative of } \\
\text { the Committee of Supervision of the } \\
\text { Use of Water Resources, having heard } \\
\text { the River Basin Authorities, and the } \\
\text { Standing Committees for the } \\
\text { Relationships between the State, the } \\
\text { Regions, and the Autonomous Provinces } \\
\text { of Trento and Bolzano. }\end{array}$ & None. \\
\hline $\begin{array}{l}\text { Art. 22, par. } \\
5\end{array}$ & $\begin{array}{l}\text { The Chairman of the Council of Ministers issues a decree which determines the } \\
\text { staff and management positions of the technical secretary of the Committee of } \\
\text { Supervision of the Use of Water Resources and the Observatory of Water } \\
\text { Resources. }\end{array}$ & $\begin{array}{l}\text { The Chairman of the Council of } \\
\text { Ministers, following the initiative of the } \\
\text { Minister of Public Works, in concert } \\
\text { with the Ministers of Treasury and of } \\
\text { Public Function }\end{array}$ & None. \\
\hline Art. 30 & $\begin{array}{l}\text { The Inter-ministerial Committee of Economic Planning regulates: } \\
\text { a) the production and transfer of desalinated water by coastal electricity } \\
\text { generation plants; } \\
\text { b) the use of water stored in dams for electric generation plans in the case of } \\
\text { water emergencies; } \\
\text { c) the protection and reclaim of quality and quantity of water stored in dams for } \\
\text { electric generation plants. }\end{array}$ & $\begin{array}{l}\text { The Inter-ministerial Committee of } \\
\text { Economic Planning, following the } \\
\text { initiative of the Committee of Ministers } \\
\text { for the national technical services and } \\
\text { interventions in the protection of the } \\
\text { soil, having heard the River Basin } \\
\text { Authorities. }\end{array}$ & None. \\
\hline $\begin{array}{l}\text { Art. } 32 \text {, par. } \\
3\end{array}$ & $\begin{array}{l}\text { The government adopts one or more regulations which identify the rules } \\
\text { contained in other laws and incompatible with those of law } 36 / 1994 \text {, and sets } \\
\text { the deadlines for their abrogation in relation to the stages of implementation of } \\
\text { the law } 36 / 1994 \text { in the various optimal territorial areas. }\end{array}$ & $\begin{array}{l}\text { The government, following the initiative } \\
\text { of the Minister of Public Works, in } \\
\text { concert with the Ministers interested in } \\
\text { the various subject matters affected by } \\
\text { the law } 36 / 1994 \text {, having heard the } \\
\text { competent Parliamentary Committees.. }\end{array}$ & None. \\
\hline
\end{tabular}

Table 3.2. The tasks provided by Act 36/1994. 
In essence, the 1994 water reform both provided the centralisation of the planning and regulatory functions in the OTA authorities and assigned the management of water services to water firms selected by the OTA authorities. Local governments were expected to pool together planning and regulation of water services. The OTA authorities were expected to award water concessions to one only water firm within each OTA, either a business company selected through tender offer competition or a mixed public-private ownership firm. The reformed regulatory system, therefore, included both policy tools intended to liberalise water service provision (i.e., the OTA authorities could choose water service providers through tender offer competitions), re-regulate the water industry (i.e., by moving from a system of direct public ownership and control of water firms to one where water firms would be subjected to tariff regulation by local regulatory authorities), and privatise water firms (i.e., private operators and investors could enter the water industry either through water firms selected through tender offer competitions or through mixed public-private ownership water firms).

\section{Chapter summary.}

This chapter provided the historical background of the implementation of the 1994 water reform in Italy. After outlining the evolution of water policy in Italy in the period between 1865 and the 1970s, it described the content of the water reforms passed in 1976, 1989, and 1994. The 1976 water reform, which especially focused on issues of water planning, environmental protection, and water administration, provided some decentralisation of water functions to the regions and local governments. The 1989 water reform, which was particularly concerned with issues of pollution and environmental protection, introduced some centralisation of water functions at the watershed river basin level. The 1994 water reform, lastly, mainly intended to improve the financial performance of the water sector, water service performance, and efficiency of water firms by separating ownership and control of water firms from water regulatory functions.

The design of the 1994 water reform contained policy tools that would stimulate the liberalisation, re-regulation, and privatisation of the water sector in the 
country. The liberalisation and re-regulation part of the water reform provided that local governments would define new water districts, called Optimal Territorial Areas (OTAs), and would establish local regulatory authorities (OTA authorities) within each of them. Local regulatory authorities would negotiate water infrastructure development and tariff plans with water firms, monitor the investment programme, and enforce the tariff regulatory system. The privatisation part of the water reform provided that the OTA authorities would award water franchises to either business companies selected through tender offer competition or to mixed public-private ownership firms. 


\section{Chapter 4}

\section{The Implementation of the Water Reform in Italy (1994-2001)}

This chapter narrates the implementation of the 1994 water reform in Italy in the period between 1994 and 2001. During these years, early efforts to transpose the national water legislation to the regional level accomplished relatively modest results. Setting aside some parts of Tuscany (in the area named Alto Valdarno), generally local governments' early reaction towards the water reform was to resist collaborating to define the boundaries of the new watershed service areas - the Optimal Territorial Areas or OTAs. From 1997 onwards, instead, OTA boundaries started to be defined all over the country and the regions started to pass the required regional legislation for making the water reform enforceable at the regional level. Most of local governments, however, kept proceeding relatively slowly to establish the OTA authorities. In 2001 the implementation of the water reform still lagged much behind expectations and - to any external observer at that time - it could appeared inescapably doomed to failure.

This chapter is organised into five sections. The first one will provide an overview of the 1994 water reform implementation in the period between 1994 and 2001. The second section will narrate the event of aligning the regional legislation to the national water reform in the period 1994-1997. Section three will focus on narrating the event related to the implementation of the water reform in the Alto Valdarno area in Tuscany in the period 1994-1999. Sections four will go back to 
narrating the alignment of regional legislations to the national water reform in the period 1997-1999. Sections five and six, then, will shift the narration towards the events of establishing OTA authorities in the period 1997-2001 and of awarding water franchises in the period 1999-2001. The sixth section, finally, will provide an assessment of the intermediate results achieved by the efforts to implement the water reform at the end of the period between 1994 and 2001.

\section{The implementation of the water reform in Italy (1994-2001): an overview.}

After Act 36/1994 came into force, in January 1994 officers working in both the central and regional governments begun parallel efforts to set up the new water regulatory system. At the central government level, attention focused on the formulation of the rules for the eligibility to manage the integrated water service, for the award of water concessions, and for water tariff setting. At the regional governments level, the main task at hand consisted of drafting bills for "transposing" Act 36/1994 into regional legislations and thus making the water reform enforceable at the regional level. The water reform provided that regional legislations should include, in particular, the definition of the territorial boundaries of the OTAs and the specification of some parts of the new regulatory system, such as, for example, providing the eligibility criteria for applying the exemption regime to incumbent water firms.

At the local government level, instead, the water reform did not stimulate much efforts to put the new regulatory system into effect. Local governments were generally reluctant to take part to the consultations on the definition of the OTAs, 
and rather regarded the water reform as threatening their established positions within the local water industries. Inertia prevailed for a few years, until in 1997 changed features of water infrastructure policy - namely, new subsidies provided for improving wastewater and sewage networks - awoke sub-national governments from their torpor. Slowly but decisively, from 1997 onwards a growing number of local governments came to agree on the OTAs, an increased number of regions passed the required legislations, and a larger number of water infrastructure development plans were prepared. By 2001, relatively little of the new regulatory systems had been put into place, but actions made by sub-national governments suggested that the course of the reform implementation could not be reversed or blocked anymore.

While the establishment of the new regulatory system was under way, various incumbent local government-owned water firms embarked in operations of massive restructuring and consolidation. In Tuscany, for example, several local government-owned water firms reincorporated as business companies and merged together into new entities, especially Nuove Acque (established in 1999 and serving the area around Arezzo) and Publiacque (established in 2000 and serving the area around Florence and Pisa). In other regions, the local government-owned water firms of various major cities, such as Rome (served by ACEA), Genoa (served by AMGA), and Turin (served by SMAT), increased their size through mergers and acquisitions and expanded the range of their activities outside the municipal territories. As a result of these operations, by 2001 several local government-owned water firms had positioned themselves as credible candidates for the award of water 
franchises, once the new regulatory system would be fully put into place.

The implementation of these parts of the water reform proceeded at different pace in various regions of the country. The region Tuscany, in particular, promptly transposed the water reform into the regional legislation in 1995 - remarkably faster than any other region. Within Tuscany, some local governments, especially located in the Alto Valdarno area, came to establish OTA authority relatively quickly, and their OTA authority came to approve water infrastructure development and tariff plans already since 1998 and to award the water franchise in 1999. During the same period, most of the OTAs in the rest of the country had not been defined yet, nor had other local governments established any OTA authority. Setting the Alto Valdarno experience aside, therefore, by 2001 the implementation of the water reform had proceeded slowly in most of the country.

\section{Aligning regional legislation to the national water reform (1994-1997).}

In January 1994, the regional governments invited local governments to participate to the process of drafting the regional legislation, which was required to enforce the water reform at the regional level ${ }^{56}$. According to Act 36/1994, local governments were expected to make proposals on the definition of the territorial boundaries of the OTAs. Defining the boundaries of the OTAs would determine which local governments were to collaborate with each other to establish the OTA authorities and pool together their water management and water regulatory

56 All the twenty regions of the country were originally required to transpose Act 36/1994 into their respective regional legislation. The autonomous provinces of Trento and Bolzano, however, appealed to the Constitutional Court, which on $7^{\text {th }}$ December 1994 ruled that the Alpine region Trentino-Alto Adige was not obliged to comply with Act 36/1994 because of the terms of the region's special statute. 
functions. The design of the OTAs, therefore, bore important implications for the rest of the water reform implementation. Larger OTAs implied that several local governments would pool together their water functions into relatively bigger firms. Smaller OTAs, in contrast, meant that water services would be provided by relatively small water firms, which would focus their operations in tiny user basins.

When called to take part to meetings with regional governments, local governments contended that they were incapable to make any decision on the definition of the OTAs. They typically claimed that, since Act 36/1994 did not detail the rules about how the water tariff would be set and what eligibility criteria would be applied for exemption of incumbent water firms from the application of the water reform, they missed some important pieces of the new regulatory system that they would take into account in order to design the OTAs. Such argument, however, only papered over the diffused local governments' deep-seated aversion towards the core principles of the water reform - especially the overturn of the "municipal model" of water service provision. In a later commentary on the attitudes that local governments held towards the new water regulatory system, the Supervising Committee on the Use of Water Resources noticed that, at the local level, there was "a widespread belief that direct management was the best possible way to manage [water services], and that spoiling [local governments] of the direct management of water services was a sort of offence, the effect of a 'self-conscious act of violence': some local governments even referred to it as a 'robbery"' (Supervising Committee on the Use of Water Resources, 1998).

Generally, local governments tended to rely on the "municipal model" of 
water service provision for reasons that were profoundly rooted in the political economy of the local water industries. Some insights into the role that water played in local governments' politics was provided, in an interview held during data collection for this thesis, by Francesco Bosco, manager of ACEA (the water firm serving the city of Rome), who commented on the behaviour of local governments in this way: "The Galli law affected the vicious circle between politicians, water firms' managers, and the voters. The mayor loses power if water is managed by someone else outside the local government, as water has always been important for electoral purposes. We can even quote a movie, 'The Postman' [1994], where a local politician gains the votes for his election by promising to bring water supply to the town. [Local government-owned] water firms were afraid to lose their role and not to be protected, while local politicians perceived that the Galli law could spoil them of their power" ${ }^{\prime 57}$. Rather than defining the OTA boundaries, generally local governments were concerned with obstructing the establishment of the new regulatory system, and they tried to either delay the implementation process, or to exploit the exemption clauses in order to allow their incumbent water firms to keep their position in the water industry, or both.

In April 1995, the Supervising Committee on the Use of Water Resources, which had been established on $21^{\text {st }}$ December $1994^{58}$, advised Minister of Public Works, Paolo Baratta ${ }^{59}$, that at that time no region had passed any legislation to

57 Interview conducted in September 2001, Rome.

58 The Supervising Committee on the Use of Water Resources was established under the government chaired by Silvio Berlusconi, which lasted from $10^{\text {th }}$ May 1994 until $17^{\text {th }}$ January 1995. In 1995, the government of Berlusconi terminated because of conflicts within the government coalition parties, in particular between Berlusconi's Forza Italia and the Lega Nord (Northern League).

59 Paolo Baratta was Minister of Public Works in the government chaired by Lamberto Dini, which lasted from $17^{\text {th }}$ January 1995 until $17^{\text {th }}$ May 1996. The government terminated because new 
implement the water reform yet. After the notification, Baratta could exercise the substitutive powers of the central government by sending special commissioners to the regions that had missed the deadline set by Act 36/1994, which had expired in June 1994. Baratta chose not to pursue this option, on the basis that most of regional governments were still regaining stability after the corruption scandals which took place in $1992-1993^{60}$ and taking over their competences could send a potentially destabilising signal to the local political environments ${ }^{61}$. He rather tried to encourage the regions to pass the required legislation through more indirect means, however. In August 1995, he led the Committee of Ministers for the National Technical Services ${ }^{62}$ to approve various regulations concerning the criteria for the definition of the OTA territories, for the organisation and management of water services, for planning water infrastructure development, for drafting the general regulatory water plan, and for sharing water resources between conflicting uses. After that, he expected that local governments would have no more excuses for not defining the OTA boundaries. As he said in an interview to the press in August 1995: "We have quickly recovered the time lost and completed issuing the elections had been called on $21^{\text {st }}$ April 1996.

60 The 1992-1993 corruption scandals (known as "tangentopoli", or "city of bribes") had dramatically reshaped the national political environment. Influential traditional parties, like Democrazia Cristiana, Partito Socialista, and Partito Comunista Italiano, dissolved, demerged, and changed their most influential leaders and higher ranks.

61 The political "spirit of the time" can be partially grasped from the words of Paolo Baratta in an interview with the business press (Il Sole 24 Ore, 19.07.1995): "We cannot put all of Italy under commissioners, it's time to finish talking about making use of commissioners and prefects. Governing the territory cannot be solved with extraordinary means, which are only useful to overcome temporary obstacles".

62 Established by law 183/1989, paragraph 4, the Committee of Ministers for the National Technical Services included the Chairman of the Council of Ministers (chairman) and the ministers of Public Works, of the Environment, and of Agriculture and Forests. Its responsibilities included issues related to coordination of civil protection, extraordinary interventions in the southern regions of the country, regional affairs and institutional matters, and cultural and environmental heritage. 
required regulations. Now it's the turn of local governments. We have already solicited them and we are available for everyone who needs a technical support on this matter. I hope that it is not necessary, but if it is, we will activate the substitutive powers which are provided by the law and we will eventually propose new rules to facilitate the transition to more effective water service management" ${ }^{63}$.

No substantive action was undertaken until a change of government, that took place in May 1996. After coming to office, the newly appointed Minister of Public Works of the Romano Prodi government ${ }^{64}$, Antonio Di Pietro, reviewed the state of national infrastructure development programmes and realised that water infrastructure works had been carried out with considerable delay with respect to the schedule. The southern regions of the country, in particular, risked losing the appropriation of funds made available by the 1994-1999 Community Support Framework (CSF), a EC programme for funding infrastructure development, if they did not speed up submitting funding applications. On $1^{\text {st }}$ June 1996, then, Di Pietro sent a letter to regional governments urging them "to transmit the projects related to new or ongoing infrastructure development works within 30 days". He also invited the regional governments to a meeting at the Minister of Public Works on $25^{\text {th }}$ June, where they would jointly review the state of the implementation of the water reform.

At the $25^{\text {th }}$ June 1996 meeting, Di Pietro recognised that the implementation of the water reform had been largely neglected. At that time, regional legislations

63 La Repubblica, 15.08.1995.

64 Romano Prodi chaired the Italian government from $17^{\text {th }}$ May 1996 until $21^{\text {st }}$ October 1998. The government of Prodi terminated because of conflicts within the government coalition parties, in particular between Prodi's Ulivo centre-left aggregation and the Communist Party. 
had been passed in Tuscany and Lazio only. Some of the regions (Basilicata, Calabria, Piemonte, and Umbria) were still debating bills in the respective regional councils. Others (Abruzzo, Campania, Emilia Romagna and Marche) had not even started any debate yet, although the respective regional governments had submitted some bill proposals. In other regions (Friuli Venezia Giulia, Molise, Sardinia, Sicily and Veneto) a proposal had just been drafted by the relevant technical committees. In Lombardy and Puglia, no substantial action had been taken at all ${ }^{65}$. Di Pietro urged the regional governments to move on faster in passing the required legislations, otherwise - after a deadline that he set on $31^{\text {st }}$ December 1996 - he would exercise the central government's substitutive powers.

As the regional governments objected that they could not progress in the implementation of the water reform because no regulation of the new tariff system had been issued yet, Di Pietro turned to speed up the accomplishment of this task ${ }^{66}$. On $1^{\text {st }}$ August 1996, he issued the regulation of the new water tariff system (the socalled "normalised method"), that included a formula based on an econometric model of the average efficiency of water firms in the country and some discretionary parameters, especially the yearly return on capital invested that water firms were allowed to earn ${ }^{67}$. The normalised method would play a key role within

65 Some decisions which had been made in the definition of the OTA territories also seemed to contradict the very principles of the reform. For example, Di Pietro criticised the size of the OTA territories established in Abruzzo, because they were too small with respect to the size which was generally believed to allow water firms to achieve economies of scale.

66 A proposal of water tariff regulation had been drafted by the Supervising Committee and transmitted to Baratta on $31^{\text {st }}$ July 1995. Baratta, however, had preferred to postpone the issue of the water tariff regulation after the approval of other pieces of regulation to which he granted priority (e.g., those on surveying water resources, on water resource planning, on the minimum water service standards, and on the criteria for managing the integrated water service, which were issued under the Dini government on $4^{\text {th }}$ March 1996).

67 The Chairman of the Supervising Committee, Walter Mazzitti, welcomed the issue of the normalised method in an interview to the press Il Sole 24 Ore on $1^{\text {st }}$ August 1996: "with the issue of the normalised method for the calculation of the reference tariff of the integrated water 
the water infrastructure development and water service management plans. Its function was illustrated by Giancarlo Galli, member of the Supervising Committee, in an interview to the press Il Sole 24 Ore on $12^{\text {th }}$ August 1996:

We have decided a methodology for calculating operating costs, and also we set the criteria for the maximum allowed increase of the water tariff over time, on the basis of the reference tariff of the specific watershed river basin. The [increase of water tariff] takes into account the production costs, but it is also limited by a price cap in order to protect the users, based on the British model. For example, let's think of a watershed river basin which needs to build new treatment plants and new distribution networks; the local authority may decide to repay the investment in 20 years, by gradually increasing the water tariffs, or to increase water tariffs up to the maximum cap allowed and repay the investment faster. The price of water is going to increase, but in relation to the improvement of the service and the remuneration of the investment made. In the Supervising Committee, we decided to set a $7 \%$ return on capital invested.

Even after the issue of the new water tariff regulation, the regions did not progress much further in passing the required legislations, however. While the $31^{\text {st }}$ December 1996 deadline was approaching, Di Pietro repeatedly reminded the regions of the pending threat. In an interview to the press La Repubblica on $5^{\text {th }}$

service, we made the first important step for the creation of a water market and the industrialisation of water services in the country". 
November 1996, for example, he said: "The law gives me the possibility to intervene and I am willing to use the substitutive powers on those regions - most of the regions - which have not established the Optimal Territorial Areas yet, which are needed for the management, control and rationalisation of water resources. (...) On $1^{\text {st }}$ January 1997 , I'll personally take care of those regions which do not comply with the task of establishing the Optimal Territorial Areas as required by the law. One day only will be enough for me to bring this game to an end". Di Pietro's threat, however, could not materialise because, on $14^{\text {th }}$ November 1996 , he resigned from his office ${ }^{68}$.

In February 1997, Di Pietro's successor Paolo Costa, who had been appointed Minister of Public Works on $20^{\text {th }}$ November 1996, asked the Chairman of the Council of Ministers to send an intimation to the regions that had missed the $31^{\text {st }}$ December deadline - that is, all the regions except for Tuscany, Lazio, Basilicata (that had established the OTAs with Regional Act 63 issued on $23^{\text {rd }}$ December 1996), Piemonte and Abruzzo (whose regional laws were, at the time, under the scrutiny of the government commissioner) - to comply with the transposition of the water reform by the new deadline set on $15^{\text {th }}$ March 1997 . The intimation seemed to generate a sense of urgency for transposing the water reform ${ }^{69}$, but only a few regional governments came to pass the required legislations, namely Piemonte, Abruzzo, Calabria, Campania, Sardinia, and Umbria. After the expiry of the $15^{\text {th }}$ March 1997 deadline, Costa initiated the procedure for commissioning the

68 After quitting his career as magistrate, Di Pietro had been subjected to investigation because of allegations of graft while in office. Despite the supposed victim of the extortion denied the accusation, political pressure persuaded Di Pietro to give up his position.

69 The "sense of urgency" generated by Costa's intimation was highlighted in the 1998 Report to the Parliament of the Supervising Committee, which contained an account of the apparent surge of efforts to draft the required legislations at the regional level. 
defaulting regions.

\section{Implementing the water reform in Alto Valdarno (1994-1999).}

Differently from the rest of Italy, in part of Tuscany the implementation of the water reform proceeded at relatively fast pace. In one such areas, called Alto Valdarno, local governments had been negotiating the centralisation of water service provision since 1990 (Lobina, 2005). At that time, the gas firm Coingas, owned by the municipality of Arezzo, had proposed to the mayor of the same city, Valdo Vannucci, to let the firm develop into a multi-utility company operating in both the gas and water industries. Having gained the support of the centre-left parties that backed the city executive, in October 1992 Coingas submitted a plan that provided that the firm would be reincorporated as a municipal company and would be assigned the water concessions of Arezzo (which directly managed water services at that time) and of 24 other neighbouring local governments. The Coingas plan was approved, first, by the Arezzo city council in December 1992 and, later, by all the other 24 local governments by October 1993.

Within this historical context, after the coming into force of the water reform local governments of this part of Tuscany carried out the task of defining the OTA boundaries relatively fast. Local governments of Alto Valdarno area had already agreed to centralise their water management functions in one water firms only, that would service a larger territory than those of single municipalities. Following the lead of Alto Valdarno, moreover, also local governments of other areas of Tuscany had already taken into consideration the merger of their water 
service providers. More generally, local governments of Tuscany were prepared to define the OTA boundaries, in the sense of having already gone through part of the negotiations needed to agree on the territorial organisation of centralised water service provision. Having received the required input from local governments, the region Tuscany came to pass the regional legislation already in 1995 (Regional Act 81/1995).

In 1995, the support for the Coingas plan dissolved after the formation of a new centre-left coalition executive in Arezzo, chaired by the mayor Paolo Ricci. Following the political orientation of the regional branch of the leftist Democratici di Sinistra (DS) of that time, Ricci favoured the formation of mixed public-private ownership companies rather than municipal companies for the management of local public services. The Coingas plan was overruled on the basis of the lack of transparency that would arise from cross-subsidisation between the gas and water activities, and of the modest experience of Coingas in managing water services. In February 1996, the city council of Arezzo approved, instead, Ricci's proposal to establish a local government majority-owned water company ${ }^{70}$, to whom local government would assign the management of their local water services.

Local governments seemed to prefer establishing mixed public-private ownership companies, rather than municipal companies, for a variety of reasons. First, a mixed public-private ownership company allowed a clearer separation between the planning and control functions (retained by local authorities) and operational management (carried out by the firm), as provided by Regional Act

70 The local government of Arezzo would hold 95\% of the water firm, while the remaining 5\% would be owned by one or more banks. 
81/1995. Second, the company laws regulating mixed public-private ownership companies allowed more managerial flexibility than the administrative laws which regulated municipal companies. Third, mixed public-private ownership companies could allow local governments to benefit from the expertise of the private owners in managing water services, especially if they included other water companies. Fourth, mixed public-private ownership companies could more easily access financial resources, which were needed to fund local water infrastructure development, than municipal companies. For all these reasons, the organisation of local public services through mixed public-private ownership companies elicited the appreciation of several local governments in Tuscany, and, during next years, in other regions too. In the national academic and professional water community circles, it became to be addressed as "the Tuscany model", because of its very first conception and practical application in this region of the country (this form of organising water services was later adopted in all the 6 OTAs established in Tuscany).

The decision of the city council of Arezzo could not be implemented, however, because of violation of the terms of the water legislation. In March 1996, the Regional Control Committee (the regional branch of the Court of Auditors, charged with the task of verifying the legitimacy of the decisions of the regional and local governments) declared that Arezzo's city council was not entitled to award any water franchise, because the water reform had assigned this prerogative to the OTA authorities. Promptly reacting to the decision of the Regional Control Committee, Arezzo and the other local governments included in the OTA Alto Valdarno established the OTA Authority just the day after Arezzo city council 
decision was annulled ${ }^{71}$. After the region Tuscany completed all the details of the transposition of the water reform in April 1997², in July 1997 local governments of the OTA Alto Valdarno decided that the OTA Authority would award the water concession to a mixed public-private ownership company and that a minority share of this company would be tendered out to private operators and investors ${ }^{73}$.

Within a couple of years, the OTA Alto Valdarno Authority progressed to complete the implementation of the water reform by awarding the first water franchise in the country. After the approval of the water infrastructure development and tariff plan in June 1998, on $3^{\text {rd }}$ October 1998 local governments of Alto Valdarno published a call for tender offer for selecting the private partner for the water company that they would form by merging their incumbent water operators. The call, that set relatively demanding requirements ${ }^{74}$, was answered by three applicants only: one bid was submitted by a syndicate led by the French multinational Suez-Lyonnaise des Eaux, another by the French multinational Vivendi, and another by the water company owned by the municipality of Rome,

71 The OTA Alto Valdarno Authority was established as a consortium of local governments, where each municipality participated in proportion to the respective population. The local government of Arezzo, for example, accounted for $31.02 \%$ of votes and capital contribution.

72 Passed in April 1997, Regional Act 26/1997 provided the procedure for surveying water infrastructure, the criteria for the exemption regime, the transfer of personnel from the incumbent water firms to the new solitary operator in each OTA, and the template contract for the water concessions between the OTA authorities and the water firms.

73 In April 1997, Coingas tried to regain political support for being assigned the water concession by circulating a plan according to which Coingas could jointly manage the water services with the local government-owned firm CIGAF, that provided water supply, sewage, and wastewater treatment services in eight local governments included in the OTA Alto Valdarno. The plan failed to attract political support, however local governments decided that the OTA Alto Valdarno Authority would collaborate with Coingas in some limited areas, such as customer relationship management.

74 The call for tenders required the that the bidders had experience of providing water, sewage and wastewater treatment services to at least 400,000 people in the preceding two years, of which at least 200,000 had to be served on the basis of the same contract, and to have an annual turnover of at least Italian lire 150 billion (about $2009 € 93.6$ million) (Lobina, 2005; Drusiani and Nilberto, 2001). 
ACEA. On $14^{\text {th }}$ January 1999 , the OTA Authority's selection committee ruled that the tender offer competition had been won by the syndicate led by Suez-Lyonnaise dex Eaux (that held a share of 51\%), which included AMGA (35\%), a local artisans association Iride (10\%), and the banks Banca Popolare dell'Etruria e del Lazio and Monte dei Paschi di Siena (2\% each). After local governments finalised their negotiations for merging their incumbent water operators, on $21^{\text {st }}$ May 1999 they made the OTA Alto Valdarno Authority award a 25-year water franchise to the mixed public-private ownership firms called Nuove Acque, owned by the local government (54\%) and by the Suez-led consortium (46\%).

The award of the first water concession in the country marked an event of important symbolic relevance. The business press praised the implementation of the water reform in the OTA Alto Valdarno as the "showcase" of innovative practices for water regulation and governance ${ }^{75}$, arguing that local governments of the OTA Alto Valdarno would benefit from the award of the water franchise in terms of prestige, attractiveness of investors, and high consideration from the regional and the central government. The regional government of Tuscany had succeeded in showing that local public services could be awarded to mixed public-private ownership companies. Most of all, water policy experts heralded the award of the water franchise to Nuove Acque as evidence that the water reform could be implemented, eventually.

\section{Aligning regional legislation to the national water reform (1997-1999).}

The implementation of the water reform abruptly accelerated from 1997 75 Il Sole 24 Ore, 21.06.1999 and 02.08.1999. 
onwards, when the central government took the initiative to improve the quality and capacity of sewage and wastewater treatment systems in the country. The policy initiative led to the enactment of a piece of legislation (Act 344/1997) that allocated public funds for a programme intended to improve the sorry state of the sewage and wastewater treatment infrastructure. The programme was mainly intended to comply with the environmental standards set by $91 / 271 / \mathrm{CE}$ directive, that the EC Commission had issued in 1991 and that the Italian government had not implemented yet $^{76}$. The legislation passed in 1997 provided that the central government would assign funds to the regions on the basis of plans prepared on an OTA-by-OTA basis. The definition of the OTA boundaries, then, was an essential requisite for the appropriation of shares of the budget for infrastructure development.

The 1997 legislation also included the provision that, in the event local governments did not come to an agreement on the definition of the OTA boundaries, these water administrative areas would correspond to the territories of the provinces. This provision was included in the bill by the Environment and Environmental Goods Committee of the Senate, who might have considered that the implementation of the legislation under consideration could be blocked by the same constellation of factors that had hampered the implementation of the national water reform ${ }^{77}$. At that time, senators had been informed that local governments were not

76 The 91/271/CE directive was fully transposed into the national legislation with the legislative decree no. 152/1999. This decree also slightly amended law 36/1994, by decentralising some tasks on pollution control, water saving, and infrastructure development to the regions.

77 Unfortunately, minutes of the works conducted at the Territory, Environment and Environmental Goods Committee of the Senate are extremely sparing. No explicit evidence was found regarding the rationales that led legislators to insert the "default" definition of the OTA boundaries as equalling the provincial territories. The narration here is based on reasonable inference supported by interviews conducted with Drusiani, chairman of Federgasacqua. 
collaborating to define the OTA boundaries by the Supervising Committee on the Use of Water Resources, that had recently presented to the Parliament its first yearly report on the state of water services and the implementation of the water reform. To prevent this same source of prospective implementation failure, the Environment and Environmental Goods Committee adjusted the proposed legislation, so that resistance of local governments could be bypassed by imposing the territory of the provinces as "default" definition of the OTA boundaries.

After the enactment of the 1997 legislation, the issue of OTA formation quickly raised up in local governments' agenda. Local government were generally eager to appropriate funds for infrastructure development within their jurisdictions. They were also interested, however, in asserting their prerogatives on the organisation of local water services rather than letting the regions sanction the OTA boundaries as corresponding to the territories of the provinces. For some time, local governments engaged in lengthy and fruitless negotiations concerning the design of OTA authorities according to watershed criteria. Eventually, however, they came to agreements by generally resorting to criteria related to the mere territorial extension of the existing administrative jurisdictions. In twelve regions, the OTA boundaries resulted equal (or very proximate) to those of the provinces, while in five other regions they were set as corresponding to the whole regional boundaries. Only in Tuscany and Campania (that had progressed relatively fast in the design of the OTAs in ways similar to Tuscany) were OTAs defined according to watershed areas.

Special attention to the issue of the definition of the OTA boundaries was 
placed in the southern regions of the country, where particular conditions applied. In 1998, the central government issued regulations for the appropriation of funds provided by the 2000-2006 Community Support Framework, which established a link between the funding scheme and the implementation of the water reform. The regulation provided that extra funds would be granted if the regions passed the regional legislations for transposing the water reform, if local governments established the OTA authorities, and if the OTA authorities formulated water infrastructure development and tariff plans. In order to fulfil these requirements, local governments located in the southern regions became especially concerned with speeding up the definition of the OTA boundaries with respect to their central and northern counterparts.

Once sub-national governments settled agreements on the definition of the OTAs, the number of legislations passed by the regions quickly increased. While three regional legislations only had been passed by 1996, the total number of regional laws that transposed the water reform grew up to nine by the end of 1997 , 13 by the end of 1998 , and 18 by the end of 1999. In the north-eastern border region Friuli-Venezia Giulia only was not the water reform transposed into regional legislation until 2005. Within the couple of years 1997-1999, then, the regions recovered the lost ground with respect to the original water reform implementation schedule.

\section{Establishing the OTA authorities (1997-2001).}

After the regions passed the required legislations, the issue of establishing 
the OTA authorities gained attention in local governments' agendas. Establishing the OTA authorities entailed that local governments included in each OTA negotiated the terms for pooling together their water planning and regulatory functions. Local governments should choose whether to establish the OTA authorities as a reciprocal contractual obligation ("convenzione") or as organisations jointly owned by local governments ("consorzi"), and what rules would affect the management of the OTA authorities, the mechanisms for financing them, the terms for awarding the water concessions, and the regulatory powers that the OTA authorities would exercise.

Local governments' attention towards the issue of establishing the OTA authorities grew as they became increasingly exposed to information about other parts of Italy where OTA authorities had been already established. The early experiences of implementing the regulatory reform in Tuscany, in particular, were a common reference within the ongoing discourse of the national academic and professional water community circles. In Alto Valdarno and neighbouring OTAs, local governments had progressed relatively fast in the establishment of the OTA authorities. Since then, water policy experts, who maintained contacts with each other especially through the association of municipal water and gas companies Federgasacqua, channelled accounts of Tuscany's experience as an advantageous one for local governments ${ }^{78}$. In Alto Valdarno, indeed, local government-owned firms had merged into a relatively large business company partially owned by the

78 Water policy experts placed lot of attention to the experiences of establishing OTA authorities in Tuscany, as witnessed by the yearly water conference H2Obiettivo 2000 proceedings, several business press articles, and a stock of publications issued in the period 1996-1997. Experiences such as the establishment of the OTA Alto Valdarno were commonly referred to as "success stories" that showed the viability of pooling water service provision within watershed areas. 
multinational corporation Suez-Lyonnaise des Eaux and local financial investors. Far from losing their influence on local water industries, local governments understood that they had rather gained the opportunity to generate job appointments and public contracts at a much larger scale than the municipal service areas ${ }^{79}$, setting aside the prospects for a more efficient and effective water service delivery.

The establishment of the OTA authorities proceeded rapidly especially in the southern regions of the country. As already told, in 1998 the central government issued regulations for the appropriation of funds for infrastructure development provided by the 2000-2006 Community Support Framework which provided extra funding if local governments established the OTA authorities. Local governments in the southern regions, then, anticipated that, by establishing the OTA authorities, they could benefit from stimulating further infrastructure development within their municipal jurisdictions. Such material incentive made sub-national governments in the southern regions favourably inclined towards establishing the OTA authorities, although such task was generally performed as an act of fulfilment of an administrative requirement rather than as a component part of a deliberate strategy to re-regulate water service provision.

All in all, the number of OTA authorities established in the country grew steadily from 1997 onwards. After the establishment of the OTA Alto Valdarno Authority in 1997, the total number of OTA authorities raised to 20 by the end of 1998,30 by the end of 1999 , to 48 in 2000, and 74 in 2001 - out of 89 OTAs which

79 In general, consensus about centralising local governments' planning and regulatory functions was not easily attained. As in many countries in the world, also in Italy the liberalisation and regulation (not to mention, of course, privatisation) of water service provision was (is) a highly politically sensitive issue. Ideological positions in favour of public ownership as the only regulatory system of water service provision characterised both right-wing and left-wing parties (e.g., Lega Nord and Partito Comunista Italiano). 
had been defined by that time (Figure 4.1). Within a few years' time, then, most of local governments had come to centralise their water planning and regulatory functions. While the establishment of the OTA authorities had languished during the initial period 1994-1997, after a "turning point" in 1997 the process speeded up and resulted in a partial satisfactory outcome by 2001 .

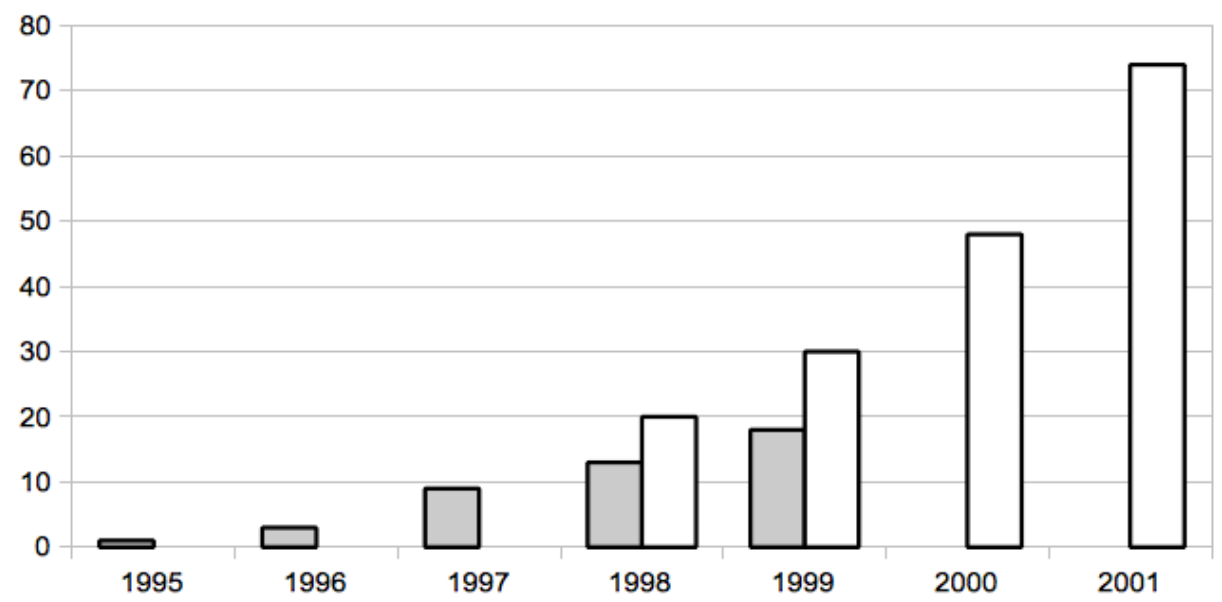

Figure 4.1. Total number of regions which passed regional laws for transposing the national water legislation (grey bars) and total number of OTA authorities established (white bars), per year. Source: Supervising Committee on the Use of Water Resources (1996-2000).

\section{Awarding water franchises (1999-2001).}

After their establishment, the OTA authorities slowly started to be concerned with their statutory duties, especially the award of water franchises. As a preliminary task, OTA authorities first embarked in the survey of the installed water infrastructure. Since the newly established OTA authorities generally lacked adequate resources, surveys were often carried out by local governments or by the regions or, on a few occasions, by the same incumbent water firms. In the southern regions of the country, the survey of water infrastructure was accomplished by Sogesid, a central government-owned agency which had been established in 1993 
and charged with the task of managing the water infrastructure formerly developed within the "Cassa per il Mezzogiorno" programme. By 2001, surveys had been completed in 54 OTAs - 10 located in the northern regions, 19 in the central ones, and 21 in the southern ones.

Once the surveys of the installed water infrastructure was completed, the OTA authorities moved on to draft water infrastructure development and tariff plans. Different OTA authorities confronted with particular issues: generally, the OTA authorities based in the southern regions of the country planned water infrastructure development in order to improve water catchment, transportation, and sewage networks; those in the central and northern regions, instead, mostly planned investments in sewage networks and wastewater treatment plants in order to tackle pollution issues related to more intense population density and manufacture. The water infrastructure development plans typically provided that the new investments would be financed by bank loans to be repaid from operating cash inflows originating from gradual increases of the water tariff over time. Tariff setting rules (issued in accordance to the so-called "normalised method" prepared by the Supervising Committee on the Use of Water Resources), however, placed stringent constraints on the extent to which water tariffs could be increased, at least in the short term.

When drafting the water infrastructure development and tariff plans, the OTA authorities tried to accommodate conflicting pressures from water firms and local governments. The former were generally interested in investing in the water infrastructure and charge capital depreciation and remuneration in the water tariff, 
while the latter typically aimed to contain water tariff increases in order not to alienate the support of the local communities. Water firms were broadly supported by Federgasacqua, which conducted various campaigns aimed at changing the public perception of "fair" water charges. Local governments, instead, were supported by the central government, that generally aimed to contain inflationary pressures by setting relatively low tariffs for public services. Before the issue of the "normalised method", the Inter-Ministerial Committee on Economic Planning $(\mathrm{CIPE})^{80}$ used to set water tariff increase caps up to a maximum of $2.5 \%$ per year. Higher water tariff increases could be conceded only if water firms demonstrated that they would not be able to cover full $\operatorname{cost}^{81}$ of water service provision at a lower tariff level.

Over time, the OTA authorities slowly reconciled the conflicting pressures which originated from water firms and local governments by containing water tariff increase within presumably affordable rates. By the end of 2000, 12 OTA authorities had completed drafting their water infrastructure development and tariffs plans. Out of these OTA authorities, 10 were based in the central regions of the country (6 of them in Tuscany and 4 in Lazio), one in the north (OTA "Valle del Chiampo" in Veneto) and one in the south (OTA "Sarnese Vesuviano" in Campania). Seven of these OTA authorities (those of the OTA "Valle del Chiampo" and "Sarnese Vesuviano", plus five OTAs in Tuscany) had also approved these plans, that provided a gradual increase of water tariff of about $27.1 \%$ on average

80 The CIPE had been charged with competences on water tariff setting by DPR 373 on $20^{\text {th }}$ April 1994, which had abolished the Inter-Ministerial Price Committee (CIP).

81 Differently from the water supply tariffs, the yearly maximum and minimum increase of tariffs for sewage and wastewater treatment were set by the regions. The charges for sewage and wastewater treatment service, anyway, had been kept traditionally very low, even with respect to the water supply tariff. 
after 5 years, $50.1 \%$ after 10 years, and $58.9 \%$ after 20 years (Supervising Committee on the Use of Water Resources, 2001).

While water infrastructure development and tariff plans were prepared, local governments did not really urged the OTA authorities to move further towards the award of water franchises. Apart from Alto Valdarno and a very few other areas ${ }^{82}$, most of the OTA authorities did not undertake any action to open up the local water industries to private operators and investors. Generally, local governments were reluctant to make the OTA authorities call tender offer competitions for selecting business company that would replace the incumbent water providers, because local governments would then lose much of their influence on local water industries. Somehow, local governments were more inclined towards considering awarding water franchises to mixed public-private ownership firms, that was considered as an ownership structure that allowed them to both retain some control of water management and get private capital and entrepreneurial skills involved in water service provision. The awarding of water franchises was kept on hold, then, while several local governments devoted themselves to restructure their water firms in order to be prepared to fit the requirements for forming mixed public-private ownership firms.

The restructuring of local governments' water firms entailed various efforts

82 Among OTA authorities, the one based in the OTA "Latina" in Lazio regions was especially active. In April 2000, local governments of the area (which included 32 municipalities of the province of Latina, 2 of the one of Rome, and 4 of the one of Frosinone) called a tender offer competition for the minority stake (49\%) of Acqualatina, the water firm that they had formed by merging their incumbent providers. In July 2001, the minority share of Acqualatina was sold to a syndicate formed by the central government-owned water firm Acquedotto Pugliese, the French multi-national company Vivendi-Générale des Eaux, and the water subsidiary of the main national electricity company, Enel Hydro. Acqualatina was eventually awarded the water franchise on $2^{\text {nd }}$ August, 2002. 
to reincorporate, merge, and diversify the range of activities of their water providers. Several local government-owned water firms were reincorporated as public limited companies, whose statute granted more freedom of action from local government councils than other organisational forms (i.e., local government departments and municipal companies). Many of these firms (for example, the Turin-based firms Acqua Metropolitana, operating water supply, and Po Sangone, operating sewage and wastewater treatment) merged with each other or acquired other providers in order to secure the size and capabilities needed to be able to manage the whole water services within the OTAs. A number of these firms (for example, ACEA, based in Rome, and AMGA, based in Genoa) also pursued the diversification of their activities into related utility business areas, such as gas, electricity, and telecommunications, in order to gain additional revenue sources and economies of scale from complementary services. All in all, these restructuring operations firms gradually reshaped the traits of the water industry, especially by reducing the long-dated fragmentation of water service providers.

Three examples may illustrate the kind of changes that are described here. In Tuscany, in 1997 the 42 local governments located in the provinces of Prato, Pistoia, and Empoli started negotiating the merger of their water firms. These local governments intended to create a water company that could be awarded the water franchises in the two most populated OTAs in Tuscany, the "Medio Valdarno" (which included Florence) and "Basso Valdarno" (which included Pisa). Their strategy was expressed succinctly by the mayor of Pistoia, Lido Scarpetti, who argued that "we want to pool together the resources and the managerial capabilities 
that we accumulated in the past, in order to enter the market in a strong position, and be ready for the opportunities arising from the institutional changes [in the regulation of the water sector]. Nowadays there is a trend towards overcoming particularism $^{83}$ and achieving economies of scale in order to optimise costs and services" ${ }^{\$ 4}$. In 1999, the water firms of these local governments merged together and were reincorporated into Publiservizi, a holding company that diversified into water (through the subsidiary Publiacqua), energy (Publienergia), and waste management (Publiambiente). A few years later, in 2002, Publiacqua was awarded the water franchises by both the OTA authorities of "Medio Valdarno" and "Basso Valdarno".

In Liguria, in 1995 the water and gas municipal company owned by the local government of Genoa, AMGA, was reincorporated as a public limited company, whose shares were floated in the Milan stock exchange in 1996. In 1997, AMGA launched a hostile takeover bid on the business company De FerrariGalliera, which served about $60 \%$ of Genoa's water supply system. The offer was not accepted because of a syndicate pact between the major shareholders of the target firm, but the search for new business ventures intensified, both in the domestic and the international markets. For a few years, the expansion of AMGA was constrained by the adverse decisions of regional administrative courts. In Liguria, in 1997 the administrative court ruled that the award of water franchise that AMGA had received from the small municipality of Ventimiglia was illegitimate

83 The interview literally referred to particularism as the application of 'logiche di campanile', that is, 'bell-tower logics'. This expression refers to the inclination, attributed to local governments, to narrowly focus on their own local affairs only, typically in conjunction with a mixed attitude of mistrust and competition against neighbouring municipalities.

84 Il Sole 24 Ore, 24.4.1997. 
because AMGA should not operate outside the territory of Genoa. AMGA appealed against this decision, and in June 2001 the Council of State restored the water franchise award because it acknowledged that AMGA operated as an entrepreneurial entity with relative autonomy from the municipality of Genoa, and therefore its operations should not be limited to the territory of the owner. After this decision of the Council of State, AMGA (as well as other local government-owned firms across the country) intensified their initiatives outside the territories of the local government owners.

In Lazio, in 1998 the water, gas, and electricity company of the local government of Rome, ACEA, was reincorporated as a public limited company, whose shares were floated in the Milan stock exchange in 1999. In order to expand its water business, in 1999 ACEA acquired a minority stake in the business company De Ferrari-Galliera, and later in 2000 it launched a friendly takeover bid for both De Ferrari-Galliera and Nicolay, another business company managing part of Genoa's water supply system. AMGA reacted to the entry of ACEA into the Genoa water market by acquiring the shares of De Ferrari-Galliera and Nicolay held by its business partner Vivendi-Générale des Eaux. In turn, ACEA increased its ownership stake in AMGA by buying shares on the stock exchange ${ }^{85}$. The friction between ACEA and AMGA was settled when the management of the two companies came to agree on a joint strategy for managing the water supply system of Genoa, which would lead to the merger of De Ferrari-Galliera and Nicolay. The collaboration between the two companies, however, deteriorated from 2001 onwards, and while AMGA regained a prominent role in the water industry in 85 Il Sole 24 Ore, 5.4.2000. 
Genoa, ACEA dismissed its stakes in De Ferrari-Galliera and Nicolay and diverted its interest towards other areas of the country.

\section{An assessment of the partial water reform implementation outcome (2001).}

How would an observer of the national water sector assess the implementation of the water reform in 2001? In an OECD report issued on $25^{\text {th }}$ September 2001, the Supervising Committee on the Use of Water Resources provided an answer to this question ${ }^{86}$. In the report, the Committee summarised what the implementation efforts had achieved so far in these following lines:

At which stage is the implementation of the law, more than seven years after it was issued? Out of the 89 basins into which the national territory has been divided by regional laws, only 48 have an official governing body already constituted. They include $49 \%$ of the Italian population and $44 \%$ of the 8,102 municipalities of Italy. The situation is very uneven throughout the country: the percentage of ATOs constituted with respect to those that have been planned is 100 in the Centre, 66 in the South and only 30 in the North. In 8 regions (Valle d'Aosta, Lombardia, Friuli Venezia Giulia, Liguria, Molise, Puglia, Sicilia, Sardegna), no ATO is fully constituted. The average population of the planned ATOs is around 692,000 inhabitants, with a maximum of more than 4 million in Puglia, where the ATO coincides with the geographical region. As far as the number of associated municipalities is concerned, there is an extreme variability range from a maximum of 377

86 Memorandum for the OECD ERP mission, Rome, $25^{\text {th }}$ September 2001. 
municipalities in the ATO Sardegna, to a minimum of one municipality for the ATO Milano. Out of 89 ATOs planned, 41 have not started the infrastructure survey yet, 23 are carrying it out and 25 have completed it. Again, central Italy is the leader, followed at a distance by the south, while in the north the process is still at the beginning. At the planning level, 12 plans have already been completed [...]; 6 in Tuscany, 4 in Lazio, 1 in Veneto and 1 in Campania. Seven of these plans have been approved by the respective ATO authorities.

The Committee argued that, on the whole, the implementation of the water reform had achieved disappointing results. The Committee highlighted, however, that the pace of the implementation efforts had relatively increased in the last couple of years. The report concluded:

How to evaluate the implementation process of this reform? We repeat the sequence of figures: 89 ATOs planned, 48 constituted, 25 infrastructure surveys carried out, 12 plans prepared, 7 plans approved, 2 tenders under way and 2 concessions granted. It looks as if a perverse geometric progression at a rate of 0.5 has been in action, with the consequence that half of the subjects were lost at every subsequent step. Therefore, given where we are now, after seven years from the passing of the law, it seems legitimate to speak of failure of the reform, especially since the law established a time span of 12 months for its full implementation. However, 
the evaluation changes if we consider the dynamics of the events that have taken place in these seven years. Indeed, in the last two years there has been a reassuring acceleration of the process.

The assessment of the implementation of the water reform, therefore, included both a positive and a negative side. On the negative side, the intermediate outcome of the water reform implementation in 2001 was a failure in at least two respects. First, the tasks provided by Act 36/1994 (i.e., passing the regional legislations, establishing the OTA authorities, and awarding the water franchises) had been only partially executed. In 2001, most of the institutions of the new regulatory system had been established (i.e., regional legislations had been passed and several OTA authorities had been established), but no further substantive change of the regulatory system of the water industry had taken place yet. Secondly, the tasks provided by Act 36/1994 had been systematically delivered later than the deadlines set by the water reform statute, or, for certain activities (e.g., passing the regional legislations), by the Minister of Public Works.

On the positive side, the intermediate 2001 outcome of the water reform implementation was a partial success in at least two respects. First, as the Supervising Committee highlighted in the 2000 Report to the Parliament, passing the regional legislation after the definition of the OTA boundaries marked a "point of no return" within the implementation process. The formation of new regulatory institutions (in particular, the establishment of the OTA authorities) started to affect decisions bearing important long-term consequences for the organisation of water 
service provision (e.g., the award of the water franchise in the OTA Alto Valdarno) and the design of public policies for the water industry (e.g., the requirement to implement the water reform in order to access funds for water infrastructure development).

Secondly, the pace of the water reform implementation had clearly increased from 1997 onwards. The number of established OTA authorities grew from 20 by the end of 1998 to 74 by the end of 2001. In 1998, just a few OTA authorities were drafting water infrastructure development and tariffs plans, while, by the end of 2001, 18 such plans had been formulated. In 1998, no water franchise had been awarded yet, while, by the end of 2001, several OTA authorities were preparing themselves to award the water franchises according to the new regulatory system. All in all, in 2001 there were encouraging signals that an irreversible process had been put in motion for changing the regulation and governance of the water industry in the country. Resistance to privatise water service delivery from the side of local governments, however, still questioned the extent to which the water policy domain would be substantially affected by the implementation of the 1994 reform.

\section{Chapter summary.}

In sum, the implementation of the water reform in Italy in the period between 1994 and 2001 was relatively hesitant first, while later steadily accelerated. Passing the regional legislations which were required to make the water reform enforceable at the regional level was especially faltering, at the beginning of this

period. After the central government passed a legislation which established a 
linkage between the implementation of the water reform and access to extra funding for infrastructure development in 1997, local governments intensified their efforts to define the OTA boundaries and cleared the way to passing the regional legislations. By 2001, regional legislations had been passed almost close to all the regions of the country.

Also establishing the OTA authorities progressed relatively slowly in the early years after the water reform was enacted. As for the passing of the regional legislation, after the central government tied the implementation of the water reform to funding infrastructure development in 1997 , local governments intensified their efforts to establish the OTA authorities. By the end of 2001, 74 OTA authorities had been established in the country - out of 89 OTAs which had been provided by regional legislations at that time. Several of the OTA authorities started to carry out their statutory duties by drafting water infrastructure development and tariff plans. By the end of 2001, 18 such plans had been formulated, while many others were being drafted and close to completion at that time.

Awarding water franchises, instead, progressed relatively slowly. Apart from the OTA Alto Valdarno, in the rest of the country local governments generally restrained the OTA authorities from progressing to award the water franchises, and they rather focused on preparing their incumbent water firms to become eligible to manage water service provision in the OTAs. Several local government-owned water firms were reincorporated, merged with other water firms in order to gain the size and competences to fit the requirements for being awarded the water franchises, and diversified into other utility business areas. This process was 
particularly evident in the water firms of the main cities in the country, like Rome, Florence, Pisa, and Genoa, whose restructuring contributed to deeply reshape the traits of the water industry.

The Supervising Committee on the Use of Water Resources assessed the outcome of the implementation of the water reform in 2001 as mostly a failure and partially a success. On the negative side, no substantive change of regulatory regime of the water industry had taken place yet. The intermediate results of the water reform implementation had been systematically delivered later than the deadlines originally set by the reform statute or central government officers. On the positive side, however, the water reform implementation process seemed irreversible. The formation of regulatory institutions started affecting long-term decisions about the organisation of water service provision and the design of public policies. The pace of the implementation process, moreover, had clearly accelerated from 1997 onwards. At that time, however, the opening up the water industry to private operators and investors seemed beyond easy reach. 


\section{Chapter 5}

\section{The Implementation of the Water Reform in Italy (2001-2006)}

This chapter narrates the implementation of the 1994 water reform in Italy in the period between 2001 and 2006. During these years, the privatisation part of the water reform, which had been largely neglected beforehand, steadily accelerated. After 2001, an increasing number of OTA authorities awarded water franchises to mixed public-private ownership firms. From 2003 onwards, the total number of awards of water franchises continued to grow, although generally the OTA authorities assigned water service provision to fully local government-owned firms ("in house") rather than opening up the water industry to private operators and investors. By 2005, water franchises had been awarded in 47 OTAs - out of 91 OTAs which had been defined in the country by that time.

The chapter is organised into four sections. The first one will provide an overview of the 1994 water reform implementation in the period between 2001 and 2006. Next two sections will focus, in turn, on awarding the water franchises in the periods 2001-2003 and 2003-2006. The fourth section of this chapter, finally, will provide an assessment of the results achieved in implementing the water reform in Italy in 2006.

\section{The implementation of the water reform in Italy (2001-2006): an overview.}

Until 2001, the privatisation part of the water reform had been fully 
implemented in the OTA Alto Valdarno only. In late 2001, instead, the privatisation of water service provision abruptly accelerated. Several OTA authorities completed the surveys of the installed water infrastructure, formulated water infrastructure development and tariff plans, and awarded water franchises to mixed public-private ownership firms. These efforts took place especially from December 2001, when the Parliament passed a reform of local public services - a category of local governments' field of action which comprised local water services together with others, such as urban waste collection and local gas distribution. The 2001 local public services reform provided the general rule that water franchises should be awarded to business companies selected through tender offer competitions. Alternatively, special provisions allowed to bypass this regulation and award the water franchise to mixed public-private ownership firms, if certain requirements were met within a deadline. In order to exploit these special provisions, a number of OTA authorities speeded up the privatisation process and came to assign water service provision relatively fast.

In 2003, the central government passed another reform of local public services which brought about further stimuli to the privatisation of the water reform. The 2003 local public services reform restated the general rule that local public services should be assigned to business companies selected through tender offer competitions. In the water sector, however, this reform also allowed the OTA authorities to directly assign water franchises to either mixed public-private ownership firms or to fully local government-owned firms, if they serviced their proprietors only and if they were were controlled by local governments as tightly as 
local government departments - the so-called "in house" kind of firm. The "in house" provision clearly offered the opportunity for local governments to make their water firms retain their positions in the local water industries rather than opening up access to the water sector through tender offer competitions for the water franchises. After the 2003 local public services reform, indeed, several OTA authorities directly assigned water franchises to "in house" water firms that were established through the merger of incumbent local government-owned water firms.

On the whole, the implementation of the water reform led, by the end of 2006 , to the set up of the new regulatory system in most of the country and to considerable consolidation of the water industry. In the report to the Parliament in July 2006, the Supervising Committee on the Use of Water Resources highlighted that the water reform implementation had resulted in the establishment of 87 OTA authorities, out of 91 provided in the regional legislations at that time ${ }^{87}$; in the approval of 80 water infrastructure development and tariff plans; and in the award of water concessions in $47 \mathrm{OTAs}^{88}$. The fragmentation of the sector had been largely reduced through the formation of relatively large water companies, although the Supervising Committee estimated that water service provision was still directly managed by at least about 1,480 local governments.

The water regulatory system which had been put into place failed to deliver some expected benefits, however. In the 2006 report to the Parliament, the Supervising Committee highlighted that water firms had not carried out the planned

87 Originally, the regional legislations provided 89 OTAs. The number of OTAs later increased to 91, after the region Friuli Venezia Giulia established 4 OTAs in 2005 and the merger of some OTAs in other regions. In 2009, the number of OTAs increased to 92, because Veneto and Friuli Venezia Giulia established a new OTA named "Lemene" which spanned between the two regions.

88 In 2009, the total number of awarded water franchises increased up to 67. 
investments in water infrastructure and that the water industry had failed to attract private operators and investors. The amount of money spent in infrastructure development projects in the OTAs was significantly lower $(-22.7 \%)$ than what had been included in the water infrastructure development and tariff plans. Funding these investments mostly originated from public sources (national budget and EU programmes) rather than from private capital ones, which were not offered any attractive return because of the relatively low water tariff and persistent inefficiencies in the management of water operations. Only six out of all the OTA authorities had awarded water franchises to business companies selected through tender offer competitions. In all the other OTAs, instead, local governments had been able to prevent opening the water industry to competition and to protect the position of their water firms in the local water industries.

\section{Awarding water franchises (2001-2003).}

In May 2001, the Minister of the Environment and the Safeguard of the Territory of the Berlusconi government, Altero Matteoli, realised that some OTA authorities had directly awarded water franchises to local government-owned firms in apparent violation of the water reform statute. In his view, the water reform strictly implied the application of EU regulations on tender offer competitions for public sector contracting ${ }^{89}$. Local governments, instead, claimed that the direct award of water franchises was legitimate, according to general rules concerning the provision of local public services contained in Act 142/1990, which the water

89 The reference to EU regulations on public sector contracting was mentioned in Article 20, paragraph 1, of the Act 36/1994. 
reform explicitly recalled. Determined to impede any further direct award of water franchises, on $17^{\text {th }}$ October 2001 Matteoli issued a directive where he urged the OTA authorities to award the water franchises through tender offer competitions and to limit the application of direct awards only to firms which qualified according to criteria of efficiency, effectiveness, and financial self-sufficiency ${ }^{90}$. A warning to initiate an infraction procedure against the government of Italy, sent by the EU Commission on $8^{\text {th }}$ November 2000 on the basis that some provisions contained in Act 142/1990 violated EU directives on public sector contracting and the general EU Treaty rules on non-discrimination and transparency, provided Matteoli some ground for publicly justify his efforts to steer local governments' actions.

After a few days, Matteoli filled a gap which had been left still open in the new regulatory system. On $22^{\text {nd }}$ November 2001, he issued the regulation of the procedure that the OTA authorities should follow for conducting tender offer competitions for awarding water franchises (the regulation was required according to article 20 of Act 36/1994, but former Ministers of Public Works and Ministers of the Environment had never approved earlier drafts $\left.{ }^{91}\right)$. On the same day, he also issued another directive where he recommended that the OTA authorities should apply the regulation of tender offer competitions for awarding the water franchises. In this directive, he also reminded that the EU Commission had warned the government of Italy to start an infraction procedure because of mounting evidence

90 The direct award of water concessions was provided by Act 36/1994 as an exemption regime (usually called "safeguard rule"), ruled in article 9, par. 4.

91 Until that time, the OTA authorities actually lacked a regulation on how to conduct the tender offer competitions for the award of water concessions. The regulation should have been issued, as originally provided by Act 36/1994, by the Minister of Public Works, having heard the Minister of the Environment. After a reform of the structure of the executive in 1999 (Legislative Decree no. 300), the task of issuing the regulation had been given to the Minister of the Environment and Safeguard of the Territory. 
of non compliance with EU competition rules in the area of public sector contracting.

Local governments reacted to these directives by questioning the legitimacy of the Minister of the Environment to regulate how water franchises should be awarded. In an interview to the business press, for instance, Leonardo Dominici, Chairman of ANCI, the national association of local government, said: "the directives [provided by the Minister of the Environment] are confusing and contradictory. The laws currently in force do not compel to do any tender offer competition. We need to distinguish the award of the water franchise to a public sector-owned firm from the selection of a business company. In the second case only is a tender offer competition required"92. More generally, local governments claimed that the OTA authorities had the right to directly assign the water concessions to local government-owned water firms, as the tender offer competition rule only applied in the case they wished to award of the water franchises to fully privately owned business companies.

Shortly after Matteoli issued these directives, in December 2001 the Parliament passed 2002 Budget Law (Act 448/2001), which contained, in article 35, a reform of local public services. Until that time, the organisation of local public services had been ruled by Act 142/1990 (later amended by Legislative Decree 267/2000), which provided that local governments could assign them to either local government departments, or to municipal firms, or to mixed public-private ownership firms, or to business companies selected through tender offer competitions. The 2001 local public services reform, instead, provided the general 92 Il Sole 24 Ore, 5.12.2001. 
rule that local public services should be contracted out through tender offer competitions only. Special provisions, however, allowed to apply exemption and transition regimes, under special conditions, to the water industry. These exemption and transition regimes had been introduced in the reform package by the most conservative wing of the Berlusconi-led coalition, which, lobbied by local government-owned water firms, was concerned that incumbent water firms might not win the tender offer competitions if challenged by business companies especially, water multi-nationals.

The application of the exemption and transition regimes provided by the 2001 local public services reform required that specific conditions were met. The exemption regime consisted of the possibility to postpone tender offer competitions for a period from 3 up to 9 years, if water services were managed by relatively small firms which operated in local governments with up to 5,000 inhabitants only. The transition regime provided the possibility to postpone the tender offer competitions if water firms were restructured into bigger size operators. According to this regime, the OTA authorities could directly award water franchises lasting 5 years within 18 months after the enactment of the reform (i.e., by $30^{\text {th }}$ June 2003) to companies entirely owned by the local governments of an OTA, provided that local governments select a private operator or investor as a partner in the ownership of the water firm within 2 years after receiving the franchise. The duration of the franchise could be increased one year if the local government-owned firms merged with other firms to form a new company which would double the user basin. The duration could be further increased two more years if the new companies operate in 
at least one provincial territory, one further year if at least $40 \%$ of the companies is owned by private investors, and one additional year if $51 \%$ of the companies is owned by private investors. These extensions could be accumulated - so that the direct award of water franchises to local government-owned water firms could extend up to 10 years (Petretto, 2001) ${ }^{93}$.

As soon as the Parliament passed the 2001 local public services reform, some local governments urged their OTA authorities to speed up the procedure for awarding water franchises before Act 448/2001 came into force ${ }^{94}$. Within a few weeks in December 2001, then, most OTA authorities based in Tuscany rushed to award water franchises to local government-owned water firms, whose minority shares would be later tendered out to private operators and investors. In this way, local governments could preserve the position of their water firms in the local water industries while bypassing the tender offer competition rule for awarding the water franchises, and they could also avoid complying with the strict requirements set in order to benefit from the transition regime provided by the 2001 local public services reform. As a result of this acceleration of the awarding process, by the end of 2001 water concessions had been granted in 5 out of 6 OTAs in Tuscany.

After the 2001 local public services reform came into force, several local governments sensed the opportunity to protect the incumbent position of their water firms in the local water industries by exploiting the exemption and - mostly - the

93 The local government-owned water firms which benefited from the transition regime were subjected to some limitations to their operations, however. For example, they could not participate in tender offer competitions if they had received direct concessions without tender offers (the same rule applied to their subsidiaries or controlling entities). This rule, however, only applied at the end of the transition period.

94 Generally, within the Italian juridical systems laws come into force 15 days after their publication in the Official Bulletin (Gazzetta Ufficiale). 
transition regimes. In order to accomplish this objective, local governments first required the OTA authorities to speed up the completion of water infrastructure development and tariff plans. While only 11 such plans had been formulated by the OTA authorities by the end of 2001, the number of approved water infrastructure development and tariff plans increased to 38 by the end of 2002 and to 55 by the end of 2003. Local governments also made their water firms restructure in order to match the requirements set to apply the transition regime. Several local government-owned water firms were reincorporated as business companies, including those based in Milan, Brescia, Monza, Parma, Verona, Modena, and Bologna. Some of these companies also floated their shares on the Milan stock market, like Brescia's ASM in July 2002 and Bologna's Hera in June 2003.

After the water infrastructure development and tariff plans were formulated and the water firms had been restructured, several OTA authorities proceeded to the award of water franchises. While only 6 water concessions had been awarded by the end of 2001, their number went up to 9 by the end of 2002 and to 17 by the end of 2003. All but one of the new water franchises were awarded to local governmentowned water firms. Only in the OTA "Frosinone" in Lazio the local OTA authority launched, in May 2001, a tender offer competition for the selection of a business company to which the water franchise would be awarded. In April 2002, the OTA Frosinone Authority granted the water franchise to a consortium led by Rome's water firm ACEA.

The direct award of water franchises according to the terms provided by the transitory regime was opposed by the Minister of the Environment Matteoli. In an 
interview to the business press, he said: "From Piemonte to Campania, passing through Tuscany, there are many instances of firms that define themselves as the legitimate operators in the OTAs in accordance with law 36/1994, but their franchises have been awarded through procedures that have bypassed the tender offer competitions, made possible by the presumption, contrary to the law and counter-productive for the citizens, that public sector-owned companies have the right of exemption [from the tender offer competition rule]"95. Despite Matteoli's concern, during next months local governments persisted in making the OTA authorities directly award the water franchises to local government-owned firms.

The direct award of water franchises was strongly supported by local governments, by the the association of local government-owned public service firms (Confservizi), and by the association of local government-owned water firms (Federgasacqua). These organisations justified the direct award of water franchises on the basis of four arguments ${ }^{96}$. First, they argued that the EU Commission had never issued a directive on the liberalisation of water services (while it did so for other infrastructure industries), and that the EU directive on liberalisation of service contracts (which Matteoli had invoked) regulated competition between business companies rather than public services delivered to the citizens ${ }^{97}$. Second, the 2001 95 Il Sole 24 Ore, 21.11.2002.

96 The positions of local governments, Confservizi and Federgasacqua were expressed on several occasions, including, in particular, the yearly H2Obiettivo 2000 conferences on the water services organised by Federgasacqua. An illustration of the position of these associations was also expressed in two articles that Fulvio Vento, Chairman of Confservizi, and Andrea Lolli, Chairman of Federgasacqua, published in the business press Il Sole 24 Ore on $21^{\text {st }}$ November 2002.

97 In the article published in Il Sole 24 Ore on $21^{\text {st }}$ November 2002, Fulvio Vento wrote: "We should remember that there have not ever been [EU] directives on the liberalisation of the water services, contrary to what happened in the fields of telecommunications, electricity, and gas, just to mention the main ones. Furthermore, we generate confusion if we claim that we should apply the general directives on competition of service contracts, because these communitarian rules have been issued to guarantee the competition within the EU between business service 
reform of local public services ruled out the application of the provisions contained in the national water reform that referred to tender offer competitions, which should no longer be considered enforceable. Third, the Minister of the Environment and the Safeguard of the Territory did not have competences on regulating water services, because a reform of the Constitution of Italy, which came into force on $8^{\text {th }}$ November 2001, limited the State's competences to a strict list of subjects which did not include the water domain ${ }^{98}$.

Lastly, the direct award of water concessions was justified because domestic water firms did not want to be exposed to the threat of competition from foreign companies, while other countries did not provide equal opportunities to expand their business. In an article published in the business press Il Sole 24 Ore on $21^{\text {st }}$ November 2002, Andrea Lolli, Chairman of Federgasacqua, wrote:

If the Parliament decides to open up the [water] market, the water firms will not withdraw from competing [for the franchises]. However, we [as a country] should not be the "only and unique in Europe" following this route. It would be better, as we can learn from foreign experiences, to allow the time needed to favour the construction of national competitors through mergers and public-private partnerships. [...] There is the real risk of a

companies, and they do not refer to the public services delivered to the citizens, rather to the services that might operate in monopoly regime".

98 In the article published in Il Sole 24 Ore on $21^{\text {st }}$ November 2002, Fulvio Vento wrote: "We should remember that an article of the constitution, numbered 117, which has been recently modified [by the November 2001 reform], does not explicitly give to the State the competences on water services, therefore it assigns them to the regions. Then we should deduce that the Minister of the Environment and the Safeguard of the Territory is spoiled of any such competence. We should also remind that local governments enjoy an autonomy acknowledged by the constitution". 
colonisation of the national water market - affected by large size firms based in countries where there is actually no competition.

Thus, local governments' efforts to preserve the position of incumbent water firms was also related to the public discourse concerning the industrial development of the domestic water firms with respect to other EU countries.

\section{Awarding the water franchises (2003-2006).}

In September 2003, the central government passed another reform of local public services. The 2003 local public services reform originated, in part, from pressures of the most conservative wing of the governmental coalition, which was interested to provide local governments with legal ways to bypass the application of tender offer competition rules after the expiry of the $30^{\text {th }}$ June 2003 deadline. The reform also originated, in part, from a request to amend the 2001 local public services reform sent by the EU Commission, that, on $26^{\text {th }}$ June 2002 , had warned the government of Italy to start an infraction procedure against some cases of direct award of water franchises that violated EU legislation on public sector contracts (in particular, directives 92/50/CEE and 93/38/CEE, and general rules of the EU Treaty on non-discrimination and transparency, that contradicted the transitory regime provided by the 2001 local public services reform in the part that allowed postponing tender offer competitions for several years). In relatively short time, then, the central government drafted a revised regulation of local public services, and the new reform was approved by the Council of Ministers with the Legislative 
Decree no. $269^{99}$.

The 2003 reform restated the general rule that local public services should be awarded through tender offer competitions. It also provided that all franchises that had been awarded without any tender offer competition would automatically expire on $31^{\text {st }}$ December 2006. However, the reform also allowed, in accordance with EU legislation, that franchises for local public services could be legitimately awarded in a direct way either to mixed public-private ownership firms, where the private partners were selected through tender offer competitions, or to firms fully owned by local governments, provided that these firms deliver most of their services to the same local governments and that local governments exercise on these firms a control as tight as the one exerted on their own divisions (the so-called “in house" arrangement).

The automatic expiry of franchises awarded without any tender offer competition on $31^{\text {st }}$ December 2006 alarmed several local government-owned water firms, which had directly received the water franchises in accordance with the transition regime provided by the 2001 local public services reform. Pending the threat to lose their water franchises, local government-owned water firms lobbied the central government to amend the 2003 reform and, in December 2003, their efforts succeeded in making the central government introduce an exemption rule to the expiry of franchises ${ }^{100}$. The exemption rule provided that no automatic expiry on $31^{\text {st }}$ December 2006 would apply to those franchises that had been awarded before $1^{\text {st }}$ October 2003 to firms whose shares had already been floated in the stock

99 Later converted into law by Act 326 on $24^{\text {th }}$ November 2003. 100 Act 350 issued on $24^{\text {th }}$ December 2003, article 4, paragraph 234. 
exchange. Furthermore, the December 2003 amendment also contained the provision that the firms which had been directly awarded local public service franchises could take part in tender offer competitions for other local public services, an option that the 2003 reform had banned.

After the 2003 reform and the December 2003 amendments, several OTA authorities started to award the water franchises in accordance with the new rules. Most of these franchises were granted to "in house" firms, which secured local governments' influence on the local water industries. The provision concerning "in house" firms, whose origins within the juridical system originated from a decision of the European Court of Justice taken in $1999^{101}$, was introduced in the 2003 local public services reform as a way of providing legitimacy to franchises already awarded to fully local government-owned water firms ${ }^{102}$. From December 2003 onwards, instead, the OTA authorities started to apply the "in house" provision for awarding new water franchises to fully local government-owned firms. It became apparent, then, that the "in house" provision was exploited as a way to bypass the tender offer competition rule or the requirement to partially open the ownership of the water firms to private operators or investors.

101 The "in house" arrangement had been ruled legitimate by the European Court of Justice in the case C-107/98 Tekal vs. local government of Viano (Italy) on $18^{\text {th }}$ November 1999 . The case originated from the appeal of Tekal, a business company, against the direct award of heating services for certain municipal buildings from the local government of Viano to a fully local government-owned business company. The Court ruled in favour of the local government, on the basis that the local government can contract out the local public service to a third party, juridically distinct from itself, without any tender offer competition and in derogation to sectorspecific rules, if the local government is able to exercise a control on the entity analogous to the one on its own departments, and the other entity delivers most of its services to the controlling local government.

102 The Italian Council of State, Section V, in the sentence 19/2004, n. 679, explicitly commented that the provisions contained in the 2003 reform of the local public services had been written with the aim to safeguard the legitimacy of local public service franchises awarded to fully local government-owned firms and to those awarded in accordance with the special transition regime provided in the 2001 local public service reform. 
The diffusion of "in house" water firms eventually attracted the attention of the Minister of the Environment Matteoli. On $6^{\text {th }}$ December 2004, he issued a directive which aimed to constrain the applicability of this kind of water franchise. The directive ruled that the OTA authorities could apply the "in house" provision only if three requirements were met. First, the statute of the local governmentowned water firms had to explicitly limit the company's objectives to serving the proprietors (hence, the directive limited the possibility that local government-owned water firms could be awarded concessions in other OTAs). Second, all (and only) the local governments included in the OTAs had to own stakes in these water firms. Third, the OTA authorities had to provide an explicit rationale for applying the "in house" provision in the deliberation of the direct award of the water franchise, and they could extend the franchise duration only for a reasonable time needed before the launch of tender offer competitions ${ }^{103}$. On the whole, Matteoli regarded the "in house" provision as a scheme for awarding water franchises to use "only in exceptional and residual cases", and on the basis of "a justified and proved reason of public interest that objectively prevents any possibility to make use of a tender offer competition" 104 .

103 On $6^{\text {th }}$ December 2004, Matteoli also issued a second directive, that ruled that water franchises could be directly awarded to mixed public-private ownership firms only after local governments had selected a business partner through tender offer competitions. Generally, the OTA authorities had directly awarded the water franchises to local government-owned firms whose minority share were later tendered out or floated in the stock exchange. This procedure, for example, had been followed for the selection of the business partners of water firms in the OTA "Medio Valdarno" and "Basso Valdarno" in Tuscany, and in the OTA of Rome. By issuing this second directive, Matteoli intended to make water franchises, that had been awarded to local government-owned water firms without any prior tender offer competition, illegitimate.

104 Directive of the Minister of the Environment and the Safeguard of the Territory, $6^{\text {th }}$ December 2004. The stringent conditions when the "in house" provision could be applied were later restated by the European Court of Justice in the sentence C-458/03 Parking Brixen vs. local government of Bressanone (Italy) on $13^{\text {th }}$ October 2005. The sentence originated from the appeal of Parking Brixen against the direct award of the parking services from the local government of Bressanone to a fully local government-owned business company. The Court ruled against the 
Despite Matteoli's directive, the OTA authorities persisted in directly awarding water concessions to "in house" firms. Local governments and OTA authorities effectively contented that the 2003 local public services reform did not explicitly limit the applicability of the "in house" provision to any condition. Matteoli's efforts to influence the award of water franchises were also formally counteracted by the region Tuscany on legal grounds. On $21^{\text {st }}$ January 2004, the regional government of Tuscany appealed to the Constitutional Court against the part of the 2003 reform of the local public services that provided a detailed regulation of how franchises for local public services should be awarded to business companies selected through tender offer competitions. The regional government of Tuscany claimed that these provisions violated the Constitution of Italy as modified by the 2001 constitutional reform, which granted competences on local public services to the regions ${ }^{105}$. After the Constitutional Court accepted most of Tuscany's appeal on $27^{\text {th }}$ July 2004 (sentence no. 272), Matteoli's directives lost much of their legal relevance.

By awarding water franchises to either mixed public-private ownership firms or to "in house" firms, local governments maintained much of their influence

local government, on the basis that, despite the full ownership, the local government-owned firm enjoyed considerable autonomy and the control that the local government exerted over it could not be assimilated to the one it could employ on its own departments. Thus, failing to launch a tender offer competition for the parking services violated the rules of the EC Treaty referring to non-discrimination and transparency.

105 The 2001 constitutional reform originated from the works conducted in the parliamentary special-purpose committee "Commissione Bicamerale per le Riforme" (bicameral committee for reforms), established in 1997 under the government of Romano Prodi and charged with the task of drafting a constitutional reform bill which would redesign the allocation of authority and the relationship between layers of the State. The issue of reforming the Constitution of Italy in such a way as to reallocate authority between the state and sub-national governments had floated in governmental agendas since early 1980s. Two special-purpose parliamentary committees had been established already (in 1983 and 1993) but were not able to deliver any reform bill until that time. 
on the local water industries. To some extent, local governments even showed to prefer to manage water services through (fully or partially) local governmentowned water firms than through their own departments. An illustrative description of this view was provided, for example, by the major of Grosseto (a municipality located in Tuscany) and chairman on the Local Public Services Committee of ANCI (national association of local governments), Alessandro Antichi, during a conference of Federgasacqua held in Trieste on 24-26 September 2003, where he said: "We know well, we mayors, that a tight control on third entities, like the companies which provide local public services, is actually more effective than the one we have on our own managers, that we find in a local authority because they won a public selection, they chair a division which is only respondent to them, and, as a matter of fact, for us it is much easier to manage through the companies than through the managers [of the local governments]". The award of water franchises to "in house" firms, then, seemed to allow local governments to retain influence over the management of local water services in the same way - if not more - than the direct management of water services through local government departments.

During next years, several local governments followed the common pattern of making their water firms restructure, grow in size, and directly receive water franchises from the OTA authorities. In the north of the country, most profound changes in the industrial organisation of the water sector took place especially in Piemonte, Liguria, and Lombardy. In Piemonte, in October 2004 the water firms of Genoa and Turin, AMGA and SMAT, jointly acquired the majority stake of the water firm Acque Potabili from the gas company Italgas, resulting in the creation of 
the third biggest water firm in the country ${ }^{106}$. In Liguria, in July 2005 AMGA acquired ACEA's stakes in the water companies De Ferrari-Galliera and Nicolay, which later merged together in December 2005. In Lombardy, parallel efforts to merge local government-owned water firms took place between the cities of Cremona, Mantova, Lodi, and Pavia (resulting in the incorporation of the multiutility Linea Group company), Brescia and Bergamo (which merged their water companies, ASM and BAS, in May 2005), and Brescia and Milan (whose mayors in September 2006 agreed to merge the water companies of the two cities, ASM and AEM). Since 2004, moreover, the regional government of Lombardy started sponsoring a project to merge the water, electricity, and waste management firms of most of the region ${ }^{107}$.

In the central regions, the most apparent efforts to restructure the local water industries took place in Emilia Romagna, Tuscany, and Lazio. In Emilia Romagna, in November 2002 fourteen local government-owned water firms (in particular, those of the cities of Ferrara and Modena) merged into HERA, and in March 2005 the multi-utility firms of Piacenza, Parma, and Reggio Emilia merged into ENIA. The regional legislation that transposed the national water reform in Emilia Romagna, Act 25/1999, had provided that water franchises could be awarded to business companies selected through tender offer competitions or to local government majority-owned companies. In order to comply with these requirements, the shares of HERA and ENIA were partially sold to private investors

106 Later on, in October 2006, AMGA also merged with AEM, the electricity and gas company of Turin, leading to the incorporation of Iride, a multi-utility company also operating water services through 17 subsidiaries.

107 The initiative, sponsored by the Governor of Lombardy Roberto Formigoni, took off in November 2004 with a plan presented by a committee formed by 21 utility firms. The programme would involve about 130 firms operating in various utility sectors. 
by floating them in the Milan stock exchange in June 2003 and in June 2007, respectively. In Tuscany, where about 230 firms originally operated in the region (Baggiani, 2003), the consolidation of the local water industry led to only 6 water firms operating in 2003, i.e., one for each of the 6 OTAs established in the country. Aiming to push the consolidation even further, from 2004 the regional government started promoting among local governments of the main cities (Florence, Pisa, Pistoia, Prato, Empoli, Grosseto, and Sienna) the idea to merge their water firms into a large "regional player" water firm. In Lazio, from 2001 onwards the water and electricity firm of Rome, ACEA, carried out a series of mergers and acquisitions which led the company to become, in February 2003, the biggest player in the country's water sector, overcoming Acquedotto Pugliese ${ }^{108}$.

In the southern regions of the country, part of the water industry consolidated around the relatively large incumbents, such as Acquedotto Pugliese and Acquedotto Lucano (originally owned by the State and later transferred to the regions Puglia and Basilicata, respectively), ESAF (based in Sardinia), and EAS (based in Sicily). In Sicily, however, the water industry remained rather fragmented. Several OTA authorities there launched tender offer competitions for the selection of private operators, but often no applications were received, mostly because of the vagueness of the calls, the difficulty for the applicants to assess the risks and returns from investments, and the lack of credibility of the OTA authorities in regulating the water tariff according to the franchise terms (Antonioli, 2006; Drusiani et al., 2004; Massarutto, 2007). The difficulty of attracting private operators when conducting tender offer competitions for the selection of partners for local 108 Il Sole 24 Ore, $7^{\text {th }}$ March 2003. 
government-owned water firms had also been experienced in other OTAs in the country, however. On average, tender offer calls for selecting private operators as partners of local government-owned water firms received 1.6 applications, and those for the selection of business companies for managing the water services counted 1.2 bids (Anwandter and Rubino, 2006a, 2006b).

On the whole, by the end of 2006 the water reform had been largely implemented. At the end of 2001, 11 water infrastructure development and tariff plans had been approved and 6 water franchises had been awarded. The number of plans approved rose to 38 in 2002, 55 in 2003, 66 in 2004, and 70 in $2005^{109}$. The number of OTAs which had awarded water franchises increased to 9 in 2002, 17 in 2003, 33 in 2004, and 47 in $2005^{110}$ (Figure 5.1). A survey of water firms conducted in December 2009 showed that water franchises had been awarded in 67 OTAs to a total number of $102^{111}$ water service providers (the total number exceeded the one of the OTAs because sometimes the same OTA authorities had jointly awarded water franchises to more than one water firm within the same OTA). Most of the water franchises were awarded to "in house" water firms (58) and to mixed public-private ownership firms (27). In 11 cases water concessions were assigned to public sector firms which enjoyed transitory or exemption regime, and in 6 cases only were they awarded to business companies ( 5 of them were selected through tender offer competitions, and one of them was granted the water franchise in a negotiated temporary regime).

109 Supervising Committee on the Use of Water Resources (2002-2006).

110 Supervising Committee on the Use of Water Resources (2002-2006).

111 According to data provided by the Supervising Authority on Water Resources and Urban Waste (2008), Bluebook (2008), and direct inspection of the web sites of the 92 OTA authorities established in the country (last access, December 2009). 


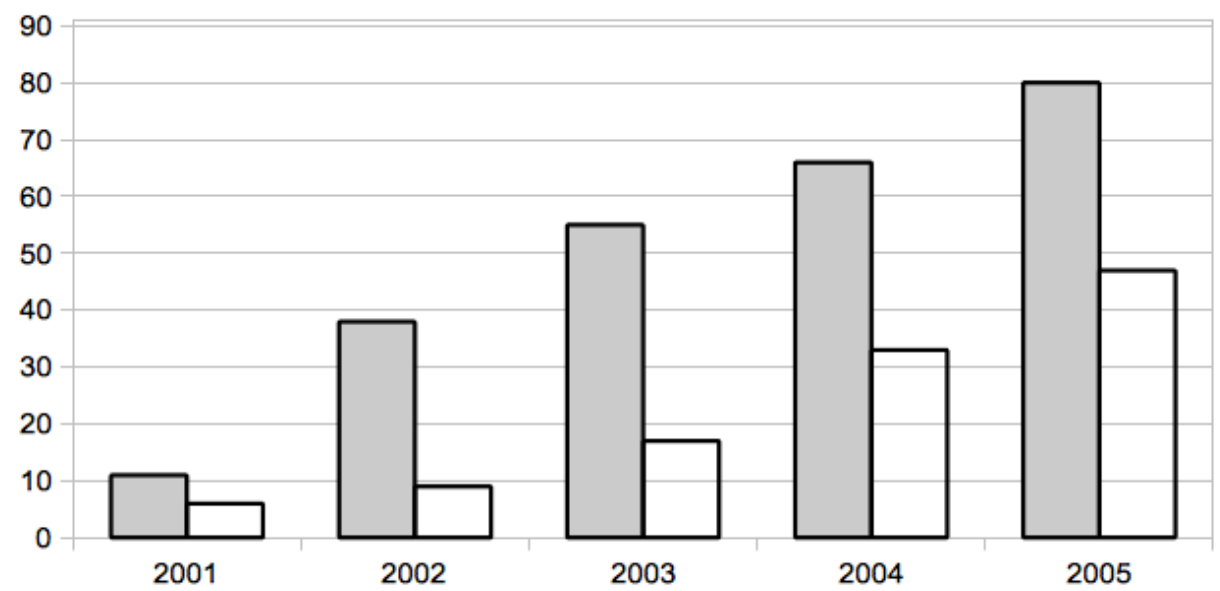

Figure 5.1. Total number of water infrastructure development and tariff plans (grey bars) and total number of water franchises awarded (white bars), per year. Source: Supervising Committee on the Use of Water Resources (2001-2005).

In 2006, the implementation of the water reform came to an end. On $23^{\text {rd }}$ October 2000, the EU Commission had issued the Water Framework Directive (WFD) (2000/60/CE), which provided a regulatory framework for the protection of the aquatic environment and for the sustainable, balanced, and equitable water use. The WFD provided, in particular, that water resource planning would be conducted by the authorities of water districts, that is, new jurisdictions that the member states were mandated to establish according to the hydro-geographical features of the territories. The transposition of the WFD into the Italian national legislation began in October 2001, when the central government submitted a bill to the Parliament. Since the WFD was not transposed within the deadline set on $22^{\text {nd }}$ December 2003, the EU Commission started an infraction procedure against the government of Italy. After the European Court of Justice sanctioned Italy on $12^{\text {th }}$ January 2006, the central government speeded up the transposition of the WFD, which was 
accomplished on $3^{\text {rd }}$ April 2006 (Legislative Decree 152/2006).

The legislation which transposed the WFD introduced several changes into the regulatory framework of water management and various other water-related areas, such as waste collection, protection of the territory, quality of air, and management of natural and marine parks. In the area of water management, Legislative Decree 152/2006 provided the establishment of eight water districts in the country, whose authorities would plan the interventions needed for the preservation of water resources and the development of water infrastructure. For what matters the implementation of the water reform enacted in 1994, Legislative Decree $152 / 2006$ also abrogated Act $36 / 1994^{112}$, hence putting an end to a process which had deeply affected the organisation and management of the water industry in the country over the previous twelve years ${ }^{113}$.

\section{An assessment of the water reform implementation outcome (2006).}

Having narrated the events which took place between 2001 and 2006, this section will outline an assessment of the final implementation outcome of the water reform from the viewpoint of an observer of the water sector in 2006. Until 2006, the last available dataset on the state of the water industry provided by the national statistics office ISTAT dated back to a survey conducted in 1999, which showed that

112 Apart from article 22, paragraph 6, of the law no. 36/1994, which provided the budget for the Supervising Committee on the Use of Water Resources and the Observatory.

113 With the abrogation of Act 36/1994, the main institutional framework regulating the organisation and management of the local water services became the Legislative Decree 152/2006 and the 2003 local public services reform. More recently, however, a referendum held on 12-13 Jun 2011 resulted in the abrogation of part of Legislative Decree 152/2006 that provided that the water tariff should also remunerate the capital invested by water firms for the construction and maintenance of infrastructure. After this referendum, therefore, the regulation of the water tariff lacked providing adequate incentives for the participation of private operators and investors in the water industry. 
most of the water services were still directly managed by local governments (the survey counted 6,452 local governments directly involved in managing water services out of about 8,100 municipalities in the whole country $\left.{ }^{114}\right)$. A survey of the OTA authorities conducted by the Supervising Committee in 2005 reported, instead, a relatively minor role played by the direct management of local government (apparently only 1,480 local governments still directly managed water services), even if the same Committee held doubts about the reliability of the survey results ${ }^{115}$.

In July 2006, the Supervising Authority on Water Resources and Urban Waste (which took over the tasks of the Supervising Committee on the Use of Water Resources after Legislative Decree 152/2006) issued a report based on a new dataset on the state of the water industry. This report, which followed a survey conducted in 2005, showed that, of the 91 OTA authorities provided by the regional legislations, 87 had been established, 70 had approved water infrastructure development and tariff plans, and 47 had completed the award of the water service franchises. In the same month, also the research centre of the association of local government-owned utility firms Federutility, Utilitatis, issued a report named Bluebook. This report, which referred to 2006 data, showed that 90 water infrastructure development and tariff plans had been approved, and 54 water franchises had been awarded by the OTA authorities - 31 directly granted to "in house" firms, 13 to mixed public-private ownership firms, and 3 only to business

114 The 1999 ISTAT survey also reported that the water sector included 107 special (i.e., incorporated in accordance with public sector law) local government-owned firms, 526 consortia, 52 public sector companies, 214 business companies (i.e., companies incorporated in accordance with business law, but which might be local government-owned), and 460 other non-classified firms. On the whole, the water sector included 7,822 firms. These data were reported in the 2003 Report to the Parliament of the Supervising Committee on the Use of Water Resources.

1152006 Report to the Parliament of the Supervising Committee on the Use of Water Resources, page 61 . 
companies (in the OTAs of "Frosinone", "Siracusa" and "Enna"). In 8 cases, the water franchises had been awarded to water firms which enjoyed exemption regimes.

The report of the Supervising Authority also illustrated the results of an analysis conducted on a sample of 40 water infrastructure development and tariff plans. The analysis showed that, on average, the OTA authorities had planned investments in water infrastructure for about $€ 3.7$ billion/year over approximately the next 26 years. The main financing sources consisted of public sector funds, which accounted, on average, for about $€ 850$ million/year (i.e., about $22.7 \%$ of the investments planned). Commenting on these figures, the Supervising Authority expected that private finance could hardly be raised to support the investments planned, because the planned water tariff increase did not seem sufficient to provide an attractive return on investment ${ }^{116}$. Additionally, the Supervising Authority criticised the quality of these plans, because they often showed an incomplete survey of the installed water infrastructure, questionable water demand forecast, and unreliable data on leakage and infrastructure maintenance needs.

On the whole, the Supervising Authority 's assessment of the state of the water industry in 2006 included a positive and a negative side. On the positive side, the Supervising Authority acknowledged that "the implementation of the reform of

116 The issue of the insufficient tariff increases had been repeatedly raised by the association of local government-owned utility firms Federgasacqua. In an interview with the business press Il Sole 24 Ore on $14^{\text {th }}$ March 2006, for example, the Chairman of Federgasacqua Renato Drusiani said: "We need to review the tariffs [regulation], otherwise no operator will ever take part in the tender offers for 'maecenatism'. [...] If we want to award the management of water service to private operators, then we need to offer the operators an adequate return [...] Italy has tariffs three, four, five times less that in France and Germany. The truth is that everything must be paid. With higher tariffs, operators could make investments, for example in the areas of sewage and wastewater treatment, which have never been properly upgraded in the country". 
the integrated water service $[\ldots]$ seems to have finally started after the delimitation of the OTAs and the establishment of the OTA authorities" ${ }^{117}$. Most of the OTA authorities of the country, moreover, had come to award water franchises according to the new regulatory system. Although the OTA authorities were still developing their skills to manage the regulatory process, many of them showed to be committed to improve regulatory performance. Some of them, for example, had established a network (Associazione Nazionale degli Enti ed Autorità d'Ambito, ANEA) for sharing experiences and develop common standards for monitoring and assessing the performance of water firms and water services. Moreover, the reorganisation of the water industry had led to the reduction of the fragmentation of the sector and the emergence of some water firms which had gained a relatively large scale at the regional level.

On the negative side, however, the Supervising Authority highlighted that, twelve years after the enactment of the water reform, local governments still dominated, although indirectly, local water industries and the presence of private operators and private investors in the sector was minimal. The OTA authorities had awarded the water franchises following local governments' directives, which generally consisted of preserving the position of their incumbent water firms in the local water industries. Generally, this resulted in foreclosing the development of a competitive water industry, prevented attracting private capital for investment in water infrastructure, and provided little pressure to improve water firms' performance. In sum, the Supervising Authority concluded that "if these conditions

117 Report to the Parliament of the Supervising Committee on the Use of Water Resources, 2006, p. 23. 
persist, the objectives of efficiency, effectiveness and financial self-sufficiency declared by the reform can be hardly achieved" ${ }^{118}$.

A more recent picture of the water industry in the country was provided by data collected for this thesis through the access to the web sites of the 92 OTA authorities established in the country (in December 2009). Data show (Table 5.1) that "in house" firms were the most common form of water franchise, particularly in the northern regions (counting $78 \%$ of all the water franchises awarded in that part of the country). Mixed public-private ownership firms were relatively more frequent in the central regions $(22 \%)$ than in the southern $(15 \%)$ and the northern (7\%) ones. The award of water franchises to "in house" firms whose shares were traded in the stock exchange was relatively diffused in the northern $(11 \%)$ and the central $(19 \%)$ regions, but absent in the southern ones. Most of the safeguards of incumbent water firms took place in the central regions $(22 \%)$, and the tendering out of the water franchises to business companies was more frequent in the south $(31 \%)$.

Recent research also showed a relatively encouraging picture of the investment trend in the water sector, however. Based on ISTAT data, Ermano (2012) calculated pro-capita investment in water infrastructure during the period 19542010, grouped into periods each approximately a decade long (Table 5.2). The table exhibits that, after the relative decline of pro-capita investment during part of the 1990 's, both planned and realised investments in water infrastructure remarkably increased after the new regulatory regime was put into place. Based on ISTAT data,

118 Report to the Parliament of the Supervising Committee on the Use of Water Resources, 2006, p. 209. 
however, some documentary sources (non-profit organizations Cgiamestre, 2011, and Cittadinanzattiva, 2011) also highlight that water tariffs sharply increased during the 2000's (about 64.4-70\%). 


\begin{tabular}{|c|c|c|c|c|c|c|c|c|}
\hline Regions & $\begin{array}{l}\text { No. OTAs which have } \\
\text { awarded concessions } \\
\text { (No. OTAs } \\
\text { established) }\end{array}$ & $\begin{array}{l}\text { 'In house' } \\
\text { firms }\end{array}$ & $\begin{array}{l}\text { Mixed public-private } \\
\text { ownership firms }\end{array}$ & $\begin{array}{l}\text { Firms traded in } \\
\text { stock exchange or } \\
\text { owned by } \\
\text { financial } \\
\text { institution }\end{array}$ & $\begin{array}{c}\text { Safeguarded } \\
\text { public sector firms }\end{array}$ & $\begin{array}{l}\text { Private firms } \\
\text { selected through } \\
\text { tender offer } \\
\text { competition }\end{array}$ & $\begin{array}{l}\text { Private firms in } \\
\text { negotiated } \\
\text { transitory regime }\end{array}$ & Total \\
\hline Piemonte & $6(6)$ & 17 & 3 & 4 & & & & 24 \\
\hline Valle d'Aosta & $0(1)$ & & & & & & & \\
\hline Lombardy & $6(12)$ & 8 & 1 & & 2 & & & 11 \\
\hline Friuli Venezia Giulia & $1(4)$ & 1 & & & & & & 1 \\
\hline Liguria & $2(4)$ & 4 & & 1 & & & & 5 \\
\hline Total northern regions & $22(35)$ & $42(78 \%)$ & $4(7 \%)$ & $6(11 \%)$ & $2(4 \%)$ & $0(0 \%)$ & $0(0 \%)$ & 54 \\
\hline Emilia Romagna & $9(9)$ & 1 & & 6 & 3 & & & 10 \\
\hline Tuscany & $6(6)$ & 1 & 5 & & & & & 6 \\
\hline Umbria & $3(3)$ & 1 & 2 & & & & & 3 \\
\hline Lazio & $4(5)$ & 1 & 1 & 1 & & 1 & & 4 \\
\hline Abruzzo & $6(6)$ & 4 & & & 2 & & & 6 \\
\hline Molise & $0(1)$ & & & & & & & 0 \\
\hline Total central regions & $32(35)$ & $12(33 \%)$ & $8(22 \%)$ & $7(19 \%)$ & $8(22 \%)$ & $1(3 \%)$ & $0(0 \%)$ & 36 \\
\hline Campania & $2(4)$ & 1 & 1 & & & & & 2 \\
\hline Puglia & $1(1)$ & & & & 1 & & & 1 \\
\hline Basilicata & $1(1)$ & 1 & & & & & & 1 \\
\hline Calabria & $3(5)$ & 2 & & & & & 1 & 3 \\
\hline Sicily & $5(9)$ & & 1 & & & 4 & & 5 \\
\hline Sardinia & $1(1)$ & 1 & & & & & & 1 \\
\hline Total southern regions & $13(21)$ & $5(38 \%)$ & $2(15 \%)$ & $\mathbf{0}$ & $1(8 \%)$ & $4(31 \%)$ & $1(8 \%)$ & 13 \\
\hline Interregional OTAs & $0(1)$ & & & & & & & \\
\hline Total & $67(92)$ & 58 & 14 & 13 & 11 & 5 & 1 & 102 \\
\hline
\end{tabular}

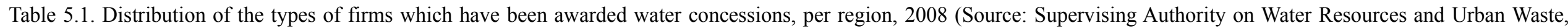
2008; web sites of the OTAs, last access in December 2009). 


\begin{tabular}{cc}
\hline Periods & Per-capita investment \\
\hline $1954-1969$ & 16.2 \\
$1970-1979$ & 18 \\
$1980-1989$ & 32.4 \\
$1990-1997$ & 17.3 \\
$1997-2010$, as provided in OTA plans $\left(^{*}\right)$ & 30.6 \\
1997-2010, realised & 33
\end{tabular}

Table 5.2. Pro-capita investments in water infrastructure, values in constant prices $2010 €$. (*) Values inferred on the basis of 19 OTAs (Source: Ermano, 2012, on the basis of ISTAT data and Bluebook, 2010).

\section{Chapter summary.}

In sum, the privatisation part of the water reform was largely implemented during the period between 2001 and 2006. By 2005, the water reform resulted in the establishment of 87 OTA authorities, out of 91 OTAs provided by regional legislations; in the approval of 80 water infrastructure development and tariff plans; and in the award of water concessions in 47 OTAs - which later rose to 67 in 2009. The implementation of the water reform, moreover, proceeded together with significant changes in the industrial organisation of the water sector. The fragmentation of the water industry, in particular, was significantly reduced through several mergers and acquisitions which took place between local governmentowned water firms. All in all, in 2006 the water industry and its regulatory system looked quite different than they had been before the enactment of the water reform in 1994.

In the period between 2001 and 2003, the implementation of the privatisation part of the water reform largely resulted in the award of water franchises to mixed public-private ownership firms. The period begun with the enactment of the 2001 reform of local public services, which provided the general 
rule that franchises of local public services should be awarded to business companies selected through tender offer competitions. The 2001 reform, however, also contained provisions for derogating to the tender offer competition rule by applying an exemption or a transition regime to water firms. In order to take advantage of these provisions, several local governments restructured their water firms, opened them partially to private ownership, and made the OTA authorities directly assign them the water franchises.

In the period between 2003 and 2006, the implementation of the privatisation part of the water reform speeded up further. The period begun with the enactment of another reform of local public services, which restated the general rule that franchises of local public services should be awarded to business companies selected through tender offer competitions. The 2003 reform, however, also allowed that the franchises are awarded to mixed public-private ownership firms or to fully local government-owned firms that complied with the requirements of the "in house" model. From 2003 onwards, a growing number of water franchises were awarded in the country especially to "in house" firms, despite efforts to open up the sector to the participation of private operators and investors from the side of the Minister of the Environment.

The implementation of the water reform terminated in 2006, when Legislative Decree 152 abrogated the national water reform statute (Act 36/1994). The outcome of the process of implementing the water reform in 2006 was, according to the Supervising Authority on Water Resources and Urban Waste (which took over the tasks of the Supervising Committee on the Use of Water 
Resources), a mix of success and failure. On the one hand, the water reform had eventually been implemented in most of the country and had been accompanied by significant changes in the industrial organisation of the water sector, whose fragmentation had been largely reduced. On the other hand, local governments still dominated, either through full or partial ownership of water firms, the water industry, while the presence of private operators and private investors was minimal. Incumbent local government-owned water firms had effectively preserved their positions in the local water industries, while no competition mechanisms had been substantially put into place, relatively little private capital had been attracted for investments in the water infrastructure, and little pressure had been put on water firms to improve their performance. 
PART III 


\section{Chapter 6}

\section{Analysing the implementation of the water reform in Italy (1994-2006): institutional rational choice approach}

This chapter presents an analytic narrative of the implementation stage of the water reform in Italy in the period 1994-2006 conducted by following an institutional rational choice approach. The chosen explanandum is what accounts for the variation in the pace of the implementation of the water reform between a first period, that amounted to a failure to execute the regulatory reform mandate, and a second period, that resulted in a final state close to full implementation; and what accounts for the variation in the pace of the implementation of the water reform between Alto Valdarno area in Tuscany and the rest of country.

The chapter is divided into two parts. The first part will focus on the analysis of the implementation of the liberalisation and re-regulation part of the water reform. This part of the analysis is conducted in two steps. First, we will explain why, after the enactment of the water reform, local governments did not define the boundaries of the OTAs. We will move, then, to explain why local governments in Alto Valdarno deviate from this general pattern. Next step will be to explain why, after a "turning point" that we date in 1997, local governments progressed to define the OTA boundaries and establish the OTA authorities.

The second part of this chapter will be concerned with analysing the implementation of the privatisation part of the water reform. This part of the analysis is conducted in two steps, too. First, we will explain why, once the OTA 
authorities had been established, they generally did not execute the regulatory reform mandate to award the water franchises. We will move, then, to explain why, after a "turning point" that we date in 2001, the OTA authorities started to award the water franchises to mixed public-private ownership firms. Finally, we will provide an explanation for why, after 2003, OTA authorities generally awarded the water franchises to "in house" firms.

\section{Explaining the implementation of the liberalisation and re-regulation part of} the water reform.

1.1. Explaining the faltering implementation in the first period (1994-1997).

The first step of this part of the analysis is explaining why, after the enactment of the water reform, local governments did not define the boundaries of the OTAs. In order to tackle this question, we turn to modelling the interaction between actors of the water policy domain (i.e., local governments and the regions) in a game theoretic fashion. Let $\mathrm{R}_{\mathrm{i}}$ indicate any of the 19 regions of the country involved in the implementation of the water reform, with $\mathrm{i}=$ integer, $1<=\mathrm{i}<=19$. Because of water reform design features, any $R_{i}$ can pass regional legislation, that is required to enforce the water reform at the regional level, only after local governments agree on the definition of the boundaries of the OTAs. The agreement between local governments is conceived as an equilibrium of a coordination game, where local governments choose whether to agree with neighbouring municipalities on the definition of the OTA boundaries or not.

Let $\mathrm{LG}_{\mathrm{ji}}$ indicate any $\mathrm{j}$-th local government within the $\mathrm{i}$-th region. Any $\mathrm{LG}_{\mathrm{ij}}$ plays a coordination game with an unspecified number (tens or even hundreds) of neighbouring municipalities. Any local government could, in principle, negotiate 
the definition of the OTA boundaries with any bordering and surrounding municipalities. Modelling this coordination game in detail would be particularly complex, because (a) the number of players of the game is not given (i.e., any local government can choose whether to sit the negotiation table or not) and (b) any player can participate to several games at the same time (i.e., any local government can negotiate the definition of the OTA boundaries with different sub-sets of municipalities). For the sake of simplicity, let us consider an overly simplified scenario in which two local governments only, $\mathrm{LG}_{1}$ and $\mathrm{LG}_{2}$, play the coordination game. Players have infinite horizon and a time discount factor of $\delta \in(0,1)$, that is assumed constant for all players.

Each local government is assumed to hold relatively homogeneous preferences ${ }^{119}$. Generally, local governments are assumed to be relatively indifferent towards the execution of the water reform mandate by itself, while they care about the consequences of executing the water reform at the local level. Taking into account that the control of water firms grants local governments the possibility to affect water-related jobs and public contracts and the role that the water business traditionally plays within the local political environments, local governments are assumed to prefer holding direct control of water firms rather than giving up any of the water planning, regulatory and management functions. In addition, local governments are assumed to prefer controlling relatively larger water organisations than smaller ones, for reasons related to increased budget (and, relatedly, jobs and

119 The modelling assumptions may be relaxed in such a way as to allow heterogeneity between the preferences held by each local government. Indeed, some degree of heterogeneity between local governments' preferences will be discussed later on in the analysis. At this stage, however, the assumption of homogeneous local governments' preferences allows to make the issue of analysing the strategic interaction between local governments more tractable. 
public contracts) with respect to those of water firms that operate in smaller territories. Local governments' utility function, therefore, is assumed to be positively related to direct control of the water planning and regulatory functions, to direct control of water management functions, and to the size of water firms.

Each local government can choose whether to agree on the definition of OTA boundaries or not. If both local governments do not agree, then they maintain the status quo and get nil payoff. If any local government chooses to agree while the other does not, then no agreement can be reached and they both get nil payoff. If both local governments agree, then they allow the region $\mathrm{R}_{\mathrm{i}}$ to pass regional legislation. In this case, local governments anticipate the expected payoff which would arise from progressing to implement the water reform. This payoff includes (a) the cost $\mathrm{C}_{\lg 1}$ of losing direct control of water planning and regulatory functions (which, if the water reform is implemented, are centralised into the OTA authorities), (b) the cost $\mathrm{C}_{\mathrm{lg} 2}$ of losing direct control of water management functions (which, if the water reform is implemented, are centralised into partially or fully privatised water firms), and (c) the benefit $\mathrm{B}_{\mathrm{lg} 1}$ of shared influence on larger water firms (if the water franchise is awarded to firms partially owned by local governments). Costs $\left(\mathrm{C}_{\mathrm{lg} 1}\right.$ and $\left.\mathrm{C}_{\mathrm{lg} 2}\right)$ and benefits $\left(\mathrm{B}_{\mathrm{lg} 1}\right)$ take place at future times $\left(\mathrm{t}_{1}\right.$, $t_{2}$, and $t_{3}$ ). Hence, the payoff for each local government can be written in the form:

$$
p_{l g}=\frac{-C_{l g 1}}{(1+\delta)^{t_{1}}}+\frac{-C_{l g 2}}{(1+\delta)^{t_{2}}}+\frac{B_{\lg 1}}{(1+\delta)^{t_{3}}}
$$




\begin{tabular}{|c|c|c|}
\hline & $\begin{array}{l}\text { To define the OTA } \\
\text { boundaries (D) }\end{array}$ & $\begin{array}{l}\text { Not to define the OTA } \\
\text { boundaries (ND) }\end{array}$ \\
\hline $\begin{array}{l}\text { To define the OTA boundaries } \\
\text { (D) }\end{array}$ & $\mathrm{p}_{\mathrm{lg}}, \mathrm{p}_{\mathrm{lg}}$ & 0,0 \\
\hline Not to define the OTA (ND) & 0,0 & 0,0 \\
\hline
\end{tabular}

Table 6.1. Payoff matrix of local governments' coordination game of defining the OTA boundaries.

Table 6.1 shows the payoff matrix of the game played by the two local governments. If $\mathrm{p}_{\mathrm{lg}}$ is negative, then the strategy not to define the OTA boundaries (ND) weakly dominates the strategy to define the OTA boundaries (D). The strategy (ND, ND) is a Nash equilibrium, i.e., if both local governments choose ND, then none of them would be better off by deviating to play D. Instead, (D, D) is not a Nash equilibrium, i.e., if at least one local government deviates to play ND rather than $\mathrm{D}$, then both local governments would be better off by getting 0 rather than $\mathrm{p}_{\mathrm{lg}}$. If $\mathrm{p}_{\mathrm{lg}}$ is positive, then the strategy $\mathrm{D}$ weakly dominates the strategy ND. In this case, playing $(\mathrm{D}, \mathrm{D})$ is a Nash equilibrium, i.e., if both local governments choose $\mathrm{D}$, then neither would be better off by deviating to play ND. However, in this case also the strategy (ND, ND) is a Nash equilibrium, i.e., if one local government deviates to play $\mathrm{D}$ rather than ND, then it would be no better off than playing ND. Thus, even if $p_{\mathrm{lg}}$ is positive, local governments may be "stuck" to play not to agree with each other to define the OTA boundaries.

When is $p_{\mathrm{lg}}$ positive, anyway? The value of $\mathrm{p}_{\mathrm{lg}}$ is affected by four factors. First, $\mathrm{p}_{\mathrm{lg}}$ is greater - ceteris paribus - the lower is the value of the costs incurred by local governments for the loss of direct control of the water planning and regulatory functions $\left(\mathrm{C}_{\mathrm{lg} 1}\right)$ and water management functions $\left(\mathrm{C}_{\mathrm{lg} 2}\right)$. Control of these functions is assumed to provide benefits to local governments in terms of influence on water- 
related jobs and public contracts. Second, $\mathrm{p}_{\mathrm{gg}}$ is greater - ceteris paribus - the higher is the value of the benefits which arise from the joint control of larger organisations, once the water planning and regulatory functions are pooled together into the OTA authorities and the water firms are merged and (partially) privatised. These benefits $\left(\mathrm{B}_{\mathrm{lg}}\right)$ may offset the costs of the loss of direct local governments' influence on water-related jobs and public contracts. The realisation of $\mathrm{B}_{\mathrm{lg}}$, however, is dependent on setting up governance arrangements in the OTA authorities and in the privatised water firms that protect the stakes of each local government. Local governments may not know in advance how well future governance arrangements will protect their stakes, hence they do not possess information as to whether $\mathrm{B}_{\mathrm{lg}}$ is higher than the costs of the loss of direct influence on water-related jobs and public contracts.

The third and the fourth factors which affect the value of $p_{\lg }$ are the time in which the costs $\left(\mathrm{C}_{\lg 1}\right.$ and $\left.\mathrm{C}_{\mathrm{lg} 2}\right)$ and benefits $\left(\mathrm{B}_{\mathrm{lg}}\right)$ materialise $\left(\mathrm{t}_{1}, \mathrm{t}_{2}\right.$, and $\left.\mathrm{t}_{3}\right)$ and the discount rate $(\delta)$. The earlier the costs and the later the benefits are believed to materialise, - ceteris paribus - the lower the value of $\mathrm{p}_{\mathrm{lg}}$. If local governments believe that the costs of the loss of direct influence on water-related jobs and public contracts materialise relatively early, while the benefits that arise from the joint control of larger organisations materialise relatively late, then discounted $\mathrm{B}_{\lg }$ may be quite small with respect to discounted $\mathrm{C}_{\mathrm{gg} 1}$ and $\mathrm{C}_{\mathrm{gg} 2}$. The extent to which future benefits offset future costs is also affected by the discount rate $\delta$ (which is assumed as a given constant). The more local governments are "patient" or "forward looking" (i.e., $\delta$ is relatively low), - ceteris paribus - the more future benefits at 
time $t_{3}$ may offset future costs at time $t_{1}$ and $t_{2}$.

This analysis suggests that local governments may not come to agree on the definition of the OTA boundaries because of two reasons. First, if $\mathrm{p}_{\mathrm{lg}}$ is negative, then local governments may choose not to define the OTA boundaries because of avoiding negative outcomes. If $\mathrm{p}_{\mathrm{lg}}$ is positive, local governments may choose not to define the OTA boundaries because they have no incentive to deviate from playing the defection strategy. The belief that $p_{\lg }$ is positive, therefore, is a necessary but not sufficient condition for local governments to agree to define the OTA boundaries. In other words, the lack of negative payoff when playing the strategy not to define the boundaries of the OTAs has important effects on the outcome of the game interaction $^{120}$.

Evidently, features of the water reform design effectively put local governments in the position of "veto players", which could block passing regional legislations. As recounted in the historical narrative, the central government exerted pressures on the regional governments to pass regional legislations even if local governments did not collaborate to define the OTA boundaries. A question arises, then, concerning whether the regions could pass the regional legislations anyway, irrespective of local governments' lack of agreement on this matter. In order to

120 The analysis could be extended to model the strategic interaction between several local governments rather than two of them only. Issues related to the conditions for the emergence of cooperation to define the OTA boundaries between some of local governments, and to the effect that cooperation between some local governments has on other defecting local governments, would arise. It may be possible, for example, that "early movers" that show to cooperate to define the OTA boundaries affect other local governments' beliefs about expected payoff, e.g., by signalling privately held information concerning future costs and benefits, and therefore "recruit" other local governments to cooperate with them. This further line of analysis is not pursued, however, because of the lack of empirical evidence that any such negotiations or imitation patterns between local governments ever took place, in the phase of the implementation process under consideration. 
tackle this question, we model the game interaction between a region $\mathrm{R}_{\mathrm{i}}$ and any local government $\mathrm{LG}_{\mathrm{ji}}$ located within $\mathrm{R}_{\mathrm{i}}$.

Similarly to modelling local governments' preferences, also the regions are assumed to hold relatively homogeneous preferences and to be relatively indifferent towards the execution of the water reform mandate by itself. Also the regions are rather assumed to care about the consequences of executing the water reform at the regional and local level. Taking into account that regional governments wished to avoid hostile confrontations with local governments - either in the form of passing regional legislations while local governments had not reached any agreement on the boundaries of the OTAs, or in the form of neglecting passing regional legislations while local governments wished to progress in the execution of the water reform mandate - regions' utility function is assumed to be negatively related to any rise of political conflict with the municipalities.

If the region $R_{i}$ chooses to pass the regional legislation while local government $\mathrm{LG}_{\mathrm{ji}}$ does not define the OTA boundaries, then the region incurs the cost of a political conflict with the local government $\left(\mathrm{C}_{\mathrm{r} 1}\right)$, that would struggle to affirm its prerogatives on the organisation of the water service areas against the "violation" perpetrated by the region. If the local government chooses to define the OTA boundaries while the region does not pass any regional legislation, then the region incurs the cost of a political conflict with the local government $\left(\mathrm{C}_{\mathrm{r} 2}\right)$ as well, because the latter would struggle against the "blockade" of the execution of the water reform mandate. If the region chooses to pass the regional legislation while the local government chooses to define the OTA boundaries, then the region gets 
payoff nil while the local government gets the payoff $\mathrm{p}_{\mathrm{gg}}$ (as defined above). Finally, if the region chooses not to pass any regional legislation while the local government chooses not to define any OTA boundaries, then both players get nil payoff. The payoff matrix for this game is:

\begin{tabular}{|c|c|c|c|}
\hline & \multicolumn{2}{|c|}{$\mathrm{LG}_{\mathrm{ij}}$} \\
\hline & & $\begin{array}{l}\text { To Contribute defining the } \\
\text { OTA boundaries (D) }\end{array}$ & $\begin{array}{l}\text { Not to contribute defining the } \\
\text { OTA boundaries (ND) }\end{array}$ \\
\hline & To pass regional legislation $(\mathrm{P})$ & $0, \mathrm{p}_{\mathrm{lg}}$ & $-\mathrm{C}_{\mathrm{rl}}, \mathrm{p}_{\mathrm{lg}}$ \\
\hline $\mathrm{R}_{\mathrm{i}}$ & $\begin{array}{l}\text { Not to pass regional legislation } \\
\text { (NP) }\end{array}$ & $-\mathrm{C}_{\mathrm{r} 2}, 0$ & 0,0 \\
\hline
\end{tabular}

Table 6.2. Payoff matrix of the game played by the region and any local government.

The game shown in Table 6.2 presents two Nash equilibria. The first Nash equilibrium is (P, D), i.e., the region passes the regional legislation and the local government contributes defining the OTA boundaries. In this case, no player has any incentive to deviate to play another strategy: if the region plays NP, then it would get a worse payoff $\mathrm{C}_{\mathrm{r} 2}$; if the local government plays ND, then it would not improve its payoff. The second Nash equilibrium is (NP, ND), i.e., the region does not pass the regional legislation and the local government does not contribute defining the OTA boundaries. Also in this case no player has any incentive to deviate to play another strategy: if the region plays $\mathrm{P}$, then it would get a worse payoff $\mathrm{C}_{\mathrm{r} 1}$; if the local government plays $\mathrm{D}$, then it would not improve its payoff ${ }^{121}$. This analysis suggests, then, that the regions did not have any available strategy (i.e., course of action) for making local governments define the OTA boundaries. The model suggests that, if the local government chooses not to define the OTA 
boundaries, then it would not deviate to play to define the OTA boundaries even if the region plays to pass the regional legislation ${ }^{122}$.

Could the central government affect the definition of the OTA boundaries, then? The central government is understood here to care about the execution of the water reform mandate, for reasons especially related to central government's interest to increase the appropriation of public funds for water infrastructure development. Accordingly, the utility function of the central government is assumed to be positively related to the passing of regional legislations. The interaction between the central government $C G$, any region $R_{i}$, and any local government $L_{j i}$ can be modelled here as a sequential game. In the first stage of the game, $\mathrm{R}_{\mathrm{i}}$ chooses whether to pass the regional legislation $(\mathrm{P})$ or not $(\mathrm{NP})$. If $\mathrm{R}_{\mathrm{i}}$ plays $\mathrm{P}$, then provided that, within this scenario, local governments do not agree on the definition of the OTA boundaries - it incurs the cost of the political conflict with $\mathrm{LG}_{\mathrm{ji}}\left(\mathrm{C}_{\mathrm{r} 1}\right)$ while the CG gets the benefit of getting this implementation task accomplished $\left(\mathrm{B}_{\mathrm{ng} 1}\right)$. As recounted in the historical narrative, however, the regions generally withheld passing the required legislation, and the central government pondered whether to exercise its substitutive powers.

If $\mathrm{R}_{\mathrm{i}}$ plays $\mathrm{NP}$, then the $\mathrm{CG}$ can choose whether to exercise its substitutive powers $(\mathrm{E})$ against the region or not $(\mathrm{NE})$. If the CG plays NE, then it incurs the cost of having misallocated budgetary resources to infrastructure works which are not accomplished $\left(\mathrm{C}_{\mathrm{ng} 2}\right)$, while $\mathrm{R}_{\mathrm{i}}$ does not incur any cost. If the $\mathrm{CG}$ plays $\mathrm{E}$ (i.e.,

122 The interaction between the region and the local governments could be modelled, alternatively, as a sequential game, i.e., first local governments coordinate to find an agreement on the definition of the OTA boundaries, and then the region chooses its strategy. This game structure, however, does not seem to fit the characteristics of the interaction between the regions and local governments, which included a negotiation process where regions consulted with local governments for designing the regional legislation rather than a clear-cut division of tasks. 
central government's special commissioner passes the regional legislation), then payoff depends on the strategy played by $\mathrm{LG}_{\mathrm{ji}}$. Previous analysis showed that, even if $R_{i}$ plays the strategy to pass the regional legislation, $L_{\mathrm{ji}}$ may not define the OTA boundaries anyway, depending on the value of $\mathrm{LG}_{\mathrm{ji}}{ }^{\prime}$ expected payoff $\mathrm{p}_{\mathrm{gg}}$. If $\mathrm{LG}_{\mathrm{ji}}$ plays the strategy to define the OTA boundaries (D), then the CG gets the benefit of getting this implementation task accomplished $\left(\mathrm{B}_{\mathrm{ng} 1}\right)$ and incurs the cost of the political conflict with $\mathrm{R}_{\mathrm{i}}\left(\mathrm{C}_{\mathrm{ng} 1}\right)$ while $\mathrm{R}_{\mathrm{i}}$ incurs the cost of having being spoiled of its competences ${ }^{123}\left(\mathrm{C}_{\mathrm{r} 2}\right)$. If $\mathrm{LG}_{\mathrm{ji}}$ plays not to define the OTA boundaries (ND), then the CG gets the cost of the political conflict with the regions $\left(\mathrm{C}_{\mathrm{ng} 1}\right)$ while $\mathrm{R}_{\mathrm{i}}$ incurs both the cost of the political conflict with local governments $\left(\mathrm{C}_{\mathrm{r} 1}\right)$ and the one of having being spoiled of its competences $\left(\mathrm{C}_{\mathrm{r} 2}\right)$. Picture 7.1 shows this game in extensive form.

In the last stage of this game, $\mathrm{LG}_{\mathrm{ji}}$ is indifferent whether to play $\mathrm{D}$ or ND. The CG, then, is uncertain whether the strategy to exercise the substitutive powers (E) brings a payoff $\mathrm{B}_{\mathrm{ng} 1}-\mathrm{C}_{\mathrm{ng} 1}$ (if $\mathrm{LG}_{\mathrm{ji}}$ plays $\mathrm{D}$ ) or $-\mathrm{C}_{\mathrm{ng} 1}$ only (if $\mathrm{LG}_{\mathrm{ji}}$ plays $\mathrm{ND}$ ). Even if the CG believes that $\mathrm{LG}_{\mathrm{ji}}$ plays D, it would exercise the substitutive powers only if $\mathrm{B}_{\mathrm{ng} 1}-\mathrm{C}_{\mathrm{ng} 1}>-\mathrm{C}_{\mathrm{ng} 2}$. If the cost of the political conflict with the region $\left(\mathrm{C}_{\mathrm{ng}}\right)$ is higher than the benefit of accomplishing the implementation task and avoiding the misallocation of budgetary resources $\left(\mathrm{B}_{\mathrm{ng} 1}+\mathrm{C}_{\mathrm{ng} 2}\right)$, then the $\mathrm{CG}$ is better off by playing not to exercise its substitutive powers (NE). In the first stage of this game, $\mathrm{R}_{\mathrm{i}}$ can anticipate that the CG plays NE. The region, therefore, is better off by

$123 \mathrm{We}$ assume here that the region is interested to protect its prerogatives against any form of "expropriation" of legislative competences. If the central government appoints a special commissioner for taking over the competences on passing the regional legislation, then the region incurs a political cost, including the detriment of its "public image" for not exercising its competences. 
playing not to pass the regional legislation (NP, which brings to $\mathrm{R}_{\mathrm{i}}$ a payoff nil) rather than playing to pass it (P, which brings to $\mathrm{R}_{\mathrm{i}}$ a payoff $\left.-\mathrm{C}_{\mathrm{r} 1}\right)$. This analysis suggests, than, that also the CG has no strategies available for affecting the definition of the OTA boundaries. Even if CG plays to substitute the region in passing the regional legislations, the $\mathrm{LG}_{\mathrm{ji}}$ does not necessarily coordinate with other local governments to define the OTA boundaries.

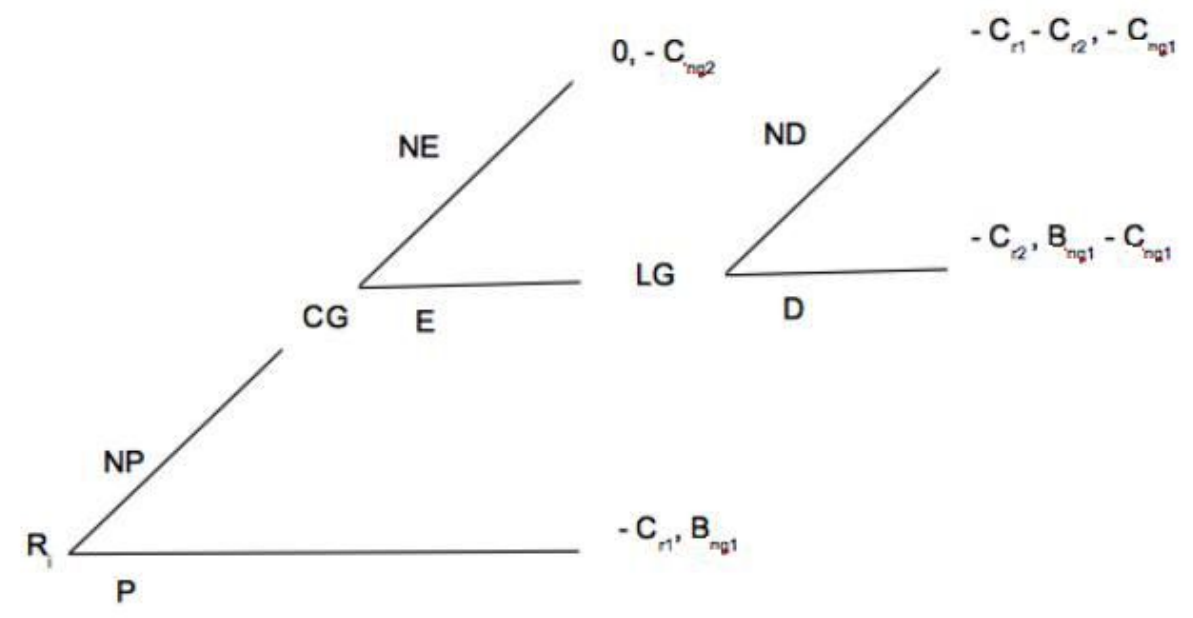

Picture 7.1. Sequential game between the region $R_{i}$, the central government $C G$, and local government $\mathrm{LG}_{\mathrm{j} i}$. Payoffs refer to (the regions, the central government).

\subsection{Explaining variation from the overall pattern in Alto Valdarno area (1994- 1999).}

As recounted in the historical narrative, some parts of Italy - especially, some areas of Tuscany named Alto Valdarno - deviated from the overall pattern of non-implementation after the enactment of the water reform. In order to explain this part of the episode, we focus on modelling the interaction between local governments in the Alto Valdarno area in the same fashion of the coordination game 
of defining the OTA boundaries (Table 6.1). For the sake of simplicity, we consider again an overly simplified scenario where two local governments only, $\mathrm{LG}_{1}$ and $\mathrm{LG}_{2}$, play the coordination game (negotiations to define shared water service area actually involved the city of Arezzo and 24 neighbouring local governments). Each player can choose whether to agree on the definition of the OTA boundaries or not. The payoff structure is equivalent to the coordination game presented in the first step of the analysis. If both local governments agree to define the OTA boundaries, they both get a payoff which includes the cost of losing direct control of water planning and regulatory functions $\left(\mathrm{C}_{\mathrm{lg} 1}\right)$, the cost of losing direct control of the water management functions $\left(\mathrm{C}_{\mathrm{lg} 2}\right)$, and the benefit of influencing the activities of the partially privatised water firm $\left(\mathrm{B}_{\mathrm{lg} 1}\right)$.

As shown in the first part of the analysis, coordination between local government may arise if players perceive $p_{\text {lg }}$ to be positive. Differently from the rest of the country, particular conditions which apply to the Alto Valdarno area may contribute increasing the value of $\mathrm{p}_{\mathrm{lg}}$. Local governments of the Alto Valdarno area had already negotiated the merger of their water firms well before the enactment of the water reform. Even if previous negotiations did not result in any reorganisation of local water services, local governments could form the belief that future benefits of pooling together their water firms offset the costs of losing direct control of the water functions within their respective municipal service areas. The past experience of negotiation could facilitate the emergence of cooperation (Axelrod, 1984) between local governments when they played the game to define the boundaries of the OTAs. Local governments of the Alto Valdarno area, moreover, were especially 
receptive to the political orientation of the regional branch of the party Democratici di Sinistra (DS), which favoured the privatisation of local public services into mixed public-private ownership firms. Local governments of the Alto Valdarno area could form the belief that the other municipalities of Alto Valdarno shared equivalent views about how to privatise water firms. Within the model, then, we can assume that local governments expect that future benefits of pooling together the water functions materialise relatively fast, i.e., that little negotiation would be required to agree on the governance institutions of the centralised water service provision.

Taking these conditions into account, we can infer that local governments of the Alto Valdarno believe (a) the costs of losing direct control of the water planning and regulatory functions $\left(\mathrm{C}_{\mathrm{lg} 1}\right)$ and of the water management functions $\left(\mathrm{C}_{\mathrm{lg} 2}\right)$ to be lower than believed by local governments in other areas of the country, because preparatory actions have been taken already to give up their direct involvement in water service provision, (b) the benefits of influencing the activities of the partially privatised water firm $\left(\mathrm{B}_{\lg 1}\right)$ to be higher, and (c) the time in which benefits materialise to be shorter because of shared views about reorganising water service provision. Additionally, we can argue that not defining the OTA boundaries bore negative implications for local governments of the Alto Valdarno area, because of the loss of the political capital that had been accumulated when forming the consensual view about the benefits of pooling together water services in a partially privatised water firm. Taken together, these conditions account for relatively higher benefits from the definition oft the OTA boundaries that local governments of the 
Alto Valdarno expect to get with respect to local governments in other areas of the country, and lower costs that these local governments expect to incur if not defining the OTA boundaries. The payoff structure outlined here, therefore, suggests that local governments of the Alto Valdarno area were more inclined to coordinate with neighbouring municipalities to define the OTA boundaries because, having already made preliminary steps in negotiating the pooling together of their water services, net benefits from implementing the water reform were more apparent to them than to local governments in other parts of the country.

\subsection{Explaining the acceleration of the implementation process after the turning point (1997-2006).}

As recounted in the historical narrative, in 1997 the central government enacted a legislation which provided funding for sewage and wastewater treatment infrastructure. This legislation provided that funds would be allocated on the basis of plans formulated on an OTA-by-OTA basis. Additionally, the legislation provided that, in those regions which did not transpose the water reform, the boundaries of the OTAs would coincide with the territorial jurisdictions of the provinces. The analysis conducted in this section is concerned with explaining why, after the 1997 legislation, local governments accelerated the implementation of the liberalisation and re-regulation part of the water reform. The analysis will focus on two questions in particular, namely, why local governments defined the OTA boundaries, and why they also progressed to establish the OTA authorities.

In order to tackle the first question, we model the interaction between local governments and the regions in the same fashion of the game shown above (Table 
6.2). After the 1997 legislation, any region $R_{i}$ can choose whether to pass the regional legislation by including the "default" definition of the OTA boundaries as equalling the provincial territories $(\mathrm{P})$ or not to pass it (NP). Any local government $L_{i j}$ included in the region $R_{i}$ can choose whether to coordinate with other municipalities to define the OTA boundaries (D) or not (ND). Similarly to the model shown in Table 6.2, if the region plays $\mathrm{P}$ and the local government plays $\mathrm{D}$, then payoff is $\left(0, \mathrm{p}_{\mathrm{g}}\right)$. If the region plays NP while the local government plays $\mathrm{D}$, then payoff is $\left(-\mathrm{C}_{\mathrm{r} 2}, 0\right)$. Differently from the model shown in Table 6.2, if the region plays $\mathrm{P}$ while the local government plays $\mathrm{ND}$, then payoff is $\left(-\mathrm{C}_{\mathrm{rl}}, \mathrm{p}_{\mathrm{lg}}-\mathrm{C}_{\mathrm{lg} 3}\right)$, i.e., the region incurs the cost of a political conflict with the local government $\left(\mathrm{C}_{\mathrm{r} 1}\right)$, while the local governments gets the discounted net benefit $\mathrm{p}_{\mathrm{lg}}$ minus the cost incurred for having been overridden in the definition of the OTA boundaries ${ }^{124}$. If the region plays NP while the local government plays ND, then payoff is $\left(0,-C_{\lg 3}\right)$, i.e., the regions does not incur any cost while the local government suffers the cost for having been overridden in the definition of the OTA boundaries anyway. The payoff matrix for this game interaction is:

$\mathrm{LG}_{1}$

To contribute defining the Not to contribute defining To pass the regional legislation $(\mathrm{P})$

$\mathrm{R}_{\mathrm{i}} \quad$ Not to pass the regional legislation (NP)

\begin{tabular}{|c|c|}
\hline OTA boundaries (D) & the OTA boundaries (ND) \\
\hline $0, \mathrm{p}_{\mathrm{lg}}$ & $-\mathrm{C}_{\mathrm{r} 1}, \mathrm{p}_{\mathrm{lg}}-\mathrm{C}_{\mathrm{lg} 3}$ \\
\hline$-\mathrm{C}_{\mathrm{r} 2}, 0$ & $0,-\mathrm{C}_{\mathrm{lg} 3}$ \\
\hline
\end{tabular}

Table 6.3. Payoff matrix of the game played by the region and any local government after 1997.

The game shown in Table 6.3 presents one only Nash equilibrium, (P, D)

124 We assume, as before, that local governments care about protecting their prerogatives against any form of "violation". 
(while the one shown in Table 6.2 contained two Nash equilibria). If the region plays $\mathrm{P}$ and the local government plays $\mathrm{D}$, no player has any incentive to deviate to play any other strategy. The strategy (NP, ND) is not a Nash equilibrium, instead. While the region would not deviate to play P rather than NP (because it would get a negative payoff - $\mathrm{Cr} 1$ rather than nil), the local government would be better off if playing D rather than ND (because it would get a payoff nil instead of negative $\mathrm{Clg} 3$ ). We note that the strategy (NP, D) is not a Nash equilibrium either, because, if the local government plays $\mathrm{D}$, then the region would be better off by deviating to play the strategy $\mathrm{P}$ (because of getting a payoff nil instead of - $\mathrm{Cr} 2$ ). In sum, if we assume that the imposition of the "default" definition of the OTA boundaries as equalling the provincial territories is perceived by local governments as a cost (because it overrules their competences on the organisation of local water provision), then both the regions and the local governments end up better off if they cooperate to define the OTA boundaries and passing the regional legislation.

In order to tackle the second question, namely why local governments established the OTA authorities after the regions passed the regional legislation, we again model the interaction between local governments as a coordination game. Let us assume, for the sake of simplicity, that two local governments only ( $\mathrm{LG}_{1}$ and $\mathrm{LG}_{2}$ ) are located in the same OTA. Each local government can choose whether to establish the OTA authority (E) or not (NE). If both local governments choose to establish it (E), then they incur the costs of losing direct control on the water planning and regulatory functions because of centralising them into the OTA authority (the $\operatorname{cost} \mathrm{C}_{\mathrm{lg} 1}$ is incurred at the present time) and on the water management 
function because of the privatisation of water service provision $\left(\mathrm{C}_{\lg 2}\right.$ at future time $\left.t_{1}\right)$, and get the benefit of jointly controlling larger water firms $\left(B_{\lg 1}\right.$ at future time $\mathrm{t}_{2}$ ). Local governments, therefore, get the payoff:

$$
q_{l g}=-C_{l g 1}+\frac{-C_{l g 2}}{(1+\delta)^{t_{1}}}+\frac{B_{l g 1}}{(1+\delta)^{t_{2}}}
$$

If both local governments choose not to establish the OTA authority (NE), then they incur the cost of political blame for not implementing the water reform ${ }^{125}$ $\left(\mathrm{C}_{\mathrm{lg} 4}\right)$. If any local government chooses to establish the OTA authority while the other does not, the former gets a payoff nil while the latter receives the negative payoff $\mathrm{C}_{\mathrm{lg} 4}$. The payoff matrix of this game is shown in Table 6.4. Any local government's strategy depends on the value of $\mathrm{q}_{\mathrm{lg}}$. If $\mathrm{q}_{\mathrm{lg}}$ is greater than $-\mathrm{C}_{\mathrm{lg} 4}$, then strategy E dominates the strategy NE, hence the strategy (E,E) is a Nash equilibrium. If $\mathrm{q}_{\mathrm{lg}}$ is less than $-\mathrm{C}_{\mathrm{lg} 4}$, then the game shown in Table 6.4 has no (even weakly) dominant strategies: if any local government plays E, then the other plays NE, while if any local government plays NE, then the other plays E. In this case, the game has two Nash equilibria when one local government chooses to establish the OTA authority while the other does not $[(\mathrm{E}, \mathrm{NE})$ and $(\mathrm{NE}, \mathrm{E})]$. Local governments, therefore, are not able to coordinate a joint strategy to establish the OTA authorities.

125 We assume here that, once the OTA boundaries are defined and regional legislation is passed, local governments bear the responsibility for carrying out the implementation tasks for liberalising and re-regulating water service provision. If they do not cooperate to establish the OTA authorities, then they would incur the political blame for not contributing reorganising the water services. 


\begin{tabular}{|c|c|c|c|}
\hline & \multicolumn{2}{|c|}{$\mathrm{LG}_{1}$} \\
\hline & & $\begin{array}{c}\text { To establish the OTA } \\
\text { authority (E) }\end{array}$ & $\begin{array}{c}\text { Not to establish the OTA } \\
\text { authority (NE) }\end{array}$ \\
\hline \multirow{2}{*}{$\mathrm{LG}_{2}$} & $\begin{array}{l}\text { To establish the OTA authority } \\
\text { (E) }\end{array}$ & $\mathrm{q}_{\mathrm{lg}}, \mathrm{q}_{\mathrm{lg}}$ & $0,-\mathrm{C}_{\mathrm{lg} 4}$ \\
\hline & $\begin{array}{l}\text { Not to establish the OTA } \\
\text { authority (NE) }\end{array}$ & $-\mathrm{C}_{\mathrm{lg} 4}, 0$ & $-\mathrm{C}_{\mathrm{lg} 4},-\mathrm{C}_{\mathrm{lg} 4}$ \\
\hline
\end{tabular}

Table 6.4. Payoff matrix of local governments' game of establishing the OTA authorities.

This analysis shows that the values of $\mathrm{q}_{\mathrm{lg}}$ and $\mathrm{C}_{\mathrm{lg} 4}$ are important in order to determine whether local governments establish the OTA authorities or not. The establishment of the OTA authorities is more likely to happen the higher the value of $\mathrm{q}_{\mathrm{lg}}$ and the higher, in absolute terms, the value of $\mathrm{C}_{\mathrm{lg} 4}$. As for $\mathrm{q}_{\mathrm{lg}}$, its value is higher - ceteris paribus - the lower are the costs incurred by local governments for the loss of direct control of the water planning and regulatory functions $\left(\mathrm{C}_{\mathrm{lg} 1}\right)$ and of the water management function $\left(\mathrm{C}_{\mathrm{lg} 2}\right)$, the higher is the value of the benefits which arise from the joint control of larger water firms $\left(\mathrm{B}_{\mathrm{lg} 1}\right)$, the earlier the benefits materialise in time $\left(t_{2}\right)$ with respect to the costs $\left(t_{1}\right)$, and the lower the discount rate $(\delta)$. The value of $\mathrm{C}_{\mathrm{lg} 4}$, is higher in absolute terms if the cost of the political blame charged on the local governments for not implementing the water reform is relatively high.

Particular conditions of water sector characteristics after 1997 could play an important causal role in the establishment of the OTA authorities. As recounted in the historical narrative, at that time local governments became exposed to accounts of early experiences of implementing the liberalisation and re-regulation part of the water reform, with the Alto Valdarno being a frequent reference. This information could make local governments believe that the costs of losing direct control of the 
water planning and regulatory functions and the water management functions were relatively small in comparison to the benefits that related to shared control of larger organisations. Local government, then, may believe that the value of $\mathrm{q}_{\lg }$ is relatively high with respect to $-\mathrm{C}_{\mathrm{lg} 4}$, with the effect that local governments choose to establish the OTA authorities. Also a mechanism of imitation in playing strategic games (Levine and Pesendorfer, 2007) could affect local governments' beliefs in such a way as to make the emergence of cooperation more likely to happen.

In sum, this part of the analysis provides an explanation for why, after the "turning point" that we date in 1997, local governments progressed to define the boundaries of the OTAs and to establish the OTA authorities. This explanatory research argument highlights the importance of the 1997 legislation, that provided funding for sewage and wastewater treatment works, for making local governments play the strategy to define the OTA boundaries, and of earlier experiences of implementing the water reform conducted in Alto Valdarno area for making local governments establish the OTA authorities. The explanatory argument, therefore, is particularly sensitive to changed features of the water reform design (especially, the provision of a "default" definition of the OTA boundaries) and of the water policy domain (i.e., accomplished implementation in the Alto Valdarno area), in conjunction with steady conditions of the sector characteristics (i.e., local governments' stakes in the water industry) and of the territorial organisation of the sector (i.e., fragmentation of water service areas). 


\section{Explaining the implementation of the privatisation part of the water reform.}

\subsection{Explaining the obstructed implementation in the first period (1994-2001).}

The first step of this part of the analysis is explaining why, after their establishment, generally the OTA authorities did not award water franchises, while a few OTA authorities chose to privatise water service provision in the hands of mixed public-private ownership firms. In order to tackle this question, we turn to modelling the options that OTA authorities have for privatising water services. According to the regulatory system provided by the water reform, after 1994 the OTA authorities can award water franchises to either mixed public-private ownership firms or to business companies selected through tender offer competition $^{126}$. If any OTA authority awards the water franchise to a mixed publicprivate ownership firm, then any local government included in the OTA gets a payoff of $-C_{\mathrm{lg} 1}-\alpha \mathrm{C}_{\mathrm{lg} 2}+\beta \mathrm{B}_{\mathrm{lg} 1}$, where $\mathrm{C}_{\mathrm{lg} 1}$ is the cost of the loss of direct control of the water planning and regulatory functions, $\alpha \mathrm{C}_{\mathrm{lg} 2}$ is the (partial) cost of the loss of control of the water management function, with $0<\alpha<1\left(\mathrm{C}_{\lg 2}\right.$ is the cost of the total loss of control of the water management function that any local government incurs if the concession is awarded to a business company), and $\beta \mathrm{B}_{\lg 1}$ is the (partial) benefit of jointly controlling the privatised water firm, with $0<\beta<1$ ( $\mathrm{B}_{\lg 1}$ is the total benefit that any local government would enjoy if it is the sole proprietor of the water firm). If any OTA authority awards the water franchise to a business

126 It may be recalled here that, according to Act 142/1990 on the management of local public services, water services could be managed wither through (a) direct local government management, (b) special-statute municipal organisation, (c) mixed public-private ownership firms, or (d) business company selected through tender offer competition. Features of the water reform statute, however, explicitly referred to the assignment of water franchises, therefore only options (c) and (d) were considered legitimate. 
company selected through tender offer competition, instead, then any local government included in the OTA gets a payoff of $-\mathrm{C}_{\mathrm{lg} 1}-\mathrm{C}_{\mathrm{lg} 2}$. The local government, in fact, would incur the (total) cost of losing direct control of both the water planning and control functions and the water management function, and does not get any benefit from controlling the water firm. Finally, if any OTA authority does not award any water franchise, then any local government included in the OTA gets a payoff of $-\mathrm{C}_{\mathrm{lg} 1}$, that is, the cost of the loss of direct control of the water planning and regulatory functions which are centralised into the OTA authority. The payoff are shown in Table 6.5.

\begin{tabular}{lc}
\multicolumn{1}{c}{ OTA authority's options } & Local governments' payoff \\
\hline To award to mixed public-private ownership water firm & $-\mathrm{C}_{\mathrm{lg} 1}-\alpha \mathrm{C}_{\mathrm{lg} 2}+\beta \mathrm{B}_{\mathrm{lg} 1}$ \\
To award to business company selected through tender offer & $-\mathrm{C}_{\mathrm{lg} 1}-\mathrm{C}_{\mathrm{lg} 2}$ \\
competition & $-\mathrm{C}_{\mathrm{lg} 1}$
\end{tabular}

Table 6.5. Local governments' payoff depending on OTA authorities' choice.

Given this payoff structure, what choice would local governments make to privatise water service provision ${ }^{127}$ ? The option not to award the water franchise is preferred to the option to award the water franchise to a business company selected through tender offer competition $\left(-\mathrm{C}_{\mathrm{lg} 1}>-\mathrm{C}_{\mathrm{lg} 1}-\mathrm{C}_{\mathrm{lg} 2}\right)$. The option to award the water franchise to a mixed public-private ownership firm is preferred to the one to award the water franchise to a business company selected through tender offer

127 OTA authorities are not considered here as "actors" that can make choices independently from the local governments. The basic argument is that the OTA authorities are owned and controlled by local governments, therefore the choice to privatise water service provision is made by local governments in consent. In other words, it is assumed here that the OTA authorities make choices which run in favour of the interest of local governments. 
competition (as $0<\alpha<1$ and $\beta>0$, then $-\mathrm{C}_{\mathrm{lg} 1}-\alpha \mathrm{C}_{\mathrm{lg} 2}+\beta \mathrm{B}_{\mathrm{lg} 1}>-\mathrm{C}_{\mathrm{lg} 1}-\mathrm{C}_{\mathrm{lg} 2}$ ). Local governments, evidently, get the lowest payoff if they make the OTA authorities award the water franchise to business companies selected through tender offer competition. They would rather make the OTA authorities award the water franchise to mixed public-private ownership firms if $-\mathrm{C}_{\mathrm{lg} 1}-\alpha \mathrm{C}_{\mathrm{lg} 2}+\beta \mathrm{B}_{\mathrm{lg} 1}$ is higher than $-\mathrm{C}_{\mathrm{lg} 1}$. i.e., if $\beta \mathrm{B}_{\mathrm{lg} 1}-\alpha \mathrm{C}_{\mathrm{lg} 2}>0$. Otherwise, they would prefer the OTA authorities not to award the water franchise to anyone. Clearly, local governments prefer that the OTA authorities award the franchise to a mixed public-private ownership firm if the benefit of jointly controlling the privatised water firm is higher than the (partial) cost of the loss of direct control of the water management function.

This analysis suggests that, after local governments establish the OTA authorities, they may not find it advantageous to also make them privatise water services. The option to make the OTA authorities award the water franchise to business companies selected through tender offer competition is not exercised. Local governments may prefer to privatise water services in the hands of mixed public-private ownership firms, because this option allows them to retain some control of the water management function and enjoy some benefits because of the shared control of the privatised water firm. However, if local governments do not get any net benefit from the privatisation of water services in the hands of mixed public-private ownership firms, then they rather prefer not to make the OTA authorities award any water franchise (i.e., if $\beta \mathrm{B}_{\mathrm{lg} 1}-\alpha \mathrm{C}_{\mathrm{lg} 2}<0$ ). 


\subsection{Explaining the acceleration of the implementation process after the}

turning point (2001-2006).

In 2001, the central government enacted a reform of local public services that contained the general provision that water franchises should be awarded to business companies selected through tender offer competition. The reform design, however, also provided that, within 18 months (i.e., by $30^{\text {th }}$ June 2003), incumbent local government-owned water firms could be awarded the water franchises for a period up to 10 years if certain requirements are satisfied (especially, if a growing part of water firms' shares were sold to private water operators or investors over time). Taking into account these provisions, we can re-model local governments' payoff for any of the options available to the OTA authorities for privatising water service provision, as shown in Table 6.6.

\begin{tabular}{lcc}
\multicolumn{1}{c}{ OTA authority's options } & \multicolumn{2}{c}{ Local governments' payoff } \\
\hline & Before 30.6.2003 & After 30.6.2003 \\
\hline $\begin{array}{l}\text { Award to mixed public-private ownership } \\
\text { water firm }\end{array}$ & $-\mathrm{C}_{\mathrm{lg} 1}-\alpha \mathrm{C}_{\mathrm{lg} 2}+\beta \mathrm{B}_{\mathrm{lg} 1}$ & $-\mathrm{C}_{\mathrm{lg} 1}-\alpha \mathrm{C}_{\mathrm{lg} 2}+\beta \mathrm{B}_{\mathrm{lg} 1}$ \\
$\begin{array}{l}\text { Award to business company selected through } \\
\text { tender offer competition }\end{array}$ & $-\mathrm{C}_{\mathrm{lg} 1}-\mathrm{C}_{\mathrm{lg} 2}$ & $-\mathrm{C}_{\mathrm{lg} 1}-\mathrm{C}_{\mathrm{lg} 2}$ \\
Not award & $-\mathrm{C}_{\mathrm{lg} 1}$ & $-\mathrm{C}_{\mathrm{lg} 1}-\mathrm{C}_{\mathrm{lg} 2}$
\end{tabular}

Table 6.6. Local governments' payoff depending on OTA authorities' choice after the 2001 local public services reform.

If any OTA authority awards the water franchise to a business company selected through tender offer competition, any local government included in the OTA gets a payoff $-\mathrm{C}_{\mathrm{lg} 1}-\mathrm{C}_{\mathrm{lg} 2}$. If local governments make the OTA authority award the water franchise to a mixed public-private ownership firm, then (if certain 
requirements were met) local governments get the payoff $-\mathrm{C}_{\lg 1}-\alpha \mathrm{C}_{\mathrm{lg} 2}+\beta \mathrm{B}_{\mathrm{lg} 1}$. If the OTA authority does not award the water concession before the deadline set on $30^{\text {th }}$ June 2003 , then local governments get the payoff $-C_{\lg 1}$ until the deadline only. After the deadline, the OTA authorities must award the water concession to business companies only, therefore local governments get the payoff $-\mathrm{C}_{\mathrm{lg} 1}-\mathrm{C}_{\mathrm{lg} 2}$. Local governments can anticipate that if they do not make the OTA authorities award the water franchise before the deadline, then they would get a payoff as negative as the one that they get if privatising water service provision to any business company selected through tender offer competition. Local governments, therefore, prefer to make the OTA authorities award the water franchise to mixed public-private ownership firms, because $-\mathrm{C}_{\mathrm{lg} 1}-\alpha \mathrm{C}_{\mathrm{lg} 2}+\beta \mathrm{B}_{\mathrm{lg} 1}>-\mathrm{C}_{\mathrm{lg} 1}-\mathrm{C}_{\mathrm{lg} 2}$ (provided that $0<\alpha<$ 1 and $\beta>0)$.

This analysis suggests that, after the enactment of the 2001 local public service reforms, local governments' beliefs about the payoff could induce them to privatise water service provision to mixed public-private ownership firms. This result, however, holds if local governments believe that, after the expiry of the $30^{\text {th }}$ June 2003 deadline, the OTA authorities have no other choice but to award the water franchise to business companies selected through tender offer competitions if they did not privatise the water service provision yet. If local governments believe that this provision of the 2001 local public service reform is not enforced, or that it is subject to amendments, than the option to wait cannot be ruled out.

Indeed, in 2003 the central government enacted another reform of local public services. The 2003 reform restated the general provision that water 
franchises should be awarded to business companies selected through tender offer competition. The reform design, however, also provided that, under particular circumstances, water franchises could be also awarded to either mixed publicprivate ownership firms or to firms fully owned by the local governments and that subjected their business activity to the limitation of servicing the proprietors only (i.e., so-called "in house" firms). Taking into account these provisions contained in the 2003 local public services reform, we can again re-model local governments' payoff as shown in Table 6.7 .

\begin{tabular}{lc}
\multicolumn{1}{c}{ OTA authority's choices } & Local governments' payoff \\
\hline Award to 'in house' firm & $-\mathrm{C}_{\mathrm{lg} 1}-\gamma \mathrm{C}_{\mathrm{lg} 2}+\varepsilon \mathrm{B}_{\mathrm{lg} 1}$ \\
\hline Award to mixed public-private ownership water firm & $-\mathrm{C}_{\mathrm{lg} 1}-\alpha \mathrm{C}_{\mathrm{lg} 2}+\beta \mathrm{B}_{\mathrm{lg} 1}$ \\
& $-\mathrm{C}_{\mathrm{lg} 1}-\mathrm{C}_{\mathrm{lg} 2}$ \\
$\begin{array}{l}\text { Award to business company selected through tender offer } \\
\text { competition }\end{array}$ & $-\mathrm{C}_{\mathrm{lg} 1}$
\end{tabular}

Table 6.7. Local governments' payoff depending on OTA authorities' choice after the 2003 local public services reform.

Part of Table 6.7 is congruent to the original option choice and payoff structure of Table 6.5. If any OTA authority awards the water franchise to a mixed public-private ownership firm, then any local government included in the OTA gets a payoff of $-\mathrm{C}_{\mathrm{lg} 1}-\alpha \mathrm{C}_{\mathrm{lg} 2}+\beta \mathrm{B}_{\mathrm{lg} 1}$. If any OTA authority awards the water franchise to a business company selected through tender offer competition, then any local government included in the OTA gets a payoff of $-\mathrm{C}_{\mathrm{lg} 1}-\mathrm{C}_{\mathrm{lg} 2}$. If any OTA authority does not award any water franchise, then any local government included in the OTA gets a payoff of $-\mathrm{C}_{\mathrm{lg} 1}$. After the enactment of the 2003 local public services reform, 
local governments can also make the OTA authorities award the water franchises to "in house" firms. In this case, each local government included in the OTA gets a payoff $-\mathrm{C}_{\mathrm{lg} 1}-\gamma \mathrm{C}_{\mathrm{lg} 2}+\varepsilon \mathrm{B}_{\mathrm{lg} 1}$, where $\gamma \mathrm{C}_{\mathrm{lg} 2}$ is the cost incurred by the local government for the (partial) loss of control of the water management function, with $\gamma, 0<\gamma<1$, and $\varepsilon \mathrm{B}_{\mathrm{lg} 1}$ is the (partial) benefit which arises from the joint control of the local government-owned water firm, with $\varepsilon>0$.

Given this payoff structure, what choice would local governments make to privatise water service provision? The option not to award the water franchise is again preferred to the one to award the water franchise to a business company selected through tender offer competition, because $-\mathrm{C}_{\mathrm{lg} 1}>-\mathrm{C}_{\mathrm{lg} 1}-\mathrm{C}_{\mathrm{lg} 2}$. The option to award the water franchise to a mixed public-private ownership firm is also preferred to the one to award the water franchise to a business company selected through tender offer competition, because $-\mathrm{C}_{\mathrm{lg} 1}-\alpha \mathrm{C}_{\mathrm{lg} 2}+\beta \mathrm{B}_{\mathrm{lg} 1}>-\mathrm{C}_{\mathrm{lg} 1}-\mathrm{C}_{\mathrm{lg} 2}$ (provided that $0<\alpha<1$ and $\beta>0$ ). Also the option to award the water franchise to an "in house" firm is preferred to the one to privatise water service provision in the hands of a business company selected through tender offer competition, because $\mathrm{C}_{\mathrm{lg} 1}-\gamma \mathrm{C}_{\mathrm{lg} 2}+\varepsilon \mathrm{B}_{\mathrm{lg} 1}>-\mathrm{C}_{\mathrm{lg} 1}-\mathrm{C}_{\mathrm{lg} 2}$ (provided that $0<\gamma<1$ and $\varepsilon>0$ ). Again, local governments get the lowest payoff if they make the OTA authorities award the water franchise to business companies selected through tender offer competition. Whether local governments make the OTA authorities award the water franchise to "in house" firms, or to mixed public-private ownership firms, or not to award any water franchise, instead, depends on the relative value of $-\mathrm{C}_{\mathrm{lg} 1}-\gamma \mathrm{C}_{\mathrm{lg} 2}+\varepsilon \mathrm{B}_{\mathrm{lg} 1}$, $\mathrm{C}_{\mathrm{lg} 1}-\alpha \mathrm{C}_{\mathrm{lg} 2}+\beta \mathrm{B}_{\mathrm{lg} 1}$, and $-\mathrm{C}_{\mathrm{lg} 1}$. 
The payoff of privatising water service provision in the hands of "in house" firms may be the highest among other choice option. If local governments pool together their water management functions in an "in house" firm, then the cost of the (partial) loss of direct control of the water management function may be lower than in the case where local governments share ownership of the water firm with a private investor (i.e., $\gamma<\alpha$ ). In terms of benefits which arise from jointly controlling a larger water firm, if local governments are the only owners of the water firm then they can arguably get higher benefits than if they share control with private operators or investors too (i.e., $\varepsilon>\beta$ ), because of greater congruence of preferences between local governments than between local governments and private actors. The option to award the water franchise to "in house" firms, then, may be the preferred one with respect to both privatising water service provision in the hand of a mixed public-private ownership firm (if $\varepsilon \mathrm{B}_{\mathrm{lg} 1}-\gamma \mathrm{C}_{\mathrm{lg} 2}>\beta \mathrm{B}_{\mathrm{lg} 1}-\alpha \mathrm{C}_{\mathrm{lg} 2}$ ) or not awarding the water franchise (if $\varepsilon \mathrm{B}_{\mathrm{lg} 1}-\gamma \mathrm{C}_{\mathrm{lg} 2}>0$ ).

In sum, this part of the analysis accounts for why, after the "turning point" dated in 2001, the OTA authorities accelerated the process of awarding the water franchises. This explanatory research argument highlights the importance of the institutional changes brought about by the 2001 and 2003 local public services reforms, and of the ways ownership structure of water firms may affect the allocation of costs and benefits related to local governments' give up of water management functions and shared control of larger water firms. The explanatory argument, therefore, is particularly sensitive to changed features of the local public service reforms design (especially, the inclusion or removal of option choices for 
the award of water franchises) and of the sector characteristics (i.e., local governments' stakes in the water management function).

\section{Chapter summary.}

The analytic narrative presented in this chapter provides an explanation of the path and outcome of the implementation of the water reform in Italy in the period 1994-2006 by following the institutional rational choice approach. The explanation for the trajectory of the implementation of the liberalisation and reregulation part of the water reform accounts for both the faltering implementation process in the period 1994-1997 and the acceleration of the implementation process after the "turning point" in 1997, as well as for the divergent trajectory of the water reform implementation in Alto Valdarno with respect to the general pattern in the country. The core of the explanatory argument is that, after the enactment of the water reform in 1994, features of the water reform design, of the water sector characteristics, and of the territorial organisation of water service provision induced local government to neglect defining the OTA boundaries. In 1997, however, changes in the water policy domain related to the piece of legislation that provided funding for sewage and wastewater treatment works, in conjunction with steady conditions of water sector characteristics, resulted in making local governments active to define the OTA boundaries. Once regional legislations were passed, local governments also progressed to establish the OTA authorities, when information about early experiences of implementing the water reform in the Alto Valdarno area contributed persuading local governments of the viability and net benefits of 
executing the water reform mandate.

The explanation for the privatisation part of the water reform accounts for both the obstructed implementation process in the period 1994-2001 and its acceleration after the "turning point" in 2001, together with the resulting heterogeneous organisational forms of water service delivery at the local level. The core of the explanatory argument is that, after the enactment of the water reform in 1994, features of the water reform design and of water sector characteristics induced local governments not to make the OTA authorities award any water franchise. In 2001, a reform of local public services brought about changes of the water reform design features which, in conjunction with steady conditions of water sector characteristics, made local governments seriously consider to award water franchises to mixed public-private ownership firms. In 2003, another reform of local public services changed again the features of the water reform design, that, in conjunction with the conditions recalled above, opened up to local governments the option to award water franchises to "in house" firms. 


\section{Chapter 7}

\section{Analysing the implementation of the water reform in Italy (1994-2006): institutional processualist approach}

This chapter presents an analysis of the implementation stage of the water reform in Italy in the period 1994-2006 conducted by following an institutional processualist approach. The chosen explanandum of the analysis is, as in the previous chapter, what accounts for the variation in the pace of the implementation of the water reform between a first period, that amounted to a failure to execute the regulatory reform mandate, and a second period, that resulted in a final state close to full implementation; and what accounts for the variation in the pace of the implementation of the water reform between the Alto Valdarno area in Tuscany and the rest of country.

As the previous chapter, also this one is divided into two parts. The first part is concerned with analysing the implementation of the liberalisation and reregulation part of the water reform. We will again follow two steps in the analysis. First, an explanation will be provided of why, after the enactment of the water reform, local governments did not define the boundaries of the OTAs, while those in Alto Valdarno progressed relatively faster. Then, we will explain why, after the "turning point" set in 1997, local governments progressed to define the OTA boundaries and establish the OTA authorities.

The second part of this chapter will analyse the implementation of the privatisation part of the water reform. Again, this part of the analysis is conducted 
in two steps. First, an explanation will be provided of why, after the establishment of the OTA authorities, generally water franchises were not awarded. Next step will be to explain, then, why, after the 2001 "turning point", water franchises started to be awarded especially to mixed public-private ownership firms and, after 2003, generally to "in house" firms.

\section{Explaining the implementation of the liberalisation and re-regulation part of the water reform.}

1.1. Explaining the faltering implementation process in the first period (19941997).

The first step of this part of the analysis is explaining why, after the enactment of the water reform, local governments did not define the boundaries of the OTAs. In order to tackle this question, we consider first the role played by two features of the water reform statute. First, Act 36/1994 required that responsibility for settling the geographical boundaries of OTA authorities be shared by regional and local governments. Regions were given the exclusive authority to divide their territories into watershed areas. They could not exercise this authority, however, before local governments had agreed on the boundaries of the OTAs within the regional territories. Neither the regional nor central government could impose the OTA boundaries on their own authority, because of the constitutional autonomy granted to local governments on the organisation of local public services. Second, Act 36/1994 required that the regions passed regional legislation which made the water reform enforceable at the regional level within six months after its coming into effect. No penalty, however, was provided in case the regions missed the deadline. 
Explaining why the water reform statute contained these provisions lies outside the scope of this analysis of the implementation stage of the water reform. At least two features of the context within which the water reform was made are relevant here, however. First, the Constitution of Italy, which granted to local governments some autonomy from the national legislation on such matters as the organisation and management of local public services. Second, national legislation on local public services (Act 142/1990), which provided that local governments could choose whether to pool together the delivery of local public services or not, and to which kind of firm local public service franchises could be awarded. These conditions clearly constrained the alternatives available to policy-makers when designing the water reform statute.

What kind of behaviour of local governments did these features of the water reform statute elicit? ${ }^{128}$ The provision contained in the water reform statute that required local government to define the OTA boundaries can be understood as a "cooperative intergovernmental policy mandate" (May, 1995). The water reform mandated sub-national governments to collaborate in order to achieve a given objective - defining the OTA boundaries - while remaining largely silent on how implementers were expected to accomplish it. As highlighted by May (1995), in such scenario the implementation of the policy mandate is sensitive to implementers' technical and financial capacity, inducements for compliance, structure of the policy community, and implementers' commitment. In the absence

128 For the sake of simplicity, this analysis will generally refer to local governments and regional governments as actors within the water reform implementation process, although it should more appropriately mention the politicians in executive positions within local governments and regional governments. Whenever appropriate, the analysis will more precisely refer to individual level. 
of any of these conditions, May (1995) argued, there is no guarantee that the mandate is carried out.

Conditions within the water sector in Italy, especially related to features of the water industry and of local governments' stakes in water firms, seemed loaded against the implementation of the water reform statute. Such conditions included widespread direct local governments' ownership of water firms all over the country. As recounted in the historical background, these features of the water sector originated from local governments' traditional role in the supply of local public services (including water) in the early twentieth century. Over time, local governments had come to dominate the water industry by directly providing water services either through own agencies or local governments' consortia. Local governments' stakes in water firms also came to play an important role in local government politics, because they allowed politicians to gain support of voters' clienteles by granting favours in the form of water-related job and public contracts.

Conditions within the water sector also included the fragmentation of the water industry into relatively small service areas. These areas generally corresponded to the administrative territories of single local governments or local government consortia. Also these features of the water sector originated from local governments' traditional role in the supply of water services about one century before, when local governments established water providers and took over privately owned water firms which serviced the municipal areas. In some southern regions of the country only, where local communities were mostly scattered over relatively dry and cragged territories, did the central government and the regional governments 
organise part of water service provision through relatively large firms (e.g., Acquedotto Pugliese, EAF, and ESAF). In the rest of the country, the same hydrogeographical characteristics of the territory generally induced the construction of relatively small-scale water supply systems.

These conditions need to be taken into account for understanding the identities of local governments, the ways in which they perceived their situations, how they interpreted their role and, consequently, how they considered appropriate to behave (March and Olsen, 1989; March, 1994). When called to collaborate to define the boundaries of the OTAs, local government could anticipate that this activity would commit them to later centralise their water planning and regulatory functions, and that they would be later expected to pool together water service provision with other neighbouring local governments. Given local governments' identities as direct providers of water services to local communities, as well as their stakes in the water firms, they could consider appropriate to their role to resist implementing the liberalisation and re-regulation of the water sector as provided by the water reform. Acting in this way allowed them to protect their position as direct providers of water services and to retain their influence on water-related jobs and public contracts.

Both features of the water reform design (that put local governments in the position of "veto players" in the definition of the OTA boundaries) and of the water sector concurred in making local governments hamper the implementation process. The central government tried to make the regional governments pass the regional legislation irrespective of local governments' inertia. A question arises, then, about 
whether the regions could surrender to central government's pressure. As actors within the multi-layered governance structure of Italy, the regions were not compelled to conform to the central government's instructions. Additionally, conditions of the polity and historical context - especially, the constitutional autonomy granted to local governments on the organisation and management of local public services, and the political weakness of the central government and the regional governments in the aftermath of the 1992-1993 corruption scandals - could also contribute making the regions resist passing the required legislations despite local governments' inertia to define the OTA boundaries.

Another question arises concerning whether the central government could affect the definition of the OTA boundaries. The central government threatened the regions to exercise the substitutive powers to circumvent the obstruction to pass the regional legislations. The resignation of the Minister of Public Works Di Pietro, however, weakened the sense of urgency that he had tried to instil on the regional governments. The postponing of deadlines for passing the regional legislation by his successor, Costa, plausibly undermined the credibility of the threat that the regions might attribute to national governments' prospective actions. Conditions such as turnover of government officers, then, are also part of the explanation for the ineffective actions conducted by the central government to stimulate the implementation process.

1.2. Explaining variation from the overall pattern in Alto Valdarno area (19941999).

Differently from the general pattern described above, in the area of Tuscany 
called Alto Valdarno local governments collaborated with each other to define the OTA boundaries since immediately after the passing of the water reform. In explaining what accounts for this within-case variation, we focus on the particular initial and context conditions that were especially present in Alto Valdarno with respect to the rest of the country.

In Alto Valdarno, local governments had been concerned with the reorganisation of water service provision since well before the enactment of the water reform. We briefly recall that, by 1993, the gas firm owned by the municipalities of Arezzo, Coingas, had marshalled the consensus of local governments of the Alto Valdarno area for merging local government-owned water and gas firms. Even if Coingas' plan was eventually dropped after turnover in mayor's office, local governments of Alto Valdarno had come to broadly agree on the terms of consolidation of water and gas service provision and of the ownership structure of the consolidated public service firm. Arezzo's mayor Paolo Ricci, in addition, subscribed to the policy idea held by the Tuscany branch of Italy's party Democratici di Sinistra (DS), which envisioned the award of local public services to mixed public-private ownership companies. Specifically, the mayor advocated the merger of local government-owned water firms within the Alto Valdarno area surrounding Arezzo.

By the time the national water reform was enacted in 1994, a cohesive "water policy community" within Alto Valdarno had formed. This policy community - mainly constituted by a network of local water policy experts - had reached accord on the advantages and on the details of reorganising water service 
provision in Alto Valdarno. Differently from other local governments in the rest of country, that resisted the definition of the OTA boundaries because anticipating that the consolidation of water firms would make them lose some influence on the local water industry, those of Alto Valdarno were united by a common definition of the problem and the domain. As a whole, the policy community formed around local governments of Alto Valdarno was capable and motivated to act as an advocacy coalition (Sabatier, 1988) for the implementation of the national water reform.

The social mechanism of committed interpretation can help explaining why local governments of Alto Valdarno collaborated to define the OTA boundaries. Committed interpretation (Salancik and Pfeffer, 1978) is an important mechanism that generates sense-making in organisational settings (Weick, 2001). Briefly put, it provides that actors' behaviour is rationalised by referring to confirmatory features of the environment, and that attention to environmental features is selectively placed on those that better support actors' behaviour itself. Once actions are made public and volitional, actors cannot easily deny, disown, or reverse them. They rather search for environmental cues that help justifying why actors should stick to the same course of action.

In Alto Valdarno, the mayors of Arezzo and of the other local governments openly committed themselves to consolidate water services since before the enactment of the water reform. When they approved Coingas' plan for merging water and gas services, they made public a policy orientation that they later could hardly disown. Features of the water reform design, especially the requirement to pool together local governments' water planning and regulatory functions within the 
OTAs, provided cues that water services should be consolidated. Local governments of Alto Valdarno, then, shared a sense of unity of purpose and commitment that facilitated the negotiations for defining the OTA boundaries, once the water reform was enacted.

\subsection{Explaining the acceleration of the implementation process after the turning point (1997-2006).}

The implementation of the liberalisation and re-regulation part of the water reform remarkably accelerated after the "turning point" in 1997. In order to explain why this happened, we examine, first, how contemporaneous events changed the context where local governments were required to define the OTA boundaries. An important contemporaneous event was the policy-making cycle that culminated with the passing, in October 1997, of Act 344/1997. This legislation provided that the central government would allocate funds for investments in sewage and wastewater treatment systems on the basis of plans prepared by regional or local governments. This planning and budgeting scheme also provided that plans would be formulated according to OTA territories - hence, the definition of the OTA boundaries was required in order to get the plans funded.

The making of the 1997 legislation was affected by local governments' inertia to define the OTA boundaries. In June 1997, the Supervising Committee on the Use of Water Resources had issued its first report to the Parliament on the state of the implementation of the water reform, which briefed MPs about the obstacles encountered in implementing the liberalisation and re-regulation part of the water reform. Legislators of the Territory, Environment and Environmental Goods 
Committee of the Senate might have considered that the implementation of the legislation then under consideration could well be blocked by the same constellation of factors that had halted the implementation of the water reform. In order to prevent this source of implementation failure, the committee included in the legislation under consideration the provision that, in the event local governments did not reach a mutual agreement on OTA boundaries, the regional governments could pass regional legislations that made OTA boundaries coincide with the provincial ones. With this provision, the legislation cleared both the Senate and the House in September 1997.

A side issue arises, here, concerning how the central government could overrule the autonomy of local governments under the constitution on the matter of defining water service areas. As narrated in the historical background, policymakers of the 1994 water reform could not mandate local governments to establish compulsory consortia because of local governments' constitutional autonomy on the organisation and management of local public services. The making of the 1997 legislation, however, did not compel local governments to define the OTA boundaries nor, for that matter, to establish the OTA authorities. In other words, the 1997 legislation required local governments to define territories where funds for infrastructure development would be allocated, not where water services would be centralised. Taking into consideration the difficulties encountered in the implementation of the liberalisation and re-regulation part of the water reform under way, the Senate committee members decided to relate allocation of infrastructure development funds to prospective water service areas. This link, as 
we are going to see, had important consequences for the trajectory of the implementation process.

Another side issue that also deserves some consideration, however, is why policy-makers did not include this provision in the design of the water reform in the first place. As narrated in the historical background, the making of the water reform took place in an historical context characterised by particular conditions. These conditions include the outbreak of one of the worst financial crisis of Italy in 19921993, which had brought public finance under considerable stress. Given these conditions, at that time the national government could make limited use of the instrument of "treasure" (Hood, 1983) as a way of stimulating local governments' interest to get the liberalisation and re-regulation part of the water reform implemented. By 1997, instead, these conditions had largely disappeared, while other conditions related to access to EU funds for infrastructure development programmes enabled the allocation of funds on the basis of the new water service areas.

What was the effect of the 1997 legislation on local governments' response to the liberalisation and re-regulation of water services? The legislation passed in 1997, in conjunction with given initial conditions, had the effect to rise the issue of the definition of the OTA boundaries in local governments' agendas. This effect resulted, in particular, from the joint combination of two conditions. First, the provision contained in the 1997 legislation that required the definition of the OTAs in order to access funds for infrastructure development. Second, local governments' stakes in water firms among the characteristics of the water sector, that induced 
local governments to appropriate funds to be spent in their administrative jurisdictions.

Provided that the issue of the definition of the OTA boundaries had gained attention in local governments' agendas, another question is how local governments solved this issue under consideration. We can recall that local governments agreed to define the OTAs according to existing administrative jurisdictions. In most of the regions (12), the OTA boundaries equalled, or were very proximate to, provincial territories. In some regions (5), local governments agreed to define one only OTA which corresponded to the territory of the whole region. In Tuscany and Campania only did the OTA boundaries map onto watershed river areas. Setting the cases of OTAs in Tuscany and Campania aside ${ }^{129}$, then, generally local governments found their way out of the negotiations over the definition of the OTA boundaries by resorting to status-quo conditions.

The fact that local governments generally defined the OTA boundaries according to the territories of existing administrative jurisdictions may be related to how they anticipated the consequences of executing the water reform mandate for the organisation of water service provision. Had local governments been concerned with the design of centralised water planning and regulatory functions in accordance with the principles of the water reform, they would arguably define the OTA boundaries according to features of the watershed river areas. Instead, local

129 Evidence collected on the implementation of the water reform in Alto Valdarno area shed some light onto the conditions that concurred to affect the path and outcome of the implementation process in this region. No evidence has been collected, instead, on the implementation of water reform in Campania. This gap, which is primarily imputed to lack of resources for zooming in the implementation process at the local level, might be well filled by further research, intended to undertake explicit comparative case study between single trajectories of the implementation stage of the water reform at the local (i.e., OTA) level. 
governments seemed mainly concerned with defining the OTA boundaries as a way of catching the opportunity (McAdam et al., 2001) of appropriating funds to be spent in their administrative jurisdictions - with little regard to the implication that water franchises would be awarded on an OTA-by-OTA basis, and therefore future water service providers would serve users' basins tailored to administrative jurisdictions that did not necessarily fit technical or economic efficiency criteria.

Once local governments had reached an agreement on the OTA boundaries, the regions progressed to pass the regional legislation relatively fast. Much of the political controversy that had impeded the making of regional legislations rested in the definition of the boundaries of the OTAs. Once this issue ad been settled, the regions did not encounter any tough resistance form local governments anymore. Why, anyway, did the regions care to pass the regional legislations? In order to address this question, we again consider that the context where such decisions were made included conditions related to the linkage between the implementation of the water reform and access to funding water infrastructure development. Provided that also regional governments were interested to appropriate funds for infrastructure investments likewise local governments, this condition played an important role in making the regions pass the regional legislations in relatively short time.

After the regions passed the required legislations, local governments progressed in establishing the OTA authorities. Why did they care? The establishment of the OTA authorities implied that these new local regulatory entities were transferred the water planning and regulatory functions of the local governments. According to canons of instrumental rationality, local governments 
should have resisted centralising these functions into the OTA authorities in order to retain stronger influence on local water industries. As already recalled, influence on local water industries allowed local government politicians to affect water-related jobs and public contracts. Within local governments' political economy, influence on the local water industries helped local politicians in executive positions to cultivate supportive constituencies.

Conditions associated with changing sector characteristics and interests of water policy experts need to be taken into account, then, to explain local governments' decisions to establish the OTA authorities. We can recall that, from 1997 onwards, local governments became exposed to information about other parts of Italy where the OTA authorities had been established. The early experiences conducted in Tuscany were frequently referenced as exemplars of how water service provision could be liberalised and re-regulated. This view was especially channelled, in the forms of a stock of publications and conference speeches, through a network of water policy experts whose professional identification centred in the association of municipal water and gas companies Federgasacqua. Generally, water policy experts referred to the establishment of the OTA authorities in Alto Valdarno (and, later, in other areas) as "success stories" of the "Tuscany model" that showed the viability of pooling together water service provision within watershed areas.

Early experiences of establishing the OTA authorities in Tuscany, then, brought about changes of water sector characteristics. First, these events changed the organisation of the local water industry in Alto Valdarno, in the sense of making 
it partially aligned with the water reform objectives. Second, these events also affected the formation of local water policy communities in the same OTA in Tuscany, in the sense of making the network of water policy experts more interconnected. These changing sector characteristics, in conjunction with water policy experts' efforts to advocate the merits of implementing the liberalisation and re-regulation part of the water reform, triggered the activation of a mechanism of diffusion of ideas concerning the merit of establishing the OTA authorities.

The social mechanism of diffusion (or network diffusion) is widely employed as a processual theoretical resource in social sciences (Hedström and Swedberg, 1998; Coleman et al., 1957). In essence, the mechanism of diffusion centres on the notion that "one individual's belief in the value or necessity of performing a certain act is partially a function of the number of other individuals who have already performed the act. In an uncertain decision context, the number of individuals who perform a particular act signals to others the likely value or necessity of the act, and this signals will influence other individuals' choice of action" (Hedström and Swedberg, 1998: 313). At the very core of the diffusion mechanism, then, rests the view that imitation of others' actions is one main driver of individual behaviour (Schelling, 1998; Hedström, 1998). Within any social process, the mechanism of diffusion results in the progressive enlargement of the number of actors involved in performing similar activities over time.

In the implementation of the liberalisation and re-regulation part of the water reform, the mechanism of diffusion contributes explaining how policy ideas spread from early experiences conducted in Alto Valdarno (and, later, in other areas 
of Tuscany, too) to the rest of the country. Conditions related to the alignment of the local water industry in Tuscany with the water reform objectives and to the interconnection of the network of water policy expert in the country played the role of an enabling factor for the activation of the diffusion mechanism. Policy ideas that gained currency in Tuscany, clearly, could not "spread" to the rest of the country if water policy experts had not exerted efforts to advocate water liberalisation and reregulation. Water policy experts generally endorsed these ideas, which matched well-regarded guidelines for organising and managing water service provision as developed in the international water policy community.

In explaining why the idea to establish the OTA authorities gained currency among local governments, we can also consider some benefits that local governments gained from the centralisation of water planning and regulatory functions. The early experiences in Alto Valdarno showed that local governments could enjoy shared control of the activities carried out by the OTA authorities, especially the award of water franchises to local government-owned firms and the selection of private partners. Control of these activities could help mayors and local governments' cabinet officers to marshal the political consensus to centralise water regulation in the municipal councils, where resistance to give up close control of the local water industry was rooted in strong ideological positions (especially, both right-wing and left-wing parties, like Lega Nord and Partito Comunista Italiano, regarded public ownership as the most appropriate regulatory system of water service provision).

In explaining how local governments agreed to establish the OTA 
authorities, we can also consider the absence of coordination costs required to negotiate the territorial jurisdictions of future water service providers. Once OTA boundaries had been defined, local governments did not need to devote their attention to issues related to the formation of the coalitions of municipalities taking part to the establishment of the OTA authorities. In other words, the issue of defining which local governments are included in the OTAs had been de-coupled from the one of defining the terms of centralisation of the water planning and regulatory functions. Also this condition could play an important role in the framing of local governments' agenda when they came to consider the issue of establishing the OTA authorities.

\subsection{Synthesis.}

The explanation for the path and outcome of the liberalisation and reregulation part of the water reform can be illustrated, in synthesis, in Table 7.1. Table 7.1 exhibits the component parts of the explanatory argument across the different trajectories followed in the liberalisation and re-regulation part of the water reform implementation over time and across space. Component parts of the explanatory argument include initial conditions that characterise the "status quo" of the water sector before the coming into force of the 1994 water reform; policy content features related to the water sector; policy process features related to the mode of interaction within the water policy domain; and historical context conditions that originate from contemporaneous events. In addition, component parts of the explanatory argument also include the social mechanisms that have 
been employed for providing hypothetical causal linkages between the joint occurrences of causal conditions and the features of the water reform implementation trajectory that are explained. These component parts of the explanatory arguments are provided for both explaining the inertia to implement the liberalisation and re-regulation part of the water reform in the period 1994-1997, the implementation that took place in Alto Valdarno in the period 1994-1999, and the acceleration of the overall implementation pattern in the country in the period 1997-2001. 


\begin{tabular}{|c|c|c|c|}
\hline & $\begin{array}{l}\text { Inertia part } \\
(1994-1997)\end{array}$ & $\begin{array}{l}\text { Alto Valdarno part } \\
\quad(1994-1999)\end{array}$ & $\begin{array}{l}\text { Accelerated liberalization and re-regulation part } \\
\qquad(1997-2006)\end{array}$ \\
\hline Explananda & No execution of the water reform mandate & Establishment of the new water regulatory system & Establishment of the new water regulatory system \\
\hline Initial conditions & $\begin{array}{l}\text { Features of the water industry (fragmentation of the water } \\
\text { sector and diffused local government ownership of water } \\
\text { service providers) } \\
\text { Stakes of local governments (cultivation of electoral } \\
\text { support of local constituencies) }\end{array}$ & $\begin{array}{l}\text { Features of the water industry (diffused local government } \\
\text { ownership of water service providers) } \\
\text { Stakes of local governments (cultivation of electoral } \\
\text { support of local constituencies) } \\
\text { Negotiated agreement on reforming water service provision } \\
\text { (consolidating water services and opening up access to } \\
\text { private operators and investors) }\end{array}$ & $\begin{array}{l}\text { Features of the water industry (diffused local government } \\
\text { ownership of water service providers) } \\
\text { Stakes of local governments (cultivation of electoral } \\
\text { support of local constituencies) }\end{array}$ \\
\hline Policy content features & $\begin{array}{l}\text { Consolidation of water services } \\
\text { Centralisation of water regulatory functions }\end{array}$ & $\begin{array}{l}\text { Consolidation of water services } \\
\text { Centralisation of water regulatory functions }\end{array}$ & $\begin{array}{l}\text { Consolidation of water services } \\
\text { Centralisation of water regulatory functions } \\
\text { Funding of sewage and wastewater treatment infrastructure }\end{array}$ \\
\hline Policy process features & $\begin{array}{l}\text { Water reform procedural rules } \\
\text { (required agreement between local governments; lack of } \\
\text { penalty for missing deadline) }\end{array}$ & $\begin{array}{l}\text { Formation of an advocacy coalition } \\
\text { (shared views about re-regulating local water service } \\
\text { provision) }\end{array}$ & $\begin{array}{l}\text { Activation of the policy community of water experts } \\
\text { (diffusion of ideas about early experience of water reform } \\
\text { implementation) } \\
\text { Sequencing of water reform implementation tasks } \\
\text { (definition of the OTAs decoupled from the negotiation } \\
\text { about the centralisation of water planning and regulatory } \\
\text { functions) }\end{array}$ \\
\hline $\begin{array}{l}\text { Historical context } \\
\text { conditions }\end{array}$ & $\begin{array}{l}\text { Constitutional autonomy of local governments on } \\
\text { organisation and management of local public services } \\
\text { Political weakness of governmental authorities after 1992- } \\
1993 \text { corruption scandals } \\
\text { Turnover of government officers }\end{array}$ & $\begin{array}{l}\text { Constitutional autonomy of local governments on } \\
\text { organisation and management of local public services } \\
\text { Policy orientation of Tuscany's DS party }\end{array}$ & $\begin{array}{l}\text { Constitutional autonomy of local governments on } \\
\text { organisation and management of local public services }\end{array}$ \\
\hline $\begin{array}{l}\text { Hypothesized social } \\
\text { mechanisms }\end{array}$ & $\begin{array}{l}\text { Logic of appropriateness (March and Olsen, 1989; March } \\
\text { 1994) }\end{array}$ & $\begin{array}{l}\text { Committed interpretation } \\
\text { (Weick 2001; Salancik and Pfeffer 1978) }\end{array}$ & $\begin{array}{l}\text { Attribution of opportunities and threats (McAdam et al. } \\
\text { 2001) } \\
\text { Network diffusion (Hedström and Swedberg 1998; } \\
\text { Coleman et al., 1957) }\end{array}$ \\
\hline
\end{tabular}

Table 7.1. Components of the explanatory argument for the path and outcome of the liberalisation and re-regulation part of the water reform implementation (1994-2006). 


\section{Explaining the implementation of the privatisation part of the water reform.}

2.1. Explaining the obstructed implementation process in the first period (1994-2001).

While the liberalisation and re-regulation part of the water reform was implemented, generally the newly established OTA authorities did not undertake any action to award water franchises. In order to explain this inertia, we first need to review how the decision to privatise water service provision was made. An important condition, in this respect, is the governance system of the OTA authorities. The OTA authorities were established as organisations owned and controlled by local governments, rather than as independent agencies. Local governments, in other words, retained considerable influence on the decisions made by the OTA authorities, including those related to the privatisation of water service provision. These features of the governance system of the OTA authorities resulted from the decisions that local governments made in the establishment of the OTA authorities themselves. These decisions, in turn, were especially affected by features of the water reform statute (which did not provide that the OTA authorities should be necessarily established as independent regulators of local water industries) and of general legislation of local public services, in conjunction with local governments' interest to retain influence on the local water industries.

Another important condition to take into account relates to the characteristics of the water sector, especially diffused local government ownership of water service providers and local governments' stakes in the local water industries. As already recalled, local governments' influence on the local water industries played an important role in the local political economy, because 
politicians could acquire support of voters' clienteles by granting favours in the form of influence on water-related jobs and public contracts. Local governments, then, were inclined to resist privatisation schemes that implied any significant loss of control of water management functions, if not compensated by any (at least) commensurate benefit. The governance system of the OTA authorities allowed them to affect the selection of privatisation schemes, provided that only the majority of local governments could make the OTA authorities adopt binding decisions. Local governments' stakes in the local water industries, in this respect, were rather homogeneous within any given OTA, therefore conflicts between local governments concerning the adoption of privatisation schemes were unlikely to arise.

Why, then, did local governments not make the OTA authorities award the water franchises in this part of the episode? In order to answer this question, we especially take into account design features of the water reform and initial conditions of the water industry. Design features of the water reform included the provisions that each OTA authority would award water franchises to one only water company - apart from exceptional circumstances in which water franchises could be awarded to more than one water company in the same OTA (by partitioning the OTA service area) if incumbent water firms satisfied criteria of economic selfsufficiency. In order to be eligible to receive the water franchise, water firms were required to possess the size and capacity to service entire OTA users' basins.

Initial conditions of the water industry include the ownership structure of the water industry, especially the predominance of local government-owned firms and 
consortia among water service providers in the country. Given that the design features of the water reform required that water franchises should be awarded to mixed public-private ownership firms or to business companies selected through tender offer competitions, then incumbent local government-owned firms were not eligible for managing water service provision. Local governments, however, were generally inclined to resist sharing ownership of water firms with private partners, because the joint ownership of water firms would limit the discretion that they had traditionally exercised on the management of water firms. Typically, local governments were even less inclined to contract out water service provision, because the award of water franchises to business companies would have spoiled them of their sway on water business.

Taking these conditions into account, we argue that local governments considered it appropriate for their identity and role to keep the privatisation of water service provision out of their agendas (March, 1994; March and Olsen, 1989). Design features of the water reform implied that local governments should consolidate their incumbent water firms into larger providers and give up at least part of their ownership. Given local governments' traditional role in the supply of local public services, the costs of pursuing privatisation of water service provision were apparent, in the form of loss of influence on water-related jobs and public contracts. No apparent benefits, instead, did local governments expect from the decision to privatise water services according to any of the schemes provided by the water reform.

As recounted in the historical narrative, during the period 1994-2001 only 
one area of the country did deviate from the general pattern of implementing the privatisation part of the water reform. In Alto Valdarno, the OTA Authority came to award the water franchise to a mixed public-private ownership firm, Nuove Acque, in 1999. As already explained in the first part of this chapter, particular features of the setting of Tuscany in general and Alto Valdarno in particular contribute accounting for the deviation of the trajectory of implementation of the water reform in this area from the general pattern in the country. Well before the enactment of the water reform in 1994, in this part of Tuscany the idea to consolidate and partially privatise incumbent water and gas service providers had gained serious consideration among local policy-makers. Negotiations conducted for the privatisation of Coingas and other local utility firms, in particular, had contributed to the formation of a water policy community that had come to agree on the terms of the merger between incumbent local government-owned firms and the sale of minority shareholding to private water operators and investors.

This agreement between local governments of Alto Valdarno played an important role in the privatisation of local water service providers. Once the OTA Alto Valdarno Authority was established, local governments required little further negotiation to come to agree to merge their water firms and make the OTA authority select the private partner. Indeed, the privatisation of water service provision seems to have never been removed from local governments' agendas - at least, from the one of the leading municipality in the area, Arezzo, that had openly committed to this course of action (Salancik and Pfeffer, 1978; Weick, 2001). Additionally, the privatisation scheme which had been considered for the centralisation of water 
service provision - namely, the award of water franchise to a mixed public-private ownership firm - corresponded to one of those allowed by the water reform design. These conditions, then, facilitated the privatisation of water service provision in Alto Valdarno and account for the deviation of this local trajectory of the implementation of the privatisation part of the water reform from the general pattern in the rest of the country.

\subsection{Explaining the acceleration of the implementation process after the turning point (2001-2006).}

From 2001 onwards, the number of OTA authorities that awarded water franchises sharply increased. In order to explain why this acceleration took place after a "turning point" in 2001, we examine, first, how a piece of legislation (Act 448/2001) passed in 2001 changed conditions relate to features of the water reform and of the context of the water sector. As we shall see, these changed conditions played an important role in the privatisation of water service provision. Then, we examine how other pieces of legislation (Legislative Decree 269/2003 and Act 350/2003) passed in 2003 and a constitutional reform (Constitutional Act 3/2001) changed again conditions related to features of the water reform, and how these changes contributed affecting the implementation of the privatisation process.

As recounted in the historical narrative, in 2001 the central government led the Parliament to pass a reform of local public services. The reform originated, in part, from central government's liberalisation agenda, and, in part, from the requirement to transpose EU directives 92/50/CE and 93/38/CE on transparency and publicity of procedures for awarding public service franchise and public 
contracts into the national legislation. The 2001 reform provided the general rule that local public services should be awarded through tender offer competitions, but it also contained special provisions for water services. In this particular sector, the award of water franchises through tender offer competitions could be postponed for a period up to 10 years if the OTA authorities assigned water concessions to local government-owned firms within 18 months (i.e., by $30^{\text {th }}$ June 2003 ) and if certain requirements were satisfied (especially, if a growing part of water firms' shares were sold to private water operators or investors over time). After the passing of the 2001 reform, several OTA authorities intensified their efforts to finalise the privatisation process.

Within the conditions of the water sector at that time, the legislation passed in 2001 contributed to raise the issue of the privatisation of water service provision in local governments' agenda. One important effect of the 2001 legislation, in this respect, was to change design features of the water reform, especially in relation to the privatisation schemes allowed to OTA authorities. While the original water reform statute provided that water franchises should be awarded to either mixed public-private ownership firms or to business companies selected through tender offer competitions, the provisions introduced by the 2001 local public services reform mandated to tender out water service provision while it also allowed to bypass the tendering out rule by awarding the water franchises to mixed publicprivate ownership firms within a set deadline (provided that certain conditions were met).

Among the conditions of the water sector at that time, local governments' 
stakes in the local water industries are especially relevant. This condition made local governments generally inclined to retain ownership of water firms rather than to give up water service provision to business companies. Given the changed design features of the water reform, local governments faced the alternative between surrendering ownership of water firms by tendering out the water franchises to business companies or opening up partial ownership of water firms to private operators and investors. The deadline set for selecting the option to make the OTA authorities award the water franchises to mixed public-private ownership firms generated a sense of urgency to consider the privatisation issue in local governments' agendas. Even if, for the reasons articulated above, local governments generally preferred to retain the status quo, the requirement to tender out water service provision after the $30^{\text {th }}$ June 2003 deadline made them seriously consider the merits of privatising water service provision according to the mixed public-private ownership scheme.

Since 2001 onwards, several local governments merged their water firms within OTAs, reincorporated them as business companies, awarded them water franchises, and gradually shared their ownership with private operators and investors. Many others, however, did not carry out any action before the $30^{\text {th }}$ June 2003 deadline ${ }^{130}$. Particular conditions, especially related to features of local context, may account for this variety of local trajectories of the privatisation process. One among such conditions is the fragmentation of local water industries

130 No data are available concerning the number of water franchise concessions awarded by $30^{\text {th }}$ June 2003, but a rough inference suggests that possibly about one third of OTA authorities might have accomplished this task. By the end of 2002, water franchises had been awarded in 24 out of 84 OTAs (29\%), while by the end of 2003 the figure had climbed up to 38 out of 87 OTAs $(44 \%)$. 
into several small-scale firms, which required more or less extensive periods needed to negotiate the terms of the privatisation scheme.

Another of such conditions is the heterogeneity of ownership forms ${ }^{131}$, which related to diverse attitudes towards privatisation held by water firms' management. Among the types of water firms, municipal companies were generally associated to more favourable conditions towards privatisation than other organisational forms, i.e., local government departments and consortia. Municipal companies typically possess particular institutional features (especially statutory autonomy with respect to the municipal owner) that make them enjoy relatively more "freedom to act" with respect to other types of public service firms. In other words, it seems that local government departments and consortia encountered mode sources of "institutional inertia", in such forms as statutory or legislative constraints, that played against the privatisation of water service provision.

Another of such conditions is the presence of policy ideas that were supportive of partial privatisation schemes. As recalled in the historical narrative, the Tuscany branch of the party Democratici di Sinistra (DS) had become favourably inclined towards the award of franchises for local public services to mixed public-private ownership firms. Other areas of the country, however, did not share the same policy orientation, especially where parties located towards the poles of the national political spectrum (e.g., Lega Nord and Partito Comunista Italiano) formed part of the executive. As an effect of this variety of conditions, then, Italy was not uniform in the readiness of local governments towards the privatisation of

131 Part of water firms consisted of local government departments, others of municipal companies, and others of consortia jointly owned by several municipalities. 
water service provision after the 2001 legislation. Only part of the country, therefore, came to privatise water service provisions by mid-2003.

The social mechanism of attribution of opportunities and threats (McAdam et al., 2001) may be recalled here to contribute explaining why local governments accelerated the privatisation of water service provision after the 2001 legislation. Attribution of opportunities and threats is "an activating mechanism responsible in part for the mobilisation of previously inert population" (McAdam et al., 2001: 45). At the core of the mechanism is an interpretation of the context that frames conditions as originating potentially beneficial or harmful outcomes. In the implementation of the privatisation part of the water reform, local governments could perceive the 2001 legislation as both a source of opportunities and threats. On the one hand, the mandate to tender out water service provision evidently threatened local governments to lose their influence on local water industries. On the other one, the possibility to award water franchises to mixed public-private ownership firms offered the opportunity to retain some ownership of the privatised water firms. The deadline set on $30^{\text {th }}$ June 2003 could play the role of focusing event (Kingdon, 1984) that catalysed local governments' efforts to speed up the privatisation of water service provision.

As recounted in the historical narrative, from 2003 onwards water franchises were typically awarded to fully local government-owned firms ("in house") rather than to mixed public-private ownership ones. An important event that should be taken into account in order to explain this part of privatisation is the reform policy cycle that resulted in legislation passed in 2003, which contained another reform of 
local public services. The 2003 reform originated, in part, from the request of the EC Commission to amend the 2001 local public services reform because its provisions allowed the OTA authorities to postpone the call of tender offer competitions for too many years. In part, the 2003 reform also originated from pressures that came from the most conservative wing of the governmental coalition, which was interested to provide local government with legal ways to bypass the application of tender offer competition rules even after $30^{\text {th }}$ June 2003 deadline. The 2003 reform provided, in particular, that if certain requirements were met then local public services could be assigned, rather than to business companies selected through tender offer competitions or to mixed public-private ownership firms, also to companies fully owned by local governments only ("in house").

The legislation passed in 2003 brought about important changes of the water sector institutional context. Until that time, this context included general legislation on local public services that had banned the assignment of local public services franchises to fully local government-owned firms. The 2003 legislation, instead, granted legitimacy to the award of water service provisions to "in house" firms, although under exceptional circumstances. This change of conditions, in conjunction with steady features of the water sector and interests of local governments recalled above, played an important role in enhancing local governments' efforts to privatise water service provision. These conditions generally stimulated local governments to collaborate to merge their water firms and reincorporate them as business companies, while retaining joint local government owned of the "formally" privatised water firms. In addition, these 
conditions made local governments inclined to select the "in house" scheme for making the OTA authorities award the water franchises.

The award of water franchises to "in house" firms offered local governments the benefit of retaining influence on local water industries, albeit in a way that entailed shared ownership of water service providers. Rather than giving up ownership of water firms to private operators and investors either completely or partially, however, local governments could merge their water firms with neighbouring municipalities within the OTAs. According to this privatisation scheme, each and single local government would not enjoy full control of water firms, nevertheless it could exercise some influence on larger organisations jointly with other municipalities.

Another important event that needs to be taken into account to explain this part of privatisation is the reform policy cycle that resulted in the 2001 constitutional reform. The 2001 Constitutional reform, that redesigned the allocation of authority and the relationship between government layers of the State, provided (among others) that competences on the organisation of local public services and the management of water resources were transferred from the state to the regions. On the basis of this reallocation of authority, the regional government of Tuscany appealed to the Constitutional Court against some provisions of the 2003 legislation that (among others) narrowly specified the requisites for awarding water franchises to "in house" firms ${ }^{132}$. The Constitutional Court ruled in favour of

132 It may be recalled here that these requirements included, in particular, the provision that the award of franchises to "in house" companies should be justified by particular efficiency or service delivery circumstances for which the benefits of the "in house" firms offset those of awarding the franchise to business companies. On the basis of these requirements, in 2004 the Minister of the Environment Altero Matteoli, who advocated the use of tender offer competitions for the selection of business companies, issued a couple of directives which remarked local 
region Tuscany's appeal in July 2004, and after this pronouncement local governments faced no more restrictions to the award of franchises to "in house" water firms.

Again, the social mechanism of attribution of opportunities and threats (McAdam et al., 2001) contributes explaining why local governments made the OTA authorities award water franchises to "in house" firms after the 2003 legislation. The 2003 legislation could be perceived by local governments as a source of opportunity to retain greater influence on local water industries than other privatisation schemes - the award of water franchises to mixed public-private ownership firms or to business companies selected through tender offer competition. The 2001 Constitutional reform, instead, could be perceived by the regions as a source of opportunity to assert their competences on regulating local public services. Both conditions, therefore, come into play in order to explain local governments" efforts to privatise water service provision to "in house" firms despite the efforts of the central government (especially, the Minister of the Environment Matteoli) to steer the selection of the privatisation scheme.

\subsection{Synthesis.}

The explanation for the path and outcome of the privatisation part of the water reform can be illustrated, in synthesis, in Table 7.2. Similarly to Table 7.1, Table 7.2 exhibits the component parts of the explanatory argument across the

governments' obligation to award the franchise through competitive tenders, and that unjustified awards to "in house" firms would be persecuted as illegitimate. Local governments that had not applied the tender offer competition rules put forward legal arguments against the Minister, including the claim that the 2001 Constitutional reform had limited the competence of the national government on the matter of the organisation of local public services. 
different trajectories followed in the privatisation part of the water reform implementation over time and across space. Component parts of the explanatory argument include initial conditions that characterise the "status quo" of the water sector before the coming into force of the 1994 water reform; policy content features that relate to provisions of the water reform statute; policy process features that refer to traits of the mode of interaction within the water policy domain; and historical context conditions that arise from contemporaneous events. In addition, component parts of the explanatory argument also include the social mechanisms that have been employed for providing hypothetical causal linkages between the joint occurrences of causal conditions and the features of the water reform implementation trajectory that are explained. These component parts of the explanatory arguments are provided for explaining the inertia to implement the privatisation part of the water reform in the period 1994-2001, the implementation that took place in Alto Valdarno in the period 1994-2001, and the acceleration of the overall implementation pattern in the country in the period 2001-2006 - including an explanation for why water franchises were awarded to mixed public-private ownership firms in the period 2001-2003 and typically to "in house" firms in the period 2003-2006. 


\begin{tabular}{|c|c|c|c|c|}
\hline & $\begin{array}{c}\text { Inertia part } \\
(1994-2001)\end{array}$ & $\begin{array}{l}\text { Alto Valdarno part } \\
\quad(1994-1999)\end{array}$ & $\begin{array}{l}\text { Mixed ownership } \\
\text { privatization part } \\
\quad(2001-2003)\end{array}$ & $\begin{array}{l}\text { "Formal" } \\
\text { privatization part } \\
(2003-2006)\end{array}$ \\
\hline Explananda & No execution of the water reform mandate & Privatisation into mixed ownership firms & Privatisation into mixed ownership firms & Privatisation into "in house" firms \\
\hline Initial conditions & $\begin{array}{l}\text { Features of the water industry (diffused local } \\
\text { government ownership of water service } \\
\text { providers) } \\
\text { Stakes of local governments (cultivation of } \\
\text { electoral support of local constituencies) }\end{array}$ & $\begin{array}{l}\text { Features of the water industry (diffused local } \\
\text { government ownership of water service } \\
\text { providers) }\end{array}$ & $\begin{array}{l}\text { Features of the water industry (diffused local } \\
\text { government ownership of water service } \\
\text { providers) } \\
\text { Stakes of local governments (cultivation of } \\
\text { electoral support of local constituencies) }\end{array}$ & $\begin{array}{l}\text { Features of the water industry (diffused local } \\
\text { government ownership of water service } \\
\text { providers) } \\
\text { Stakes of local governments (cultivation of } \\
\text { electoral support of local constituencies) }\end{array}$ \\
\hline Policy content features & $\begin{array}{l}\text { Privatisation of water service provision in the } \\
\text { forms provided by Act } 142 / 1990\end{array}$ & $\begin{array}{l}\text { Privatisation of water service provision in the } \\
\text { forms provided by Act } 142 / 1990\end{array}$ & $\begin{array}{l}\text { Privatisation of water service provision through } \\
\text { tender offer competitions or mixed ownership } \\
\text { firms by a set deadline }\end{array}$ & $\begin{array}{l}\text { Privatisation of water service provision through } \\
\text { tender offer competitions or "in house" firms }\end{array}$ \\
\hline Policy process features & & $\begin{array}{l}\text { Formation of an advocacy coalition } \\
\text { (shared views about privatising local water } \\
\text { service provision) }\end{array}$ & $\begin{array}{l}\text { Activation of the policy community of water } \\
\text { experts } \\
\text { (diffusion of ideas about early experience of } \\
\text { water reform implementation) }\end{array}$ & \\
\hline $\begin{array}{l}\text { Historical context } \\
\text { conditions }\end{array}$ & $\begin{array}{l}\text { Constitutional autonomy of local governments } \\
\text { on organisation and management of local } \\
\text { public services }\end{array}$ & $\begin{array}{l}\text { Constitutional autonomy of local governments } \\
\text { on organisation and management of local } \\
\text { public services } \\
\text { Policy orientation of Tuscany's DS party }\end{array}$ & $\begin{array}{l}\text { Constitutional autonomy of local governments } \\
\text { on organisation and management of local } \\
\text { public services } \\
\text { Constitutional reform strengthening regional } \\
\text { competences on organisation of local public } \\
\text { services }\end{array}$ & 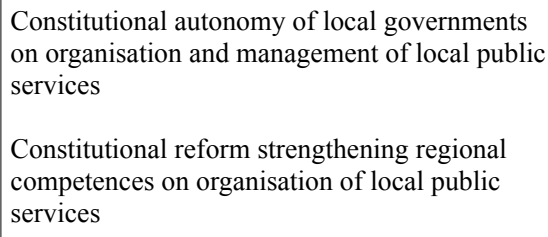 \\
\hline $\begin{array}{l}\text { Hypothesized social } \\
\text { mechanisms }\end{array}$ & $\begin{array}{l}\text { Logic of appropriateness (March and Olsen, } \\
\text { 1989; March, 1994) }\end{array}$ & Committed interpretation (Weick, 2001) & $\begin{array}{l}\begin{array}{l}\text { Attribution of opportunities and threats } \\
\text { (McAdam et al., 2001) }\end{array} \\
\text { Network diffusion (Hedström and Swedberg } \\
\text { 1998; Coleman et al., 1957) }\end{array}$ & $\begin{array}{l}\text { Attribution of opportunities and threats } \\
\text { (McAdam et al., 2001) }\end{array}$ \\
\hline
\end{tabular}

Table 7.2. Components of the explanatory argument for the path and outcome of the privatisation part of the water reform implementation (1994-2006). 


\section{Chapter summary.}

The analysis presented in this chapter offers an explanation of the trajectory and outcome of the implementation of the water reform in Italy in the period 19942006 based on institutional processualist approach. The explanation accounts for the traits of the liberalisation and re-regulation part of the water reform implementation - especially, the faltering part in the period 1994-1997 and the acceleration after the "turning point" in 1997, as well as the divergent trajectory of the water reform implementation in Alto Valdarno with respect to the general pattern in the country. The core of the explanatory argument is that, after the enactment of the water reform in 1994, the behaviour of local governments can be understood taking into account how initial conditions contributed framing their identities and roles in such a way as to make them consider appropriate to resist implementing the water reform. In 1997, however, changes in the water policy domain related to the piece of legislation that provided funding for sewage and wastewater treatment works, made local government react to perceived opportunities and changing features of the water sector, as diffused throughout the network of water policy experts.

The explanation also accounts for the traits of the privatisation part of the water reform - especially, the obstructed part in the period 1994-2001 and the acceleration after the "turning point" in 2001, together with the resulting heterogeneous organisational forms of water service delivery at the local level. The core of the explanatory argument is that, after the enactment of the water reform in 1994, the behaviour of local governments can be understood taking into account 
how their perceived identities and roles made them consider appropriate to retain direct ownership of water service providers rather than giving up full or partial ownership to private operators and investors. After 2001, two successive reforms of local public services brought about changes in the water policy domain that induced local governments to react to perceived opportunities to retain their sway on the local water industries. 


\section{Chapter 8}

\section{Discussion}

This final chapter aims to draw the implications of the present case study for improving our understanding of the public policy implementation process. First, the chapter contrasts and compares the explanatory arguments for the path and outcome of the implementation of the water reform in Italy provided by the two theoretical perspectives followed in this study, namely the institutional rational choice (analytic narrative) and the institutional processualist ones. Then, it discusses how findings of this case study relate to - and partially qualify - existing generalised arguments about the process dynamics of public policy in the implementation stage. Implications of this case study include the identification of a different research agenda but the one currently followed in mainstream public policy implementation research and that should be pursued in further research.

The chapter is organised into three parts. The first part will recall the key features of the alternative explanatory arguments that have been made for the implementation of the liberalisation and re-regulation part of the water reform, i.e., for the original inertia to implement the water reform, for the within-case variation of the water reform implementation trajectory in Alto Valdarno with respect to the rest of the country, and for the acceleration to implement the water reform after the "turning point" in 1997. The second part will recall the key features of the alternative explanations made for the implementation of the privatisation part of the 
water reform, i.e., for the obstructed privatisation of water services before 2001, and for the acceleration of the privatisation process after that year. Finally, the last part of this chapter will discuss the implications of the findings of the present case study for our theoretical understanding of the public policy implementation process.

\section{Explaining the implementation of the liberalisation and re-regulation part of the reform.}

The implementation of the liberalisation and re-regulation part of the water reform included two types of variation, along time and across space. Along time, this part of the water reform episode included two sequential trajectories, linked by a "turning point" in 1997. During the first trajectory (1994-1997), the implementation of the water reform was largely ineffective, as indicated by the very few OTA authorities established in the country by the end of the period. After the "turning point" in 1997, the implementation process shifted into a higher gear. During the second trajectory (1997-2006), an increasing number of OTA authorities were established - resulting in a cumulative number of 74 out of 89 OTAs that had been provided by regional legislation by that time. Across space, this part of the water reform episode included the different trajectory of the water reform implementation in Alto Valdarno - where local governments came to establish the OTA authority already in 1997 - with respect to the rest of the country. These stylised facts play the role of explananda in the analysis of the implementation of the liberalisation and re-regulation part of the water reform. The explanatory issues that have been tackled are (1) what accounts for the original inertia to define the OTA boundaries, (2) what accounts for the particular features of the trajectory of 
the water reform implementation in Alto Valdarno with respect to the rest of the country, and (3) what accounts for the acceleration of the implementation process after 1997.

\subsection{Accounting for the inertia to implement the water reform.}

The first analytic issue at stake is explaining what accounts for the inertia to define the boundaries of the OTAs during the period 1994-1997. It should be recalled here that, under provisions of the water reform legislation, the OTAs were to be designed by regional legislation, but local governments were supposed to voluntarily agree to have their territories comprised within watershed areas. In a sense, responsibility for setting the geographical boundaries of watershed authorities was shared by regional and local governments. Regions were given exclusive authority to divide their territories into watershed areas, but they were disallowed from exercising this authority before local governments had manifested their consent to a particular organisation of the regional territory into watershed areas. Regional governments were not given any means of recourse in the event that local governments did not arrive at any agreement. In effect, water reform legislation's procedural rules turned local governments into veto players within the implementation process, since neither the regional nor central governments could implement the watershed boundary scheme on their own authority.

Following the institutional rational choice perspective, expected payoff and structure of interaction between sub-national governments play the important role of causal factors for explaining the original inertia to define the OTA boundaries 
during the first period (1994-1997). Building on assumptions that include local governments' preferences for retaining control of water functions, the explanatory argument developed under this approach holds that local governments had no incentives to deviate from choosing not to define the OTA boundaries (i.e., playing the strategy not to define OTA boundaries resulted in a Nash equilibrium). The lack of apparent negative payoff when local governments play the strategy not to define the OTA boundaries, in particular, had important effects on the outcome of the game interaction. Given the structure of interaction provided by the water reform statute and by the country's multi-layered governmental system, moreover, neither the regional governments nor the central government could induce local governments to define the OTA boundaries. Both the prospect of passing the required regional legislation even without local governments' consent and the threat to exercise central government's substitutive powers, in fact, did not result in any effect on local governments' strategy.

In contrast, the institutional processualist approach entails an explanation that calls into play the combined influence of features of the policy reform design, initial conditions, and historical context. Features of the reform legislation (that relate to both features of the policy content and of the policy process contained in the water reform statute) were causal factors because they intersected in time and space with other conditions, including especially features of the water industry (fragmentation of the water sector and diffused local government ownership of water service providers), of local governments' stakes in the water firms (related to cultivation of electoral support of local constituencies), and of the historical context 
(such as local governments' constitutional autonomy on organisation and management of local public services, political weakness of governmental authorities after 1992-1993 corruption scandals, and turnover of government officers). All these conditions are taken jointly into consideration in the explanatory argument of why few agreements were reached by local governments on OTA boundaries during this period.

Features of the water industry and local governments' stakes in the water sector are especially important in order to account for local governments' decision not to define the OTA boundaries. Features of the water industry include the fragmentation of the sector into relatively small service areas, generally corresponding to the administrative territories of single local governments or local government consortia, and diffused local government ownership of water service providers, which dated back to about one century before. Local governments' stakes in water firms originated from the role that was played often by water provision in local government politics, that especially related to local governments' interest to exert influence on water-related job appointments and public contracts for the sake of gaining electoral support of local constituencies. These conditions figure importantly for explaining local governments' attitude towards the prospect of giving up control of water regulation and management functions. Given local governments' perceived identity and role, they considered appropriate to resist the definition of the OTA boundaries, because they anticipated that the regulatory system provided by the water reform, once implemented, would spoil them of their traditional role within the political economy of the local water industry (March 
1994; March and Olsen, 1989).

\subsection{Accounting for within-case variation.}

While the implementation of the water reform generally faltered in the country, one OTA authority came to be established in the Alto Valdarno area in Tuscany. In this sense, part of Tuscany deviates from the general pattern of implementation of the water reform in Italy during this period, which we can code as a case of non-implementation. Before discussing how this within-case variation is analytically significant, we briefly recall the particular features of the Alto Valdarno case. In this part of Tuscany, high-level concern about the organization of water provision pre-dated the national water reform. Beginning in 1990, the subject of water provision came to figure prominently in the agenda in the mayor of Arezzo, the principal urban centre of Alto Valdarno. The principal issue was whether to consolidate the water firms that served Arezzo and its surrounding municipalities; the secondary issue was how to structure the ownership of a consolidated water firm. Arezzo's mayor, influenced by leaders of the Tuscany branch of Italy's party Democratici di Sinistra (DS), pressed for both consolidation and limited privatization. Specifically, the mayor advocated the merger of municipally-owned entities providing water within the part of Alto Valdarno centred in Arezzo. The movement toward a merged and semi-privatised entity for water provision, however, was blocke, as a consequence of elections that brought a different mayor (party) to power in Arezzo. Nonetheless, by the time the national water reform was enacted in 1994, a "water policy community" within Alto 
Valdarno had come together, a network that had reached accord on the advantages of reorganizing the provision of water in the area surrounding Arezzo and had agreed on details of how water provision should be organized within this area.

Following the institutional rational choice perspective, expected payoff and structure of interaction between sub-national governments are pivotal causal factors for explaining what took place in Alto Valdarno area. While retaining the same assumptions regarding local governments' preferences for keeping control of water functions, the explanatory argument for the execution of the tasks related to the liberalisation and re-regulation part of the water reform in Alto Valdarno holds that local governments of this particular area of the country chose to collaborate to define the OTA boundaries and establish the OTA Authority because they believed that merging and semi-privatising their water firms would result in greater benefits than status quo conditions and, in addition, past experience of negotiation could facilitate the emergence of cooperation between them (Axelrod, 1984). While local governments in Alto Valdarno faced the same structure of interaction as other subnational governments in the country, then, they held different expectations for the payoff of the strategic interaction and for the likely strategies that other local governments in Alto Valdarno could play, both formed on the basis of past interactions about merging water providers and semi-privatisation plans.

In contrast, the institutional processualist approach provides an explanation that places greater emphasis on how initial and context conditions are brought to bear in local governments' decisions to collaborate to liberalise and re-regulate local water services. Differently from local governments in the rest of the country, those 
in Alto Valdarno faced a situation that included particular features of initial conditions, of the policy process, and of historical circumstances. Initial conditions include the negotiated agreement on reforming water service provision (in the form of consolidating water services and opening up access to private operators and investors) built on past interactions with other local governments of Alto Valdarno. Historical circumstances specifically include the policy orientation of Tuscany's DS party, that favoured the policy idea to semi-privatise local public services. Features of the policy process relate to the formation of an advocacy coalition of water experts who shared similar views about re-regulating local water service provision. An hypothesised mechanism of committed interpretation (Weick 2001; Salancik and Pfeffer 1978) helps explaining how these conditions, taken together, jointly resulted in local governments' decision to collaborate to define the OTA boundaries and establish the OTA Authority in Alto Valdarno.

On the basis of this examination of the Alto Valdarno case, we infer that clearly Italy was not uniform in the readiness of sub-national governments to respond to the liberalisation and re-regulation part of the water reform. Needless to say, the success achieved in defining some OTA boundaries in Tuscany (the one of Alto Valdarno first, and of a few other OTAs within a few years later) was relatively small with respect to the overall failure to implement the liberalisation and reregulation part of the water reform in the rest country. The success achieved in this part of the country, however, plays an analytically important role for explaining the acceleration of the implementation process after the "turning point" in 1997, as we shall recall shortly. In a sense, the success achieved in implementing part of the 
water reform in Alto Valdarno generated a feedback effect into the policy implementation processes that took place in other local areas of the country.

\subsection{Accounting for the acceleration part of the implementation process.}

As already recalled, the total number of OTA authorities established in the country increased from 1997 onwards, and reached 74 out of 89 OTAs that had been designed by 2005. In this sense, 1997 marks a "turning point" in the pattern of implementation of the liberalisation and re-regulation part of the water reform in Italy. Before reviewing the alternative explanations for why local governments increased their efforts to establish the OTA authorities at that time, we briefly recall that, in 1997, the central government enacted a legislation at the end of a policy cycle centred on a different issue but reforming the economic regulation of the water sector. The policy cycle whose decisional stage concluded in 1997 was centred on the quality and capacity of sewage and wastewater treatment systems in the country. The matter to be decided was how to use fiscal resources available to the central government by the EU to improve wastewater management. The approach incorporated into the legislation was for the central government to allocate funds for investment in sewage and wastewater treatment systems on the basis of plans prepared by regional or local governments. A specific feature of this planning and budgeting scheme was for plans to be formulated on an OTA-by-OTA basis. This feature evidently created a link between the wastewater treatment issue and the implementation of the water reform. The legislation, with this provision, cleared both the Senate and the House in September 1997. 
Following the institutional rational choice perspective, changed expected payoff play an important causal role for explaining the acceleration to implement the liberalisation and re-regulation part of the water reform after 1997. While keeping the same assumptions regarding local governments' preferences for retaining control of water functions, local governments' strategy to collaborate to define the OTA boundaries within the strategic interaction scenario provided after the 1997 legislation is explained by the expectation that collaborating to define the OTA boundaries would result in higher payoff than resisting it, provided that regions could progress to design the OTA boundaries as equalling the provincial territories anyway, and that local governments would then suffer the political cost of having been overridden in the definition of the OTA boundaries. In addition, once the OTA boundaries are defined and regional legislation is passed, local governments bear the responsibility for carrying out the rest of the liberalisation and re-regulation part of the water reform and, if they do not cooperate to establish the OTA authorities, then they would incur the political blame for not contributing reorganising the water services. Local governments' belief that the strategy not to establish the OTA authorities would result in inferior payoff than the one of collaborating, then, is an important causal factor for explaining local governments' collaboration to set up the local water regulatory agencies. Taking into account that several such games were played in various local areas in the country, a mechanism of imitation (Levine and Pesendorfer, 2007) can also suggest that, as some local governments collaborated to establish OTA authorities, others might follow suit because of adapting their belief to changed strategies played by surrounding 
counterparts.

In contrast, the institutional processualist approach provides an explanation that places particular emphasis on changed features of the policy process under consideration. In part, this explanation holds that the provision contained in the legislation passed in 1997, in conjunction with conditions related to the interests of local governments to appropriate funds to be spent in their administrative jurisdictions, resulted in raising the issue of OTA formation in local governments' agendas and in inducing local governments to agree to define the OTA boundaries for the sake of clearing access to funding public works. In part, however, this explanation also highlights that the 1997 legislation has the effect to help the sequencing of water reform implementation tasks, in the sense of de-coupling the issue of the definition of the OTAs from the negotiation about the centralisation of water planning and regulatory functions. The first issue at hand, namely the definition of the OTA boundaries, could be collectively framed as an opportunity (McAdam et al., 2001) to access funds for water infrastructure development rather than part of a threat to lose control on the local water industries. Once local governments had reached an agreement on the OTA boundaries, the regions progressed to pass the required legislation relatively fast. Since much of the political controversy about the design of the regional legislation had been solved, the regional governments did not encounter any resistance from local governments anymore.

After local governments agreed on the definition of the OTA boundaries, they also progressed to establish the OTA authorities. This part of the episode is 
apparently at odds with the presumed attitude of local governments to resist centralising water planning and management functions because of their interest to retain control of local water industries. The explanation for the establishment of the OTA authorities, however, highlights the causal role played by the activation of the policy community of water experts, that contributed to the diffusion of ideas (Hedström and Swedberg 1998; Coleman et al., 1957) about the net benefits of liberalising and re-regulating water service provision in the same way as it had been done in the early experiences of water reform implementation at the local level in Alto Valdarno and, later, also in other areas of the country. The policy advocacy played by this network of water experts contributed making local governments more favourable towards centralising water regulation in the OTA authorities. In accounting for this change of attitudes, we can also recall that, once coordination costs incurred to agree on the definition of the OTA authorities were sunk, local governments assessed that by establishing the OTA authorities they could enjoy benefits (in the form of influencing job appointments and public contracts of the jointly owned OTA authorities) that offset the loss of planning and regulatory functions in the respective municipalities. This belief helped mayor and cabinet officers to marshal the political consensus to centralise water regulation in the municipal councils, overcoming resistance to liberalise and re-regulate water service provision from part of local politicians.

\section{Explaining the implementation of the privatisation part of the reform.}

Also the implementation of the privatisation part of the water reform 
included two types of variation, along time and across space. Along time, this part of the water reform episode included two sequential trajectories, linked by a "turning point" in 2001. During the first trajectory (1994-2001), the implementation was largely ineffective, as indicated by the only one water franchise awarded in the country by the end of the period. After the "turning point" in 2001, the implementation process swiftly accelerated. The cumulative number of franchises awarded increased smoothly during the second trajectory (2001-2006), totalling 47 by 2005 (out of 89 OTA authorities which had been established by that time). The explanatory issues that have been tackled are (1) way was privatisation so obstructed during the first period, and (2) what accounts for the acceleration of the of the privatisation process after 2001 - and, after 2003, for the award of water franchises to "in house" water firms.

\subsection{Accounting for the obstructed part of the implementation process.}

The first analytic issue at stake is explaining what accounts for the obstructed privatisation process during the period 1994-2001. Following the institutional rational choice perspective, expected payoff and structure of interaction between sub-national governments play an important causal role for explaining the resistance of local governments to privatise water service provision. While keeping the assumptions related to local governments' preferences for retaining control of water functions, the explanatory argument developed under this approach holds that local governments had no incentives to give up ownership of water firms if they expected that payoff under conditions of full local government ownership exceeded 
those under different ownership arrangements. Provided that, within the explanatory argument, local governments' beliefs are inferred from their conduct, we conclude that neither semi-privatisation nor full privatisation of water service providers were expected by local governments to result in higher net benefits with respect to retaining the status quo, and were therefore discarded as disadvantageous alternatives.

In contrast, the institutional processualist approach entails an explanation that calls into play the combined influence of features of the policy reform design, initial conditions, and historical context. Design features of the reform included the provisions that, in principle, each OTA authority would award water franchises to one only water company ${ }^{133}$, which could be either a mixed public-private ownership company or a business company selected through tender offer competition. In effect, water reform legislations' procedural rules made the establishment of the OTA authorities an essential condition within the privatisation part of the implementation process. Therefore, the delay to privatise water service provision can be explained, in part, by the delay to accomplish the liberalisation and reregulation part of the water reform. After the liberalisation and re-regulation part of the water reform was implemented, however, the privatisation process was obstructed by the combined effects of adverse conditions especially related to characteristics of the water industry and local governments' stakes.

Features of the water industry that are relevant here include the fragmentation of the water sector and the predominance of local government 133 Award of water franchises to more than one water company in the same OTA (through a partition of the OTA service area) was allowed only if incumbent water firms satisfied criteria of economic self-sufficiency. 
agencies and consortia among water service providers in the country. The water industry was largely fragmented into service areas that generally corresponded to municipal jurisdictions or administrative territories of local governments' consortia. This industrial structure allowed local governments' politicians to enjoy influence on water service provision operated in the respective municipal territories, that could serve their interest to distribute favours to electoral constituencies in the form of job appointments and public contracts. Taking these initial conditions and historical circumstances into account, local governments could consider appropriate for their identity and role (March 1994; March and Olsen, 1989) to resist privatisation because, if water firms were fully or partially transferred to private operators and investors, then the influence of local government politicians on water firms (that would be then jointly owned with private shareholders) would be significantly diminished.

The case of privatisation of water services in Alto Valdarno only deviates from the general pattern of implementing the privatisation part of the water reform during the 1994-2001 period. As already recalled, particular features of the setting of Tuscany in general and Alto Valdarno in particular contribute accounting for the deviation from the general water reform implementation pattern. Briefly put, in this part of Tuscany the policy idea to consolidate and partially privatise incumbent municipal water service providers had gained serious consideration among local policy-makers since 1990. A water policy community within Alto Valdarno had formed and came to agree on the terms of the merger between incumbent water firms and of the sale of minority shareholding to private water operators and 
investors. This agreement played an important causal role in the privatisation of local water service providers. Once the OTA Alto Valdarno Authority was established, local governments required little further negotiation to come to agree to merge their water firms and make the OTA authority select the private partner for awarding the first water franchise in the country, in 1999.

\subsection{Accounting for the acceleration part of the implementation process.}

As already recalled, from 2001 onwards an increasing number of water franchises were awarded in the country, reaching the total number of 47 by 2005 . In this sense, 2001 marks a "turning point" in the pattern of implementation of the privatisation part of the water reform in Italy. Before reviewing the alternative explanations for why local governments become inclined to privatise water services at that time, we briefly recall that, in 2001 , the central government led the Parliament to pass a reform of local public services that provided that local public services should be awarded through tender offer competitions. Special provisions, however, applied to water services so that the award of water franchises through tender offer competitions could be postponed up to 10 years if the OTA authorities assigned water concessions to local government-owned firms by the end of a transitory period of 18 months (i.e., by $30^{\text {th }}$ June 2003) and if certain requirements were satisfied (especially, if part of water firms' shares were sold to private water operators or investors over time). In 2003, then, another reform of local public services included the provision that, if certain requirements were met, local public services could be also assigned to companies fully owned by local governments 
only ("in house").

Following the institutional rational choice perspective, changed expected payoff play an important causal role for explaining the acceleration to implement the privatisation part of the water reform after 2001. While keeping the same assumptions regarding local governments' preferences for retaining control of water functions, local governments' choice to privatise water services is explained by the expectation that awarding water franchises to a mixed ownership firm results in higher net benefits than the alternative option available provided by the legislation namely, to award the franchise to business companies selected through tender offer competition - and than the option to wait until the end of the transitory period. If we agree with the part of the explanatory argument that local governments' beliefs are inferred from their conduct, then we infer that, after the 2001 legislation, a growing number of local governments expected that awarding water franchises to mixed ownership firms would deliver higher net benefits than any alternative, including maintenance of status quo.

In contrast, the institutional processualist approach provides an explanation that places particular emphasis on both changed features of the policy content and of the policy process under consideration. In part, this explanation holds that the provisions contained in the 2001 local public services reform, together with steady conditions related to the interests of local governments to retain control of water functions, resulted in rising the issue of water privatisation in local governments' agendas and affected local governments' decision to award water franchises to mixed ownership firms, also taking into account the perceived threat that water 
franchises should be awarded to business companies selected through tender offer competition after the end of the transitory period (McAdam et al., 2001). In part, however, the explanation also highlights the causal role played by the activation of the policy community of water experts, that contributed to the diffusion of ideas (Hedström and Swedberg 1998; Coleman et al., 1957) about the net benefits of privatising water services in the same way as it had been done in the early experiences of water reform implementation at the local level in Alto Valdarno and, later, also in other areas of the country. Similarly to the influence exerted on the diffusion of ideas about the liberalisation and re-regulation of water service provision, the policy advocacy played by this network of water experts contributed making local governments also more favourable towards privatising water services to mixed ownership firms.

The institutional rational choice perspective also informs an explanation for the "formal privatisation" that took place from 2003 onwards, when water franchises were generally awarded to "in house" firms rather than to mixed ownership ones. Under the same assumptions regarding local governments' preferences for retaining control of water functions, local governments' strategy to award water franchises to fully local governments owned firms is explained by the belief that payoff resulting from "formal privatisation" (that, as an option, was made available by the provisions contained in the 2003 local public services reform) were higher than alternative privatisation schemes. If we again hold that local governments' beliefs are inferred from their conduct, then we conclude that, after the 2003 legislation, retaining full ownership of water firms (albeit jointly with 
other neighbouring municipalities) was expected to deliver higher net benefits to the local governments than any alternative.

In contrast, the institutional processualist approach especially highlights the causal role played by both changes of policy content conditions and historical circumstances. In part, this explanation holds that local governments' decision to award water franchises to "in house" firms is related to important changes of rules about the allowed privatisation schemes brought about by the 2003 local public services reform, together with steady conditions related to local governments' interests to retain control of water functions. In part, however, the explanatory argument also highlights the role played by changed historical conditions, especially related to the enlargement of competences on the organisation of local public services and the management of water resources attributed to the regions as provided by the reform of the Constitution in 2001. This reallocation of authority between government layers of the country enabled the regional government of Tuscany to appeal to the Constitutional Court against some provisions of the 2003 legislation that narrowly specified the requisites for awarding water franchises to "in house" firms. After the Constitutional Court ruled in favour of region Tuscany's appeal in July 2004, local governments faced no more restrictions to the award of franchises to "in house" water firms, especially in relation to central governments' efforts to steer the privatisation process away from the "formal privatisation" scheme. 


\section{Drawing implications from this case study.}

Having recalled the key features of the alternative explanatory arguments for the implementation of the liberalisation, re-regulation, and privatisation parts of the water reform, this final section will contrast and compare the two alternative explanations for the sake of drawing the implications of the present case study for our theoretical understanding of the process of implementing regulatory reforms. It should be highlighted, first, that the two explanatory arguments exhibit several similarities. Both the explanations formulated by following the institutional rational choice and the institutional processualist perspectives highlight, in particular, the causal role played by past experience of negotiation in accounting for the different trajectory of water reform implementation in Alto Valdarno with respect to the rest of the country, by changes of policy content features brought about by 1997 legislation and by the activation of the policy community of water experts in accounting for the acceleration of the liberalisation and re-regulation part of the water reform, and by changes of policy content features brought about by 2001 and 2003 legislations and by the activation of the policy community of water experts in accounting for the acceleration of the privatisation part of the water reform and for the kind of privatisation schemes pursued when awarding water franchises. Both theoretical perspectives, then, are relatively congruent in identifying relevant causal factors that contribute explaining within-case variation both over time and across space.

At a more fine-grained level, however, differences between the explanatory arguments provided by the two alternative perspectives become more apparent. The 
explanatory arguments made by following the institutional rational choice approach especially highlight how features of the water reform implementation trajectory relate to equilibrium strategies played by the actors under conditions that arise from different sets of expected payoff and changing features of the institutional context. The different trajectory of water reform implementation in Alto Valdarno with respect to the rest of the country, for example, especially is explained by the particular expectations, held by local governments that strategically interacted in that area and related to past experience of interaction, that cooperating to define the OTA boundaries and to establish the OTA authority would result in higher net benefits than maintaining the status quo. The explanation for the acceleration of the liberalisation and re-regulation part of the water reform highlights the role played by changed expectations of local governments concerning future net benefits that would arise from defining the OTAs, that especially included access to infrastructure development funding provided by 1997 legislation, and that could become apparent to local governments on the basis of the observed strategies played by other local governments in other local interactions. The explanation for the acceleration of the privatisation part of the water reform especially relates to the role played by changed expectations about payoff that local governments would get if choosing to make OTA authorities award water franchises to mixed ownership firms, for reasons related to features of the 2001 local public services reform, and, after the enactment of the 2003 local public services reform, if putting water service provision in the hands of "in house" firms.

In contrast, the institutional processualist perspective especially highlights 
how features of the water reform implementation trajectory relate to the joint combination of initial conditions, features of the policy content and process, and changing historical circumstances. With respect to the institutional rational choice explanation, the one formulated under this theoretical perspective is especially attentive to how various context conditions jointly contribute orienting the conduct of implementers in ways that are not exclusively related to expected payoff calculations. The explanation for the different trajectory of water reform implementation in Alto Valdarno with respect to the rest of the country, for example, is especially attentive to past experience of negotiation between local governments in that area and builds on the hypothesised mechanism of committed interpretation to account for local governments' efforts to define the OTA boundaries and establish the OTA authority. The acceleration of the liberalisation and re-regulation part of the water reform is explained especially by placing particular attention to how changed policy content features, that related to the introduction of default definition of OTA boundaries for bypassing local governments' inertia, contributed framing the opportunity to appropriate infrastructure development funding, and to how changed policy process features, in the form of an activation of the policy community of water experts, contributed to diffuse the policy idea to liberalise and re-regulate water service provision throughout the water policy network in a way akin to Alto Valdarno experience. These sources of causal factors had the combined effect to induce local governments to speed up the execution of the tasks to define the OTA boundaries and establish the OTA authorities. Finally, the acceleration of the privatisation part 
of the water reform is explained by especially highlighting the causal role played by changed policy content features, that related to the menu of option choices for privatisation schemes provided by 2001 and 2003 local public services reforms, and changed policy process features related to the activation of the policy community of water experts. These sources of causal factors jointly contributed to frame the opportunity for local governments to avoid full privatisation scheme and (after 2003) retaining full control of water service provisions.

Taken together, how do the explanations provided by the two theoretical perspectives contribute improving our understanding of the political economy of implementing regulatory reforms? It is worth briefly recalling, first, the argument made in the literature review (Chapter 1) that current scholarly literature on public policy implementation places relatively little attention to the jagged and ineffectual type of implementation process that especially takes place when the execution of the policy reform mandate entails the political confrontation between government authorities situated at different levels of a governmental system. This "gap" is especially evident when considering the implementation of infrastructure regulatory reforms (as a particular type of public policy reform), where the technical, economic, and territorial characteristics of the target domain of the policy reform play an important role in the path and outcome of the implementation process, especially when the reform implementation under consideration takes place in multi-level governance systems. Within this scenario, the implementation of infrastructure regulatory reforms entails a complex pattern of political confrontations whose effects on the path and outcome of the implementation 
process are difficult to discern through the "lenses" of existing general theories of public policy implementation.

Generalised arguments about the political economy of policy reform implementation hold that the political confrontation between implementers and target groups plays an important role in the "sustainability" of policy reform in the post-enactment stage. In recent works made by Patashnik (2003, 2008), for example, the issue of what makes a policy reform sustainable (in the sense of being able to "maintain its stability, coherence, and integrity as time passes, achieving its basic promised goals amid the inevitable vicissitudes of politics"; Patashnik, 2003: $207)$ in the post-enactment stage is related to the strength of forces within the reform target domain that seek to reverse or corrupt the reform. Factors that seem especially important to make policy reforms sustainable include the extent to which the reforms induce a shift of political institutions (i.e., legal rules, bureaucratic structures, and administrative procedures) that effectively disable policy-makers from taking new actions contrary to the "spirit" and objectives of the reform, and the generation of policy feedback effects that reshape identities, political resources, and strategic behaviour of the relevant actors.

In contrast with existing works such as those of Patashnik's (2003, 2008), the present case study evokes a more complex understanding of the process dynamics of the implementation stage of the policy cycle in various respects. First, it suggests that common categories used for conceptualising trajectories of policy reform implementation - i.e., "sustained", "reversed", or "diverted" implementation (with respect to policy reform objectives) - may not fully capture features of the 
path and outcome of policy reform implementation episodes. Episodes of policy reform implementation may exhibit relatively "erratic" trajectories, such as those where a period of relatively ineffectual efforts is followed by another of hectic application to execute the policy reform mandate, or those where remarkable differences emerge between the behaviour of distinct implementers and target groups at the local level. Within such scenarios, important analytic issues at stake relate to what explains the "turning points" between different parts of the whole policy reform implementation trajectory or what accounts for variation of local responses to policy reform mandate, rather than to accounting for sustainability of the policy reform during the post-enactment stage.

In addition, the present case study suggests that particular attention should be placed on understanding how features of the policy reform (content and process), together with initial and changing context conditions, result in the activation of processes (such as shifts of political institutions and policy feedback effects) that impact upon the implementation path and outcome. The explanatory arguments contained in the present case study provide several propositions about the role of policy reform design features, characteristics of the water industry (e.g., sectoral fragmentation and traditional public sector ownership), changed features of the policy content and process (e.g., range of allowed privatisation schemes and activation of the policy community of water experts), and changed historical circumstances (e.g., 2001 constitutional change) in affecting the water reform implementation trajectory. In contrast, explanatory arguments such as those of Patashnik's $(2003,2008)$ do not provide any detailed account for the conditions 
under which features of the implementation process dynamics that are regarded as important to explain the trajectory of policy reform implementation, such as shifts of political institutions and feedback effects, may take place or not.

Among the conditions identified in the present case study, those related to features of the multi-layered structure of the governance system are particularly important to explain how regulatory reform implementation takes place. Such "class" of conditions (that include, for instance, allocation of authoritative powers on the regulation of water services across layers of government as provided by the constitution and relevant legislation and the embeddedness of the national governance system within the EU polity) are especially relevant to frame the political confrontation between sub-national governments situated at different levels of the governmental systems. In the implementation of the liberalisation and reregulation part of the water reform, the allocation of authoritative powers to subnational governments (specifically, local governments' relative autonomy on the regulation of local public services) affected, together with other causal factors included in the explanatory argument, the kind of interaction between local governments, regional governments, and central government that resulted in the definition of the OTA boundaries and the establishment of the OTA authorities. In the implementation of the privatisation part of the water reform, as well, the allocation of authoritative powers to sub-national governments (especially related to the devolution of some competences provided by the 2001 constitutional reform) and the embeddedness of the national governance system within the EU polity (specifically, the role played by European Court of Justice's rulings on domestic 
legislative and regulatory authorities) contributed, together with other conditions recalled above, to affect the kind of interaction between local governments, regional governments, and central government that resulted in the award of water franchises to either mixed ownership or "in house" firms.

More generally, the present case study identifies and opens up a different research agenda but the one followed by most of contemporary work on public policy implementation, especially those conducted in the so-called "third generation" approach. Rather than tackling issues related, in broad terms, to what factors affect implementation success or failure, this case study aimed to explain implementation process dynamics by itself. Rather than seeking to isolate particular factors that affect the path and outcome of the implementation process, it acknowledged that multiple conditions need to be taken into account for explaining how implementers and target groups interact with each other. Additionally, this case study aimed to identify the mechanisms through which the process dynamics of the water reform implementation took place. Such traits of the kind of research interest that has been pursued in this work qualify it as an explorative inquiry into the process dynamics of public policy implementation that deviates, in part, from current mainstream research in this area.

\section{Summary.}

This chapter aimed to draw the implications of the present case study. It first contrasted and compared the two explanatory arguments for both the liberalisation and re-regulation part and the privatisation part of the water reform that have been 
made by following the institutional rational choice and the institutional processualist approaches, respectively. Then, it made the case for some similarities between the two explanatory argument, in the extent to which both identified the causal role played by particular initial conditions and changed context circumstances on the path and outcome of the water reform implementation, and for some differences between the two, especially related to how various context conditions jointly contribute orienting the conduct of implementers in ways that are not exclusively related to expected payoff calculations.

With respect to current scholarly literature on public policy implementation, that places relatively little attention to the jagged and ineffectual type of implementation process that especially takes place when the execution of the policy reform mandate entails the political confrontation between government authorities situated at different levels of a governmental system, the findings of the present case study suggest some ways to qualify existing generalised arguments about the policy process in the implementation stage. Differently from mainstream "third generation" public policy implementation studies, the present case study evokes a more complex understanding of the process dynamics of the implementation stage of the policy cycle because of its consideration of analytical issues related to explaining "turning points" within the implementation process and variation of local responses to the policy reform mandate. In addition, the present case study places attention to understanding how features of the policy reform (content and process), together with initial and changing context conditions result in the activation of processes that impact upon the implementation path and outcome. 
Because of these features, the present case study is explorative in the sense of identifying and opening up a different research agenda but the one followed by most of contemporary work on public policy implementation. 


\section{Conclusion}

This case study provides an explanation for the features of the trajectory of the implementation of the water reform in Italy in the period 1994-2006. Features of this trajectory included both variation over time and across space. Over time, the implementation of the liberalisation and re-regulation part of the water reform proceeded slowly in the period 1997-2001, but accelerated from 1997 onwards and resulted in the set up of the new regulatory system almost all over the country; and the privatisation part of the water reform went through a period of obstructed implementation in the period 1994-2001, followed by one of intense efforts to change the form of ownership of water firms from 2001 onwards that resulted in some amount of participation of private operators and investors in the water sector. Across space, the implementation of the water reform in a particular area of the country, Alto Valdarno, proceeded remarkably faster than elsewhere, resulting in the establishment of the new regulatory system by 1997 and in the semi-privatisation of water service provision in 1999.

By the end of the period under consideration, the content of the water reform was largely implemented. As Table 1 shows, by 2006 the liberalisation and re-regulation part of the water reform resulted in the establishment of 87 OTA authorities out of 91 watershed areas that had been provided in regional legislation. The privatisation part of the water reform proceeded somehow more slowly, as illustrated by the relatively few water infrastructure development plans that had been approved and the only one water franchise that had been awarded by the 
intermediate date in 2001. By the end of the period 1994-2006, instead, water infrastructure development plans had been approved in 70 OTAs, and water franchises had been awarded in 47 watershed areas. It should be highlighted, however, that only partially does the end state of the episode count as privatisation of water service provision. As shown in a survey conducted in 2009, when 67 water franchises had been awarded by that time, only about one third of water firms took the form of mixed public-private ownership entities, while the rest consisted of "in house" water firms (i.e., fully local government owned). The privatisation part of the water reform, then, largely resulted in "formal privatisation" (i.e., water firms were reincorporated under company laws but ownership was retained by local governments) while private operators and investors only entered part of the water sector as minority shareholders of local government majority-owned entities ${ }^{134}$.

Liberalization and re-regulation part

No. OTAs defined in regional legislation 2001 2006

No. OTA authorities established 89 91

Privatisation part

No. water infrastructure development plans approved 18

No. water franchises awarded 74

18

1

Table 1. Indicators of the implementation of the liberalisation and re-regulation part and of the privatisation part of the water reform.

While it is possible to describe the end state of the water reform implementation episode in terms of execution of the policy reform content,

134 For a more detailed view of the end state of the water sector after the water reform implementation episode across regions of the country, please refer to Table 5.1 in Chapter 5. 
relatively less evidence is available about water sector performance under the new regulatory regime. Data originated from the national statistics bureau ISTAT provide some information about trends in water infrastructure development - that, within the national water policy community, has been generally regarded as an indicator of the extent to which issues of relatively poor water service performance are tackled and possibly fixed. This particular aspect of water sector performance exhibits relatively encouraging figures. As Table 2 shows, per-capita investment in water infrastructure in the period after 1997 soared to about $€ 33$, compared with about $€ 17.3$ (constant prices $2010 €$ ) during most of the 1990's. By this indicator, the establishment of the new regulatory regime seems related to water systems' greater capacity to plan, fund, and execute water infrastructure development than under the previous regime.

The amount of investment that were poured into the water sector, however, only provides a partial view for assessing how well the new regulatory regime performed. According to different independent reports based on ISTAT data (Cgiamestre, 2011; Cittadinanzattiva, 2011), during the 2000's water tariffs increased about $64.4-70 \%$. Whether higher water charges are accompanied by improved water service quality or improved efficiency and cost-effectiveness of water firms, however, is uncertain because of lack of reliable or comparable data at the water business level (especially in so-called multi-utility firms, where the same company carries out both water and other network businesses, such as gas and urban waste disposal). Further research is certainly due in order to evaluate the performance effects of the new regulatory regime that resulted from the water 
reform implementation efforts.

\begin{tabular}{cc} 
Periods & Per-capita investment \\
\hline $1954-1969$ & 16.2 \\
$1970-1979$ & 18 \\
$1980-1989$ & 32.4 \\
$1990-1997$ & 17.3 \\
$1997-2010$ & $33\left(^{*}\right)$
\end{tabular}

Table 2. Pro-capita investments in water infrastructure, values in constant prices $2010 €$. (*) Values inferred on the basis of 19 OTAs (Source: Ermano, 2012, on the basis of ISTAT data and Bluebook, 2010).

Moving back to the central concern of this study with how the present water regulatory regime came into place rather than with the performance effects of the water reform, this case study allows us to refine our understanding of the present state of water regulation in Italy. Existing research on water regulation and regulatory reforms in Italy already highlighted the role of factors such as fragmentation of the water sector, ownership structure of water firms, the presence of a policy community of water experts, and features of the reform statute in affecting the emergence of "water governance structures" in the new regulatory regime (Citroni and Lippi, 2006; Citroni et al., 2007; Lippi et al., 2008; Carrozza, 2008). The explanatory arguments contained in these studies were particularly attentive to how power relationships between influential stakeholders within local water industries contributed to the particular "modes of governance" of water services at the watershed level. These works, however, placed relatively little attention to explaining the "turning points" within the trajectory of the episode of water reform implementation and the variety of local trajectories across the country. 
Their explanations for how the water regulatory regime was put into place pay relatively little attention to the role played by outcomes of contemporaneous events (such as 1997 legislation, 2001 and 2003 local public services reform, 2001 constitutional reform, and 1999 decision of the European Court of Justice) and of feedback effects (especially the diffusion of policy ideas concerning the liberalisation and re-regulation of water services and the adoption of semiprivatisation schemes as experienced in Alto Valdarno) in affecting the course of the water reform implementation episode.

In contrast, the present case study better accounts for why the implementation of the water reform accelerated after the "turning points" that have been identified in the episode and for some variety of local trajectories across the country. Explanations for these features of the trajectory of the implementation of the water reform help better understanding of the characteristics of the resulting regulation of the water sector in the country. These characteristics include, for example, that the definition of OTA boundaries largely corresponded to the administrative territories of the provinces, while the water reform mandated that they should have been designed according to hydro-geological criteria. This case study showed that this feature of the present water regulation in Italy originated from the particular circumstances that led to the acceleration of the liberalisation and re-regulation part of the water reform, especially 1997 legislation and local governments' interest to appropriate funds for infrastructure development within their respective jurisdictions. Characteristics of the present water regulation in Italy also include that private operators and investors play a relatively minor role within 
the sector, while the intention of policy-makers in the central government was to attract larger private capital participation in order to contribute financing infrastructure development and improving efficiency of water firms. Also this feature of the present water sector in Italy is explained by this case study, that showed how the sequencing of local public services reforms in 2001 and 2003 contributed affecting local governments' decision to semi-privatise water service provision.

More generally, this case study enables an advance in our theoretical understanding of the policy process of regulatory reform implementation. It is worth briefly recalling, here, that existing theories on public policy implementation place relatively little attention to the jagged and ineffectual type of implementation process that typically relates to scenarios where government authorities situated at different levels of a governmental system engage in political confrontation over the execution of the policy reform mandate. As a particular type of public policy reform, infrastructure regulatory reforms provide an instance of such scenario because the technical, economic, and territorial characteristics of the infrastructure policy domain make the political confrontation between governmental authorities particularly relevant, especially when the reform implementation under consideration takes place in multi-level governance systems. The present case study, in this respect, allows an exploration of the effects of complex pattern of political confrontations that arise in the implementation of regulatory reforms in multi-level governance systems on the path and outcome of the implementation process. 
The analysis of the case of the water reform implementation in Italy suggests that existing generalising arguments about features of the policy cycle in the implementation stage may be qualified in various respects. First, common categories used for conceptualising trajectories of policy reform implementation i.e., "sustained", "reversed", or "diverted" implementation (with respect to policy reform objectives) - may not fully capture features of the path and outcome of policy reform implementation episodes. Provided that episodes of policy reform implementation may exhibit relatively "erratic" trajectories (such as those where a period of relatively ineffectual efforts is followed by another of hectic application to execute the policy reform mandate, or those where remarkable differences emerge between the behaviour of distinct groups of implementers and target groups at the local level), explaining the "turning points" between different parts of the whole policy reform implementation trajectory and variation of local responses to policy reform mandate are important analytic issues that should take the centre of the stage.

In addition, greater attention should be placed on understanding how features of the policy reform (content and process), together with initial and changing context conditions, result in the activation of processes (such as shifts of political institutions and policy feedback effects) that impact upon the implementation path and outcome. Existing studies have already addressed the issue of what affect the sustainability of policy reforms in the implementation, or post-enactment, stage (Patashnik, 2003, 2008), but they missed specifying the conditions under which processes such as shifts of political institutions and policy 
feedback effects may take place. In contrast, the present case study identified several conditions (e.g., sectoral fragmentation, traditional public sector ownership, range of privatisation schemes allowed by relevant legislation, and presence of a policy community of water experts) that need to be jointly taken into consideration for explaining why local governments moved away from original inclinations to resist the liberalisation, re-regulation, and privatisation of water service provision and became inclined to execute the implementation tasks. Moreover, the present case study also suggested some ways through which such conditions impacted upon the water reform implementation trajectory, especially by contributing framing opportunities or threats and by triggering a process of diffusion of policy ideas about liberalising, re-regulating, and privatising water service provision in a way akin to the early experiences in Alto Valdarno.

A lesson that can be drawn from this case study is that the sources of resistance to liberalise, re-regulate, and privatise infrastructure industries that originate from "governmental protectionism" (Landy et al., 2007) may, under certain conditions, be overcome. In part, the findings of this case study support the argument that opening up regulated sectors of the economy to competitive pressures, reducing governmental ownership and control of public services providers, and enabling private operators and investors to enter industries that were previously held under public ownership can be effectively blocked by adverse governmental authorities - as it was the case during the obstructed parts of the water reform implementation episode and, in part, during the post-2003 period of "formal privatisation" of water service provision into "in house" firms. The case 
study, however, also showed that local governments became favourably inclined towards implementing the water reform after the "turning points" in 1997, when legislation provided subsidies for infrastructure development and default definition of OTA boundaries, and in 2001, when legislation changed the menu of option choices for awarding water franchises, for reasons that especially included the activation of the policy community of water experts that contributed to the diffusion of policy ideas based on the Alto Valdarno experience.

A tentative recommendation stemming from the present case study is that overcoming governmental protectionism calls for careful attention to the design of reform policy content and process and to the management of policy networks. Within the implementation of the water reform, the explanation for the acceleration to liberalise, re-regulate, and privatise water service provision highlighted the role played by changed legislation that provided subsidies for infrastructure development that were conditional on the definition of OTA boundaries, by the default definition of OTA boundaries in case of local governments' inaction, by the modification of the menu of option choices for privatising water service provision, and by the activation of the policy community of water experts. The case study suggests, then, that policy-makers should make good use of the repertoire of policy tools at their disposal in such a way as to contribute framing implementers' conceptualisation of the issues at stake and to provide appropriate inducements and constraints for orienting implementers' decisions. Moreover, the case study suggests that successful experiences of "early movers" in the execution of implementation task should be exploited as sources of evidence for the viability and advantages of 
implementing the reform policy mandate.

Finally, this case study provides some evidence for engaging the scholarly discussion about the relative strengths and weaknesses of the institutional rational choice perspective with respect to alternative theoretical approaches such as institutional processualism. It is worth briefly recalling, here, that baseline arguments about the relationship between institutional rational choice and institutional processualism include the point that the latter has a general advantage with respect to the former because it provides an account of how features of the temporal context are brought to bear into the ways actors within the policy process under consideration make decisions and interact with each other (Barzelay and Gallego, 2006). More generally, the relationship between institutional rational choice and other new institutionalist perspectives has been sometimes characterised as a complementary one (Bates et al., 2000), especially on the basis of points of intersection and overlap with historical institutionalism in particular (Katznelson and Weingast, 2005). Sometimes, instead, it has been depicted as a conflictual one, especially on the basis that preferences are treated as exogenous in institutional rational choice while interests and objectives are created in institutional contexts in ways that make them inseparable from them in other varieties of new institutionalism (Thelen, 1999; Thelen and Steinmo, 1992).

With respect to the baseline arguments recalled above, this case study suggests some way to clarify differences in the ways features of the temporal context come into play in alternative explanatory arguments made by following the institutional rational choice and the institutional processualist perspectives, 
respectively. Explanations for the trajectory of water reform implementation made by following the institutional rational choice approach include a role for features of the temporal context in the form of assumptions concerning game structure and/or payoff formulated by the researcher and taken as a given in the analysis of game interaction. For example, explanatory arguments for the acceleration of water reform implementation after the "turning points" in 1997 and 2001 consist of exercises in comparative static, where exogenous factors related to 1997 and 2001 legislation are supposed to change payoff and consequently affect local governments' strategies. In contrast, explanations for the trajectory of water reform implementation provided by following the institutional processualist perspective include a role for features of the temporal context in the form of sources of causal factors that are connected to the observed behaviour that is to be explained by hypothesised mechanisms. For example, the acceleration of water reform implementation after the "turning points" in 1997 and 2001 is explained by the causal role of changes of relevant legislation in activating, together with other conditions, a mechanism of attribution of opportunities and threats that accounts for local governments' inclination to proceed in the execution of implementation tasks (specifically, defining OTA boundaries and semi-privatising water service provision, respectively).

Having specified how the temporal context plays different roles in the explanations made by following the two approaches, we can elaborate on what are the relative strengths and weaknesses of the two perspectives. A baseline argument here is that the institutional rational choice approach is often criticised because 
explanations made by following this approach build on assumptions about preferences of actors that are not really observable and about payoff of game interaction that may not be actually known by the researcher. This kind of criticism seems relevant also for the explanatory arguments contained in the present case study, provided that, as a matter of fact, both actors' preferences and game payoff were neither observed nor known. It seems fair to acknowledge also, however, that explanations made by following the institutional processualist perspective incorporate an important role played by hypothesised social mechanisms, that are conjectured as a way of relating sources of causal factors and the observed behaviour that is to be explained without being really observed by the researcher. In this respect, both theoretical perspectives need to resort to assumptions and conjectures that are not supported by empirical observations.

Assumptions and conjectures seem to play different role in the two explanatory arguments, however. The institutional processualist perspective suggests to make use of hypothesised social mechanisms as a way of probing the causal linkages between sources of causal factors and the explanandum under consideration. In contrast, the institutional rational choice approach suggests to assume preferences and payoff as a way of modelling game interactions that are instrumental in accounting for the explanandum under consideration. In a sense, the recourse to hypothesised social mechanisms within explanations made by following the institutional processualist perspective opens up further questions about the details of the "cogs and wheels" of social interactions that lead from sources of causal factors to the explanandum, while assumptions about preferences and payoff 
within explanations made by following the institutional rational choice approach does not seem to similarly orient further scholarly inquiry. This features of the institutional processualist approach may count as an advantage with respect to the other one, at least from the point of view of social scientists who share an interest for explaining the process through which social events unfold.

Another baseline argument that is relevant for this discussion is that the institutional rational choice approach is often praised because explanations made by following rationality assumptions are relatively parsimonious with respect to other theoretical approaches. This apparent strength of the institutional rational choice approach, however, needs to be weighed against the accuracy of its explanations. The present case study provides some evidence that explanatory arguments made by following the institutional rational choice approach may account for alternative and equally plausible course of actions, that correspond to multiple Nash equilibria within the same game interaction. For example, the explanation for whether local governments choose to cooperate or not in the definition of the OTA boundaries included the argument that both strategies were Nash equilibria, given the game structure and payoff that contributed modelling this interaction. When multiple Nash equilibria exist, the explanatory argument for why players choose one strategy rather than another one needs to make use of hypothesised mechanisms, such as the emergence of cooperation on the basis of past interaction (Axelrod, 1984) and imitation of others' strategies (Levine and Pesendorfer, 2007). In doing so, however, explanations made by following the institutional rational choice approach give up some of their presumed parsimony for the sake of better accuracy. In this respect, 
the institutional processualist approach seem better positioned than the institutional rational choice one to provide accurate explanations without necessarily adhering to rational choice's assumption of strict instrumental action.

A few reservations about the present case study should be duly acknowledged. First and foremost, the explanatory argument for the path and outcome of the water reform implementation does not fully account for local variety of implementation trajectories. No explanation is provided, for example, for the few local instances of non-implementation of the liberalisation and re-regulation part of the water reform in 4 OTAs - one based in Piedmont and 3 in Friuli Venezia Giulia regions - where no OTA authorities were established until the end of the case episode in 2006. No explanation is provided, also, for the few local instances of privatisation of water service provision into business companies selected through tender offer competitions in 6 out of 9 OTAs in Sicily, where explorative data collection (i.e., court proceedings and the press ${ }^{135}$ ) suggested that crime organisations might have played some role in the political economy of the regional water sector on sustained basis. Additional research specifically designed for investigating differences between instances of water reform implementation trajectories across the country is needed in order to shed some light onto the role played by particular initial conditions and local historical circumstance on the way the water reform was put into effect.

Second, the proposed explanations for features of the path and outcome of the water reform implementation may be challenged or refined by alternative 135 See, for instance, Il Sole 24 Ore, 18.11.2009. 
explanatory arguments. The acceleration of the implementation of the water reform, for example, is partially explained by the diffusion of policy ideas concerning liberalising, re-regulating, and privatising water service provision in a way akin to the experiences in Alto Valdarno. Although various works within political science discipline have highlighted the importance of ideas in politics and policy change (Blyth, 1997; Lieberman, 2003), other factors may have contributed to persuade reluctant local governments to surrender their control of water functions but the role played by advocates of liberalisation, re-regulation, and privatisation of water service provision. Also, the explanation for the tendency to award water franchises to "in house" firms highlights the role of 2003 legislation in affecting the menu of option choices for privatisation schemes. However, this explanation does not take into consideration how local governments first effectively "uploaded" the policy issue as to whether local public services should be always contracted out at the EU level (i.e., by bringing the "Teckal case" to the European Court of Justice) and later "cherry-picked" and "downloaded" policy solutions from the EU level to the domestic policy process in such a way that the 2003 legislation contained provisions that allowed them to escape from the mandate to privatise water services.

Third, more empirical evidence would be welcome on how local governments moved from inaction to inclination to implement the water reform. The historical narrative of water reform implementation does not provide details about how the policy community of water experts came to share the policy idea of liberalising, re-regulating, and privatising water service provision, how local 
governments were persuaded to consider liberalisation, re-regulation, and privatisation in their policy agendas, how political coalitions formed within local governments and between local governments, and how incumbent water firms affected the course of the water reform implementation efforts. Attention to such details, however, seems important in order to account for variety of water reform implementation trajectories at the local level. For example, the question of why only a fraction of OTA authorities awarded water franchises to mixed ownership water firms (i.e., about one third of water firms that were surveyed in 2009) deserves some further consideration, if we are to better understand what factors influence the decision to semi-privatise local water service provision.

Finally, the present case study lays the foundations for further research on the political economy of regulatory reforms in the implementation stage. The explanations for the trajectory of the water reform implementation in Italy provide some evidence for tentative generalised arguments about the process dynamics of regulatory reform implementation. Comparative research is needed, however, to better account for the role played by conditions that affect the situated interaction between implementers and target groups when they execute policy reform mandates. By contrasting and comparing the findings of the present case study to other cases of the same type of policy process - namely, implementation stage of policy cycles aimed at reforming the regulation of sectors of the economy - it would be possible to refine tentative generalised arguments about the role played by particular initial conditions, policy reform (content and process) features, and characteristics of the temporal context, including those that have been identified in 
the present case study.

Several dimensions for comparative analysis may be pursued. One possible dimension relates to expanding the empirical range towards instances of regulatory reform implementation that exhibit different features of the trajectory of the implementation process. For example, the present case may be contrasted and compared with others whose features of the implementation trajectory include "turning points" that relate to the slow down or to the radical diversion, rather than to the acceleration, of the reform implementation process. Another possible dimension relates to contrasting and comparing the present case study with others that exhibit different features of their system of governance, especially in relation to the degree of centralisation or decentralisation in the allocation of authoritative power across government layers. A further dimension for comparative analysis, finally, could be the one related to how sector-specific or country-specific context features affect the trajectory of regulatory reform implementation, especially whether the technical, economic, and territorial characteristics of the infrastructure policy domain and initial and historical conditions attached to the particular country environment bear any important effect on the way regulatory reforms are put into place. 


\section{Appendix}

\section{Data sources}

\section{Reports}

Associazione Nazionale Autorità ed Enti d'Ambito, Acqua (2007), per tutelare l'utente, rafforzare la regolazione pubblica. Un contributo alla revisione del D.lgs. $152 / 2006$. Rome, $11^{\text {th }}$ July.

Associazione Nazionale Autorità ed Enti d'Ambito (2008), Acqua in città. Nuovi servizi dalla rete idrica: esperienze ed innovazione. Milan, $25^{\text {th }}$ June.

ASTRID (2008) Infrastrutture e servizi a rete tra regolazione e concorrenza. Le infrastrutture idriche. Rome: Associazione per gli Studi e Ricerche sulal Riforma delle Istituzioni Democratiche e sull'innovazione nelle amministrazioni pubbliche. Rome.

Utilitatis (2007), Bluebook: I dati sul servizio idrico integrato in Italia. Rome: Utilitatis and ANEA.

Utilitatis (2008), Bluebook: I dati sul servizio idrico integrato in Italia. Rome: Utilitatis and ANEA.

Caselli R. and P. Peruzzi (1996), I servizi idrici: regolazione e riorganizzazione in Toscana. Milan: Franco Angeli.

CIPE (2002), Osservazioni relative al documento di consultazione sulla revisione del metodo normalizzato per la tariffazione del servizio idrico integrato. Unità Tecnica Finanza di Progetto. Rome.

CIPE (2002), Risorse idriche. Analisi di settore. Unità Tecnica Finanza di Progetto. Rome.

CISPEL Toscana (2001), Rapporto sui servizi pubblici in Toscana. Florence.

Comitato per la vigilanza sull'uso delle risorse idriche (1997-2009), Reports to the Parliament on the State of Water Services. Rome.

Comitato per la vigilanza sull'uso delle risorse idriche (2000), Audizione presso la VIII Commissione permanente (Ambiente, territorio e lavori pubblici) Camera dei Deputati. Rome, $12^{\text {th }}$ October. 
Comitato per la vigilanza sull'uso delle risorse idriche (2000), Audizione presso la XIII Commissione permanente (Ambiente, territorio e lavori pubblici) Senato della Repubblica. Rome, $18^{\text {th }}$ October.

Comitato per la vigilanza sull'uso delle risorse idriche (2001), Primo Rapporto sullo stato di avanzamento della legge 5 gennaio 1994, n. 36, April.

Comitato per la vigilanza sull'uso delle risorse idriche (2001), Rapporto sui Piani di Ambito, May.

Comitato per la vigilanza sull'uso delle risorse idriche (2001), Lo stato dei servizi idrici - Rapporto sulle ricognizioni, ex art. 11, comma 3, legge 36/94, disponibili al 31/01/01 sulle opere di adduzione, distribuzione, fognatura e depurazione, May.

Comitato per la vigilanza sull'uso delle risorse idriche (2001), I fabbisogni di investimenti e dinamica tariffaria nei primi piani di ambito. Rome, June.

Comitato per la vigilanza sull'uso delle risorse idriche (2001), Rapporto sullo stato degli impianti: analisi delle ricognizioni. Sintesi del rapporto. Rome, June.

Comitato per la vigilanza sull'uso delle risorse idriche (2001), Servizio idrico integrato: ricognizioni degli impianti e primi piani d'ambito. Rome, $7^{\text {th }}$ June.

Comitato per la vigilanza sull'uso delle risorse idriche (2001), The State and the Reform of Water Services, Memorandum for the OECD ERP Mission. $25^{\text {th }}$ September.

Comitato per la vigilanza sull'uso delle risorse idriche (2001), Documento di consultazione sulla revisione del metodo normalizzato per la tariffazione del servizio idrico integrato. Rome, November.

Comitato per la vigilanza sull'uso delle risorse idriche (2001), Audizione presso la VIII Commissione permanente (Ambiente, territorio e lavori pubblici) Camera dei Deputati. Rome, $18^{\text {th }}$ December.

Comitato per la vigilanza sull'uso delle risorse idriche (2001), Relazione tecnica riguardante la raccomandazione 1/2001. Rome.

Comitato per la vigilanza sull'uso delle risorse idriche (2002), Incontro con la Conferenza dei Presidenti delle Regioni e delle Province autonome. Rome, $9^{\text {th }}$ January.

Comitato per la Vigilanza sull'Uso delle Risorse Idriche (2002), Proposta al Ministro dell'ambiente e della tutela del territorio di revisione del D.M. 1 Agosto 1996: Metodo normalizzato per definire le componenti di costo e determinare la tariffa di riferimento del servizio idrico integrato. Rome, $23^{\text {rd }}$ May. 
Comitato per la vigilanza sull'uso delle risorse idriche (2002), Lo stato dei servizi idrici - Secondo rapporto sulle ricognizioni disponibili al 31/12/02, sulle opere di adduzione, distribuzione, fognatura e depurazione, May.

Comitato per la vigilanza sull'uso delle risorse idriche (2002), La convenzione tipo del servizio idrico integrato nella legislazione e nella normativa regionale, November.

Comitato per la vigilanza sull'uso delle risorse idriche (2003), Lo stato dei servizi idrici: secondo rapporto sulle ricognizioni disponibili al 31/12/2002, sulle opere di adduzione, distribuzione, fognatura e depurazione. Rome, May.

Comitato per la vigilanza sull'uso delle risorse idriche (2003), Secondo Rapporto sullo stato di avanzamento della legge 5 gennaio 1994, n.36, July.

Comitato per la vigilanza sull'uso delle risorse idriche (2004), II rapporto sui piani d'ambito. Rome, March.

Comitato per la vigilanza sull'uso delle risorse idriche (2004), Secondo rapporto sui Piani di Ambito, May.

Comitato per la vigilanza sull'uso delle risorse idriche (2004), Terzo Rapporto sullo stato di avanzamento della legge 5 gennaio 1994, n.36, July.

Comitato per la vigilanza sull'uso delle risorse idriche (2005), Audizione presso la VIII Commissione permanente (Ambiente, territorio e lavori pubblici) Camera dei Deputati. Rome, $10^{\text {th }}$ March.

Comitato per la vigilanza sull'uso delle risorse idriche (2005), Sistema di rendicontazione sul Servizio Idrico Integrato. Documento di Consultazione. January.

Federgasacqua (renamed Federutility since 2005) (1989-2009), Proceedings of the conference H2Obiettivo 2000, Rome.

Proaqua (1995), Struttura della regolamentazione economica in applicazione della legge 36/94. Paper n. 95/01.

Proaqua (1995), La remunerazione del capitale investito nel quadro della determinazione delle tariffe idriche: alcune riflessioni. Paper n. 95/02.

Proaqua (1996), Efficienza e produttività nel settore idrico. Paper n. 96/03.

Proaqua (1996), Note sul contenuto dell'AMP2. Paper n. 96/04. 
Proaqua (1996), L'attività di controllo sulla gestione dei servizi idrici. Paper $n$. 96/05.

Proaqua (1996), L'OFWAT e l'attività di tutela del consumatore. Paper n. 96/06.

Proaqua (1996), Le tariffe dei servizi idrici. Paper n. 96/07.

Proaqua (1997), Note sulla salvaguardia, coordinamento e integrazione di funzioni (ex art. 9, comma 4, legge 36/94). Paper n. 97/08.

Proaqua (1997), La struttura tariffaria dei servizi di acquedotto, fognatura e depurazione. Paper n. 97/09.

Proaqua (1997), Studio di fattibilità sull'attuazione della legge 5.1.1994, n. 36. Paper n. 97/11.

Proaqua (1997), la regolamentazione dei servizi idrici: il problema della revisione delle tariffe. Paper n. 97/12.

Proaqua (1998), Livelli di servizio - descrizione, analisi e commmento dei livelli di servizio per i piani delle autorità d'ambito. Paper n. 98/15.

Proaqua (1998), Servizi idrici tra regolazione e mercato. Paper n. 98/19.

Proaqua (1998), Prospettive di riforma dell'industria del gas: aspetti teorici e implicazioni operative. Paper n. 98/21.

Proaqua (1998), La legislazione regionale in materia di servizi idrici. Paper n. $98 / 22$.

Proaqua (1999), La legislazione regionale in materia di servizi idrici. Paper $n$. 99/28.

Proaqua (1999), Aspetti economico-finanziari della regolazione dei servizi pubblici locali. Paper n. 99/30.

Proaqua (1999), Le implicazioni operative dell'affidamento mediante gara nella fornitura dei servizi pubblici locali. Paper n. 99/31.

Proaqua (2001), Il finanziamento degli investimenti nel settore idrico. Paper $\mathrm{n}$. $01 / 37$.

Proaqua (2001), Processi di riorganizzazione industriale e liberalizzazione dei servizi pubblici locali: problemi e prospettive. Paper no. 01/39.

Proaqua (2001), La selezione mediante gara del fornitore di un servizio pubblico 
locale. Paper n. 01/40.

Proaqua (2001), Competizione ed accesso nei settori a rete: la tariffazione delle essential facilities nella esperienza italiana. Paper n. 01/41.

Proaqua (2001), Regolazione e controllo nella convenzione di gestione del servizio idrico integrato. Paper n. 01/43.

SOGESID (1999), Acqua e regioni meridionali: stato di fatto, problemi e prospettive. Incontro di lavoro su Imprese e risorsa idrica nel Mezzogiorno: soggetti industriali, lavoro e spesa pubblica. CNEL, Roma, $25^{\text {th }}$ June.

\section{Interviews}

Francesco Bosco, manager ACEA, September 2001, Rome.

Valter Pallano, manager AMGA, October 2001, Genoa.

Enrico Asquer, manager ESAF, December 2001, Cagliari.

Renato Drusiani, Chairman Federgasacqua, June 2002, Rome.

Prof. Gilberto Muraro, Chairman Supervising Committee on the Use of Water Resources, July 2002, Rome.

Giancarlo Galli, former Christian Democrat MP, former member of the Supervising Committee on the Use of Water Resources, October 2002, Mozzate (Como).

Stefano Cima, researcher, Istituto Ricerca Sociale, October 2002, Milan.

Renato Cocchi, member of the Supervising Committee on the Use of Water Resources, October 2002, Rome.

Paolo Peruzzi, member of the Supervising Committee on the Use of Water Resources, October 2002, Rome.

Luciano Baggiani, Chairman Associazione Nazionale Autorità ed Enti d'Ambito, October 2008 (phone).

Prof. Angelo Nardozza, Chairman OTA “Basilicata” Authority, April 2009 (phone).

Diomira Cretti, General Manager OTA “Lodi” Authority, April 2009 (email).

Alessandro Piotti, Manager OTA “Lazio 2” Authority, April 2009 (email).

Carlo Robutti, General Manager OTA “Piemonte 2" Authority, April 2009 (email). 
Giovanni Gravante, General Manager OTA "Savonese" Authority, April 2009 (email).

Marisa Abbondanzieri, General Manager OTA "Marche Centro - Ancona" Authority, April 2009 (email).

Carlo Casadei, General Manager OTA “Rimini” Authority, April 2009 (email).

Marco Moselli, General Manager OTA “Bologna” Authority, April 2009 (email).

Claudio Boldori, General Manager OTA “Cremona” Authority, April 2009 (email).

Francesco Peri, Manager OTA “Mantova” Authority, April 2009 (email).

\section{Press}

\subsection{Articles from Il Sole 24 Ore:}

$21.02 .1990, \quad 13.07 .1990, \quad 26.09 .1990, \quad 17.10 .1990, \quad 20.10 .1990, \quad 28.10 .1990$, 21.02.1991， 06.02.1991， 07.03.1991， 06.03.1991， 12.04.1991， 07.04.1991, 11.05.1991, 15.06.1991, 18.07.1991, 15.07.1991, 23.08.1991, 25.10.1991, 13.11.1991, 14.11.1991

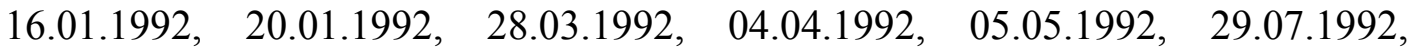
27.09.1992, 07.10.1992

04.02.1993, 03.03.1993, 03.04.1993， 06.04.1993，07.04.1993， 12.05.1993, 14.05.1993, 19.05.1993, 28.05.1993, 17.05.1993, 30.06.1993, 23.08.1993, 10.09.1993, 07.09.1993, 10.10.1993, 18.10.1993, 23.12.1993

27.01.1994, 07.01.1994, 20.02.1994, 03.03.1994, 27.04.1994, 10.04.1994, 27.05.1994, 20.06.1994, 19.07.1994, 11.09.1994, 06.10.1994, 25.10.1994, 14.11.1994, 28.12.1994

27.02 .1995

12.01.1996, 26.02.1996, 27.02.1996, 26.03.1996, 27.03.1996, 10.04.1996, 16.04.1996, 17.04.1996, 24.04.1996, 01.05.1996, 25.05.1996, 27.05.1996, 31.05.1996, 26.06.1996, 27.06.1996, 13.07.1996, 19.07.1996, 03.08.1996, 06.08.1996, 09.08.1996, 15.08.1996, 28.08.1996, 19.09.1996, 03.10.1996, 18.10.1996, 31.10.1996, 11.12.1996, 13.12.1996, 14.12.1996

22.01.1997, 25.01.1997, 27.01.1997, 28.01.1997, 12.02.1997, 13.02.1997, 14.02.1997, 20.02.1997, 28.02.1997, 19.03.1997, 24.03.1997, 26.03.1997, 
27.03.1997, 02.04.1997, 05.04.1997, 09.04,1997, 10.04.1997, 14.04.1997, 16.04.1997, 17.04.1997, 23.04.1997, 24.04.1997, 26.04.1997, 12.05.1997, 30.05.1997, 12.06.1997, 17.06.1997, 20.06.1997, 08.07.1997, 30.08.1997, 02.08.1997, 14.09.1997, 20.09.1997, 08.10.1997, 29.11.1997, 24.11.1997, 25.11.1997

09.01.1998, 29.01.1998, 11.02.1998, 20.04.1998. 29.04.1998, 28.07.1998, 10.08.1998, 14.08.1998, 19.09.1998, 10.10.1998, 19.11.1998, 18.11.1998, 23.11.1998, 26.11.1998, 30.11.1998, 04.12.1998, 05.12.1998, 08.12.1998

$\begin{array}{llllll}16.01 .1999, & 20.01 .1999, & 21.01 .1999, & 25.01 .1999, & 02.02 .1999, & 15.02 .1999,\end{array}$ 24.02.1999, $02.03 .1999, \quad 04.03 .1999, \quad 18.03 .1999, \quad 19.03 .1999, \quad 31.03 .1999$, 10.04.1999, 22.04.1999, 26.04.1999, 28.04.1999, 18.05.1999, 19.05.1999, 11.06.1999, 14.06.1999, 21.06.1999, 29.06.1999, 30.06.1999, 01.07.1999, 06.07.1999, 12.07.1999, 19.07.1999, 02.08.1999, 10.08.1999, 31.08.1999, 02.09.1999, $05.09 .1999, \quad 22.09 .1999, \quad 24.09 .1999, \quad 01.10 .1999, \quad 08.10 .1999$, 20.10.1999, 24.10.1999, 06.11.1999, 17.11.1999, 27.11.1999, 09.12.1999, 15.12.1999

19.01.2000, 26.01.2000, 28.01.2000, 02.02.2000, 05.02.2000, 21.02.2000, 22.02.2000, 08.03.2000, 11.03.2000, 20.03.2000, 21.03.2000, 04.04.2000, 05.04.2000, 22.04.2000, 06.05.2000, 08.05.2000, 12.05.2000, 20.06.2000, 06.07.2000, 22.07.2000, 05.08.2000, 26.08.2000, 29.08.2000, 30.08.2000, $31.08 .2000, \quad 01.09 .2000, \quad 04.09 .2000, \quad 27.09 .2000, \quad 09.10 .2000, \quad 26.10 .2000$, 09.11.2000, 09.12.2000, 19.12.2000, 20.12.2000, 27.12.2000

08.01.2001， 11.01.2001， 19.01.2001，24.01.2001， 12.03.2001， 13.03.2001， 23.03.2001，28.03.2001，19.04.2001，22.04.2001，23.04.2001，24.04.2001, 27.04.2001， 29.04.2001， 09.05.2001，31.05.2001， 06.06.2001， 13.06.2001, 25.06.2001， 13.07.2001， 14.07.2001， 18.07.2001， 23.07.2001， 27.07.2001, 03.08.2001，11.08.2001，13.08.2001，14.08.2001，28.08.2001，06.09.2001， 07.09.2001, 19.09.2001，24.09.2001，29.09.2001，30.09.2001， 08.10.2001, 09.10.2001, 19.10.2001, 27.10.2001，28.10.2001，28.11.2001，29.11.2001, 01.12.2001, 05.12.2001, 17.12.2001, 19.12.2001, 29.12.2001

$06.01 .2002, \quad 08.01 .2002, \quad 09.01 .2002, \quad 14.01 .2002, \quad 16.01 .2002$ $13.02 .2002, \quad 22.02 .2002, \quad 23.02 .2002,01.03 .2002,-05.03 .2002,-06.03 .2002$,

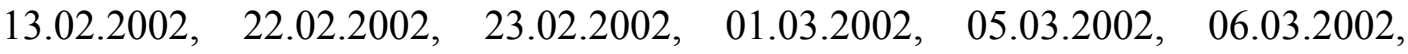
08.03.2002，10.03.2002，11.03.2002，15.03.2002，18.03.2002， 27.03.2002， 03.04.2002, $06.04 .2002, \quad 10.04 .2002, \quad 18.04 .2002, \quad 23.04 .2002, \quad 25.04 .2002$, 26.04.2002, 30.04.2002, $01.05 .2002, \quad 06.05 .2002 ， \quad 10.05 .2002 ， \quad 16.05 .2002$, 17.05.2002， 19.05.2002，20.05.2002，22.05.2002，24.05.2002，25.05.2002, 27.05.2002，31.05.2002，05.06.2002，06.06，2002，08.06.2002， 10.06.2002,

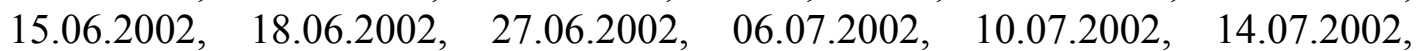

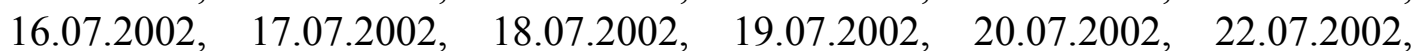
25.07.2002， 03.08.2002， 09.08.2002， 10.08.2002， 12.08.2002， 07.09.2002,

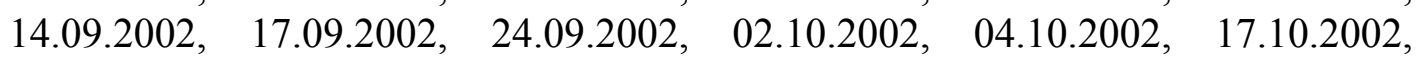


23.10.2002, 26.10.2002, 21.11.2002, 22.11.2002, 23.11.2002, 27.11.2002, 28.11.2002, 29.11.2002, $07.12 .2002, \quad 08.12 .2002, \quad 10.12 .2002, \quad 13.12 .2002$, $14.12 .2002,17.12 .2002,18.12 .2002,20.12 .2002,27.12 .2002$

11.01.2003, 14.01.2003, 30.01.2003, 04.02.2003， 07.02.2003， 10.02.2003, $12.02 .2003, \quad 15.02 .2003, \quad 22.02 .2003, \quad 26.02 .2003, \quad 01.03 .2003, \quad 05.03 .2003$, 06.03.2003, $07.03 .2003, \quad 10.03 .2003, \quad 14.03 .2003, \quad 15.03 .2003, \quad 16.03 .2003$, $21.03 .2003, \quad 22.03 .2003, \quad 29.03 .2003, \quad 03.04 .2003, \quad 07.04 .2003, \quad 12.04 .2003$, $14.04 .2003, \quad 23.04 .2003, \quad 25.04 .2003, \quad 26.04 .2003, \quad 29.04 .2003, \quad 09.05 .2003$, $15.05 .2003, \quad 16.05 .2003,23.05 .2003,24.05 .2003,27.05 .2003,13.06 .2003$, 28.06.2003, 29.06.2003, 01.07.2003, 11.07.2003, 12.07.2003, 14.07.2003, 16.07.2003, 19.07.2003, 22.07.2003, 23.07.2003, 25.07.2003, 27.07.2003, $29.07 .2003, \quad 01.08 .2003,12.08 .2003,15.08 .2003,18.08 .2003, \quad 23.08 .2003$, $20.09 .2003, \quad 21.09 .2003, \quad 25.09 .2003, \quad 05.10 .2003, \quad 07.10 .2003, \quad 11.10 .2003$, $13.10 .2003, \quad 14.10 .2003, \quad 16.10 .2003, \quad 23.10 .2003, \quad 25.10 .2003, \quad 31.10 .2003$, 03.11.2003, 11.11.2003, 12.11.2003, 13.11.2003, 16.11.2003, 20.11.2003, 19.12.2003, 22.12.2003, 23.12.2003

05.01.2004, 31.01.2004, 12.02.2004, 17.02.2004, 04.03.2004, 11.03.2004, 13.03.2004, 22.04.2004, 28.04.2004, 01.05.2004, 10.05.2004, 12.05.2004, 15.05.2004, 25.05.2004, 09.06.2004, 16.06.2004, 18.06.2004, 06.07.2004, 07.07.2004, 12.07.2004, 21.07.2004, 23.07.2004, 29.07.2004, 04.08.2004, 06.08.2004, 18.08.2004, 06.09.2004, 08.09.2004, 10.09.2004, 24.09.2004, 29.09.2004, 06.10.2004, 10.10.2004, 15.10.2004, 05.11.2004, 11.11.2004, 14.11.2004, 16.11.2004, 05.12.2004, 06.12.2004, 20.12.2004, 22.12.2004, 23.12.2004

04.01.2005, 10.01.2005, 12.01.2005, 17.01.2005, 21.01.2005, 22.01.2005, $31.01 .2005, \quad 03.02 .2005, \quad 16.02 .2005, \quad 19.02 .2005, \quad 07.03 .2005, \quad 14.03 .2005$,

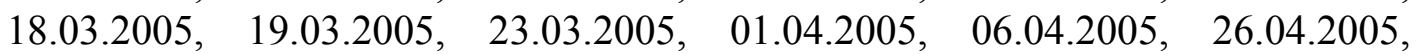
$30.04 .2005, \quad 01.05 .2005, \quad 14.05 .2005, \quad 28.05 .2005, \quad 30.05 .2005, \quad 13.06 .2005$, 05.07.2005, 08.07.2005, 13.07.2005, 10.08.2005, 21.08.2005, 22.08.2005, 03.09.2005, 05.09.2005, 06.10.2005, 16.11.2005, 28.11.2005, 15.12.2005, 22.12.2005, 23.12.2005, 27.12.2005

19.01.2006, 25.01.2006, 26.01.2006, 28.01.2006, 30.01.2006, 08.02.2006, 14.02.2006, 22.02.2006, 14.03.2006, 17.03.2006, 31.03.2006, 29.04.2006, 03.05.2006, 18.05.2006, 20.05.2006, 29.05.2006, 08.06.2006, 25.06.2006, 27.06.2006, 30.06.2006, 01.07.2006, 07.07.2006, 12.07.2006, 20.07.2006, 26.07.2006, 29.07.2006, 30.07.2006, 07.08.2006, 08.08.2006, 14.08.2006, 06.09.2006, 07.09.2006, 18.10.2006, 23.10.2006, 27.10.2006, 18.12.2006, 30.12 .2006

\subsection{Articles from La Repubblica:}

20.04.1990 
12.11 .1993

22.05.1995, 03.08.1995, 15.08.1995

27.02.1996, 19.06.1996, 19.09.1996, 05.11.1996

17.03.1997, 10.08.1997

06.09.1999, 20.09.1999, 05.10.1999

08.02.2000, 12.02.2000, 15.03.2000, 30.03.2000, 16.04.2000, 16.06.2000, 20.06.2000, 09.09.2000, 21.12.2000

10.02.2001, 01.06.2001, 19.08.2001, 07.09.2001, 30.10.2001, 14.11.2001

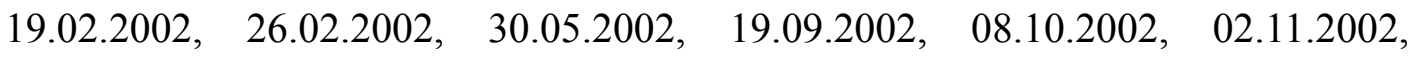
16.11.2002, 14.12.2002, 31.12.2002

04.02.2003, 21.02.2003, 22.02.2003, 08.03.2003， 15.03.2003， 06.07.2003, 09.07.2003, 14.07.2003, 15.07.2003, 20.12.2003

04.03.2004, 18.08.2004, 19.08.2004

04.02.2005, 09.07.2005, 20.07.2005, 14.11.2005, 28.12.2005

02.02.2006, 01.03.2006, 21.07.2006, 22.11.2006

\section{Coding Frame}

Events

1. Episode events

1. Aligning regional legislation to the water reform

1. Negotiating OTA boundaries

2. Drafting regional legislation bills

3. Approving regional laws

2. Establishing the OTA authorities

1. Negotiating with sub-national governments

2. Drafting establishment contracts

3. Establishing the local regulatory authorities

3. Awarding water concessions

1. Mapping the installed water infrastructure

2. Planning water infrastructure development and tariff

3. Deciding the form of award of the water concessions 
4. Tendering out the water concessions

5. Tendering out the minority share of water firms

6. Directly assigning the water concession

2. Previous events

1. Making the water reform

3. Contemporaneous events

1. Implementing the 1994-2000 CSF

2. Implementing the 2000-2006 CSF

3. Implementing EU directive $91 / 271 / \mathrm{CE}$

4. Making the 2001 local public services reform

5. Making the 2003 local public services reform

6. Making the 2001 constitutional reform

7. Adjudicating local public services trials (ECJ)

8. Implementing EU directive 2001/60/CE

Entities

1. Central government

2. Minister of Public Works

3. Minister of the Environment and Safeguard of the Territory

4. Regions

5. Local governments

6. Supervising Committee on the Use of Water Resources

7. Water firms

1. Local governments' direct water undertakings

2. Local governments' water consortia

3. Local government-owned water firms

4. Local government majority-owned water firms

5. Water business companies

8. Water firms' associations

1. Federgasacqua (later renamed Federutility from 2005)

2. ANIDA (national association of sewage and wastewater treatment business companies)

3. ANFIDA (national association of aqueduct companies)

9. Local regulatory authorities (OTA authorities)

10. CIPE (Inter-ministerial committee on economic planning)

11. European Court of Justice

12. Regional administrative courts

13. Constitutional court

Interests

1. Accomplishing water reform implementation tasks

2. Spending water infrastructure development funds

3. Appropriating water infrastructure development funds

4. Maintaining control on water planning and management functions

5. Protecting incumbents' position in the water industry

6. Maintaining current water tariff levels 
7. Opening new entrants' access to the water industry

8. Attracting private operators and investors to the water industry

9. Increasing water tariff levels 


\section{Bibliography}

Agranoff R. and M. McGuire (1999), "Managing in Network Settings", Policy Studies Review, 16(1): 18-41.

Agranoff R. and M. McGuire (2001), "Big Questions in Public Network Management Research", Journal of Public Administration Research and Theory, 11(3)295-326.

Alexander I. and T. Irwin (1996), "Price Caps, Rate-of-Return Regulation, and the Cost of Capital”, Public Policy for the Private Sector, Sept., note No. 87.

Amato A. and M. Conti (2005), The Economics of the Water Industry: Technology, Ownership, and Efficiency. Milan: Franco Angeli.

Antonioli B. (2006), "Le procedure di affidamento del servizio idrico integrato in Italia: esiste un disegno di gara?", Economia delle Fonti di Energia e dell'Ambiente, 3.

Anwandter L. and P. Rubino (2006a), "Perché la finanza privata asseta il settore idrico? Sette proposte per sette regioni", Mercato, Concorrenza, e Regole. 1: 197228.

Anwandter L. and P. Rubino (2006b), "Rischi, incertezze e conflitti d'interesse nel settore idrico italiano: analisi e proposte di riforma", Matriali Unità di Valutazione degli Investimenti Pubblici. Rome.

Armstrong M., S. Cowan and J. Vickers (1999), Regulatory Reform: Economic Analysis and British Experience. Cambridge, MA: MIT Press.

Averch H. and L. L. Johnson (1962), "Behavior of the Firm under Regulatory Constraint", The American Economic Review, 52(5): 1052-1069.

Axelrod R. (1984), The Evolution of Cooperation. New York: Basic Books.

Baggiani L. (2003), "L'esperienza delle autorità di ATO nella riforma del servizio idrico in Toscana", paper presented at the conference "L'acqua bene comune. L'esperienza della Toscana", Florence, March 10.

Baldwin R. and M. Cave (1999), Understanding Regulation: Theory, Strategy, and Practice. Oxford: Oxford University Press.

Baldwin R., C. Scott and C. Hood (1998), A Reader on Regulation. Oxford: Oxford 
University Press.

Ballance A. and A. Taylor (2005), Competition and Economic Regulation in Water: The Future of the European Water Industry. IWA Publishing.

Bardach E. (1977), The Implementation Game. Cambridge. MA: MIT Press.

Barraqué B. (1995), Les politiques de l'eau en Europe. La Découverte, Paris.

Barrett S. M. (2004), "Implementation Studies: Time for a Revival? Personal Reflections on 20 Years of Implementation Studies", Public Administration, 82(2): 249-262.

Barrett S. and C. Fudge (eds) (1981), Policy and Action: Essays on the Implementation of Public Policy. London: Methuen.

Barzelay M. (2003), "Introduction: The Process Dynamics of Public Management Policymaking”. International Public Management Journal, 6(3): 251-282.

Barzelay M. and N. Fuechtner (2003), "Explaining Public Management Policy Change: Germany in Comparative Perspective", Journal of Comparative Policy Analysis, 5, 7-27.

Barzelay M. and R. Gallego (2006), "From "New Institutionalism" to "Institutional Processualism". Advancing Knowledge about Public Management Policy Change". Governance, 19(4): 531-557.

Barzelay M. and R. Gallego (2010a), "The Comparative Historical Analysis of Public Management Policy Cycles in France, Italy, and Spain: Symposium Introduction", Governance, 23(2): 209-223.

Barzelay M. and R. Gallego (2010b), "The Comparative Historical Analysis of Public Management Policy Cycles in France, Italy, and Spain: Symposium Conclusion", Governance, 23(2): 297-307.

Barzelay M. and A. S. Jacobsen (2009), "Theorizing Implementation of Public Management Policy Reforms: A Case Study of Strategic Planning and Programming in the European Commission", Governance, 22(2): 319-334.

Bates R. H., A. Greif, M. Levi, J.-L. Rosenthal, and B. R. Weingast (1998), Analytic Narratives. Princeton, NJ: Princeton University Press.

Bates R. H., A. Greif, M. Levi, J.-L. Rosenthal, and B. R. Weingast (2000), "The Analytic Narrative Project”, American Political Science Review, 94(3): 696-702.

Baumgartner F. R. and B. J. Jones (1993), Agendas and Instability in American 
Politics. Chicago: University of Chicago Press.

Baumol W. J. (1982), "Contestable Markets: An Uprising in the Theory of Industry Structure", The American Economic Review, 72(1): 1-15.

Beecher J. A. (2001), "Privatization, Monopoly, and Structured Competition in the Water Industry: Is there a role for regulation?", in F. Holzwarth and R.A. Kraemer (eds), Umweltaspekte einer Privatisierung der Wasserwirtschaft in Deutschland: Dokumentation der internationalen Fachtagungvom 20 und 21. Berlin: Books on Demand.

Beesley M. E. and S. C. Littlechild (1989), "The Regulation of Privatized Monopolies in the United Kingdom”, Rand Journal of Economics, 20(3): 454-472.

Bel G. and X. Fageda (2007), "Factors explaining local privatisation: a metaregression analysis", Public Choice, 139(1/2): 105-119.

Bel G. and X. Fageda (2009), "Why do local governments privatize public services? A survey of empirical analysis", Local Government Studies, 33(4): 517534.

Bennett A. and A. L. George (1997), "Process Tracing in Case Study Research", paper presented at the MacArthur Foundation Workshop on Case Study Methods, Belfer Center for Science and International Affairs (BCSIA), Harvard University, October 17-19.

Berman P. (1978), "The Study of macro- and Micro-Implementation", Public Policy, 26(2): 157-84.

Bigatti G., A. Giuntini, A. Mantegazza, and C. Rotondi (1997), L'Acqua ed il gas in Italia. Milan: Franco Angeli.

Bishop S. and M. Walker (1999), The Economics of EC Competition Law: Concepts, Application and Measurement. London: Sweet and Maxwell.

Bishop M., J. Kay and C. Mayer (eds) (1995), The Regulatory Challenge. Oxford: Oxford University Press.

Blom-Hansen J. (2005), "Principals, Agents, and the Implementation of EU Cohesion Policy", Journal of European Public Policy, 12(4): 624-648.

Blyth M. M. (1997), “'Any More Bright Ideas?' The Ideational Turn of Comparative Political Economy", Comparative Politics, 29(2): 229-250.

Bogason P. and T. A. J. Toonen (1998), "Introduction: Networks in Public Administration", Public Administration, 76: 205-227. 
Boland L. A. (1981), "On the Futility of Criticizing the Neoclassical Maximization Hypothesis", American Economic Review, 71(5): 1031-1036.

Borgatti S. P. and P. C. Foster (2003), "The Network Paradigm in Organizational Research: A Review and Typology", Journal of Management, 29(6): 991-1013.

Borgonovi E. (1996), Principi e sistemi aziendali per le amministrazioni pubbliche, $5^{\text {th }}$ ed. Milan: Egea.

Börzel T. A. (1998a), "Organizing Babylon - on the Different Conceptions of Policy Networks", Public Administration, 76: 253-273.

Börzel T. A. (1998b), "Shifting or sharing the burden? The implementation of EU environmental policy in Spain and Germany", European Planning Studies, 6(5): 537-553.

Börzel T. A. (2000), "Why there is no 'Southern Problem'. On Environmental Leaders and Laggards in the European Union", Journal of European Public Policy, 7(1): 141-162.

Börzel T. A. (2001), "Non-compliance in the European Union: Pathology or Statistical Artefact?", Journal of European Public Policy, 8(5): 803-824.

Brown A. C., J. Stern, and B. W. Tenenbaum (2006), Handbook for Evaluating Infrastructure Regulatory Systems. Washington, The World Bank.

Browne A. and A. Wildavsky (1983), "Implementation as Mutual Adaptation", in J. Pressman and A. Wildavsky, Implementation. Berkeley: University of California Press, 206-231.

van Bueren E. M., E.-H. Klijn, and J. F. M. Koppenjan (2003), "Dealing with Wicked Problems in Networks: Analyzing an Environmental Debate from a Network Perspective", Journal of Public Administration Research and Theory, 13(2): 193-212.

Bunker D. R. (1972), "Policy Sciences Perspectives on Implementation Processes", Policy Sciences, 3(1): 71-80.

Caravita B. (1990), Il diritto pubblico dell'ambiente. Bologna: Il Mulino.

Carrozza C. (2008), "La riforma italiana dei servizi idrici: modi locali di governo fra continuità e rottura", Rivista Italiana di Politiche Pubbliche, 1(April): 5-36.

Castelli Avolio G. (1936), Commento alle leggi sulle acque e sugli impianti elettrici. Naples: Jovene. 
Cejudo G. (2003), "Public Management Policy Change in Mexico", International Public Management Journal, 6: 309-326.

Cgiamestre (2011), "Tariffe: acqua e rifiuti quelle aumentate di più", available at http://www.cgiamestre.com/wp-content/uploads/2011/07/TAR.doc.

Christoffersen H. and M. Paldam (2003), "Markets and municipalities: a study of the behavior of the Danish municipalities", Public Choice, 114(2): 79-102.

Citroni G. and A. Lippi (2006), "La politica di riforma dei servizi idrici. Istituzioni, processi, e poste in gioco", Regione e governo locale: Le istituzioni del federalismo, 2: $239-275$.

Citroni G., N. Giannelli, A. Lippi, and S. Profeti (2007), “'Chi governa l'acqua?': regolazione, potere locale, e arene di rappresentanza nella governance del servizio idrico integrato", SISP Conference, Catania, September 20-22.

Cittadinanzattiva (2011), "Dossier sul servizio idrico integrato", available at http://www.cittadinanzattiva.it/relazioni-annuali/doc_download/74-dossier-sulservizio-idrico-integrato-2010.html.

Cole A. and P. John (2001), Local Governance in England and France, New York: Routledge.

Coleman J. S. (1986), "Social Theory, Social Research, and a Theory of Action", The American Journal of Sociology, 91(6): 1309-1335.

Coleman J., E. Katz, and H. Menzel (1957), "The Diffusion of an Innovation Among Physicians", Sociometry, 20(4): 253-270.

Connelly F. M. and D. J. Clandinin (1990), "Stories of Experience and Narrative Inquiry", Educational Researcher, 19(5): 2-14.

Cook P., C. Kirkpatrick, M. Minogue and D. Parker (eds) (2004), Competition and Regulation in Developing Countries. Cheltenham: Edward Elgar.

Corbett A. (2010), "Public Management Policymaking in France: Legislating the Organic Law on Laws of Finance (LOLF), 1998-2001", Governance, 23(2): 225249.

Cowen T. (1998), "Do Economists Use Social Mechanisms to Explain?", in P. Hedström and R. Swedberg (eds), Social Mechanisms: An Analytical Approach to Social Theory, Cambridge: Cambridge University Press, 125-146.

Danesi L., M. Passarelli, and P. Peruzzi (2008), "Which tier of government should 
regulate water services?", Mercato, Concorrenza, Regole, 2(August): 389-416.

Daugbjerg C. (1998), "Linking Policy Networks and Environmental Policies: Nitrate Policy Making in Denmark and Sweden 1970-1995", Public Administration, 76: 275-294.

DeLeon P. (1999), “The Missing Link Revisited: Contemporary Implementation Research", Policy Studies Review, 16(3/4): 311-338.

DeLeon P. and L. DeLeon (2002), "What Ever Happened to Policy Implementation? An Alternative Approach", Journal of Public Administration Research and Theory, 12(4): 467-492.

Demsetz H. (1968), "Why Regulate Utilities?", Journal of Law and Economics, 11(April): 55-66.

Dinar A. (2000), The Political Economy of Water Pricing Reforms. Washington, DC: The International Bank for Reconstruction and Development/The World Bank.

Doern G. B. (2003), "Improving Regulatory Relations in Multi-level Governance: Principles and Mechanisms", OECD Expert Meeting on Regulatory Cooperation between Levels of Government, Paris, June 30-July 1.

Doern G. B. and R. Johnson (2006), Rules, Rules, Rules, Rules: Multilevel Regulatory Governance. University of Toronto Press.

Doern G. B. and S. Wilks (1996), Comparative Competition Policy: National Institutions in a Global Market. Oxford: Oxford University Press

Donahue J. D. (1989), The Privatization Decision: Public Ends, Private Means. New York: Basic Books.

Dror Y. (1968), Public Policymaking Reexamined. San Francisco: Chandler.

Drusiani R. and G. Nilberto (2001), "Il ruolo del gestore-impresa per una nuova politica industriale nell'ambito del servizio idrico integrato", Conference H2Obiettivo 2000, Bari, October 25-26.

Drusiani R., R. Fazioli, A. Massarutto, and P. Matino (2004), Regolazione e Ristrutturazione del Servizio Idrico Italiano. Bologna: Clueb.

Dunleavy P. (1985), "Bureaucrats, Budgets, and the Growth of the State: Reconstructing an Instrumental Mode", British Journal of Political Science, 15(3): 299-328.

Dunsire A. (1978), Implementation in a Bureaucracy. Oxford: Martin Robertson. 
Durant R. F. (1984), "EPA, TVA and Pollution Control: Implications for a Theory of Regulatory Policy Implementation", Public Administration Review, 44(4): 305-313.

Eberlein B. (2000), "Institutional change and continuity in German infrastructure management: the case of electricity reform", German Politics, 9(3): 81-104.

Eberlein B. and E. Grande (2000), "Regulation and Infrastructure Management: German Regulatory Regimes and the EU Framework", German Policy Studies, 1(1): $1-18$.

Economides N. and L. J. White (1994), "Networks and Compatibility: Implications for Antitrust", European Economic Review, 38: 651-662.

Eisner M. A. (2000), Regulatory Politics in Transition. Baltimore: The Johns Hopkins University Press.

Elazar D. J. (2005), "Contrasting Unitary and Federal Systems", International Political Science Review, 18(3): 237-251.

Elmore R. F. (1979), "Backward Mapping: Implementation Research and Policy Decisions", Political Science Quarterly, 94(4), 601-616.

Elster J. (1998), "A Plea for Mechanisms", in P. Hedström and R. Swedberg (eds), Social Mechanisms: An Analytical Approach to Social Theory, Cambridge: Cambridge University Press. 45-73.

Emirbayer M. and A. Mische (1998), "What is Agency?", American Journal of Sociology, 103(4): 962-1023.

Ermano P. (2012), Gli investimenti nel servizio idrico in Italia: un'analisi storica. Università degli Studi di Udine, Dipartimento di Scienze Economiche e Statistiche, Working paper No. 3.

Estache A. (2001), "Privatization and regulation of transport infrastructure in the 1990s", The World Bank Research Observer, 16(1): 85-107.

Estache A. (2003) "On Latin America's Infrastructure Privatization and its Distributional Effects", Available at SSRN: http://ssrn.com/abstract=411942 or http://dx.doi.org/10.2139/ssrn.411942.

Farrell J. and C. Shapiro (1988), "Dynamic Competition with Switching Costs", The RAND Journal of Economics, 19(1): 123-137.

Farrell J. and C. Shapiro (1989), "Optimal Contracts with Lock-in", The American Economic Review, 79(1): 51-68. 
Ferris J. M. (1986), "The decision to contract out: an empirical analysis", Urban Affairs Quarterly, 22: 289-331.

Ferris J. M. and E. Graddy (1988), "Production choices for local government services", Journal of Urban Affairs, 10: 273-289.

Fazioli R. and A. Massarutto (1998), "La leva tariffaria per l'uso sostenibile dell'acqua", Conferenza Nazionale Ambiente ed Energia, Rome: ENEA.

Finger M. and J. Allouche (2003), Water Privatisation. Transnational Corporations and the Re-regulation of the Water Industry. London \& New York: Spon Press.

Finger M., and R. Künneke (2006), "The need for coherence between institutions and technology in liberalized infrastructures: the case of network unbundling in electricity and railways", Paper presented at the $5^{\text {th }}$ Conference on Applied Infrastructure Research, Berlin, 6-7 October.

Finger M., and R. Künneke (2009), "Exploring socio-technical governance regimes in liberalizing network industries", Discussion paper series on the coherence between institutions and technologies in infrastructures, WP09-01.

Finger M., J. Groenewegen, and R. Künneke (2005), "The quest for coherence between institutions and technologies in infrastructures", Journal of Network Industries, 6(4): 227-259.

Finger M., N. Crettenand, M. Laperrouza, and R. Künneke (2010), "Governing the dynamics of the network industries", Discussion paper series on the coherence between institutions and technologies in infrastructures, WP10-02.

Francis J. G. (1993), The Politics of Regulation. Oxford: Blackwell.

Fraquelli G. and V. Moiso (2004), "La formazione degli Ambiti territoriali nel servizio idrico e il problema della dimensione 'ottimale", Hermes Working Paper, No. 4.

Gaetani F. (2003), "Public Management Policy Change in Brazil: 1995-1998", International Public Management Journal, 6: 327-342.

Gallego R. (2003), "Public Management Policymaking in Spain, 1982-2000: Policy Entrepreneurship and (In)Opportunity Windows", International Public Management Journal, 6: 283-308.

Gallego R. and M. Barzelay (2010), "Public Management Policymaking in Spain: The Politics of Legislative Reform of Administrative Structures, 1991-1997", Governance, 23(2): 277-296. 
Gallego R. and J. Subirats (2012), "Spanish and Regional Welfare Systems: Policy Innovation and Multi-level Governance", Regional \& Federal Studies, 22(3): 269288.

Gambetta D. (1998), "Concatenations of Mechanisms", in P. Hedström and R. Swedberg (eds), Social Mechanisms: An Analytic Approach to Social Theory, Cambridge: Cambridge University Press, 102-125.

George A. L. (1979), "Case studies and theory development: the method of structured, focused comparison", in P. G. Lauren (ed.), Diplomacy: New Approaches in History, Theory and Policy, New York: Free Press, 43-68.

George A. L. and A. Bennett (2005), Case Studies and Theory Development in the Social Sciences. MIT Press.

George A. L. and T. McKeown (1985), "Case Studies and Theories of Organizational Decision Making", in R. Coulam and R. Smith (eds), Advances in Information Processing in Organizations, Greenwich: JAI Press.

Gilardi F. (2003), "Spurious and Symbolic Diffusion of Independent Regulatory Agencies in Western Europe", paper presented at the Workshop "The Internationalization of Regulatory Reforms", Center for the Study of Law and Society, University of California at Berkeley, April 25-26.

Gilardoni A. (1936), Acque pubbliche e impianti elettrici”, $2^{\text {nd }}$ ed. Rome: Società Editrice del Foro Italiano.

Gilardoni A. and A. Marangoni (2004), Il settore idrico italiano: strategie e modelli di business. Milan: Franco Angeli.

Glachant J.-M. (2002), “Why Regulate Deregulated Network Industries?”, Journal of Network Industries, 5: 1-17.

Glaser B. G. and A. L. Strauss (1967), The Discovery of Grounded Theory: Strategies for Qualitative Research. Chicago, IL: Aldine.

Global Water Partnership (2000), Integrated Water Resources Management. Global Water Partnership Technical Advisory Committee. TAC Background Papers, No. 4.

Goggin M. L. (1986), "The 'Too Few Cases/Too Many Variables' Problem in Implementation Research", Western Political Quarterly, 39(2): 328-347.

Goggin M. L., A. O. M. Bowman, J. P. Lester, and L. J. O'Toole Jr (1990), Implementation Theory and Practice: Towards a Third Generation. Glenview, IL: Foreman/Little, Brown. 
Goldberg V. P. (1976), "Regulation and Administered Contracts", The Bell Journal of Economics, 7(2): 426-448.

Gómez Ibáňez J. A. (2003), Regulating Infrastructure: Monopoly, Contracts, and Discretion. Harvard University Press.

Gönenç R., M. Maher, and G. Nicoletti (2001), "Mise en oeuvre et effets de la réforme de la réglementation: leçons a tirer et problématique actuelle", Revue économique de l'OCDE, No. 32: 11-109.

Goria A. and N. Lugaresi (2002), The Evolution of the National Water Regime in Italy. Milan: Istituto per la Ricerca Sociale-Ewareness.

Granovetter M. (1978), "Threshold Models of Collective Behavior", American Journal of Sociology, 83(6): 1420-1443.

Grantham A. (2001), "How Network Explains Unintended Policy Implementation Outcomes: The Case of UK Rail Privatization", Public Administration, 79(4): 851870.

Groom E., J. Halpern, and D. Ehrhardt (2006), "Explanatory Notes on Key Topics in the Regulation of Water and Sanitation Services", Water Supply and Sanitation Sector Board Discussion Paper Series, The World Bank, No. 6.

Gualini E. (2004), Multi-level Governance and Institutional Change: The Europeanization of Regional Policy in Italy. Ashgate Publishing.

Guffanti L. and M. Merelli (eds) (1997), La riforma dei servizi idrici in Italia: riflessioni e spunti comparativi. Milano: Egea.

Hall T. E. and L. J. O'Toole Jr (2000), "Structures for Policy Implementation: An Analysis of National Legislation, 1965-1966 and 1993-1994", Administration and Society, 31(6): 667-686.

Hall T. E. and L. J. O'Toole Jr (2004), "Shaping Formal Networks Through the Regulatory Process", Administration and Society, 36(2): 186-207.

Hall P. A. and R. C. R. Taylor (1996), "Political Science and the Three New Institutionalisms", Political Studies, 44(5): 936-957.

Hambleton R. (1983), "Planning Systems and Policy Implementation", Journal of Public Policy, 3(4): 397-418.

Hanf K. (1982), "Regulatory Structures: Enforcement as Implementation", European Journal of Political Research, 10: 159-172. 
Hanf K. and L. J. O'Toole Jr (1992), "Revisiting Old Friends: Networks, Implementation Structures and the Management of Inter-organisational Relations", European Journal of Political Research, 21: 163-180.

Hanf K. and F. W. Scharpf (1978), Intergovernmental Policy Making: Limits to Coordination and Central Control. London: SAGE.

Harris M. (1964), The Nature of Cultural Things. New York, NY: Random House.

Harris R. A. and S. M. Milkis (1996), The Politics of Regulatory Change. Oxford: Oxford University Press.

Hedström P. (2005), Dissecting the Social: On the Principles of Analytic Sociology. Cambridge: Cambridge University Press.

Hedström P. and R. Swedberg (eds) (1998), Social Mechanisms: An Analytic Approach to Social Theory. Cambridge University Press.

Hefetz A. and M. Warner (2004), "Privatization and its reverse: explaining the dynamics of the government contracting process", Journal of Public Administration Research and Theory, 14(2): 171-190.

Hefetz A. and M. Warner (2007), "Beyond the market vs. planning dichotomy: understanding privatization and its reverse in U.S. Cities", Local Government Studies, 33(4): 555-571.

Hill M. (1997), “Implementation Theory: Yesterday's Issue?”, Policy and Politics, 25(4): 375-385.

Hill M. and P. Hupe (2002), Implementing Public Policy. London: Sage.

Hirsch W. Z. (1995), "Factors important in local governments' privatization decision”, Urban Affairs Review, 31: 226-243.

Hjern B. (1982), "Implementation Research - the Link Gone Missing", Journal of Public Policy, 2(3): 301-308.

Hjern B. and C. Hull (1982), "Implementation Research as Empirical Constitutionalism", European Journal of Political Research, 10: 105-115.

Hjern B., K. Hanf, and D. O. Porter (1978), Interorganizational Policy Making. London: SAGE.

Hjern B. and D. O. Porter (1980), "Implementation Structures: A New Unit of Administrative Analysis", Organization Studies, 2/3: 211-227. 
Hood C. (1983), The Tools of Government. London: Macmillan Press.

Hood C., H. Rothstein, and R. Baldwin (2001), The Government of Risk: Understanding Risk Regulation Regimes. Oxford: Oxford University Press.

Hooghe L. (1996), Cohesion Policy and European Integration: Building Multi-level Governance. Oxford: Oxford University Press.

Hopkins, T. D. (2005), "An Assessment of Cross-National Regulatory Burden Comparisons", Fordham Urban Law Journal, 33(4): 100-116.

Hull C. J. and B. Hjern (1987), Helping Small Firms Grow: an Implementation Approach. New York: Croom Helm.

Hupe P. L. (1990), "Implementing a Meta-policy: The Case of Decentralisation in the Netherlands", Policy and Politics, 18(3): 181-191.

ISTAT (1991), Censimento delle Risorse Idriche. Rome: Istituto Nazionale di Statistica.

ISTAT (1999), Censimento delle Risorse Idriche. Rome: Istituto Nazionale di Statistica.

James O, (2003), The Executive Agency Revolution in Whitehall: Public Interest versus Bureau-Shaping Perspectives. New York: Palgrave Macmillan.

Jones A. and J. Clark (2000), The Modalities of European Union Governance: New Institutionalist Explanations of Agri-Environmental Policy. Oxford: Oxford University Press.

Jordan G. and K. Schubert (1992), "A Preliminary Ordering of Policy Network Labels", European Journal of Political Research, 21(1/2): 7-27.

Jordana J. and D. Levi-Faur (2003), "The Rise of the Regulatory State in Latin America: A Study of the Diffusion of Regulatory Reforms across Countries and Sectors", paper presented at the Annual Meeting of the American Political Science Association, Philadelphia, August 27-29.

Jordana J. and D. Levi-Faur (2004), The Politics of Regulation: Institutions and Regulatory Reforms in the Age of Governance. Northampton, MA: E. Elgar.

Joskow P. L. (1996), "Introducing Competition into Regulated Network Industries: from Hierarchy to Markets in Electricity", Industrial and Corporate Change, 5(2): 341-382. 
Joskow P. L. (1997), "Restructuring, Competition and Regulatory Reform in the U.S. Electricity Sector”, Journal of Economic Perspectives, 11(3): 119-138.

Joskow P. L. (2005), "Regulation of Natural Monopolies", Center for Energy and Environmental Policy Research, Working Paper No. 05-008.

Joskow P. L. and N. L. Rose (1989) "The Effects of Economic Regulation", in R. Schmalensee and R. Willig (eds), Handbook of Industrial Organization (vol. II), North Holland, 1450-1506.

Kallis G. and P. Nijkamp (1999), "Evolution of EU Water Policy: A Critical Assessment and a Hopeful Perspective", Digital Academic Repository of the Vrije Universiteit Amsterdam, research memorandum.

Katznelson I. and B. R. Weingast (2005), "Intersections Between Historical and Rational Choice Institutionalism”. In I. Katznelson and B. R. Weingast (eds), Preferences And Situations: Points of Intersection Between Historical And Rational Choice Institutionalism. London: SAGE, 1-24.

Kay J. (1996), "Regulating private utilities: the customer corporation", Journal of Co-operative Studies, 29(2); 28-46.

Kay J. and D. J. Thompson (1986), "Privatization: a policy in search for a rationale", Economic Journal, 96(381): 18-32.

Kenis P. and V. Schneider (1991), "Policy Networks and Policy Analysis: Scrutinizing a New Analytical Toolbox", in B. Marin and R. Mayntz (eds), Policy Networks: Empirical Evidence and Theoretical Considerations. Frankfurt: Campus, 25-59.

Kessides I. N. (2004), Reforming Infrastructure: Privatization, Regulation, and Competition. Washington, DC: The World Bank.

Kingdon J. (1984), Agendas, Alternatives, and Public Policies. Boston, MA: Little, Brown.

Kirkpatrick C. and D. Parker (2005), "Domestic Regulation and the WTO: The Case of Water Services in Developing Countries", The World Economy, 28(10): 1491-1508.

Kirkpatrick C., D. Parker, and Y. F. Zhang (2006), "An empirical analysis of state and private-sector provision of water services in Africa", The World Bank Economic Review, 20(1): 143-163.

Klijn E.-H. (1996), “Analyzing and Managing Policy Processes in Complex Networks: A Theoretical Examination of the Concept Policy Network and its 
Problems", Administration and Society, 28(1): 90-119.

Klijn E.-H. and J. F. M. Koppenjan (2000), "Public Management and Policy Networks: Foundations of a Network Approach to Governance", Public Management, 2(2): 135-158.

Klijn E.-H., J. Koppenjan, and K. Termer (1995), "Managing Networks in the Public Sector: A Theoretical Study of Management Strategies in Policy Networks", Public Administration, 73: 437-454.

Knill C. and A. Lenschow (2000), Implementing EU Environmental Policy: New Directions and Old Problems. Manchester University Press.

Knill C. and D. Liefferink (2007), Environmental Politics in the European Union: Policy-making, Implementation, and Patterns of Multi-level Governance. Manchester University Press.

Kraemer R. A. (1998), "Public and Private Water Management in Europe", in F. N. Correia (ed.), Selected Issues in Water Resouce Management in Europe. Eurowater.

Landy M. K., M. A. Levin, and M. Shapiro (2007), Creating Competitive Markets: The Politics of Regulatory Reform. Washington, DC: Brookings Institution Press.

Lanz K. and S. Scheuer (2001), EEB Handbook on EU Water Policy under the Water Framework Directive. Brussels: European Environmental Bureau.

La Spina A. and G. Sciortino (1993), "Common Agenda, Southern Rules: European Integration and Environmental Change in the Mediterranean States", in J. D. Liefferink, P. D. Lowe, and A. P. J. Mol (eds), European Integration and Environmental Policy, London: Belhaven Press, 217-236.

Lees D. (2006), Triumph from Tragedy: I giorni dell'Alluvione. Edizioni Polistampa: Firenze.

Lennon M. C. and T. Corbett (2003), Policy into Action: Implementation Research and Welfare Reform. The Urban Institute Press.

Lester J. P., A. O'M. Bowman, M. L. Goggin, and L. J. O'Toole Jr (1987), "Public Policy Implementation: Evolution of the Field and Agenda for Future Research", Policy Studies Review, 7(1): 200-216.

Lester J. P. and L. M. Goggin (1998), "Back to the Future: The Rediscovery of Implementation Studies", Policy Currents, 8(3): 1-9.

Lett J (1990), "Emics and Etics: Notes on the Epistemology of Anthropology", in T. N. Headland, M. Harris and K. L. Pike (eds), Emics and Etics: the Insider/Outsider 
Debate, London: SAGE Publications, 127-42.

Levi M. (2002), "Modeling Complex Historical Processes with Analytic Narratives", in R. Mayntz (ed.), Akteure - Mechanismen - Modelle. Zur Theoriefähigkeit makro-sozialer Analysen, Frankfurt: Campus Verlag, 108-127.

Levi-Faur D. (2005), "The Global Diffusion of Regulatory Capitalism”, The Annals of the American Academy of Political and Social Science, 598(1): 12-32.

Levi-Faur D. (2006), "Varieties of Regulatory Capitalism: Sectors and Nations in the Making of a New Global Order", Governance, 19(3): 363-366.

Levine D.K. and W. Pesendorfer (2007), "The evolution of cooperation through imitation”, Games and Economic Behavior, 58: 293-315.

Levitt B. and J. G. March (1988), “Organizational Learning”, Annual Review of Sociology, 14: 319-340.

Levy R. (2000), Implementing European Union Public Policy. Edward Elgar.

Lichbach M. I. (2003), Is Rational Choice Theory All of Social Science? Ann Arbor, MI: University of Michigan Press.

Lieberman R. C. (2003), "Ideas, Institutions, and Political Order: Explaining Political Change", American Political Science Review, 96: 697-712.

Liou K. T. (2001), "Governance and Economic Development: Changes and Challenges", International Journal of Public Administration, 24(10): 1005-1022.

Liou K. T. (2007), "Changes and Challenges in Regulatory Reforms", International Journal of Public Administration, 30(3): 271-288.

Lippi A., N. Giannelli, S. Profeti, and G. Citroni (2008), "Adapting public-private governance to the local context”, Public Management Review, 10(5): 619-640.

Lipsky M. (1978), "Standing the Study of Public Policy Implementation on Its Head", in W. D. Burnham and M. Wagner Weinberg (eds), American Politics and Public Policy. Cambridge, MA: MIT Press.

Littlechild S. (1986), "Economic Regulation of Privatized Water Authorities and Some Further Reflections", Oxford Review of Economic Policy, 4(2): 40-67.

Lobina E. (2005), D11 Watertime case study: Arezzo, Italy. www.watertime.net.

Lobina E. and D. Hall (2003), "Problems with Private Water Concessions: a Review of Experience". http://www.psiru.org. 
Lodge M. (2002), On Different Tracks: Designing Railway Regulation in Britain and Germany. Greenwood Publishing Group.

Lodge M. (2003), "Institutional Choice and Policy Transfer: Reforming British and German Railway Regulation”, Governance, 16(2): 159-178.

Lodge M. (2008), "Regulation, the regulatory state, and European politics", West European Politics, 31(1-2): 280-301.

Lodge M. and L. Stirton (2006), "Withering in the heat? In search of the regulatory state in the Commonwealth Caribbean", Governance, 19(3): 465-495.

Lodge M. and K. Wegrich (2005), "Governing multi-level governance: comparing domain dynamics in German Land-Local Relationship and Prisons", Public Administration, 83(2): 417-442.

Lugaresi N. (1995), Le acque pubbliche, profili dominicali di tutela e di gestione. Padova: Cedam.

Majone G. (1994), "The Rise of the Regulatory State in Europe”, in W. C. Müller and V. Wright (eds), The State in Western Europe: Retreat or Redefinition? London: Routledge.

Majone G. (1996), Regulating Europe. London: Routledge.

Majone G. (1997), "The New European Agencies: Regulation by Information", Journal of European Public Policy, 4(2): 262-75.

Majone G. and A. Wildavsky (1979), "Implementation as Evolution", in J. Pressman and A. Wildavsky, Implementation, III ed., Berkeley: University of California Press, 163-180.

Malaman R. and S. Cima (1998), L'economia dei servizi idrici: indagine sulle grandezze economiche e strutturali dell'industria dei servizi idrici. Rome: Proaqua.

Malee S. (2003), "Public Management Policy Change in Thailand", International Public Management Journal, 6: 342-370.

March J. G. (1994), A Primer on Decision Making. New York: Free Press.

March J. G. and J. P. Olsen (1989), "The Logic of Appropriateness", ARENA Working Papers, Centre for European Studies, University of Oslo, 04/09.

Marks G. (1993), "Structural Policy and Multilevel Governance in the EC", in A. Cafrunyand and G. Rosenthal, The State of the European Community, Boulder, CO: 
Lynne Rienner, 391-411.

Massarutto A. (1993), Economia del ciclo del'acqua. Milan: Franco Angeli.

Massarutto A. (2005), "La legge Galli alla prova dei fatti: riflessioni su una riforma incompiuta”, Economia delle fonti di energia e dell'ambiente, 3: 87-110.

Massarutto A. (2007), "Liberalization and private sector involvement in the water industry: a review of the economic literature", MPRA - Munich Personal RePEc Archive, paper No. 5864.

Massarutto A. and M. Fontana (1994), "La valutazione economica della domanda d'acqua: metodologie di stima e applicazioni empiriche", Quaderni di ricerca Iefe. Milan: Bocconi University.

Matland R. E. (1995), "Synthesizing the Implementation Literature: The Ambiguity-Conflict Model of Policy Implementation", Journal of Public Administration Research and Theory, 5(2): 145-174.

May P. J. (1995), "Can Cooperation be Mandated? Implementing Intergovernmental Environmental Management in New South Wales and New Zealand", Publius, 25(1): 89-113.

Mayntz R. (1993), "Modernization and the Logic of Interorganizational Networks", Knowledge, Technology, and Policy, 6(1): 3-16.

Mayntz R. and F. W. Scharpf (1995), "Der Ansatz des akteurzentrierten Institutionalismus", in R. Mayntz and F. W. Scharpf (eds), Gesellschaftliche Selbstregelung und politische Steuerung, Frankfurt: Campus Verlag, 39-72.

Mazmanian D. A. and P. A. Sabatier (1981) (eds), Effective Policy Implementation. Lexington, MA: Lexington Books.

Mazmanian D. A. and P. A. Sabatier (1983), Implementation and Public Policy. Glenview, IL: Scott, Foresman.

Mazmanian D. A. and P. A. Sabatier (1989), Implementation and Public Policy. Lanham, MD: University Press of America.

McAdam D., S. Tarrow, and C. Tilly (2001), Dynamics of Contention. Cambridge University Press.

McGuire M. (2002), "Managing Networks: Propositions on What Managers Do and Why They Do It", Public Administration Review, 62(5): 599-609.

McGuire R. A., R. L. Ohsfeldt, and T. N. van Cott (1987), "The determinants of the 
choice between public and private production of publicly funded services", Public Choice, 54: 211-230.

Megginson W. L. and J. Netter (2002), "From state to market: a survey of empirical studies on privatization", Journal of Economic Literature, 30(2): 321-389.

Ménard C. and S. Saussier (2000), "Contractual choice and performance: the case of water supply in France", Revue d'Economie Industrielle, 92: 385-404.

Meier K. J. and L. J. O'Toole Jr (2003), "Public Management and Educational Performance: The Impact of Managerial Networking", Public Administration Review, 63(6): 689-699.

Meier K. J. and L. J. O'Toole Jr (2005), "Managerial Networking: Issues of Measurement and Research Design”, Administration and Society, 37(5): 523-41.

Mele V. (2010), "Innovation Policy in Italy (1993-2002): Understanding the Invention and Persistence of a Public Management Reform", Governance, 23(2): 251-276.

Merrett S. (1997), Introduction to the Economics of Water Resources. Lanham, MD: Rowman \& Littlefield.

Merton R. K. (1968), Social Theory and Social Structure. New York: The Free Press.

van Meter D. S. and C. E. van Horn (1975), "The Policy Implementation Process: A Conceptual Framework", Administration and Society, 6(4): 445-488.

Milward H. B. (1982), "Interorganizational Policy Systems and Research on Public Organizations", Administration and Society, 13(4): 457-478.

Milward H. B. and K. G. Provan (2000), "Governing the Hollow State", Journal of Public Administration Research and Theory, 10(2): 359-380.

Miranda R. A. (1994), "Explaining the privatization decision among local governments in the United States", Research in Urban Policy, 5: 231-274.

Montjoy R. S. and L. J. O'Toole Jr (1979), "Toward a Theory of Policy Implementation: An Organizational Perspective", Public Administration Review, 39(5): 465-476.

Moynihan D. (2003), "Public Management Policy Change in the United States during the Clinton Era", International Public Management Journal, 6: 371-395.

Müller M. M. (2002), The New Regulatory State in Germany. Birmingham: The 
University of Birmingham Press.

Muraro G. (2003), "Il servizio idrico integrato in Italia, tra vincoli europei e scelte nazionali". Comitato di Vigilanza sull'Uso delle Risorse Idriche, Rome.

Muraro G. and P. Valbonesi (2003) (eds), I servizi idrici tra mercato e regole. Rome: Carocci.

Newbery D. M. (2000), Privatization, Restructuring and Regulation of Network Utilities. Cambridge, MA: MIT Press.

Noll R. G., M. M. Shirley, and S. Cowan (2000), "Reforming Urban Water Systems in Developing Countries", in A. O. Krueger (ed.), Economic Policy Reform: The Second Stage, Chicago: University of Chicago Press, 243-294.

OECD (1994), Improving the Quality of Laws and Regulations: Economic, Legal, and Managerial Techniques. Paris: OECD.

OECD (1997), OECD Report on Regulatory Reform, Synthesis. Paris: OECD.

OECD (2002), Regulatory Policies in OECD Countries: From Interventionism to Regulatory Governance. Paris: OECD.

OECD (2004), Building Capacity for Regulatory Quality: Stocktaking Paper. Paris: OECD.

OECD (2006), Thematic Evaluation of the EC Support to Good Governance. Paris: OECD.

Ogus A. (1994), "Competition and Regulatory Structures", Law \& Public Policy, 26(3/4): 329-346.

O'Toole L. J. Jr (1986), "Policy Recommendations for Multi-actor Implementation: An Assessment of the Field", Journal of Public Policy, 6(2): 181-210.

O'Toole L. J. Jr (1993), “Interorganizational Policy Studies: Lessons Drawn from Implementation Research", Journal of Public Administration Research and Theory, 3(2): $232-251$.

O'Toole L. J. Jr (1997a), "Implementing Public Innovations in Network Settings", Administration and Society, 29(2): 115-138.

O'Toole L. J. Jr (1997b), Treating Networks Seriously: Practical and ResearchBased Agendas in Public Administration. Public Administration Review, 57, 1, 4552 . 
O'Toole L. J. Jr (1997c), "Networking Requirements, Institutional Capacity, and Implementation Gaps in Transitional Regimes: The Case of Acidification Policy in Hungary", Journal of European Public Policy, 4(1): 1-17.

O'Toole J. L. Jr (2000), "Research on Policy Implementation: Assessment and Prospects", Journal of Public Administration Research and Theory, 10(2): 263-288.

O'Toole L. J. Jr (2004), “The Theory-Practice Issue in Policy Implementation Research", Public Administration, 82(2): 309-329.

O'Toole L. J. Jr and R. S. Montjoy (1984), "Interorganizational Policy Implementation: A Theoretical Perspective", Public Administration Review, 44(6): 491-503.

O'Toole L. J. Jr and K. J. Meier (2004), "Public Management in Intergovernmental Networks: Matching Structural Networks and Managerial Networking", Journal of Public Administration Research and Theory, 14(4): 469-494.

Parker D. (1990), "The 1988 Local Government Act and compulsory competitive tendering", Urban Studies, 27(5): 653-667.

Passino R. (2005), La difesa del suolo in Italia dalla Commissione De Marchi ad oggi. Roma: Gruppo 183.

Patashnik E. M. (2003), "After the Public Interest Prevails: The Political Sustainability of Policy Reforms", Governance, 16(2): 203-234.

Patashnik E. M. (2008), Reforms at Risk: What Happens After Major Policy Changes Are Enacted. Princeton, NJ: Princeton University Press.

Petretto A. (2001), "Processi di riorganizzazione industriale e liberalizzazione dei servizi pubblici locali: problemi e prospettive", Paper n.01/39, Rome: Proaqua.

Pettigrew A. M. (1997), "What Is a Processual Analysis?”, Scandinavian Journal of Management, 13(4): 337-348.

Pike K. L. (1954), Language in Relation to a Unified Theory of the Structure of Human Behavior. Glendale, CA: Summer Institute of Linguistics.

Peters B. G. and J. Pierre (2004), "Multi-level Governance and Democracy: A Faustian Bargain?", in I. Bache and M. V. Flinders (eds), Multi-level Governance, Oxford: Oxford University Press, 75-92.

Pressman J. L. and A. Wildavsky (1973), Implementation. Berkeley: University of California Press. 
Provan K. G. and H. B. Milward (1995), "A Preliminary Theory of Interorganizational Network Effectiveness: A Comparative Study of Four Community Mental Health Systems", Administrative Science Quarterly, 40(1): 133.

Ragin C. C. (1989), The Comparative Method: Moving Beyond Qualitative and Quantitative Strategies. Berkeley, CA: University of California Press.

Ragin C. C. (1994), Constructing Social Research: The Unity and Diversity of Method. Thousand Oaks, CA: Pine Forge Press.

Ragin C. C. and H. S. Becker (1982), What is a Case? Exploring the Foundations of Social Inquiry. Cambridge: Cambridge University Press.

Reimer S. (1999), "Contract Service Firms in Local Authorities: Evolving Geographies of Activity”, Regional Studies, 33(2): 121-130.

Rees J. A. (1998), "Regulation and Private Participation in the Water and Sanitation Sector”, Natural Resources Forum, 22(2): 95-105.

Rees, J.A., Winpenny J., and Hall A. W. (2008), 'Water Financing and Governance', TEC Background Papers - Global Water Partnership, No. 12.

Rhodes R. A. W. (1996), “The New Governance: Governing Without Government”, Political Studies, 44(4): 652-667.

Rhodes R. A. W. (1997), "From Marketization to Diplomacy: It's the Mix that Matters", Public Policy and Administration, 12(2): 31-49.

Rhodes R. A. W. and D. Marsh (1992), "New Directions in the Study of Policy Networks", European Journal of Political Research, 21: 181-205.

Riccaboni A. and G. Grossi (2000), "Rischi politici e regolamentativi nel primo caso di attuazione della legge di riforma del settore idrico", Azienda Pubblica. 1: $11-37$.

Richardson J. J. and A. G. Jordan (1979), Governing under Pressure: The Policy Process in a Post-Parliamentary Democracy. Oxford: Martin Robertson.

Rivera D. (1996), Private sector participation in the water supply and wastewater sector: Lessons from six developing countries. Washington, DC: The World Bank.

Rouse M. (2007), Institutional Governance and Regulation of Water Services. London: IWA Publishing.

Ryan N. (1995), "Unravelling Conceptual Developments in Implementation 
Analysis", Australian Journal of Public Administration, 54(3): 353-363.

Sabatier P. A. (1986), "Top Down and Bottom Up Approaches to Implementation Research: A Critical Analysis and Suggested Synthesis", Journal of Public Policy, 6: 21-48.

Sabatier P. A. (1988), "An Advocacy Coalition Framework of Policy Change and the Role of Policy-oriented Learning therein”, Policy Sciences, 21(2/3): 129-168.

Saetren H. (2005), "Facts and Myths about Research on Public Policy Implementation: Out-of-Fashion, Allegedly Dead, but Still Very Much Alive and Relevant", The Policy Studies Journal, 33(4): 559-582.

Salancik G. R. and J. Pfeffer (1978), "A Social Information Processing Approach to Job Attitudes and Task Design", Administrative Science Quarterly, 23(2): 224-253.

Sayer R. A. (1992), Method in Social Science: A Realist Approach. London: Routledge.

Scharpf F. W. (1978), "Interorganizational Policy Studies: Issues, Concepts and Perspectives", in K. I. Hanf and F. W. Scharpf (eds), Interorganizational Policy Making: Limits to Coordination and Central Control, London: SAGE, 345-70.

Scharpf F. W. (1990), "Games Real Actors Could Play", Rationality and Society, 2(4): 471-494.

Scharpf F. W. (1991), "Games Real Actors Could Play: The Challenge of Complexity", Journal of Theoretical Politics, 3(3): 277-304.

Scharpf F. W. (1993), Games in Hierarchies and Networks. Boulder, Colo.: Westview Press.

Scharpf F. W. (1994), "Games Real Actors Could Play: Positive and Negative Coordination in Embedded Negotiations", Journal of Theoretical Politics, 6(1): 2753.

Scharpf F. W. (1997), Games Real Actors Play: Actor-Centred Institutionalism in Policy Research. Boulder, Colo.: Westview Press.

Scharpf F. W. (2001), "Notes Toward a Theory of Multilevel Governing in Europe", Scandinavian Political Studies, 24(1): 1-26.

Schelling T. C. (1978), Micromotives and Macrobehavior. Toronto: George J. McLeod.

Schelling T. C. (1998), “Social Mechanisms and Social Dynamics”, in P. Hedström 
and R. Swedberg (eds), Social Mechanisms: An Analytic Approach to Social Theory, Cambridge: Cambridge University Press, 32-44.

Schmalensee R. (1979), The Control of Natural Monopoly. Lexington, MA: Heath.

Schofield J. (2001), “Time for a Revival? Public Policy Implementation: A Review of the Literature and an Agenda for Future Research", International Journal of Management Reviews, 3(3), 245-263.

Schofield J. (2004), “A Model of Learned Implementation”, Public Administration, 82(2): 283-308.

Schofield J. and C. Sausman (2004), "Symposium on Implementing Public Policy: Learning from Theory and Practice. Introduction", Public Administration, 82(2): 235-248.

Selznick P. (1985), Focussing Organisation Research on Regulation. Regulation Policy and Social Sciences. Noll: Berkeley.

Shirley M. M. (2002) (ed.), Thirsting for Efficiency: The Economics and Politics of Urban Water System Reform. Oxford: Elsevier Science.

Simmons B. A. and Z. Elkins (2004), "The Globalization of Liberalization: Policy Diffusion in the International Political Economy", American Political Science Review, 98: 171-189.

Spadoni B. (2005), L'evoluzione istituzionale e organizzativa dei servizi pubblici locali dalla municipalizzazione alla liberalizzazione, ISSiRFA-CNR, mimeo.

Spulber N. and A. Sabbaghi (1994), Economics of Water Resources: From Regulation to Privatization. Kluwer Academic Publishing.

Stake R. E. (1994), "Case Studies", in N. K. Denzin and Y. S. Lincoln (eds), Handbook of Qualitative Research, Newbury Park: SAGE, 236-47.

Stake R. E. (1995), The Art of Case Study Research. London: SAGE.

Stern J. and S. Holder (1999), "Regulatory governance: criteria for assessing the performance of regulatorysystems: An application to infrastructure industries in the developing countries of Asia", Utilities Policy, 8(1): 33-50.

Stigler G. J. (1971), “The Theory of Economic Regulation”, The Bell Journal of Economics and Management Science, 2(1): 3-21.

Stinchcombe A. L. (1991), "The Conditions of Fruitfulness of Theorizing About Mechanisms in Social Science", Philosophy of the Social Sciences, 21(3): 367-388. 
Stoker G. (1997), "The privatisation of urban services in the UK". In D. Lorrain and G. Stoker (eds), The Privatisation of Urban Services in Europe. London: Pinter, 58178.

Strauss A. and J. Corbin (1994), "Grounded Theory Methodology: An Overview", in N. K. Denzin and Y. S. Lincoln (eds), Handbook of Qualitative Research, Newbury Park, CA: SAGE, 273-85.

Tenbücken M. (2006), "The Regulation of Network Infrastructure in the New European Union”, PhD thesis, Universität Konstanz.

Thatcher M. (2002a), "Regulation after Delegation: Independent Regulatory Agencies in Europe", Journal of European Public Policy, 9(6): 954-972.

Thatcher M. (2002b), "Analysing regulatory reform in Europe", Journal of European Public Policy, 9(6): 859-72.

Thelen K. (1999), "Historical Institutionalism in Comparative Politics", Annual Review of Political Science, 2: 369-404.

Thelen K. and S. Steinmo (1992), "Historical Institutionalism in Comparative Politics". In S. Steinmo, K. Thelen, and F. Longstreth (eds), Structuring Politics: Historical Institutionalism in Comparative Analysis. New York: Cambridge University Press, 1-32.

Toke D. and D. Marsh (2003), "Policy Networks and the GM Crops Issue: Assessing the Utility of a Dialectical Model of Policy Networks", Public Administration, 81(2): 229-251.

UNICEF (2007), Water, Sanitation, and Hygiene Annual Report. New York: UNICEF.

Vaccà S. (2002), Problemi e prospettive dei servizi locali di pubblica utilità in Italia. Milan: Franco Angeli.

Vacchelli (1940), "Caratteristiche della nuova legislazione italiana sull'uso delle acque. Scritti giuridici in onore di Santi Romano", Diritto amministrativo. 2, Padua: Cedam.

Vickers J. and G. Yarrow (1988), Privatization: an Economic Analysis. Cambridge, MA. MIT Press.

Vitale (1921), Il regime delle acque nel diritto pubblico e privato. Milan.

Vitta (1930), "L'amministrazione delle acque pubbliche", in V. E. Orlando (ed.), 
Primo trattato completo di diritto amministrativo italiano. Milan.

Vogel S. K. (1998), Freer Markets, More Rules: Regulatory Reform in Advanced Industrial Countries. Ithaca, NY: Cornell University Press.

van Waarden F. (1992), "Dimensions and Types of Policy Networks", European Journal of Political Research, 21: 29-52.

Wackerbauer J. (2007), "Regulation and Privatization of the Public Water Supply in England, France, and Germany", Competition and Regulation in Network Industries, 8(2): 101-116.

Warner M. and R. Hebdon (2001), "Local government restructuring: privatization and its alternatives", Journal of Policy Analysis and Management, 20: 315-336.

Weick K. E. (2001), Making Sense of the Organization. Malden, MA: Blackwell Scientific.

Williamson O. E. (1976), "Franchise Bidding for Natural Monopoly - in General and with Respect to CATV", The Bell Journal of Economics, 7: 73-104.

Winpenny J. (2003), "Financing water for all, Report of the World Panel on Financing Water Infrastructure" (Camdessus Commission), World Water Forum, Kyoto.

Winter S. G (1964), "Economic "Natural Selection" and the Theory of the Firm", Yale Economic Essays, 4(1): 225-72.

Yin R. K. (1994), Case Study Research: Design and Methods. London: SAGE.

Zysman J. (1994), "How institutions create historically rooted trajectories of growth", Industrial and Corporate Change, 3(1): 243-83. 